\title{
\#USGS
}

science for a changing world

Prepared in cooperation with the Bureau of Land Management

\section{Ecosystem Services Valuation to Support Decisionmaking on Public Lands-A Case Study of the San Pedro River Watershed, Arizona}

Scientific Investigations Report 2012-5251

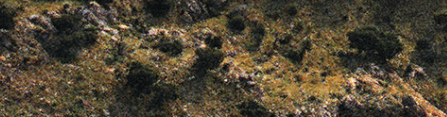

U.S. Department of the Intevior U.S. Geological Survey 
COVER: Aerial view of the San Pedro River Valley, Arizona. Photograph used by permission: (c) Adriel Heisey.

This document was produced through an interagency effort between the Bureau of Land Management and the U.S. Geological Survey. The following BLM number has been assigned for tracking and administrative purposes: BLM Technical Note 442. 


\section{Ecosystem Services Valuation to Support Decisionmaking on Public Lands- A Case Study of the San Pedro River Watershed, Arizona}

By Kenneth J. Bagstad, Darius Semmens, Rob Winthrop, Delilah Jaworksi, and Joel Larson

Prepared in cooperation with the Bureau of Land Management

Scientific Investigations Report 2012-5251 


\title{
U.S. Department of the Interior \\ KEN SALAZAR, Secretary \\ U.S. Geological Survey \\ Marcia K. McNutt, Director
}

\author{
U.S. Geological Survey, Reston, Virginia: 2012
}

For more information on the USGS - the Federal source for science about the Earth, its natural and living resources, natural hazards, and the environment, visit http://www.usgs.gov or call 1-888-ASK-USGS.

For an overview of USGS information products, including maps, imagery, and publications, visit http://www.usgs.gov/pubprod

To order this and other USGS information products, visit http://store.usgs.gov

Any use of trade, firm, or product names is for descriptive purposes only and does not imply endorsement by the U.S. Government.

Although this information product, for the most part, is in the public domain, it also may contain copyrighted materials as noted in the text. Permission to reproduce copyrighted items must be secured from the copyright owner.

Suggested citation:

Bagstad, K.J., Semmens, Darius, Winthrop, Rob, Jaworski, Delilah, and Larson, Joel, 2012, Ecosystem services valuation to support decisionmaking on public lands - A case study of the San Pedro River watershed, Arizona: U.S. Geological Survey Scientific Investigations Report 2012-5251, 93 p. 


\section{Contents}

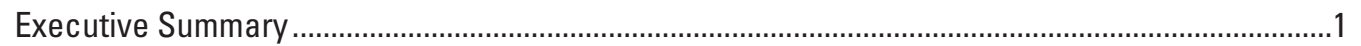

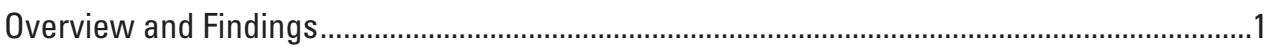

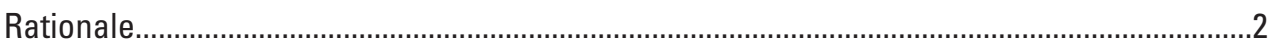

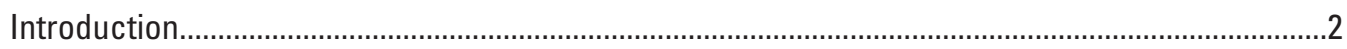

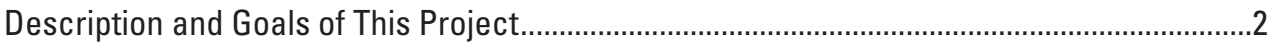

Links to Strategic Goals of Arizona Bureau of Land Management ..........................................

Literature Review............................................................................................................

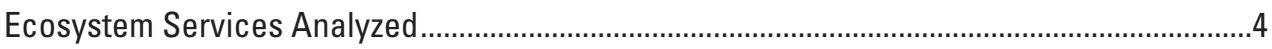

Water

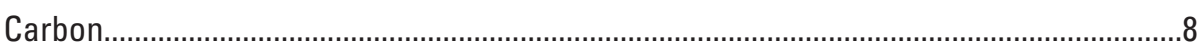

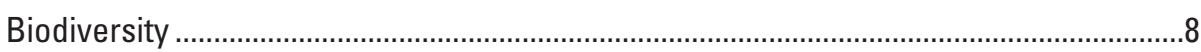

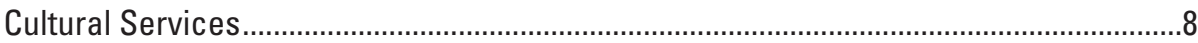

Ecosystem Services Assessment and Valuation—Methods and Tools ..................................11

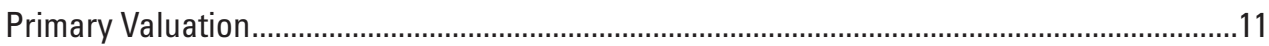

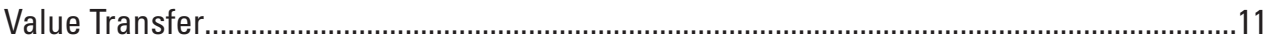

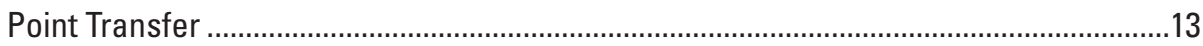

Function Transfer ................................................................................................... 13

Function Transfer Using Defenders of Wildlife's Wildlife Habitat

Benefits Estimation Toolkit..............................................................................14

Integrated Valuation of Ecosystem Services and Tradeoffs (InVEST) ...................................15

Artificial Intelligence for Ecosystem Services (ARIES) .......................................................15

Multiscale Integrated Models of Ecosystem Services (MIMES) …………….......................16

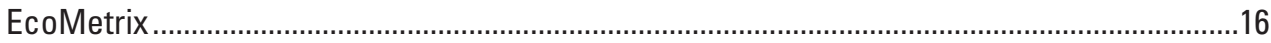

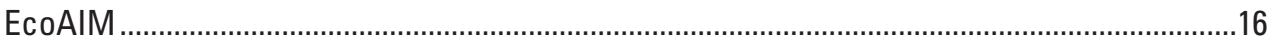

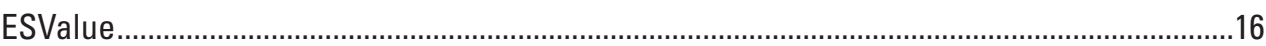

Natural Assets Information System (NAIS) and Simple, Effective Resource

for Valuing Ecosystem Services (SERVES) ................................................................16

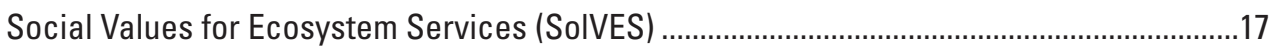

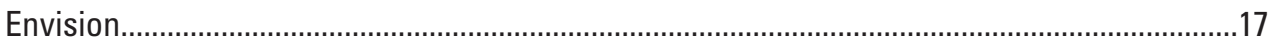

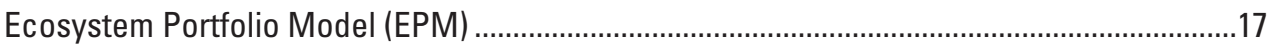

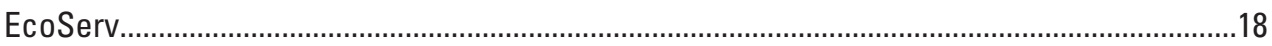

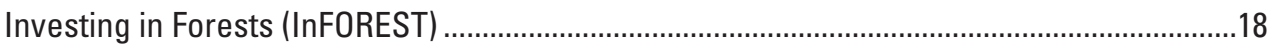

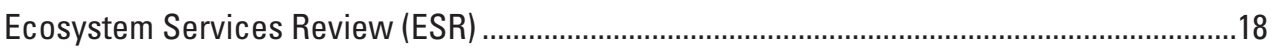

United Nations Environment Programme-World Conservation Monitoring Centre

Ecosystem Services Toolkit ........................................................................................18

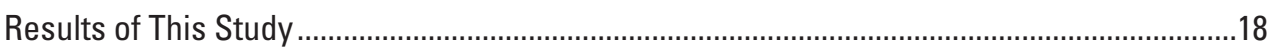

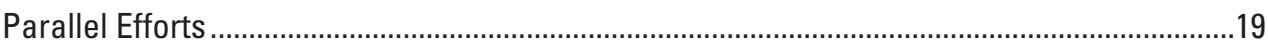

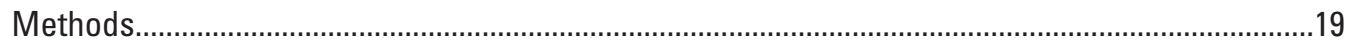

Selection and Description of the Study Area ...................................................................19

Selection and Application of Ecosystem Services, Valuation Methods, and Tools ................20

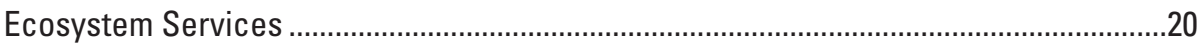

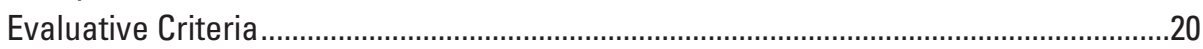

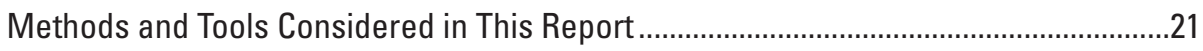

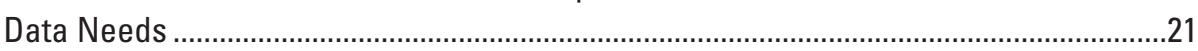

Description of Assessment and Valuation Processes.....................................................21 


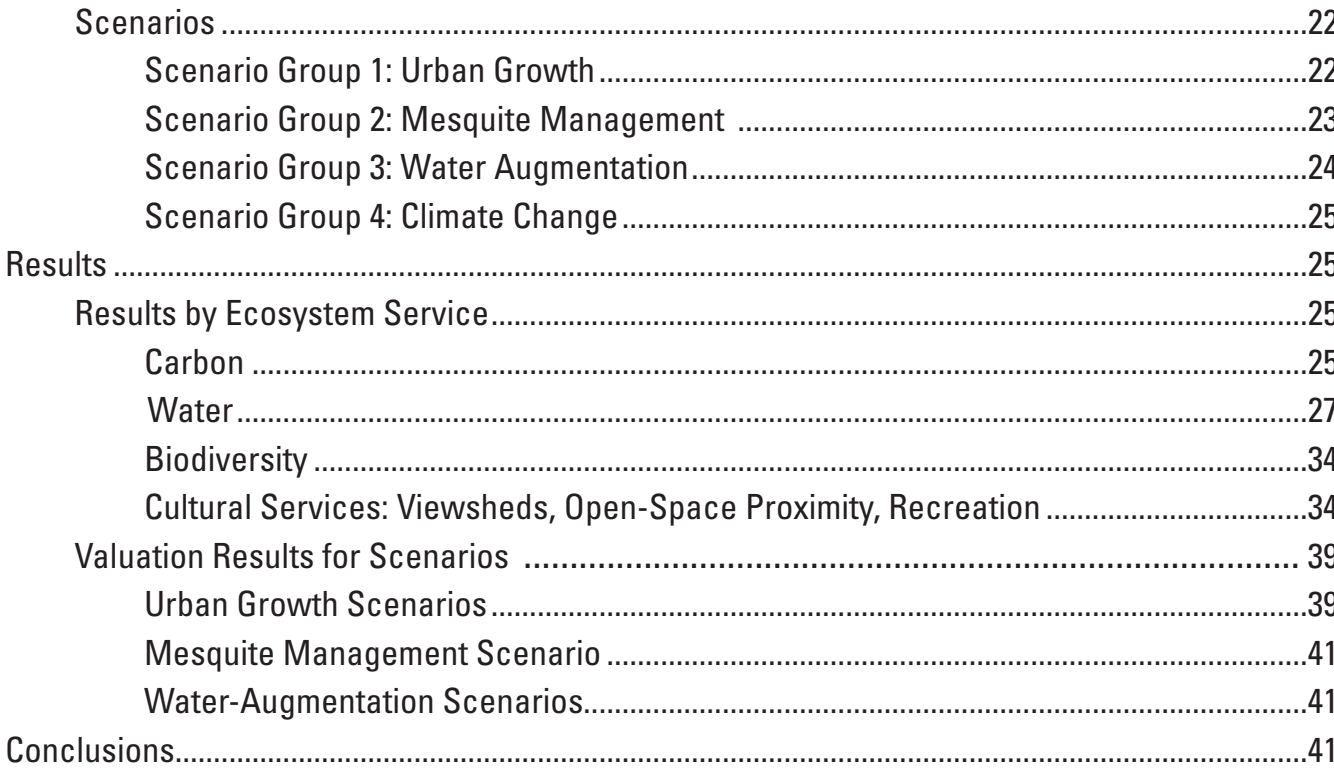

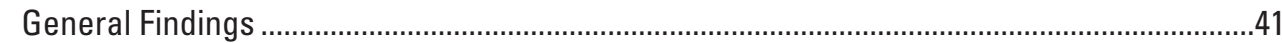

Comparability of Spatially Explicit Results from ARIES and InVEST Models...................45

Advantages and Disadvantages of Alternative Approaches .............................................46

Application of Past Primary Valuation Studies ...........................................................46

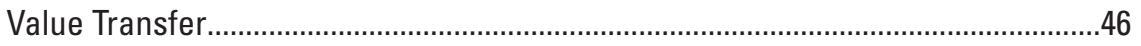

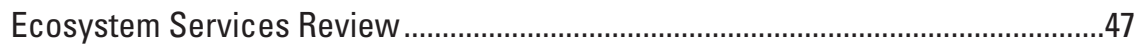

Integrated Valuation of Ecosystem Services and Tradeoffs (InVEST) .....................47

Artificial Intelligence for Ecosystem Services (ARIES) ...........................................52

Other Tools Not Tested in the Pilot Study ...............................................................52

Lessons Learned in the Valuation Process: Steps to Follow and Avoid ...........................53

Integration of Past Work on the San Pedro River Watershed into Ecosystem Service Models .........................................................................54

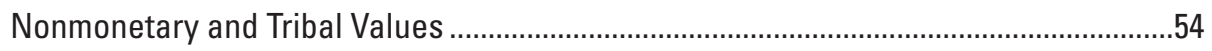

San Pedro Riparian National Conservation Area Outcomes......................................................54

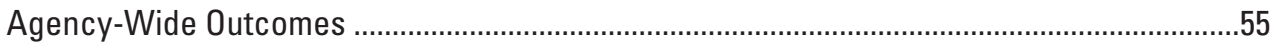

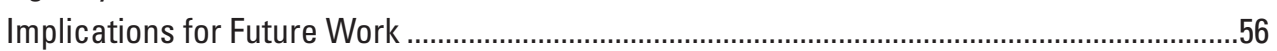

Incorporating Ecosystem Service and Value Information into the Decision Process............56

Data Sharing to Support Widespread Ecosystem Services Mapping and Valuation ........... 57

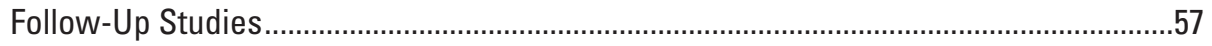

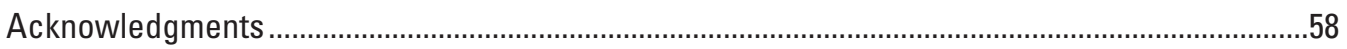

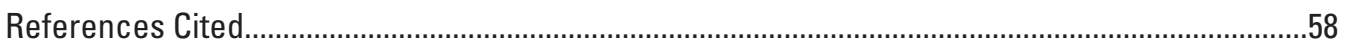

Appendix A. Spatial Data and Assumptions Used in InVEST Models...........................................69

Appendix B. Spatial Data and Assumptions Used in ARIES Models ..............................................74

Appendix C. Literature Review of Value Transfer and Best Practices ...........................................75

Appendix D. Additional Participants in Model and Document Review Process..............................81

Appendix E. Annotated Bibliography of Ecological and Socioeconomic References

Related to the San Pedro River watershed and the U.S. Southwest....................................82

Appendix F. Summary of Primary Economic Valuation Studies for the San Pedro

River watershed and the U.S. Southwest 


\section{Figures}

1. Strategic goals of Arizona Bureau of Land Management ..............................................6

2. San Pedro River watershed study area, States of Arizona (United States) and Sonora (Mexico)...

3. Land ownership within the San Pedro River watershed, States of Arizona (United States) and Sonora (Mexico), and Bureau of Land Management ownership in surrounding region.

4. Urban growth scenarios, San Pedro River watershed, States of Arizona (United States) and Sonora (Mexico)

5. Land cover before $(A)$ and after $(B)$ mesquite management, San Pedro River watershed, Arizona

6. Hydrologic scenarios (groundwater futures) and year 2006 baseline conditions in the San Pedro River watershed, Arizona.

7. Carbon sequestration, storage, and valuation estimates, San Pedro River watershed, States of Arizona (United States) and Sonora (Mexico)—InVEST model results.

8. Carbon sequestration, stored carbon release, and greenhouse gas emissions estimates, San Pedro River watershed, Arizona-ARIES model results.

9. Water yield estimates for urban growth scenarios under representative wet year (2007) and dry year (2002) conditions, and year 2000 water consumption, San Pedro River watershed, Arizona_-InVEST model results.

10. Surface-water source, sink, and useage estimates, San Pedro River watershed, Arizona-ARIES model results..

11. Biodiversity (habitat quality) and change estimates under urban growth and mesquite management scenarios, San Pedro River watershed, ArizonaInVEST model results.

12. Estimates of relative value of open-space proximity and viewsheds (source, use, and flow results) under urban growth scenarios, San Pedro River watershed, Arizona-ARIES model results

13. Visual impacts to viewsheds, San Pedro River watershed, States of Arizona (United States) and Sonora (Mexico)—InVEST model results.

14. Source values for birding and deer hunting (San Pedro River watershed, Arizona) and for birding (San Pedro Riparian National Conservation Area) ARIES model results.

15. Potential steps in assessing ecosystem services.

\section{Tables}

1. Gains and losses in ecosystem services modeled under three scenario categories, San Pedro River watershed, States of Arizona (United States) and Sonora (Mexico)

2. Management issues on the San Pedro River watershed, States of Arizona (United States) and Sonora (Mexico), as identified by managers and stakeholders

3. Potential effects of mesquite management and native grassland restoration on ecosystem services, San Pedro River watershed, Arizona ...

4. Ecosystem services endpoints of services to be valued, San Pedro River watershed, States of Arizona (United States) and Sonora (Mexico)

5. Ecosystem service tools described in this report, San Pedro River watershed, Arizona 
6. Methods used for ecosystems services valuation, San Pedro River watershed, States of Arizona (United States) and Sonora (Mexico).

7. Carbon sequestration, storage, and valuation estimates, San Pedro River watershed, States of Arizona (United States) and Sonora (Mexico)—InVEST model results

8. Carbon sequestration, stored carbon release, and greenhouse gas emissions,

San Pedro River watershed, Arizona-ARIES model results.

9. Water yield and demand estimates, San Pedro River watershed, ArizonaInVEST model results.

10. Surface water sources, sinks, and usage estimates, San Pedro River watershed, Arizona-ARIES model results

11. Economic value of water in the San Pedro River watershed, Arizona.

12. Habitat quality estimates, San Pedro River watershed, Arizona-

InVEST model results

13. Relative value of open space proximity and viewsheds, San Pedro River watershed, States of Arizona (United States) and Sonora (Mexico)— ARIES model results.

14. Visual impacts to viewsheds, San Pedro River watershed, ArizonaInVEST model results.

15. Relative recreation source value estimates, San Pedro River watershed, Arizona-ARIES model results.

16. Biophysical and relative values of ecosystem service changes under alternative urban growth scenarios, San Pedro River watershed, States of Arizona (United States) and Sonora (Mexico)—InVEST model results.

17. Biophysical and relative values of ecosystem service changes under alternative urban growth scenarios, San Pedro River watershed, ArizonaARIES model results.

18. Economic value of ecosystem service changes under alternative urban growth scenarios, San Pedro River watershed, States of Arizona (United States) and Sonora (Mexico)—InVEST mode results

19. Economic value of ecosystem service changes under alternative urban growth scenarios, San Pedro River watershed, Arizona-ARIES model results

20. Total annual cost of ecosystem service loss under urban-growth scenarios, San Pedro River watershed, Arizona-ARIES and InVEST model results.

21. Biophysical and relative values of ecosystem service changes under mesquite management scenario, San Pedro River watershed, ArizonaInVEST model results

22. Biophysical and relative values of ecosystem service changes under mesquite management scenario, San Pedro River watershed, ArizonaARIES model results.

23. Economic value of ecosystem service changes under mesquite management scenario, San Pedro River watershed, Arizona_-InVEST model results

24. Economic value of ecosystem service changes under mesquite management scenario, San Pedro River watershed, Arizona-ARIES model results.

25. Total annual cost or benefit of ecosystem service gain or loss under mesquite management scenario, San Pedro River watershed, Arizona-ARIES and InVEST model results

26. Relative values of ecosystem service changes under water augmentation scenarios, San Pedro River watershed, Arizona-ARIES model results

27. Estimated time to complete ecosystem service assessment and valuation by use of alternative methods

28. All ecosystem service tools relative to key evaluative criteria 


\section{Abbreviations Used in This Report}

\begin{tabular}{|c|c|}
\hline AGAVES & Assessment of Goods and Valuation of Ecosystem Services \\
\hline AGWA & Automated Geospatial Watershed Assessment tool \\
\hline ARIES & Artificial Intelligence for Ecosystem Services \\
\hline BLM & Bureau of Land Management \\
\hline BOR & Bureau of Reclamation \\
\hline DOD & Department of Defense \\
\hline DOI & Department of the Interior \\
\hline EA & Environmental Assessment \\
\hline EIS & Environmental Impact Statement \\
\hline EPM & Ecosystem Portfolio Model \\
\hline ESR & Ecosystem Services Review \\
\hline EVRI & Environmental Valuation Reference Inventory \\
\hline FLPMA & Federal Land Policy and Management Act \\
\hline GIS & Geographic Information System \\
\hline InFOREST & Investing in Forests \\
\hline InVEST & Integrated Valuation of Ecosystem Services and Tradeoffs \\
\hline MIMES & Multiscale Integrated Models of Ecosystem Services \\
\hline NAIS & Natural Assets Information System \\
\hline NEPA & National Environmental Policy Act \\
\hline NOAA & National Oceanic and Atmospheric Administration \\
\hline NPS & National Park Service \\
\hline NRCS & Natural Resources Conservation Service \\
\hline $\mathrm{OMB}$ & Office of Management and Budget \\
\hline PRISM & Parameter-elevation Regressions on Independent Slopes Model \\
\hline RMP & Resource Management Plan \\
\hline SERVES & Simple and Effective Resource for Valuing Ecosystem Services \\
\hline SolVES & Social Values for Ecosystem Services \\
\hline SPRNCA & San Pedro Riparian National Conservation Area \\
\hline STATSGO & State Soil Geographic database \\
\hline UNEP-WCMC & $\begin{array}{l}\text { United Nations Environment Programme-World Conservation } \\
\text { Monitoring Centre }\end{array}$ \\
\hline US EPA & United States Environmental Protection Agency \\
\hline US EPA-ORD & U.S. Environmental Protection Agency-Office of Research and Development \\
\hline USDA & United States Department of Agriculture \\
\hline USGS & United States Geological Survey \\
\hline WIFA & Water Infrastructure Finance Authority \\
\hline WTP & Willingness to Pay \\
\hline
\end{tabular}





\title{
Ecosystem Services Valuation to Support Decisionmaking on Public Lands-A Case Study of the San Pedro River Watershed, Arizona
}

\author{
By Kenneth J. Bagstad, Darius Semmens, Rob Winthrop, Delilah Jaworski, and Joel Larson
}

\section{Executive Summary}

\section{Overview and Findings}

This report details the findings of the Bureau of Land Management (BLM)-U.S. Geological Survey (USGS) Ecosystem Services Valuation Pilot Study. This project evaluated alternative methods and tools that quantify and value ecosystem services, and it assessed the tools' readiness for use in BLM's decisionmaking process. We tested these tools on the San Pedro River watershed in northern Sonora, Mexico and southeast Arizona. The study area includes BLM-managed San Pedro Riparian National Conservation Area, which has been a focal point for conservation activities and scientific research in recent decades. We applied past site-specific primary valuation studies, value transfer, the Wildlife Habitat Benefits Estimation Toolkit, and the Integrated Valuation of Ecosystem Services and Tradeoffs (InVEST) and Artificial Intelligence for Ecosystem Services (ARIES) models to value locally important ecosystem services for the San Pedro River watershed - water, carbon, biodiversity, and cultural values. We tested these approaches on a series of scenarios to evaluate ecosystem service changes and the ability of the tools to accommodate scenarios. A suite of additional tools were either at too early a stage of development to run, were proprietary, or were place-specific tools inappropriate for application to the San Pedro River watershed. We described the strengths and weaknesses of these additional ecosystem service tools against a series of evaluative criteria related to their usefulness for BLM decisionmaking.

Using these tools, we quantified gains or losses of ecosystem services under three categories of scenarios: urban growth, mesquite management, and water augmentation (table 1). These results quantify tradeoffs and could be useful for decisionmaking within BLM district or field offices. Results are accompanied by a relatively high level of uncertainty associated with model outputs, valuation methods, and discount rates applied. Further guidance on representing uncertainty and applying uncertain results in decisionmaking would benefit both tool developers and BLM offices in using ecosystem services to compare management tradeoffs. Decisionmakers and BLM managers at the State-, district-, and field- office level would also benefit from continuing model improvements, training, and guidance on tool use that can be provided by USGS, BLM, and the Department of the Interior.

Tradeoffs were identified in the level of effort needed to parameterize and run tools and the amount and quality of information they provide to the decision process. We found the Wildlife Habitat Benefits Estimation Toolkit, Ecosystem Services Review, and United Nations Environment ProgrammeWorld Conservation Monitoring Centre Ecosystem Services Toolkit to be immediately feasible for application by BLM, given proper guidance on their use. It is also feasible for BLM to use the InVEST model, but in early 2012 the process of parameterizing the model required resources and expertise that are unlikely to be available in most BLM district or field offices. Application of past primary valuation is feasible, but developing new primary-valuation studies is too time consuming for regular application. Value transfer approaches (aside from the Wildlife Habitat Benefits Estimation Toolkit) are best applied carefully on the basis of guidelines described in this report, to reduce transfer error. The ARIES model can provide useful information in regions modeled in the past (Arizona, California, Colorado, and Washington), but it lacks some features that will improve its usability, such as a generalized model that could be applied anywhere in the United States. Eleven other tools described in this report could become useful as the tools more fully develop, in high-profile cases for which additional resources are available for tool application or in case-study regions where placespecific models have already been developed.

Table 1. Gains and losses in ecosystem services modeled under three scenario categories, San Pedro River watershed, States of Arizona and Sonora, Mexico.

\begin{tabular}{|c|c|c|c|c|c|c|}
\hline Scenario & $\begin{array}{c}\text { Carbon sequestration } \\
\text { and storage }\end{array}$ & Water supply & $\begin{array}{c}\text { Biodiversity } \\
\text { (habitat quality) }\end{array}$ & $\begin{array}{c}\text { Aesthetic } \\
\text { viewsheds }\end{array}$ & $\begin{array}{l}\text { Proximity to } \\
\text { open space }\end{array}$ & Recreation \\
\hline Mesquite management & Loss & Gain & Gain & & & \\
\hline
\end{tabular}


To improve the value of these tools in decisionmaking, we suggest scientific needs that agencies such as USGS can help meet - for instance, development and support of data archives. Such archives could greatly reduce resource needs and improve the reliability and consistency of results. Given the rapid state of evolution in the field, periodic follow-up studies on ecosystem services tools would help to ensure that BLM and other public land management agencies are kept up to date on new tools and features that bring ecosystem services closer to readiness for use in regular decisionmaking.

\section{Rationale}

Ecosystem service valuation has been a subject of academic interest for decades, but it has only recently matured to the point where it is beginning to inform policymaking (Salzman, 2005; Ruhl and others, 2007; Daily and others, 2009). Spurred by growing demand for more sophisticated analysis of the social and economic consequences of land-management decisions, BLM launched a pilot project with USGS to assess the usefulness and feasibility of ecosystem service valuation as an input to decisionmaking. The project analyzed ecosystem services in the entire San Pedro River watershed - not just BLM-managed portion-to more fully consider complex social and ecological relationships that transcend administrative divisions.

"Ecosystem services" are the benefits that nature provides to humans. Ecosystem services are essential for meeting basic human needs (for example, clean drinking water), including support for psychological well-being (for example, aesthetic enjoyment). Services are commonly subdivided according to the type of benefit provided. The Millennium Ecosystem Assessment, perhaps the best-known ecosystem services classification, divides services into four categories (Millennium Ecosystem Assessment, 2005):

1. Provisioning services (for example, water, timber, other raw materials)

2. Regulating services (for example, flood regulation or carbon sequestration, which supports climate regulation).

3. Cultural services (for example, recreational and spiritual uses)

4. Supporting services (for example, nutrient cycling, biodiversity, net primary productivity).

Ecosystems are commonly studied in biophysical terms; ecosystem service valuation is meant to add to, not substitute for, existing methods of analysis. Economic valuation of ecosystem services improves decisionmakers' ability to compare commodity and noncommodity uses of the land. BLM commonly analyses the economic impact of alternative resource-management scenarios on income and employment. However, outside of well-studied services such as recreation, it is much less common for BLM's economic analyses to consider the value of goods and services not traded in markets (nonmarket goods and services, including most ecosystem services). These nonmarket goods and services are typically the opportunity cost of resource extraction, and their quantification can more fully show the costs and benefits of such decisions. The public is increasingly demanding more inclusive economic analyses that encompass nonmarket values, and ecosystem service valuation is a substantial component of such analyses.

The perceived difficulty of conducting credible, replicable, and legally defensible ecosystem service valuation has limited its use among Federal agencies. One of the central aims of this pilot study was to evaluate the feasibility of conducting ecosystem service valuation given the limited capacity at BLM offices, particularly district and field offices. With this charge, we evaluated numerous valuation methods and tools to determine which are capable of providing defensible ecosystem service values without requiring resources beyond the reach of BLM.

Along with assessing the feasibility of conducting ecosystem service valuation, we were equally concerned with its relevance to BLM's district and field office managers, the primary potential consumers of value information. Ecosystem service valuation is useful only if it improves the ability to identify the tradeoffs between alternative management actions facing decisionmakers. From the outset of the project, Gila District and San Pedro Riparian National Conservation Area managers and staff were involved with defining the direction of the analysis.

\section{Introduction}

\section{Description and Goals of This Project}

The Bureau of Land Management (BLM)-U.S. Geological Survey (USGS) Ecosystem Services Valuation Pilot study was conceived to assess the usefulness of ecosystem service valuation to BLM's resource-management decisionmaking process. A relatively large body of research identifies ecosystem services (the benefits that ecosystems and their structure and processes provide to humans) (Millennium Ecosystem Assessment, 2005), studies the ecological processes that underlie ecosystem services, and values certain services. However, the development of methods and tools that integrate ecology, economics, and geography to support decisionmaking is a much more recent phenomenon (Ruhl and others, 2007; Daily and others, 2009).

The purpose of the pilot study described in this report was twofold. First, we sought to determine which, if any, methods for valuing ecosystems are ripe for operational use by BLM. Second, we explored the usefulness of an ecosystem service valuation framework to BLM's land and resource decisions. Although BLM commissioned this study and we discuss results in the context of BLM decisionmaking, we expect 
that our results will be relevant to other resource managers interested in bringing ecosystem services into various decisionmaking processes.

BLM manages some 245 million acres, primarily in the Western United States, and 700 million acres of subsurface mineral estate. BLM's multiple-use mission requires that it find an appropriate balance between nonextractive uses such as habitat conservation, recreation, and archaeological heritage protection, and the extractive use of resources such as timber, oil and gas, coal, uranium, and other minerals. Decisions that allocate lands and resources among these uses are made through the development of resource management plans (RMPs) and the analysis of proposed projects through environmental impact statements (EISs) and environmental assessments (EAs).

RMPs set overall land use allocations for a given management area, normally a field office, which usually covers several million acres. Within that framework, EISs and EAs identify the benefits and harms, both environmental and social, of proposed projects and alternative actions. Because BLM's planning decisions generally have consequences beyond BLM-administered lands, the analyses provided in RMPspotentially including information on ecosystem servicesare also used by State and local governments and other stakeholders. Two Federal laws have a particularly important role in guiding BLM's plan development and project assessment: the Federal Land Policy and Management Act (FLPMA) and the National Environmental Policy Act (Bureau of Land Management, 2005).

FLPMA declares that "the national interest will be best realized if the public lands and their resources are periodically and systematically inventoried and their present and future use is projected through a land use planning process coordinated with other Federal and State planning efforts" (FLPMA Sec. 102 [43 U.S.C 1701] (a)(2)). Several of its planning requirements are relevant for the consideration of ecosystem service values - specifically, that RMPs shall

(1) use and observe the principles of multiple use and sustained yield ...;

(2) use a systematic interdisciplinary approach to achieve integrated consideration of physical, biological, economic, and other sciences;

(3) give priority to the designation and protection of areas of critical environmental concern;

(4) rely, to the extent it is available, on the inventory of the public lands, their resources, and other values;

(5) consider present and potential uses of the public lands;

(6) consider the relative scarcity of the values involved ...; [and]

(7) weigh long-term benefits to the public against shortterm benefits (FLPMA Sec. 202 [43 U.S.C 1712] (c)).
The National Environmental Policy Act (NEPA) established a landmark national environmental policy that encourages environmental protection and informed decisionmaking. It provides the means to carry out these goals by

- mandating that every Federal agency prepare a detailed statement of the effects of "major Federal actions significantly affecting the quality of the human environment,"

- establishing the need for agencies to consider alternatives to those actions, and

- requiring the use of an interdisciplinary process in developing alternatives and analyzing environmental effects (Bureau of Land Management, 2008: 1).

Although the analysis of ecosystem services is appropriate for inclusion in NEPA documents, to date (early 2012) they have rarely contained such analyses, with the exception of historically well-quantified nonmarket values such as recreation (Ruhl and others, 2007). Indeed, the act's focus on socioeconomic and environmental effects makes ecosystem services a potentially powerful integrating factor to consider in EAs and EISs. The limitation of requiring ecosystem services analysis within NEPA documents lies in the nascent state of the science of ecosystem services. Without tools and standards for measuring, quantifying, and valuing ecosystem services, Federal agencies, the private sector, and the general public are unlikely to support incorporation of ecosystem services into NEPA or other decisionmaking processes. The recent emergence of tools designed to support such decisionmaking offers initial insight into how services could be measured and compared for such decisionmaking processes.

Because BLM manages land for multiple uses, information to better inform managers about tradeoffs between commodities production and ecosystem services could be particularly useful. Commodities are derived from ecosystem structure and have economic values that can be relatively easily monetized. Ecosystem structure, in conjunction with the ecosystem processes it supports, generates ecosystem services that are nonexcludible or nonrival, making it difficult to clearly understand their economic value (Excludability is a legal characteristic that limits access to a good to those able to pay for it - for example, nonexcludible goods can be made excludible by introducing access fees to a park or emissions fees for the release of pollutants. Rivalness is a physical characteristic of a good that limits its use to one user or user group-for example, the consumptive use of water or other resources is rival, while water use for recreation is nonrival. (Samuelson, 1954)). As a result, commodities or ecosystem goods may be overconsumed at the expense of ecosystem services. This overconsumption has been termed the "tragedy of ecosystem services" (Lant and others, 2008) or the "macroallocation problem" between ecosystem structure and function (Farley, 2008). By understanding, mapping, and valuing ecosystem services, BLM can better manage this tradeoff, a goal that directly addresses the multiple use-sustained yield mandate set forth in FLPMA. 
Incorporating ecosystem services into decisionmaking offers several potential advantages to BLM and other land managers charged with achieving a sustainable, equitable, and efficient allocation of goods and services to the public. Incorporating ecosystem services into BLM decisionmaking offers the potential for users to

- Better understand how ecosystem service benefits accrue to private land from adjacent public land, and the reverse.

- Evaluate tradeoffs in development and resourcemanagement decisions.

- Identify management discrepancies between jurisdictions, in cases in which a set of activities in one area affects neighboring jurisdictional units.

- Better differentiate categories of beneficiaries and stakeholders associated with management decisions and thus more effectively analyze their impacts.

- Reduce the incommensurability of costs and benefits when management tradeoffs are considered.

- Increase the scale of analysis by identifying cases where management activities have positive or negative effects beyond the boundaries of a BLM unit.

- Increase BLM's responsibility and responsiveness in providing market and nonmarket goods to state and local communities and stakeholders.

This pilot study is intended to guide BLM at national, State, district, and field offices concerning the current readiness of ecosystem service valuation methods and tools. It does not support a particular set of management decisions for the San Pedro River watershed or elsewhere. Although this study assessed year 2000 conditions and a series of scenarios for that watershed, results are intended as proof-of-concept for the methods used and are not at this point intended to guide management.

San Pedro Riparian National Conservation Area (SPRNCA) and Gila District managers and stakeholders identified a number of resource-management issues relevant to the San Pedro River watershed whose connection to and effect on ecosystem services could be further explored (table 2). Ecological and socioeconomic effects, appropriate valuation methods, and effects on specific stakeholders could then be identified (van Beukering and others, 2003). Potential ecosystem service effects of a specific management decision, mesquite management, with the intent of restoring native grassland, illustrate the linkages between management actions and potential changes in ecosystem services (table 3 ). Although this study did not precisely value and model changes to all of these services, it shows how a range of potential effects and affected parties can be identified by using an ecosystem services approach.

\section{Links to Strategic Goals of Arizona Bureau of Land Management}

The project estimated values for four ecosystem services. In determining which services to evaluate, the project team considered the link between the ecosystem services and Arizona BLM's strategic goals . Ecosystem services evaluated were (1) water (valued for drinking, irrigation, and recreation), (2) biodiversity (supporting, for example, birding, hunting, and wildlife viewing, (3) carbon sequestration and storage, and (4) cultural values (such as spiritual and aesthetic uses). These services link to BLM Arizona State priorities such as healthy watersheds, intact habitats, habitat stabilization, climate, working landscapes, heritage resources, and recreation (fig. 1). We intend for the results of this study to help BLM's Arizona State, district, and field offices analyze their effectiveness at meeting their strategic goals and to identify opportunities for improvement.

In this project, we considered ecosystem services throughout the San Pedro River watershed, not just BLMmanaged San Pedro Riparian National Conservation Area. External stakeholders, therefore, were critical to the success of the project. We engaged more than 40 external participants from government, academic, and nonprofit organizations. The contributions of these participants ranged from help in collecting data and running models to project scoping and dissemination of results.

\section{Literature Review}

The SPRNCA differs from most BLM units in the large amount and diversity of background research available to support decisionmaking. The watershed has been extensively researched in the fields of ecology, hydrology, geomorphology, economics and, increasingly, as an area of focus for interdisciplinary and transdisciplinary research. Hydrologic research at the Walnut Gulch Experimental watershed began in the 1950s (Moran and others, 2008), and work to integrate ecology, hydrology, and other fields dates back nearly two decades. (See appendix E, an annotated bibliography of ecological and economic studies reviewed for this study.)

\section{Ecosystem Services Analyzed}

On the basis of stakeholder discussions at the project kickoff meeting held in Tucson, Ariz., in January 2010, broad categories of ecosystem services of interest were identified for the San Pedro River watershed. Participants sought to specify concrete economic benefits and beneficiaries relevant to these broad classes of ecosystem services, as described below for each broad group of services. Ecological "endpoints"- the 
Table 2. Management issues on the San Pedro River watershed, States of Arizona and Sonora, Mexico, as identified by managers and stakeholders.

\begin{tabular}{|c|c|}
\hline \multicolumn{2}{|r|}{ Management issues } \\
\hline Broad & Specific \\
\hline Water & $\begin{array}{l}\text { Water quality. } \\
\text { Water quantity. } \\
\text { Surface and groundwater flows from Mexico: quality and quantity. }\end{array}$ \\
\hline Biodiversity & $\begin{array}{l}\text { Nonnative species. } \\
\text { Threatened and endangered species recovery. } \\
\text { Preserving biodiversity. }\end{array}$ \\
\hline Cultural & $\begin{array}{l}\text { Cultural site protection (for example, Murray Springs Clovis site). } \\
\text { Rural character and lifestyle. } \\
\text { American Indian treaty and trust responsibilities. }\end{array}$ \\
\hline International border & $\begin{array}{l}\text { Undocumented immigrants. } \\
\text { Border safety. }\end{array}$ \\
\hline Recreation & $\begin{array}{l}\text { Managing recreational demand. } \\
\text { Hunting and game management. } \\
\text { Multiple-use demand. }\end{array}$ \\
\hline Ecological process management & $\begin{array}{l}\text { Soil conservation. } \\
\text { Grassland preservation and erosion control. } \\
\text { Forage and range provision. } \\
\text { Wildfire management. } \\
\text { Habitat connectivity and corridors. }\end{array}$ \\
\hline Growth and change & $\begin{array}{l}\text { Climate change. } \\
\text { Urban growth. }\end{array}$ \\
\hline Preservation of baseline conditions & $\begin{array}{l}\text { Air quality maintenance or improvement. } \\
\text { Preserving natural soundscapes. } \\
\text { Preservation of night sky conditions. } \\
\text { Preservation of electromagnetic spectrum (Ft. Huachuca). } \\
\text { Aesthetics. } \\
\text { Migration. } \\
\text { Ft. Huachuca's viability. }\end{array}$ \\
\hline
\end{tabular}

Table 3. Potential effects of mesquite management and native grassland restoration on ecosystem services, San Pedro River watershed, Arizona.

\begin{tabular}{ll}
\hline \multicolumn{1}{c}{ Ecosystem service } & \multicolumn{1}{c}{ Aspect potentially affected } \\
\hline Hydrology & For domestic use, agriculture, mining, habitat and recreation. \\
Bird species & Habitat and recreation, nonuse value, migration support. \\
Forage & Beef, game. \\
Aesthetics & Open-space proximity, viewsheds. \\
Carbon sequestration and storage & Changes in carbon pools and uptake rates. \\
Firewood & Quantities for various user groups. \\
Raw materials & Wood for bowl and furniture making. \\
Recreation & Wildlife viewing, maintenance of microclimates, surface water, cultural features, access (trails, roads, \\
& protected status, wilderness areas). \\
Trust responsibilities & Nonuse value. \\
Migration support & Maintenance of ecosystem services in distant areas based on species migration. \\
\hline
\end{tabular}




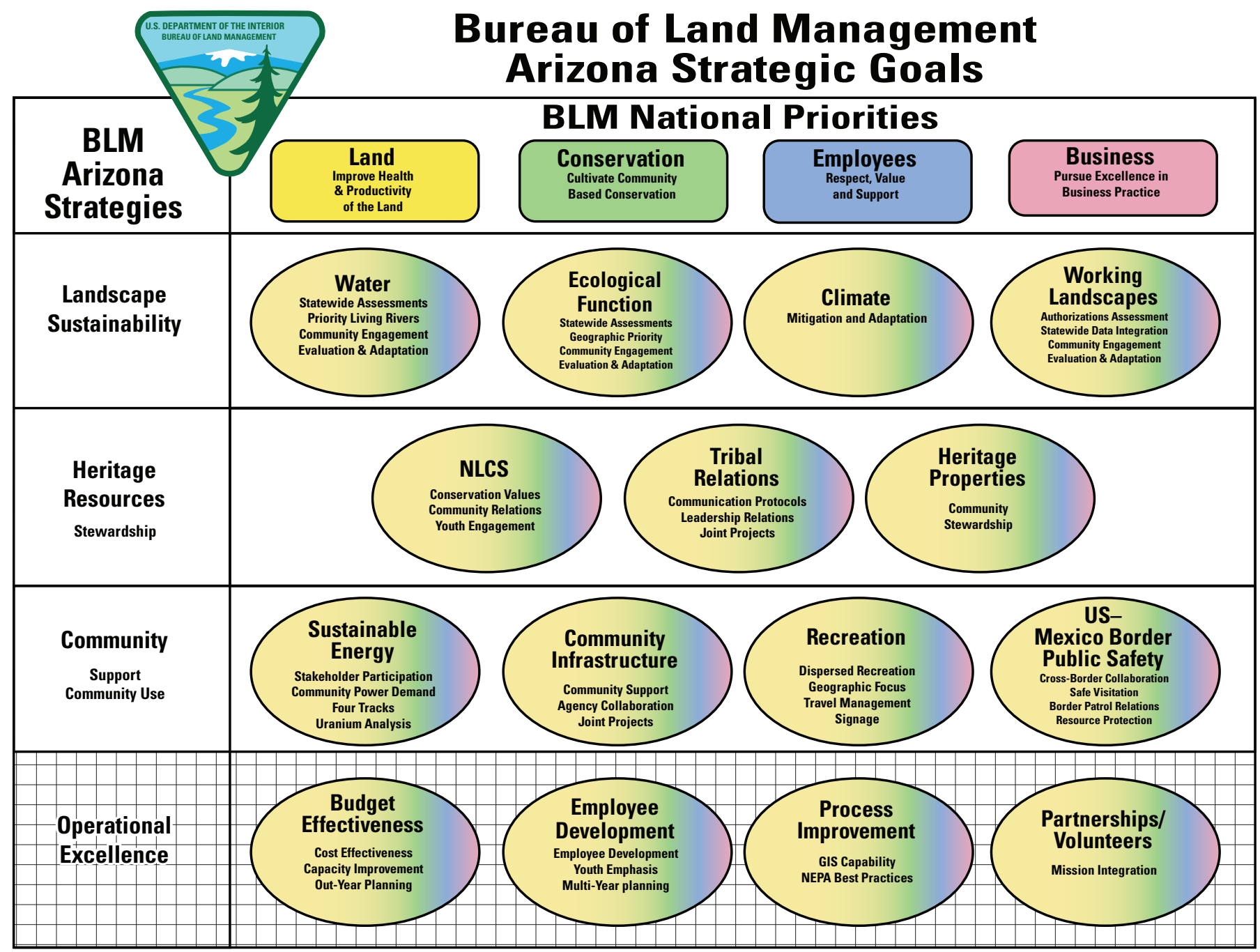

Figure 1. Strategic goals of Arizona Bureau of Land Management.

concrete biophysical attributes related to each ecosystem service that can be recognized by the general public as related to key ecosystem services (Boyd, 2007; Boyd and Banzhaf, 2007) — can be further described (table 4). Although no new primary valuation research resulted from this study, providing the public with estimates of change in these easily understandable endpoints is important for supporting primary valuation studies. These endpoints are also usually relevant as data inputs to economic models and other social evaluations.

\section{Water}

Water within the San Pedro River watershed is used for domestic supply, irrigation, and mining, and it also supports upland and riparian ecosystems that themselves provide a variety of ecosystem services (Stromberg and Tellman, 2009). We do not explicitly consider the provision of ecosystem water needs as an ecosystem service, because it lacks direct human beneficiaries, even though it underpins recreational, cultural, and other values.
Drinking water in the San Pedro River watershed is entirely drawn from groundwater. While some wells near the river draw from the riparian aquifer, particularly in the more sparsely settled Lower San Pedro watershed, wells in the more extensively developed Upper San Pedro watershed largely draw from the regional aquifer (the Upper and Lower watersheds are divided by a geologic constriction located north of Benson and known as "The Narrows"). Drinking water can be valued by using market rates, replacement costs for water augmentation alternatives (Bureau of Reclamation, 2007), or willingness to pay (WTP) for improved water quality and quantity (Piper and Martin, 1997). Agricultural water use has been declining in recent decades within the San Pedro River watershed, and irrigated agriculture was retired with establishment of the SPRNCA in 1988 and with The Nature Conservancy's purchases of water rights beginning in 2000 and continuing at the writing of this report (2012) to support in-stream flows on the Lower San Pedro River. The low profitability of alfalfa, the major irrigated crop in the region, also contributed to this decline. However, two small agricultural 


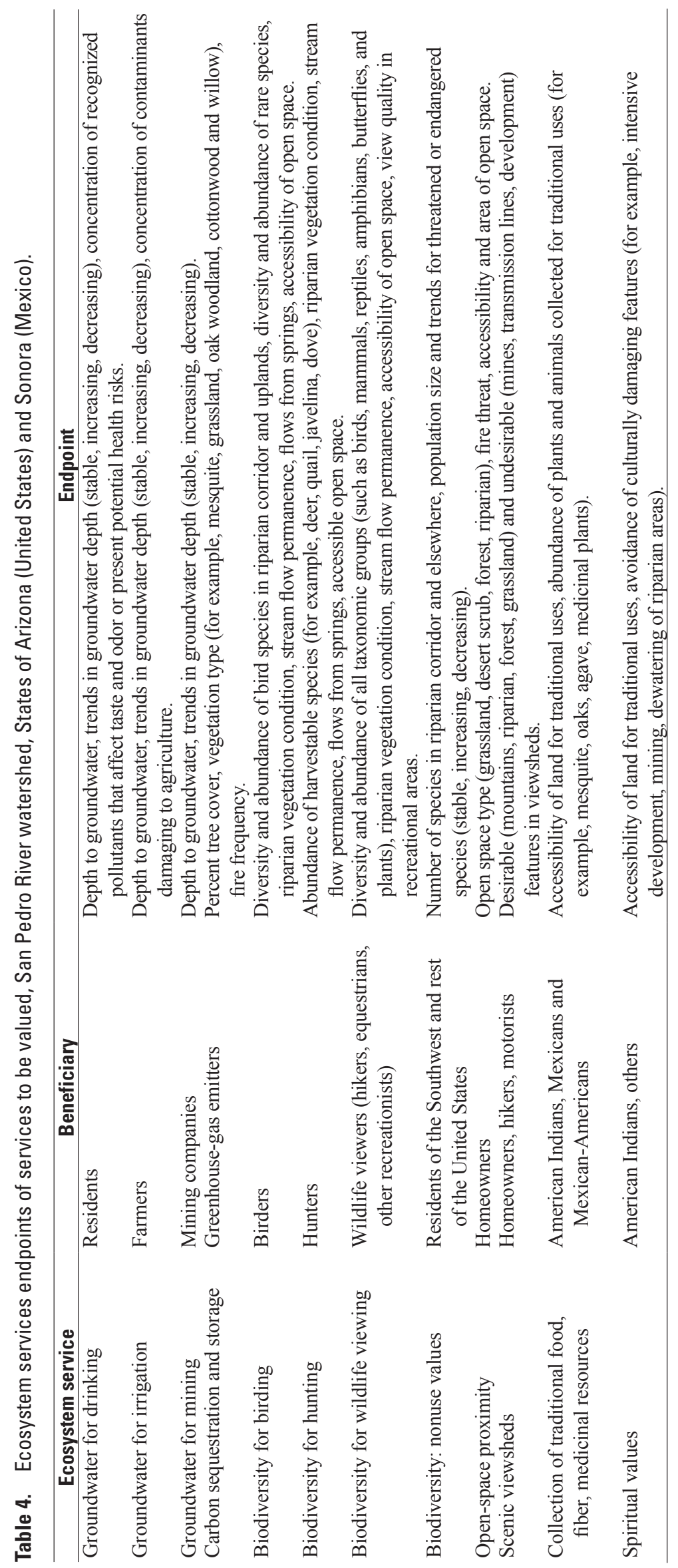


communities downstream of the SPRNCA, St. David and Pomerene (fig. 2), maintain seasonal surface water diversions for agricultural irrigation. Although major copper mines in Bisbee and San Manuel have closed in recent decades, water is still used for copper mining in Cananea, Sonora, and upstream of the San Pedro's confluence with the Gila River, where it is exported to nearby mining and smelting facilities in Hayden, Winkelman, and Ray, just outside the watershed (Katz and others, 2009).

\section{Carbon}

Carbon that is sequestered (added to soil and vegetation, typically measured on an annual basis as tons of carbon per acre per year) or stored (in vegetation and soils in tons of carbon per acre) can be valued by using carbon markets or estimates of the social cost of carbon (Tol, 2008; Ackerman and Stanton, 2012). Given the immature state of carbon markets and the fact that market caps are not tied to ecological thresholds for climate change, market prices are less appropriate than the social cost of carbon in estimating the value of carbon sequestration and storage. Data from past studies of carbon sequestration and storage in southwestern ecosystems (Schlessinger, 1982; Kaye and others, 2008; Schlessinger and others, 2009) were used to parameterize or calibrate carbon sequestration and storage models.

\section{Biodiversity}

Biodiversity is not in itself typically considered an ecosystem service, as direct anthropocentric value must be derived from it in order to qualify as such (for example, the Millennium Ecosystem Assessment (2005) considers biodiversity to be a supporting service). In the San Pedro River watershed, biodiversity supports key recreational activities such as bird watching, wildlife viewing, and hunting.

The economic value of birding is well established in the San Pedro River watershed (Orr and Colby, 2002; Colby and Orr, 2005; Brookshire and others, 2010), so valuation can rely on these primary economic studies. Hunting data are maintained by the Arizona Game and Fish Department (2009). Hunting is relatively limited in the SPRNCA, although it is important in other parts of the watershed. Deer, quail, javelina, and doves are some of the primary species of interest to hunters in the San Pedro area. Wildlife viewing is important for many visitors to the San Pedro area, although no specific studies have isolated the effect of wildlife viewing on visitor experiences.

Resource management agencies such as BLM also are responsible for protecting threatened and endangered species. Legal requirements related to the Endangered Species Act are commonly cited as evidence of public preferences for protecting threatened and endangered species (Engelmann and others, 2004). Spending on recovery is not a direct measure of consumer surplus (the price paid for a good subtracted from consumers' WTP for that good, taken as the traditional economic measure of utility or benefit derived from consumption of that good), and much of the public views it as a cost, rather than as evidence of a social benefit. However, the goals and provisions of this act do, in a blunt way, signal the American public's desire for species protection. Public interest, WTP, and actual funding levels for species recovery are typically greater for "charismatic" species - particularly large mammals and birds - and lower for fish, invertebrates, and plants (Richardson and Loomis, 2009).

\section{Cultural Services}

The economic value of several cultural services, defined by the Millennium Ecosystem Assessment (2005) as "nonmaterial benefits people obtain through spiritual enrichment, cognitive development, reflection, recreation, and aesthetic experiences," has been estimated for the San Pedro River watershed and nearby regions, providing the basis for direct valuation, value transfer, and modeling. Recreational values derived from biodiversity - birding, hunting, and wildlife viewing - are described in the previous section. Additionally, Weber and Berrens (2006) described the value of wilderness recreation in Aravaipa Creek. These values could be applied to other wilderness areas in the San Pedro region, such as Redfield Canyon (located within the Muleshoe Ranch Cooperative Management Area (fig. 3)), using value transfer.

Aesthetic values are typically revealed by increased property values of homes and other real estate near open space or with access to high-quality views. Given the population projections for Cochise County, in which the San Pedro River watershed is located, viewsheds and open-space distribution could change markedly depending on whether future development patterns are clustered or dispersed (Steinitz and others, 2003). Additionally, a proposed SunZia Transmission Line Project has the potential to impact aesthetic and other ecosystem-service values on the Lower San Pedro River watershed. Hedonic studies to estimate aesthetic value have been completed for residents near riparian areas in Tucson (Colby and Wishart, 2002; Bark and others, 2009) and central Arizona (Sengupta and Osgood, 2003) but not in the San Pedro area. (Hedonic pricing studies isolate the contribution of a particular attribute toward the total value of a good. In this case, structural attributes - such as square footage or number of bedrooms - and locational attributes - such as school district or proximity to green space- contribute to housing values, and the individual influence of each attribute can be identified).

The San Pedro River watershed holds important spiritual and cultural values, particularly for American Indian tribes with cultural or historic ties to the watershed. For instance, Fort Huachuca, an Army base adjacent to the SPRNCA, consults with 11 tribes that have connections to the San Pedro 


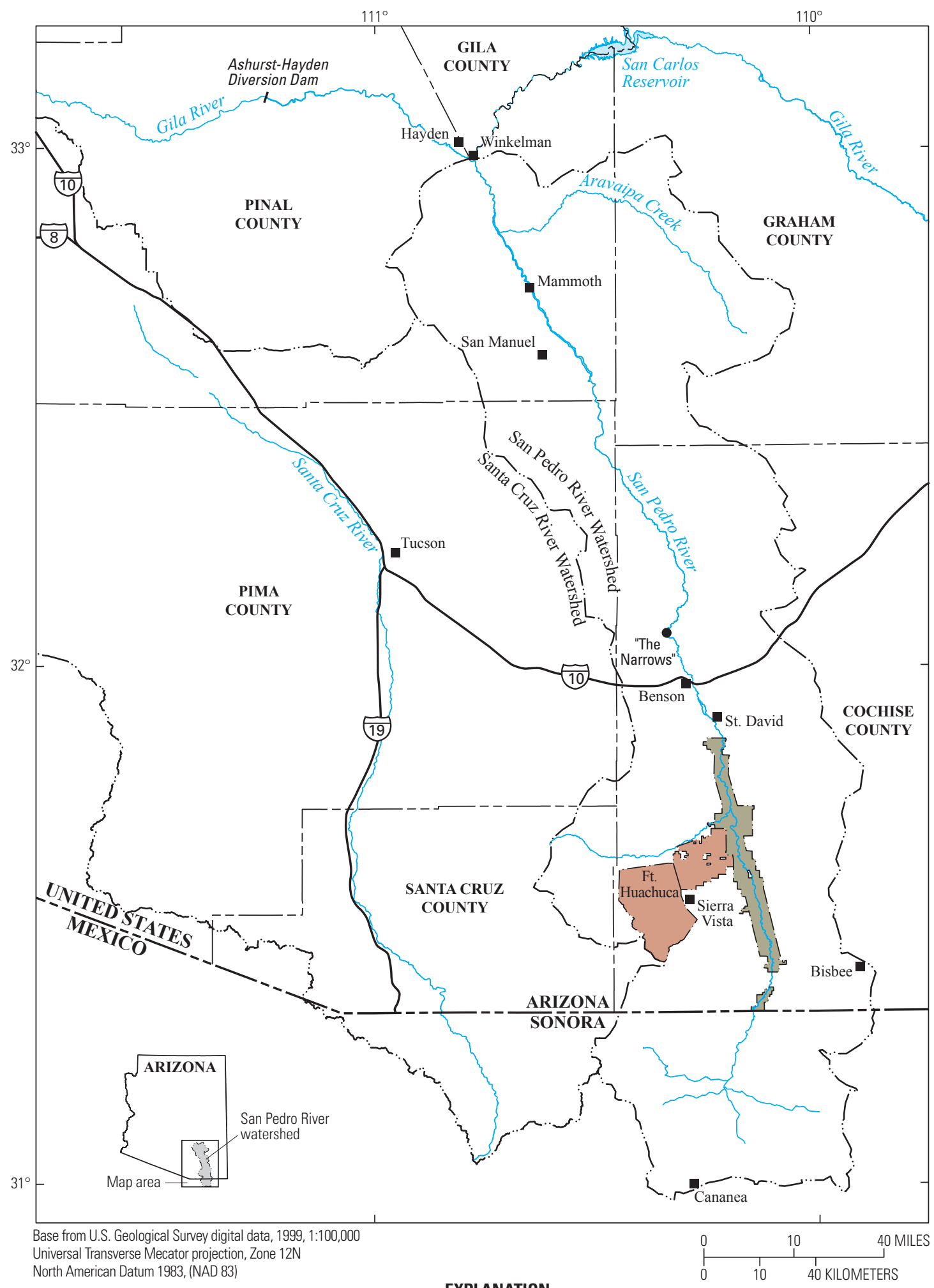

EXPLANATION

San Pedro Riparian National Conservation Area

Fort Huachuca Military Reservation

Watershed boundary

Figure 2. San Pedro River watershed study area, States of Arizona (United States) and Sonora (Mexico). 


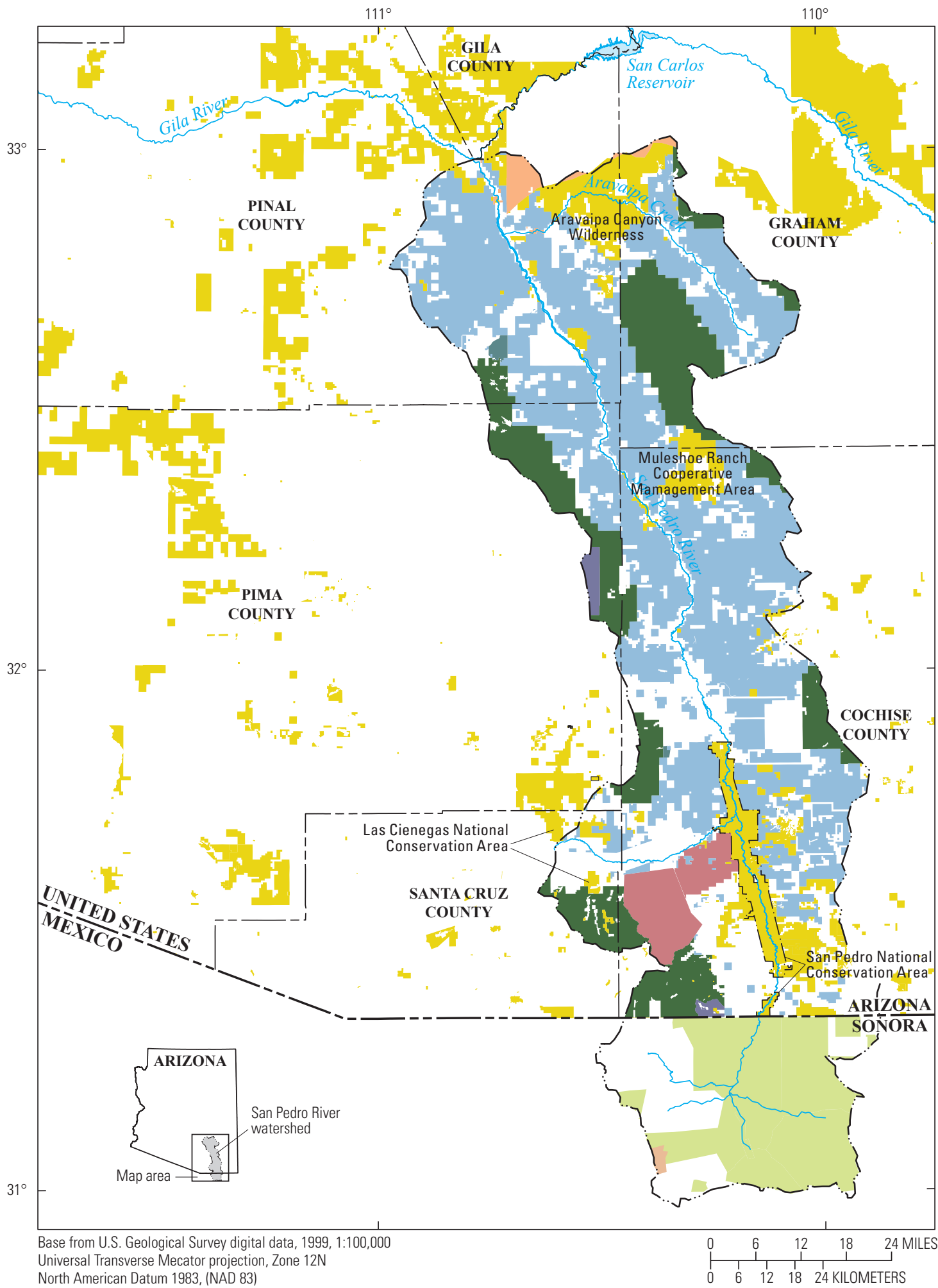

North American Datum 1983, (NAD 83)
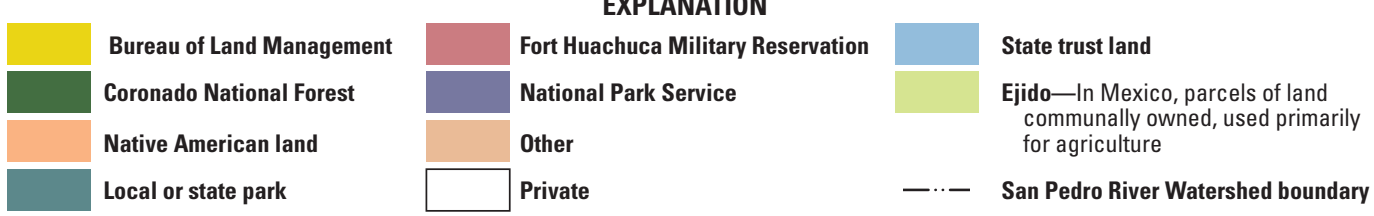

Figure 3. Land ownership within the San Pedro River watershed, States of Arizona (United States) and Sonora (Mexico), and Bureau of Land Management ownership in surrounding region. 
River (Marty Tagg, Fort Huachuca, written commun., 2012). Ferguson and Colwell-Chanthaphonh (2006) describe cultural values for the San Pedro River held by the Tohono O'odham, Hopi, Zuni, and Apache. There are serious limitations in applying economic valuation and utilitarian assumptions (in other words, that value can be derived by knowing how well it maximizes utility, which in mainstream economic terms has typically been measured in dollar values) to indigenous values (Venn and Quiggin, 2007). These authors argue that rights are more central and important than price-based measures in understanding the preferences of indigenous groups for environmental management. Important cultural ecosystem features, whether expressed in monetary terms or not, are best considered essential to any planning or evaluation exercise. Although such studies are beyond the scope of this project, they are critical in addressing these concerns in decisionmaking for BLM.

WTP surveys do not always differentiate "use" values (for example, bird watching) and "nonuse" values such as existence, option, and bequest values. Nonuse value might be expected to be important in the San Pedro River watershed region, given its regional, national, and international significance and its designation as one of The Nature Conservancy's "Last Great Places." However, the San Pedro River is less well known outside Arizona than other iconic southwestern natural features and protected areas, which might reduce its expected nonuse value relative to better-known locations. Nonuse value commonly declines with distance (Pate and Loomis, 1997; Loomis, 2000; Bateman and others, 2006). Determining this rate of distance decay can help to better define the extent of groups holding nonuse value for the San Pedro. Ongoing work by Brookshire and others (2010) is exploring the spatial extent of nonuse values for the San Pedro.

\section{Ecosystem Services Assessment and Valuation-Methods and Tools}

Selection of appropriate methods for ecosystem services assessment and valuation followed identification of relevant ecosystem services for the San Pedro River watershed. All known ecosystem-service valuation methods and assessment tools were reviewed, including those that are qualitative and quantitative, spatially explicit and nonspatially explicit, open source and proprietary, biophysically and monetarily based, and those still in development or not yet adapted for use in the semiarid southwestern United States (table 5). Tools have been developed by all sectors involved in ecosystem services research and policy, including academic institutions, government agencies, nonprofits, and the private sector. Methods and tools used to assess and value ecosystem services are rapidly evolving. Newly developed methods and tools will also need to be evaluated for their usefulness in decisionmaking on public lands. As new features are added to existing tools, similar reassessment will be needed.

\section{Primary Valuation}

Primary valuation data for an area of interest can be obtained in one of two ways: by applying past ecosystem services valuation studies that have appeared in the peerreviewed or gray literature or, where such studies are lacking, by developing new valuation studies. Studies can use stated preference (for example, contingent valuation or conjoint analysis, using monetary or nonmonetary expressions of preferences), revealed preference (for example, travel cost, hedonic, or market-based approaches), or avoided or replacement cost approaches. Development of new primary studies that use stated or revealed preference is commonly too resource intensive for all but the most important resource management contexts, although avoided or replacement costs may be more feasibly estimated. Thus, application of past values at the study site of interest is the most feasible approach for widespread use by BLM. Values can be standardized by converting them into consistent units (for example, dollars per acre per year, or dollars per visitor per day) and adjusting for inflation. However, the resources being valued are typically poorly described in the primary study, which can make it difficult to standardize values. A strict interpretation of these values means that they are best used only in the context of the scenario described by the original valuation study.

Application of past primary valuation studies typically begins by collecting studies selected from a literature review of appropriate databases (for example, Web of Science or EconLit (both available only by subscription), Environmental Valuation Reference Inventory (Environmental Valuation Reference Inventory, 2011)) or discussion with academic personnel or agencies familiar with the area of interest. A close review of each study and some basic conversions may be needed to standardize units. Primary valuation provides rigorous, locally appropriate estimates of nonmarket economic value. Primary valuation results may be relevant for most BLM offices, and assembled valuation results may be used for value transfer, as described next.

\section{Value Transfer}

Given the time and expense associated with primary valuation, value transfer has grown in popularity as a means of obtaining values when development of new primary studies is not feasible or the policy site has not been studied (Brookshire and Neill, 1992; Wilson and Hoehn, 2006). Value transfer uses economic values previously estimated at another study site and applies them to the site of interest. Several authors have described the criteria needed for sound value transfer, such as basic equivalence of the population, institutional setting, environmental resource, and constructed market (for example, mail compared with phone surveys or proposed one-time or annual payments) (Boyle and Bergstrom, 1992; Desvousges and others, 1992; Brouwer, 2000; Spash and Vatn, 2006; Plummer, 2009). 


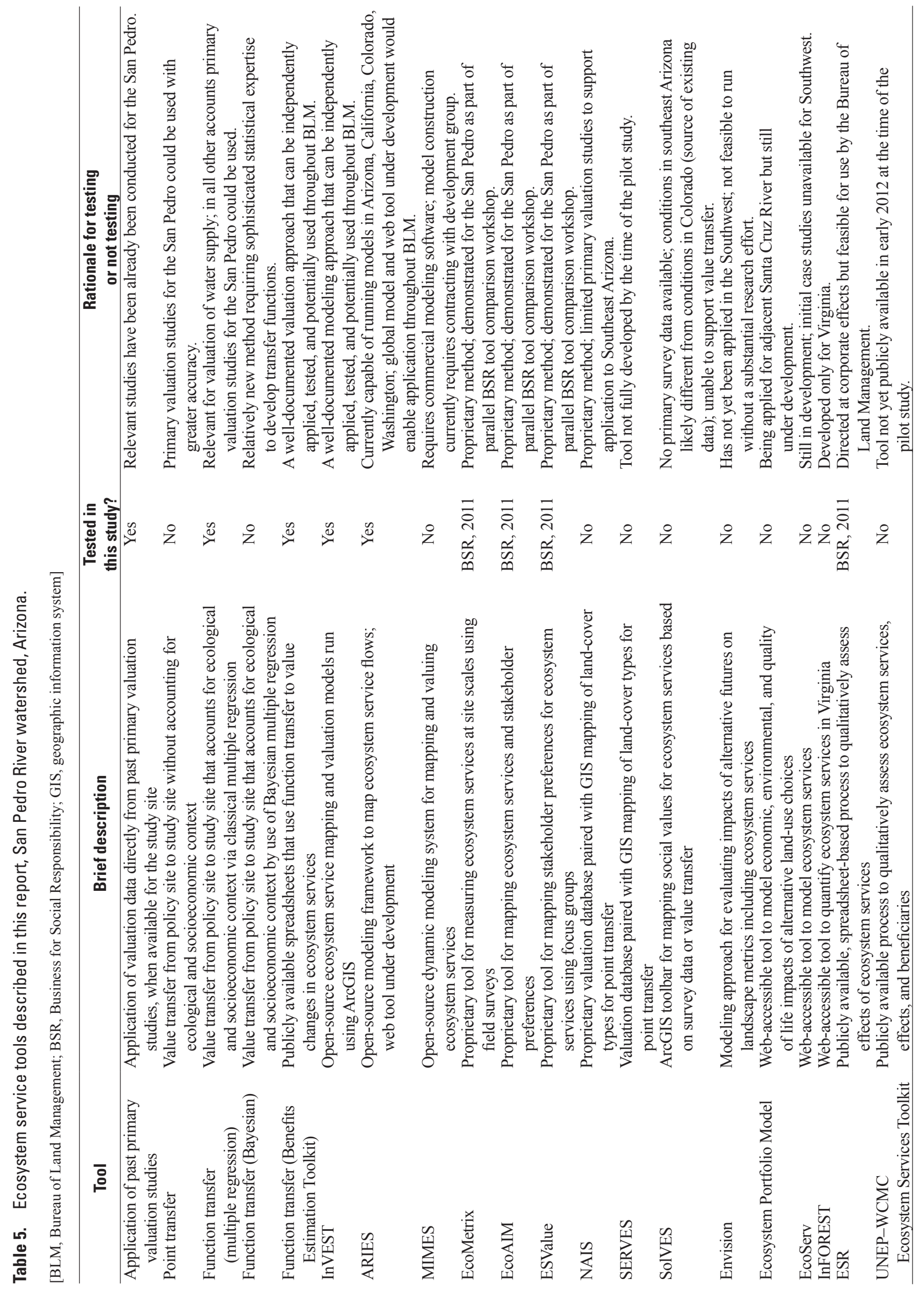


There is clear danger in transferring values between study and policy sites without considering the similarity of ecological and socioeconomic contextual factors. Function transfer, as opposed to point transfer, is designed to reduce these potential misapplications by applying a mathematical function to account for differences between study and policy sites (Loomis, 1992). The function is developed through metaanalysis of multiple studies. Function transfer is preferable to point transfer, in which values from a study site are typically transferred to a policy site without adjustment. Yet to date, function transfer has been used relatively infrequently. The lack of primary valuation studies, which leads to a shortage of quality meta-analyses, has limited opportunities to use function transfer for most ecosystem types.

\section{Point Transfer}

In point transfer, land-use-land-cover data have typically been used to link values from study site to policy site (Troy and Wilson, 2006). In point transfer, studies are assembled by land-use-land-cover type and the area and value of ecosystem services in question are estimated. Although analyses typically multiply land-cover type times per-area value and sum to obtain a total value, this approach is inconsistent with marginal economic valuation, which underpins the valuation studies upon which point transfer is built (Bockstael and others, 2000). When valuation is conducted, it should be for a change in a particular resource as opposed to the summed value of all land-cover types. For example, the statement that "a 500-acre mesquite management-grassland restoration project will provide $\mathrm{x}$ thousand dollars per year in carbon sequestration, water supply, and recreational benefits," is both more correct economically and more useful for management than the statement that "ecosystems in the San Pedro River watershed provide y billion dollars per year in benefits."

Point transfer has typically begun with development of a land-use-land-cover typology for the area of interest and assembly of a database of primary valuation studies within an area defined as acceptably similar to the study site. The landuse-land-cover types for the study site are matched to primary valuation studies and summarized by type, and then values are totaled for the area of interest (Troy and Wilson, 2006). Results may, for example, summarize high, median, and low values for ecosystem services provided by land-cover types at a policy site. Potentially useful valuation databases include the Environmental Valuation Reference Inventory, a publicly accessible environmental valuation database (Environmental Valuation Reference Inventory, 2011), the Marine Ecosystem Services Partnership database (Marine Ecosystem Services Partnership, 2011), the Natural Assets Information System (Troy and Wilson, 2006), a proprietary database developed by the Spatial Informatics Group, and the Simple and Effective Resource for Valuing Ecosystem Services (SERVES) database (http://esvaluation.org/) developed by Earth Economics.
Point transfer is the simplest form of value transfer. Its application can be quite rapid given good land-use-land-cover data and a well-developed database of primary valuation studies. Although most advocates of point transfer recognize its shortcomings, they usually suggest that it can provide rough but useful "first cut" ecosystem service values given limited time and resources (Troy and Wilson, 2006). However, the weaknesses of point transfer are well documented: if differences between the study and policy site's ecological and socioeconomic setting and constructed market characteristics are not accounted for, transfer error can be quite high (Boyle and Bergstrom, 1992; Desvousges and others, 1992; Brouwer, 2000; Spash and Vatn, 2006; Plummer, 2009). Owing to these concerns, point transfers have been criticized by most economists, despite their popularity among practitioners. Thus, although point transfer is a low-cost option for valuation among BLM offices, it also has potentially low accuracy and utility for decisionmaking.

\section{Function Transfer}

In contrast to point transfer, an analyst using function transfer develops and applies a mathematical function to account for differences in resource characteristics, geographic setting, and the constructed market when comparing values between sites (Loomis, 1992). Multiple regression is typically used to estimate the relative contribution of several independent variables describing the site and study context in order to determine their individual influence on ecosystem service value, the dependent variable. For example, the annual per-acre value of wetlands might be empirically determined to depend on wetland acreage, wetland type, human population density, and per capita income in the area of interest. By supplying values for the independent variables, the analyst can determine the per-acre value of wetlands at the policy site in question. Bayesian approaches to developing transfer functions are a more sophisticated approach than classical multiple regression and offer the added benefits of accounting for the " $\mathrm{n}$ vs. k" problem in function transfer and handling the effects of methodological independent variables when using a transfer function (Moeltner and others, 2007; Moeltner and Woodward, 2009). The "n" vs. "k" problem refers to the dilemma where, owing to poor description of resource and study characteristics in primary valuation studies, the analyst uses either a small number of well-documented studies including all variables of interest (low $\mathrm{n}$, high $\mathrm{k}$ ) or a full set of studies but only evaluating the influences of a few common variables (high $\mathrm{n}$, low $\mathrm{k}$ ). The choice of a low $\mathrm{k}$ increases the risk of omitted variable bias in the regression model. Bayesian statistics differs from classical statistics principally in its use of past experiences to derive an expected probability distribution. Information from past studies and expert opinion are used to establish a prior distribution (for example, our belief of how observations such as WTP are distributed. The predictive distribution gives the probability of observing data that do not 
correspond with the prior distribution. As new information becomes available, the distribution may be updated to reflect changes. This updated set then becomes the posterior distribution (Atkinson and others, 1992; Morrison and Bergland, 2006; Moeltner and others, 2007).

Where transfer functions already exist, function transfer requires the analyst to collect data on relevant independent variables for the study site and to insert these values into the transfer function to obtain values for the study site. If transfer functions do not exist, they need to be developed, if enough studies are available that use the same dependent variable, supporting a valid statistical analysis. Relevant primary studies on a common ecosystem or ecosystem service are collected, and values for all independent variables and the dependent variable are documented for each study. The analyst then runs regression models, drawing on economic theory to account for relevant determinants of supply and demand for the ecosystem services of interest. Lastly, appropriate diagnostics are run to ensure that classical regression assumptions are met, to suggest appropriate transformations or model respecifications to be used as needed, and to guide selection of one or more appropriate models.

In Bayesian analysis, by contrast, the goal is to estimate a probability distribution of values for the coefficient of each independent variable. This probability distribution is derived from a set of expert-defined prior probabilities. Prior probabilities are then run through an algorithm that collects random samples from a probability distribution, in order to estimate a set of final, or posterior, probability distributions. The means and standard deviations of these posterior distributions are then used as coefficients in a function transfer model.

Meta-analyses and regression equations are well developed for several ecosystem services (for example, recreation (Smith and Kaoru, 1990; Walsh and others, 1992; Rosenberger and Loomis, 2001) and water quality (van Houtven and others, 2007)) and ecosystem types (for example, forests (Barrio and Loureiro, 2010), wetlands (Woodward and Wui, 2001; Brouwer and others, 2003; Brander and others, 2006; Ghermandi and others, 2008), and coastal and marine ecosystems (Brander and others, 2007)). When transfer functions are available, it is relatively easy to transfer values with greater confidence than that provided by point transfer, while theoretically reducing transfer error. This ease makes function transfer a relatively robust and efficient way for BLM district or field offices to obtain ecosystem service values.

However, transfer functions are not available for many ecosystem services and ecosystem types outside those already mentioned. The typical cause of a lack of transfer functions is that there are too few primary valuation studies upon which researchers can draw to develop transfer functions. New transfer functions are also relatively time consuming to develop. Bayesian analysis, while more powerful, requires additional time and expertise to run, which must be weighed against the benefit of potentially more rigorous transfer functions. Finally, sharing of databases built to construct new transfer functions is uncommon. These databases are typically built by academics who use them to conduct their own research, so there may be little incentive to share or collaborate, and the effort needed to build a new database is a barrier to scientists interested in entering the field. Although public databases are one way around this problem, such databases need to be designed to support meta-analysis, and few valuation databases (as is true for many other ecosystem-based management tools) have received funding for ongoing maintenance (McComb and others, 2006, Curtice and others, 2012). For example, the Ecosystem Services Database was last updated in 2002, and the Envalue database was last updated in 2004.

\section{Function Transfer Using Defenders of Wildlife's Wildlife Habitat Benefits Estimation Toolkit}

The Wildlife Habitat Benefits Estimation Toolkit is a set of spreadsheets that incorporates transfer functions based on literature for recreation, hedonic property premiums, and WTP for threatened and endangered species recovery (Loomis and others, 2008). It is also available through Colorado State University's Department of Agricultural and Resource Economics as the Benefit Transfer and Use Estimating Model Toolkit. These transfer functions were developed by using economic studies from throughout the United States, with the goal of supporting faster and more systematic function transfers.

The Toolkit requires users to choose and apply spreadsheets for each ecosystem service of interest. The user enters values for the required independent variables for a given transfer function (for example, species to value, type of water body, open-space characteristics, and wetland type, area, and region). The spreadsheet calculates economic value per household or recreation day, on the basis of transfer functions contained in the spreadsheet. The user can propose scenarios for management changes to quantify changes in economic value or sum economic values of different services.

The Toolkit is a well-documented package of metaregression analyses that can support more comprehensive and systematic function transfer than an analyst who assembles and uses transfer functions independently. However, its usefulness is limited to cases where transfer functions have already been developed - for the ecosystem services related to recreation, hedonic property premiums, and WTP for threatened and endangered species recovery. Periodic updates would be required to account for new transfer functions and primary valuation studies to inform them, although with a large number of existing studies in the database, transfer functions are likely to be relatively stable despite the addition of new data points, suggesting that updating could take place on a roughly 5-year cycle (Timm Kroeger, The Nature Conservancy, oral commun., 2010). 


\section{Integrated Valuation of Ecosystem Services and Tradeoffs (InVEST)}

Developed by The Natural Capital Project, a collaboration of several academic and conservation nongovernmental organizations, InVEST is a set of ecosystem service models designed to map and value tradeoffs between multiple ecosystem services (Tallis and others, 2011). It has multiple releases or "tiers": the tier 1 tools available in early 2012 consisted of an ArcGIS toolbox interface for individual ecosystem service models; more detailed tier 2 tools that have been described (Kareiva and others, 2011) as of early 2012 had not yet been released. Tier 2 tools use more dataintense external ecological process models. Integration of tier 3 models - existing external ecological process models - is planned for future releases of InVEST. The marine InVEST models also include simple tier 0 models that map relative supply of or demand for ecosystem services in relative rather than biophysical units, with minimal underlying modeling and valuation. Economic valuation in InVEST can take place in biophysical units or by means of prices supplied as input by the user (for example, social cost of carbon, market price for timber, or avoided cost of sediment or nutrient removal).

InVEST is a well-documented method for mapping ecosystem service provision and comparing tradeoffs under land-use-land-cover change scenarios. In early 2012, InVEST included models for carbon sequestration, crop pollination, managed timber production, reservoir hydropower production, nutrient retention, sediment retention for reservoir maintenance, wave energy, coastal vulnerability, aquaculture, aesthetic quality, and fisheries and recreation overlap. It also includes biodiversity and habitat risk assessment models so that tradeoffs between biodiversity, habitat risk, and ecosystem services can be analyzed. Future releases of InVEST include planned models for flood mitigation, agriculture production, irrigation, open access harvest, commercial and recreational fisheries, recreation, and marine water quality, and carbon storage. Beta versions of InVEST have been in existence since summer 2008 and are reviewed through an open-source community, so they are likely at a more advanced and reliable stage than other modeling systems. Running on industry standard Geographic Information System (GIS) software (ArcGIS 9/10) and as a well-developed tool, InVEST in early 2012 had potential for widespread use by BLM in decisionmaking, assuming adequate data are available to support modeling efforts.

\section{Artificial Intelligence for Ecosystem Services (ARIES)}

ARIES is a modeling framework developed by the University of Vermont's Ecoinformatics Collaboratory at the Gund Institute for Ecological Economics, in partnership with several conservation NGO partners. ARIES seeks to address several scientific and modeling challenges in ecosystem services research and application, such as (1) the need to purchase and be proficient in commercial modeling or GIS software, (2) the difficulty of using existing ecological process models to generate outputs that are relevant for ecosystem services quantification, (3) the inability of past models to represent spatial dynamics of ecosystem services (that is, between points of provision and use, and spatial flows between them), and (4) lack of clear expression of uncertainty in past modeling efforts (Villa and others, 2011).

ARIES is accessible by means of an internet browser, and it provides users with access to a library of ecosystem service models and spatial datasets at global through local scales. Like InVEST tiers 2 and 3 models, ARIES plans integration of existing ecological process models in future releases of the system. In its early 2012 release, ARIES used a combination of Bayesian network models, deterministic models, and spatial data to quantify and map source locations that provide ecosystem services, use locations of human beneficiaries, and sink locations (the landscape features that deplete ecosystem service flows). A series of agent-based models, termed Service Path Attribution Networks, account for the full dynamics of ecosystem service flows (Johnson and others, 2012). ARIES encodes a set of artificial-intelligence-based decision rules that enable particular model components to be added or removed under appropriate circumstances (for example, to include different model influences under certain climatic regimes, above specified population or income thresholds, or for specific biomes). Once generalized global models supported by decision rules have been developed and deployed, ARIES will provide both low-cost first estimates of ecosystem service values in parts of the world where detailed local models have not yet been developed and also local models that are sensitive to regionally specific factors and make use of local data. ARIES handles uncertainty by means of Bayesian network modeling and Monte Carlo simulation (Villa and others, 2011; Bagstad and others, 2011; Johnson and others, 2012; Monte Carlo methods are a group of algorithms that use repeated random sampling to generate results that are expressed as a probability distribution).

ARIES models are open source. However, artificial intelligence, Bayesian modeling, and spatial flow modeling of ecosystem services are unfamiliar to many researchers and practitioners, and they require more sophisticated communication of results and modeling approaches. In early 2012, use of ARIES by BLM was limited to four study regions in the Western United States (southern Arizona, southern California, Colorado, western Washington), though release of global models could make its use more widely feasible for BLM. 


\section{Multiscale Integrated Models of Ecosystem Services (MIMES)}

MIMES is a system dynamics model initially developed by the University of Vermont's Gund Institute for Ecological Economics and since 2010 managed by AFORDable Futures, LLC (http://www.afordablefutures.com/). It is used to map and value ecosystem services based on interrelationships between natural and socioeconomic systems (Multiscale Integrated Models of Ecosystem Services, 2011). It is designed to account for temporal dynamics and feedback loops, incorporate existing ecological process models into ecosystem service modeling, and economically value ecosystem services by means of input-output analysis. This model uses the Simile modeling platform, a commercial software modeling package.

Running MIMES requires the user to download the latest MIMES models, prepare needed spatial data for the region and ecosystem services of interest, and develop, run, and calibrate the models. Because the models are open source, they can be accessed and used by anyone. However, many segments of this model are still in development, and local applications require it to be adapted to local conditions. Supporting documentation for the models and modeling process is currently minimal. As a result, a highly capable systems modeler could use MIMES, but in nearly all other cases, consultants would need to be hired to run the models and train BLM staff in its use.

\section{EcoMetrix}

EcoMetrix assesses ecosystem services for individual parcels of land on the basis of field measurements (Parametrix, 2010). It is a proprietary, spreadsheet-based approach developed by Parametrix, a consulting firm. EcoMetrix has been developed and parameterized for the Pacific Northwest and southwestern United States. It uses rapid field-based site evaluations to measure ecosystem services by linking observable field conditions to inputs in ecological production functions for ecosystem services of interest (ecological production functions specify relationships among the physical environment and ecosystem services along with relationships between key ecosystem services and human-induced environmental stressors-for example, human population growth affects available freshwater quantity, which affects other ecosystem services). Its primary use has been to estimate the generation of environmental credits for market-based trading by using field measurements for restoration or degradation scenarios. Because it is a proprietary method, Parametrix requires a contract for each application of EcoMetrix.

\section{EcoAIM}

EcoAIM is an ecosystem services mapping tool developed by Exponent, a consulting firm. EcoAIM is designed "to (1) inventory ecological services and help in making decisions regarding development, transactions, and ecological restoration; (2) develop specific estimates of ecosystem services in a geographically relevant context; and (3) offer the means for evaluating tradeoffs of ecosystem services resulting from different land or resource management decisions" (BSR, 2011). EcoAIM uses a series of publicly available, projectspecific spatial datasets combined with a weighting or aggregation function to derive a score for a particular ecosystem service of interest. EcoAIM can also integrate stakeholder preferences in considering ecosystem service impacts, using a modified risk analysis approach. Because it is a proprietary method, Exponent requires a separate contract for each application of EcoAIM.

\section{ESValue}

ESValue is an ecosystem services mapping and valuation tool developed by Entrix, a consulting firm. ESValue combines expert, site-specific, and literature-derived data to develop ecosystem services production functions (BSR, 2011). On the basis of available science and stakeholder preferences, ESValue specifies the relative values that society, managers, and stakeholders place on ecosystem services, as developed during a stakeholder engagement process. The ESValue tool thus facilitates the comparison of what can be produced (that is, production function) with what participants want to be produced (that is, the valuation function) to help determine the most appropriate natural resource management strategy. Because it is a proprietary method, Entrix requires a separate contract for each application of ESValue.

\section{Natural Assets Information System (NAIS) and Simple, Effective Resource for Valuing Ecosystem Services (SERVES)}

NAIS and SERVES are valuation databases that grew out of the Ecosystem Services Database initially developed by the University of Vermont's Gund Institute for Ecological Economics (Villa and others, 2002). Both combine an underlying valuation database with GIS analysis of land cover, which can be used for economic valuation using point transfer (Troy and Wilson, 2006). Analysis using these two approaches typically entails (1) identifying a study area, (2) developing a locally relevant land-use-land-cover typology and corresponding GIS layer to match with economic values, (3) searching the literature to select locally relevant studies for value transfer, linked to and-use-land-cover classes selected in step 2, (4) mapping, value calculation, and geographic summaries at the appropriate scales, and (5) scenario analysis (optional). NAIS was developed by the consulting firm Spatial Informatics Group, which requires a separate contract for each application of the database. SERVES, which is under development by the nongovernmental organization 
Earth Economics, is being designed as a subscription-based service. Earth Economics can be contacted for information about database access.

\section{Social Values for Ecosystem Services (SoIVES)}

SolVES was developed by the USGS in partnership with Colorado State University as a public domain GIS application accessible as an ArcGIS toolbar (Sherrouse and others, 2011). It is available for download at http://solves.cr.usgs.gov. This tool is intended to quantify and map the perceived social values of ecosystem services for various stakeholder groups; it includes aesthetic and recreation values and resource extraction alternatives through the derivation of a quantitative "Value Index" metric. The 10-point Value Index is calculated from a combination of spatial and nonspatial responses to public attitude and preference surveys. This model also calculates landscape metrics from spatial data describing the underlying physical environment (for example, average elevation and distance to roads and water at locations along the Value Index). The tool uses MaxEnt maximum entropy modeling software (Elith and others, 2011) to produce Value Index maps and to report landscape metrics associated with each index value. Values modeling can be repeated for various survey subgroups that are distinguished by their attitudes and preferences regarding ecosystem uses such as motorized recreation or oil and gas drilling. The Value Index provides a basis of comparison within and among survey subgroups to illustrate the effect of social context on the valuation of ecosystem services. The Value Index also facilitates statistical analysis of relationships between index values and landscape metrics. By using a form of value-transfer methodology, SolVES can be used to apply regression coefficients produced by such analyses to their corresponding landscape data layers and to produce predicted social-value maps for similar areas where primary survey data are not available or as a complement to existing survey data. Multiple applications have been completed in national forests in the Rocky Mountain region. Additional applications for several coastal and marine environments in the United States and elsewhere are also underway. These applications will enable further testing of the tool's value transfer approach.

\section{Envision}

Envision (http://envision.bioe.orst.edu/), previously known as "Evoland," is a "spatially explicit, actor (agent)based approach to landscape change and alternative futures analysis" (Bolte and others, 2006). Envision is a GIS-based planning tool designed to assist in evaluating how alternative urban development scenarios affect a series of landscape metrics. It incorporates policy choices by a set of actors, quantifies the effects of those choices on land-use-landcover change, and couples ecological and economic process models to map effects on landscape metrics. These effects are summarized as scenarios; a series of submodels are then run that account for social preferences for economic development, landscape metrics, land value, and population growth, in order to link spatial data with sets of policies that achieve certain mixes of economic and environmental goals (Guzy and others, 2008).

In recent applications of Envision, landscape metrics have increasingly included ecosystem services such as nutrient regulation, water provisioning, carbon sequestration, food and fiber production, shoreline protection, and pollination, and valuation typically uses market prices, avoided-cost, or replacement-cost methods. Envision has been applied principally in the United States Pacific Northwest, athough in 2012 international applications in Colombia and New Zealand were under development. Whereas the methods to develop new case studies for Envision are systematic and well documented, each application of Envision is place specific, meaning that transferability is low and new studies must be conducted for areas where Envision has not been previously applied. Recent applications of Envision have required approximately 1 year and $\$ 100,000-150,000$ to complete (given the variability inherent in the size and complexity of each study, most other tool developers were reluctant to provide estimates of the effort needed to conduct new case studies).

\section{Ecosystem Portfolio Model (EPM)}

The EPM is designed as a place-specific land-use planning tool to model ecological, economic, and quality-of-life values; it offers insight into the effects of land-use change (such as development, conservation, and restoration choices) on these values (Labiosa and others, 2009). For some easily monetized criteria such as the hedonic value of open space, results are monetized; for criteria that are more difficult to value monetarily, such as biodiversity, alternative user preferences can be compared by using a multiattribute utility approach. Each application is tailored to locally important ecological, economic, and quality of life issues. The model was initially developed for Miami-Dade County, Florida, and it focused on land-use and water-management issues, particularly in the context of development and maintenance of the ecological integrity of Biscayne and Everglades National Parks. Development of the EPM was underway in 2012 for two additional sites-Puget Sound, Washington and the Santa Cruz River, Arizona (Norman and others, 2010).

The EPM is a stand-alone, web-based tool. To run it, the user accesses the website (http://lcat.usgs.gov/sflorida/ sflorida.html for South Florida), chooses the area of interest, selects weights for valuation of each criteria, and views and compares results in the online viewer. The tool is well tailored to model environmental, economic, and quality-of-life issues for areas where it has been fully developed. Although its application on the Santa Cruz River, Arizona, could have informed the ecosystem service valuation and modeling work for this 
project on the San Pedro River watershed, it was at too early a stage of development to inform this study. Recent applications of the model to new regions has entailed a multiyear research and modeling effort. Thus, it is unlikely that its development and use by BLM will be feasible for regions where it has not previously been used. However, in regions where the model has already been developed, its application by BLM would be quite feasible.

\section{EcoServ}

EcoServ is an open-source, web-based ecosystem-service modeling and mapping tool under development by the USGS and the Chinese Academy of Sciences (Feng and others, 2011). The initial model was developed in the Prairie Pothole region of the north-central United States and the Canadian prairies, with additional planned case study sites in Mississippi and California's Central Valley. EcoServ's developers intend to eventually develop generalized national or global models that complement the EcoServ case studies. EcoServ links external ecosystem process models and data and will make them accessible to the public by means of a web tool. It is temporally dynamic and supports evaluation of scenarios for climate and land-use change. EcoServ does not explicitly use production functions in modeling ecosystem services; instead, it relies on a series of external models to proxy a service of interest. EcoServ does not put an monetary value on ecosystem services, although model outputs could be used in external valuation efforts. As of early 2012, EcoServ was in the development phase. However, once regional and national models are available on the web, it could be feasible for BLM offices to use EcoServ if it had been developed for their area of interest.

\section{Investing in Forests (InFOREST)}

The InFOREST model (http://inforest.frec.vt.edu/) is designed as a spatially explicit, web-based assessment tool for carbon, watershed nutrient and sediment loading, and biodiversity. The user enters the online interface, chooses the area of interest, and (if desired) enters land-cover and agricultural practices information. InFOREST is designed as an ecosystem service credit calculator; thus, it does not include economic valuation as a goal. It incorporates a series of existing carbon and hydrologic models and habitat metrics. InFOREST is under development at Virginia Tech University. Its spatial extent in early 2012 was only the state of Virginia, limiting its applicability for BLM, though its developers may eventually adapt it for other parts of the United States. InFOREST's hydrologic models are unlikely to be easily generalized to other parts of the United States, although its carbon and biodiversity models may be more easily transferred to other regions. If InFOREST is eventually expanded to a tool capable of covering Western United States ecosystems and ecological and hydrologic processes, it could be a useful tool for BLM.

\section{Ecosystem Services Review (ESR)}

The Ecosystem Services Review (World Resources Institute, 2012) is designed to identify ecosystem-servicesrelated resource and waste-sink dependencies and potential economic opportunities and liabilities for corporations. The ESR uses a spreadsheet (http://www.wri.org/publication/ corporate-ecosystem-services-review) that systematically identifies business dependencies, risks, and opportunities related to ecosystem services. However, it does not quantify, map, model, or value ecosystem services.

ESR is a free and well-documented approach to qualitatively evaluating ecosystem services from a business perspective. Although it was designed for corporate users, it could easily be used by BLM to identify ecosystem-service impacts associated with resource extraction tradeoffs. It is a relatively low-cost option for qualitative ecosystem services analysis that could be easily used by BLM.

\section{United Nations Environment Programme-World Conservation Monitoring Centre Ecosystem Services Toolkit}

This ecosystem services toolkit developed by the United Nations Environmental Programme's World Conservation Monitoring Centre (UNEP-WCMC) is a structured process for identifying stakeholders and the effects of ecosystem services at the site scale (United Nations Environmental Programme's World Conservation Monitoring Centre, 2011). It prompts users to identify ecosystem services, their beneficiaries, and impacts caused by alternative resource-management scenarios. Like the Ecosystem Services Review, this toolkit does not involve quantification, spatially explicit mapping, modeling, or valuation of ecosystem services, and its primary use would be as a low-cost framework for identifying ecosystem services of interest and impacts associated with resourcemanagement tradeoffs.

\section{Results of This Study}

This report quantifies and values four groups of ecosystem services identified by stakeholders and scientists as important to the San Pedro: those derived from water, carbon, biodiversity, and cultural values (such as recreational and aesthetic values). We used the valuation tools and methods described below.

Application of past primary valuation studies: Market and replacement cost values for water and social costs for carbon are summarized. Past nonmarket valuation studies could be used to account for some recreational and nonuse values on the San Pedro River watershed.

Value transfer: Where possible, value transfer was used to assess aesthetic value, water supply, and nonuse and recreational values not covered by primary valuation. Value 
transfer approaches include point transfer and function transfer where appropriate, and Defenders of Wildlife's Wildlife Habitat Benefits Estimation Toolkit.

InVEST model: InVEST models were used for carbon, water yield and demand, biodiversity, and aesthetic viewsheds.

ARIES model: ARIES models were used for carbon, water, aesthetic viewsheds and open-space proximity, and recreational values.

The testing of additional tools-MIMES, EPM, SolVES, SERVES, Ecosystem Services Toolkit, and EcoServ-was beyond the scope of this project, because the tools were either still in development or were not able to be run within the pilot study's time frame. This report briefly describes these tools to offer guidance on when and where they could be most useful for BLM.

During the course of this pilot study, a parallel comparative ecosystem services project was undertaken by BSR (formerly Business for Social Responsibility) in the context of corporate ecosystem service decisionmaking (see subsequent section Parallel Efforts). That effort assessed several additional tools, including the ESR, EcoMetrix (applied by Parametrix), EcoAim (applied by Exponent), ESValue (applied by Entrix), and (NAIS, applied by Spatial Informatics Group).

\section{Parallel Efforts}

A range of recent efforts is attempting to synthesize work on ecosystem services tools and approaches. Open communication is thus important so that researchers can learn from each other and minimize replication of such syntheses. Given the lag between research and publication in the peer-reviewed literature, and the fact that some of these reviews are internal documents, not all can be cited; Nelson and Daily (2010) and Vigerstol and Aukema (2011) are two published examples.

There is growing research interest in ecosystem services in the Southwest for the San Pedro and beyond. The U.S. Environmental Protection Agency's Office of Research and Development (US EPA-ORD) has undertaken placebased ecosystem services research in the Southwest United States and has applied the Ecosystem Portfolio Model to the Santa Cruz watershed, Ariz. The work in the Santa Cruz watershed is relevant to the San Pedro project owing to their similar ecological and social contexts. The Santa Cruz project also includes efforts to better understand how ecosystems and their services are valued by American Indian populations, through surveys of the San Xavier Tohono O'odham. In addition, the project team has collaborated with the Assessment of Goods and Ecosystem Services (AGAVES) group. This group is an interagency research partnership that builds on past ecosystem research in the Southwest. Its members include agency and academic scientists with expertise in hydrology, ecology, economics, and decision-support tools.

In a parallel effort, BSR undertook an evaluation of ecosystem services tools for corporate decisionmaking, and it also used the San Pedro for its comparison. BSR invited tool developers to a roundtable meeting in Phoenix, Ariz. in October 2010, where participants compared results for these tools from analysis of a set of hypothetical housing development scenarios for the San Pedro River watershed (BSR, 2011). Developers of the ARIES, InVEST, EcoMetrix, EcoAIM, and ESValue tools participated, along with others from the public and private sector.

\section{Methods}

\section{Selection and Description of the Study Area}

BLM and USGS set several criteria for the pilot study site. Because the goal of the pilot study entailed both monetary and nonmonetary valuation of ecosystem services, the study site needed extensive research that characterized its ecology in a landscape framework, including the effects of human uses, so that such information could be used to support quantification and valuation of ecosystem services. The ideal site also needed to have urban growth as a stressor, multiple management issues related to multiple ecosystem services, well-organized stakeholders (in this case, the Upper San Pedro Partnership), and native or cultural-heritage management issues, which would require consideration of how to value benefits that are not easily analyzed by monetary techniques.

The San Pedro River watershed in southeast Arizona met these criteria. This watershed contains the SPRNCA and has been studied extensively by members of the Upper San Pedro Partnership. BLM and USGS are members of the Partnership, as are many other government agencies, academic institutions, nonprofit organizations, and private interests. Although BLM has limited jurisdiction over the resources outside the SPRNCA, the San Pedro River watershed presented a robust example of the types of real-world resource-allocation dilemmas faced by BLM around the country, and it provided a good opportunity to test numerous valuation methods on a variety of resource issues.

After consulting with project partners, we selected the entire San Pedro River watershed as the study area, from its headwaters in Sonora, Mexico, to its confluence with the Gila River. Project participants generally favored studying the entire landscape within the watershed, from mountaintops to the riparian zone, to better account for the interspersion of different management practices and landowners (such as BLM, Department of Defense (DOD), U.S. Department of Agriculture (USDA) Forest Service, National Park Service (NPS), Arizona State Trust Land, and private land). In addition, the benefits of ecosystem services generally accrue to human beneficiaries at various spatial scales. Analysis of a broader geographic region allows a more complete analysis of the spatial flow of services from ecosystems to human beneficiaries.

The Upper San Pedro River watershed extends from the river's headwaters near Cananea, Sonora, to a geological constriction known as "The Narrows," north of Benson, Arizona 
(fig. 2). The Upper San Pedro has been the subject of considerable scientific study that has described the relationships between the watershed's geomorphology, hydrology, riparian vegetation, and avifauna (Moran and others, 2008; Stromberg and Tellman, 2009). Additional studies have focused on other aspects of the Upper San Pedro's ecology and have begun to document the economic value generated by riparian habitat, particularly for recreational value (Orr and Colby, 2002; Colby and Orr, 2005). Spatial data for the Upper San Pedro, including the watershed's Mexican headwaters, have also been compiled in a centralized archive (Kepner and others, 2003). The combination of intense conservation interest in the biologically diverse Upper San Pedro and the threat of groundwater decline due to pumping resulting from urban growth, particularly near Sierra Vista and Benson, have led to the integration of past research into a decision support system designed for use by local watershed groups such as the Upper San Pedro Partnership and the Benson Community Watershed Alliance (Serrat-Capdevila and others, 2009).

The San Pedro River's headwaters are located in Sonora, Mexico, an area of relatively few scientific investigations. Economic values for the river are likely to be different in the Mexican part of the watershed than in the United States part, owing to the presence of markedly different stakeholder groups that likely hold different preferences for riparian and upland habitat, and thus likely have a different demand for ecosystem goods and services (Ready and Navrud, 2006). This probable difference poses challenges to the valuation of ecosystem services in the Mexican portion of the watershed, particularly if value transfer is applied.

The Lower San Pedro River watershed is less populated and has received less scientific study than the Upper San Pedro. However, the Lower San Pedro also has high conservation significance, particularly given the threat of groundwater pumping prevalent in the Upper San Pedro. In recent years, groups such as The Nature Conservancy have been working to secure water rights for in-stream flow on the Lower San Pedro. USGS and the University of Arizona have conducted initial hydrologic modeling of the Lower San Pedro; additionally, ecological studies have been completed for parts of the Lower San Pedro, and an economic study has examined the value of recreation in Aravaipa Canyon, an important tributary to the Lower San Pedro (Weber and Berrens, 2006).

The Lower San Pedro River watershed also contains two important BLM management units: Aravaipa Canyon Wilderness and Muleshoe Ranch Cooperative Management Area; most of the remaining land is in private, state land, or USDA Forest Service ownership (fig. 3). A central data archive does not yet exist for the Lower San Pedro. Thus, spatial, ecological, and economic data are somewhat more limited for the Lower San Pedro than the Upper San Pedro.
Although we explicitly value ecosystem services generated within the San Pedro River watershed for this study, the beneficiaries of these services may be located outside the watershed, as provision and use of ecosystem services typically occur at various spatial scales (Fisher and others, 2008; Tallis and Polasky, 2009, Johnson and others, 2012). A complete analysis thus necessarily considers beneficiaries at global scales (for example, beneficiaries of carbon sequestration and storage), continental scales (bird migration support), national scales (national values about endangered species), and regional scales (recreation). Some values may extend an uncertain distance from the San Pedro (for example, nonuse values, Pate and Loomis, 1997; Loomis, 2000).

The SPRNCA is one of only two Riparian National Conservation Areas managed by BLM. Its management thus focusses predominantly on preservation of natural and cultural resources and provision of recreational opportunities (as opposed to resource extraction, which is more prominent in many other BLM units). On other BLM lands, ecosystem service values could inform tradeoffs between ecosystem services and extractive commodity uses such as energy development.

\section{Selection and Application of Ecosystem Services, Valuation Methods, and Tools}

\section{Ecosystem Services}

During a workshop held in January 2010 in Tucson, Ariz., with stakeholders and scientists involved with the San Pedro River watershed, ecosystem services was selected for further analysis. Tools and valuation methods for analysis were used as described in the Introduction and Methods sections.

\section{Evaluative Criteria}

Through discussions with stakeholders and scientists involved this pilot study and the parallel BSR project, including academic and agency scientists and practitioners applying ecosystem services concepts within the private sector, a set of eight evaluative criteria emerged that were deemed to be desirable by these potential users of ecosystem services tools. These criteria were applied to judge each tool's strengths and weaknesses in quantifying ecosystem services and its applicability within decisionmaking processes through seven questions. These questions gage the tool's ability to support ecosystem service assessments that are quantifiable, replicable, credible, flexible, and not unreasonably resource intense

1. Does this method or tool quantify ecosystem services, and can it explicitly account for uncertainty? Quantified outputs are necessary for measuring ecosystem-service tradeoffs, though qualitative tools may be useful in screening or scoping processes. Reporting a single value can inspire false confidence in the certainty of results, so uncertainty estimates are a valuable addition to the set of model outputs. 
2. What are the time requirements to use the method or tool? As the time required to apply a tool decreases, it becomes increasingly practical for widespread use in decisionmaking processes.

3. Is the tool or method open source or proprietary (would it require hiring of consultants, or could BLM staff use it if properly trained)? Ideally, BLM staff would be able to apply the tool without excessive time and training requirements or purchase of additional spatial analysis or modeling software.

4. What is the current level of development of the tool? Ideally the tool should be sufficiently developed enough to run reliably, use validated models, produce replicable results, and have its methods, assumptions, strengths and limitations well documented as part of a user manual and peer-reviewed journal articles, which may include validation exercises. Tools that are well developed and documented have greater transparency and credibility, which generates trust with decision makers and the public.

5. What is the scalability (applicability at various spatial scales) associated with this tool or method? Ideally the tool should be applicable at sites ranging from small BLM parcels to large parcels, watersheds, or district or field office boundaries.

6. What is the generalizability (ease of application at sites in different ecosystems, socioeconomic settings, or regions of the country) associated with this tool or method? Ideally the tool should be applicable throughout the Western United States, within all ecoregions and socioeconomic settings that contain BLM-managed lands.

7. How is the tool or method able to incorporate multiple valuation systems (monetary and nonmonetary) and cultural perspectives (such as tribal values)? Ideally the tool would account for nonmonetary preferences, including American Indian perspectives on how to value the environment in decisionmaking.

\section{Methods and Tools Considered in This Report}

We were unable to apply proprietary tools or those that required hiring a consultant or academic research group. These tools were EcoAIM, EcoMetrix, ESValue, NAIS, MIMES, and Envision (the last two are open source but require contracting with outside developers). We also eliminated tools that were at too early a stage of development to apply in new regions without substantial participation by an outside research group (for example, EcoServ, SERVES, UNEP-WCMC Ecosystem Services Toolkit). Tools at an early stage of development also tended to lack adequate documentation of assumptions and operating instructions. Other place-specific tools were eliminated because they were not easily applied to new locations. The Ecosystem Portfolio Model, which was initially developed for south Florida and is now under development for Puget Sound and the Santa Cruz River in Arizona falls into this category, as does InFOREST, which in early 2012 ran only for the State of Virginia. Finally, without the primary survey data needed to populate the SolVES tool, we could not apply it to the San Pedro pilot project.

We did not apply the Ecosystem Services Review, which is intended for a corporate audience, for this pilot. However, this model was applied as part of the BSR tool comparison project, and its application may be appropriate in evaluating resource-extraction scenarios. (For more information about this tool, see the Conclusions section.)

Although we did not explicitly test all of the above-listed tools as part of this project, we further discuss their application in the Introduction and Conclusions sections, on the basis of discussions with their developers and the parallel BSR comparison of tools.

After the tools mentioned previously in this section were eliminated, four tools remained that were applicable to the San Pedro River watershed within the scope of this pilot project: past primary valuation studies, value transfer (using the Wildlife Habitat Benefits Estimation Toolkit), InVEST, and ARIES.

\section{Data Needs}

Ideally an ecosystem-services tool would use nationally available datasets such as those for climate, soils, vegetation, and socioeconomic data, supplemented as needed by local data. For the San Pedro River watershed, much data were obtained from the US EPA San Pedro Data Browser (Kepner and others, 2003). See appendixes A and B for the full data needs of the InVEST and ARIES tools, as derived from their respective modeling references (Bagstad and others, 2011; Tallis and others, 2011). Loomis and others (2008) provide details on running the Wildlife Habitat Benefits Estimation Toolkit.

\section{Description of Assessment and Valuation Processes}

The valuation process began with a review of primary studies focused on the San Pedro River watershed. Primary studies were identified through database searches, specifically using Web of Science, EconLit, and EVRI and in consultation with researchers who have worked in the San Pedro region. See appendixes E and F for primary economic studies of the Southwest. Certain individual studies and the Wildlife Habitat Benefits Estimation Toolkit provide potentially relevant WTP estimates for water, biodiversity, and recreation, and hedonic studies provide value estimates for aesthetics. ARIES models were used to map carbon, water, aesthetic, and recreational values, and InVEST models were used to map carbon, water, viewsheds, and biodiversity (table 6). Ecosystem services models were reviewed at a workshop in Tucson, Ariz., September 21-23, 2010, to incorporate expert input in parameterizing the ARIES and InVEST models. Four economists also participated in a review panel that discussed the 
Table 6. Methods used for ecosystems services valuation, San Pedro River watershed, States of Arizona and Sonora, Mexico.

[--, not applicable]

\begin{tabular}{|c|c|c|c|c|c|}
\hline \multirow{2}{*}{ Method } & \multicolumn{5}{|c|}{ Ecosystem service } \\
\hline & Carbon & Water & Biodiversity & Aesthetics & Recreation \\
\hline ARIES & $\sqrt{ }$ & $\sqrt{ }$ & -- & $\sqrt{ }$ & $\sqrt{ }$ \\
\hline InVEST & $\sqrt{ }$ & $\sqrt{ }$ & $\sqrt{ }$ & $\sqrt{ }$ & -- \\
\hline Market price & $\sqrt{ }$ & $\sqrt{ }$ & -- & -- & -- \\
\hline Social cost & $\sqrt{ }$ & -- & -- & -- & -- \\
\hline Replacement cost & -- & $\sqrt{ }$ & -- & -- & -- \\
\hline Travel cost & -- & -- & -- & -- & $\sqrt{ }$ \\
\hline Willingness to pay & -- & -- & -- & -- & $\sqrt{ }$ \\
\hline Willingness to pay (transferred) & -- & -- & -- & -- & $\sqrt{ }$ \\
\hline Hedonic (transferred) & -- & -- & -- & $\sqrt{ }$ & -- \\
\hline
\end{tabular}

approaches and results of this study and to review study documents, including this report. Participants in the review workshop and the economics review panel are listed in appendix D.

\section{Scenarios}

One of the goals of this study was to compare a set of scenarios to baseline conditions to evaluate the effectiveness of tools in handling scenarios. Scenarios provide a way to explore realistic, marginal changes in ecosystem services and their values. The results of this study were not, however, intended to assess or prescribe policy mechanisms, such as growth management, or to provide definitive results for making a particular decision (for example, as part of an existing costbenefit analysis). They were intended as a proof of concept to describe the strengths and shortcomings of current ecosystemservices methods that could guide future decisionmaking.

Several ecosystem-service valuation methods were amenable to scenario analysis. InVEST and ARIES rely on spatial data. Provided that a data layer is relevant model input, inserting an alternative data layer (for example, land use, population density, or precipitation) produces a second set of results that can be compared to baseline conditions. The Wildlife Habitat Benefits Estimation Toolkit can also accommodate scenarios by including proposed changes to ecological and socioeconomic conditions in its valuation spreadsheet.

Baseline conditions for our analysis are for the year 2000, for which many spatial datasets are available, such as the Southwest Regional Gap Analysis Project land-cover dataset and urban growth scenarios comparing the year 2000 to alternative 2020 scenarios (Steinitz and others, 2003). Three scenario categories were used to evaluate the responsiveness of ecosystem services tools: urban growth, mesquite management, and water augmentation. Although a substantially greater number of scenarios can be developed by combining scenarios (for example, urban growth-mesquite management-water augmentation), in order to present more straightforward results, we evaluated each scenario category independently.

\section{Scenario Group 1: Urban Growth}

Urban growth scenarios for the Upper San Pedro River watershed were compared for the year 2020 by using year 2000 baseline plus "open" and "constrained" scenarios for 2020 (Steinitz and others, 2003; fig. 4). The open-development scenario assumes 50 percent greater-than-expected population growth by the year 2020 with relaxed restrictions on the location of new development, whereas the constraineddevelopment scenario combines 50 percent less-than-expected population growth with concentration of new development near already developed areas. These two scenarios provide upper- and lower-bound estimates for urban growth. In addition to urban development, the 2020 scenarios also assumed that nearly all grassland and mesquite in the Upper San Pedro will have converted to desert scrub. Although Steinitz and others (2003) did not justify this assumption, it means that not all ecosystem-service changes in these scenarios were brought on by development; some result from this assumed widespread vegetation change. Kepner and others (2004) also used these scenarios to model the relative hydrologic impacts of alternative development futures. Data in that study were not used in this pilot, as they were derived from an uncalibrated hydrologic model for demonstration purposes, but this model calibration approach could be used in the future as an input for ecosystem service modeling. Urban-growth and climate-scenario datasets compiled by the US EPA (Bierwagen and others, 2010) and USGS were not available within this project's timeline.

To run the urban growth scenarios using the InVEST model, the model's baseline land-cover layer was replaced by a layer appropriate for each scenario (for example, year 2020 constrained growth or open growth). For all ARIES models, we coded a series of changes in land cover and 


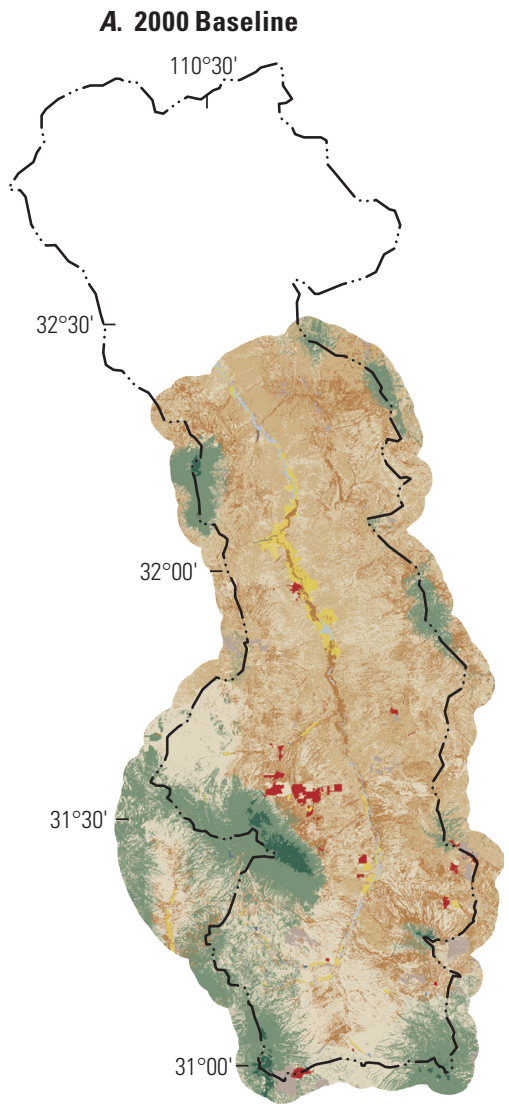

Base from U.S. Geological Survey digital data, 1999, 1:100,000 Universal Transverse Mecator projection, Zone 12N North American Datum 1983, (NAD 83 )
B. 2020 Constrained development

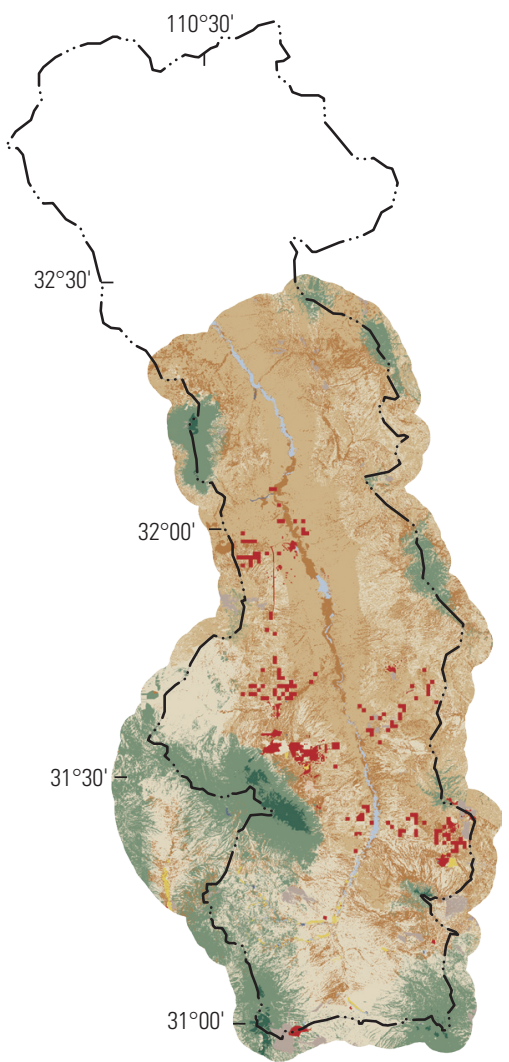

C. 2020 Open development

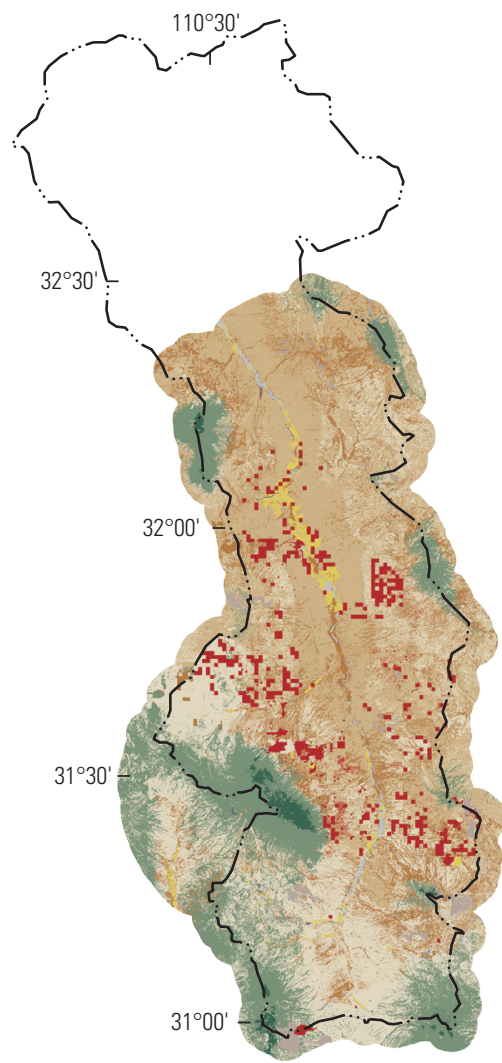

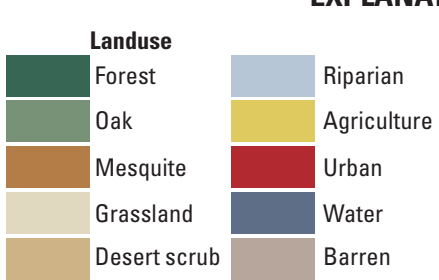

- - - San Pedro River Watershed boundary
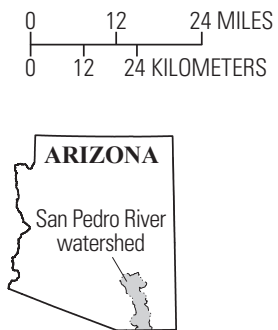

Figure 4. Urban growth scenarios, San Pedro River watershed, States of Arizona (United States) and Sonora (Mexico).

other service-relevant model attributes that typically follow development on a previously undeveloped landscape pixel. For instance, in the ARIES carbon model, percentage of tree canopy cover was reduced to "very low" and fire frequency to "no fire frequency," because fire is suppressed in developed areas. For the water-supply model, percentage of tree canopy cover was reduced to "very low" and potential mountain-front recharge was eliminated in developed pixels, because development replaces natural vegetation and soils with impervious surfaces. In the scenic-viewshed model, the preexisting vegetation type was eliminated and a new user (housing) was created simultaneously on the landscape. For the openspace-proximity model, past land cover was eliminated, fire frequency was reduced to "no fire frequency," and a new user (housing) was created on the landscape. For the recreation models, wildlife habitat and diversity measures were reduced to their lowest value and public access to those developed areas was restricted to quantify potential effects on birding, wildlife viewing, and hunting.

\section{Scenario Group 2: Mesquite Management}

In recent decades, mesquite has encroached widely onto desert scrub and grassland ecosystems in the United States Southwest (Kepner and others, 2000), causing an interest in using fire or mechanical means to remove mesquite and restore grasslands. In 2012, SPRNCA BLM staff completed a mesquite management EA identifying specific areas for management. Since these areas were not identified at the time of the modeling exercise, hypothetical mesquite management areas were identified within the SPRNCA (between Highway 

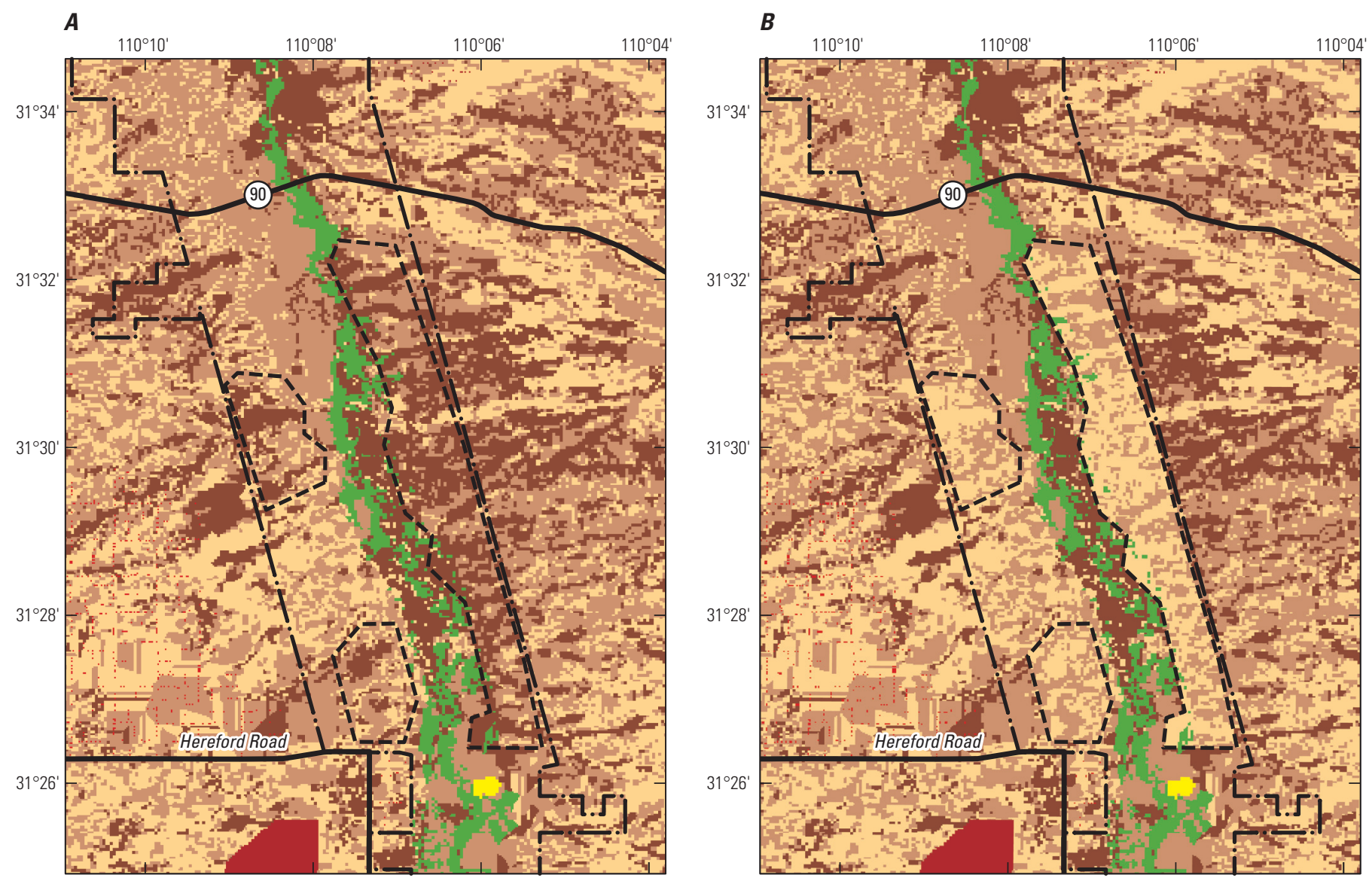

Base from U.S. Geological Survey digital data, 1999, 1:100,000 Geographic projection

World Geodetic System 1984, (WGS 84)

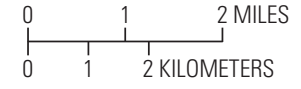

EXPLANATION

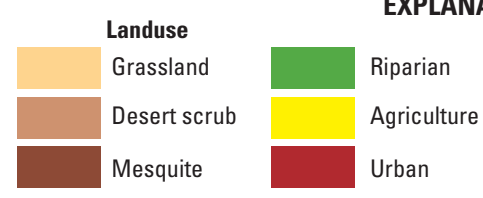

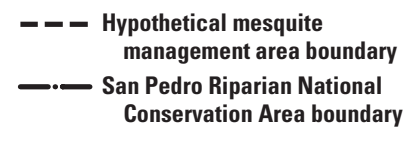

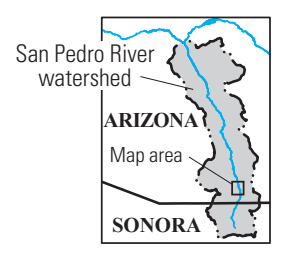

Figure 5. Land cover before $(A)$ and after $(B)$ mesquite management, San Pedro River watershed, Arizona.

90 and Hereford Road). This entailed modeling the conversion of 2,278 acres of mesquite into grassland to evaluate ecosystem service effects of this management strategy (fig. 5). The Automated Geospatial Watershed Assessment (AGWA) Land-cover Modification Tool (Miller and others, 2007) was used to convert mesquite to grassland in these areas.

In both the InVEST and ARIES models, the mesquiteremoval layer replaced the baseline land-cover layer. Additionally, because ARIES uses more attributes than land cover to model ecosystem service change, changes to other model attributes that accompany conversion of mesquite to grassland were coded. For instance, in the carbon and water supply models, the percentage of tree canopy cover was reduced to "very low."

\section{Scenario Group 3: Water Augmentation}

The Bureau of Reclamation's (BOR's) proposed extension of the Central Arizona Project from Tucson to Sierra Vista provided the basis for a third category of scenarios (Bureau of Reclamation, 2007). This proposed action would bring water from the Colorado River to the San Pedro in order to increase groundwater levels and surface flow within the SPRNCA, with the goal of maintaining or improving aquatic and riparian ecosystem quality. Scenarios for riparian condition initially developed by Stromberg and others (2006) and more recently used by Brookshire and others (2010) for ecosystem service analysis (fig. 6) were used to evaluate baseline conditions as changed by groundwater futures 3 (a uniform 0.5 -meter rise 


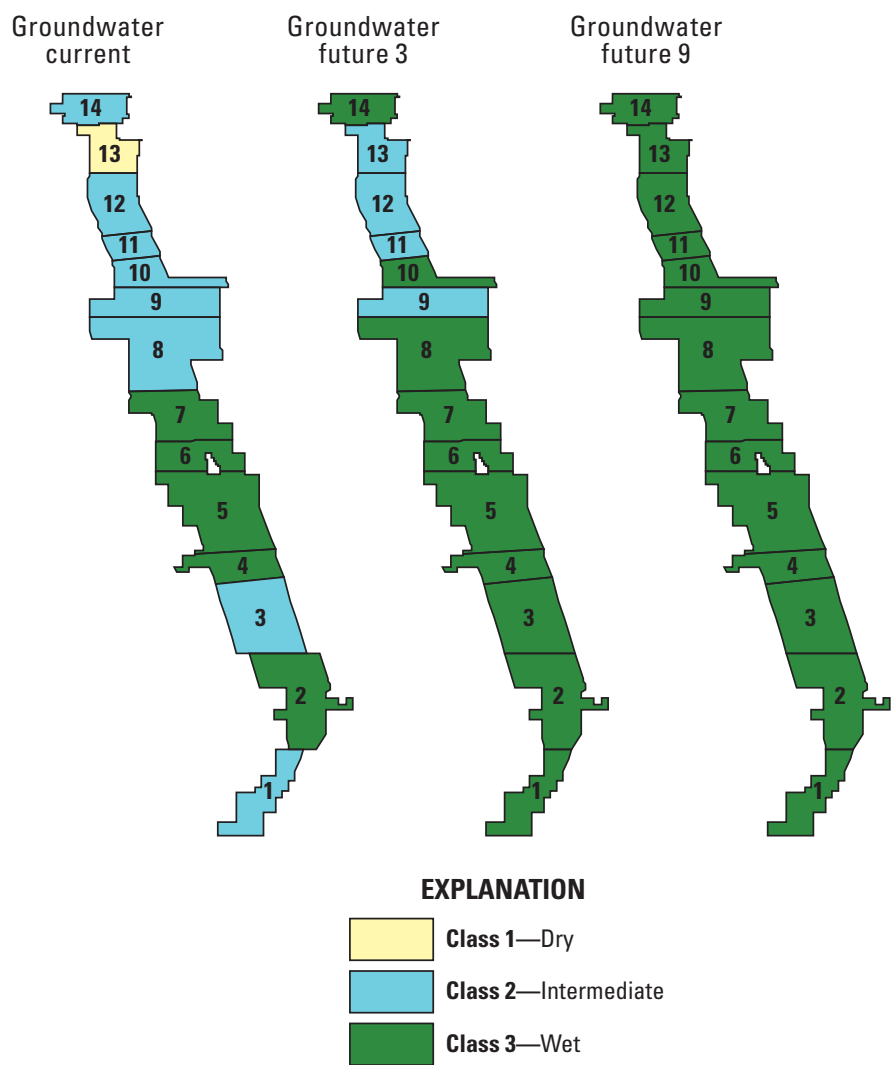

Figure 6. Hydrologic scenarios (groundwater futures) and year 2006 baseline conditions in the San Pedro River watershed, Arizona (Brookshire and others, 2010).

in groundwater throughout the SPRNCA) and 9 (achieving year-round surface flow within the SPRNCA). In 2012 the Arizona BLM and The Nature Conservancy were determining desirable groundwater and flow conditions for the Upper San Pedro River, which would provide a more objective basis for choosing desirable water-augmentation levels.

Water augmentation scenarios were used only in the ARIES recreation models, which predicted how changes in riparian-ecosystem quality could influence recreation in the SPRNCA, because the effect of these scenarios on other ecosystem services was unclear. Because riparian condition class was a direct input to the ARIES recreation models, the two groundwater-rise-scenario datasets were used instead of baseline data to obtain scenario results.

\section{Scenario Group 4: Climate Change}

Although some climate change modeling work has taken place on the San Pedro (Serrat-Capdevila and others, 2007; Dixon and others, 2009), this work is either not spatially explicit or does not contain results from the Intergovernmental Panel on Climate Change (2007) Fourth Assessment Report. We considered but did not apply climate-change scenarios for this project.

\section{Results}

\section{Results by Ecosystem Service}

\section{Carbon}

The InVEST tier 1 carbon storage and sequestration model uses a table linking land-cover type to carbon storage; sequestration is modeled as a function of land-cover change over time. Using this model, carbon sequestration and its value for the urban growth and mesquite management scenarios were mapped (fig. 7, table 7) (see appendix A for assumptions and data sources used with the InVEST models). Carbon was valued by using a set of conservative assumptions from the climate change economics literature ( $\$ 22$ social cost of carbon per ton (2011 United States dollars), 0 percent annual change in social cost, 7 percent discount rate) and a set of nonconservative climate economics assumptions (\$89/ton, 6 percent annual change in social cost, 1 percent discount rate) (for more information see appendix A). The InVEST carbon model showed a substantial loss in carbon storage under the urban growth scenarios, and more carbon storage was lost under the open-development scenario (3.4 million tons lost during a 20-year period, valued at \$35.8-144.4 million) than under the constrained-development scenario (2.2 million tons lost, valued at \$26.2-105.5 million). It also showed a smaller loss of carbon storage (34 thousand tons, valued at \$0.8-3.1 million) under the mesquite management scenario (table 7).

The ARIES carbon sequestration and storage models quantify and map the following:

1. Carbon sequestration and its uncertainty on the landscape, using a probabilistic model and sequestration values from the literature and spatial datasets.

2. Potential stored carbon release due to fire or deforestation, and its uncertainty, using stored carbon values from the literature and spatial datasets. Overlaying a polygon of fire locations in a particular year (for example, with average or high-intensity wildfire) can provide a more precise estimate of carbon release from wildfire.

3. Anthropogenic greenhouse gas emissions, using spatial data.

These three maps let a user quantify the regional carbon balance by subtracting stored carbon release and greenhouse gas emissions from sequestration to estimate whether a region is a net carbon sink or source. As in the InVEST model, a value can be placed on carbon sequestration by applying a social cost of carbon to each ton of carbon sequestration; results are presented as average annual values or summed for the policy time period as net present values. By using the ARIES carbon model, carbon sequestration and the potential release of stored carbon and their uncertainty were mapped for urban growth and mesquite removal scenarios (fig. 8, table 8) (see appendix B for assumptions and data sources used with ARIES 

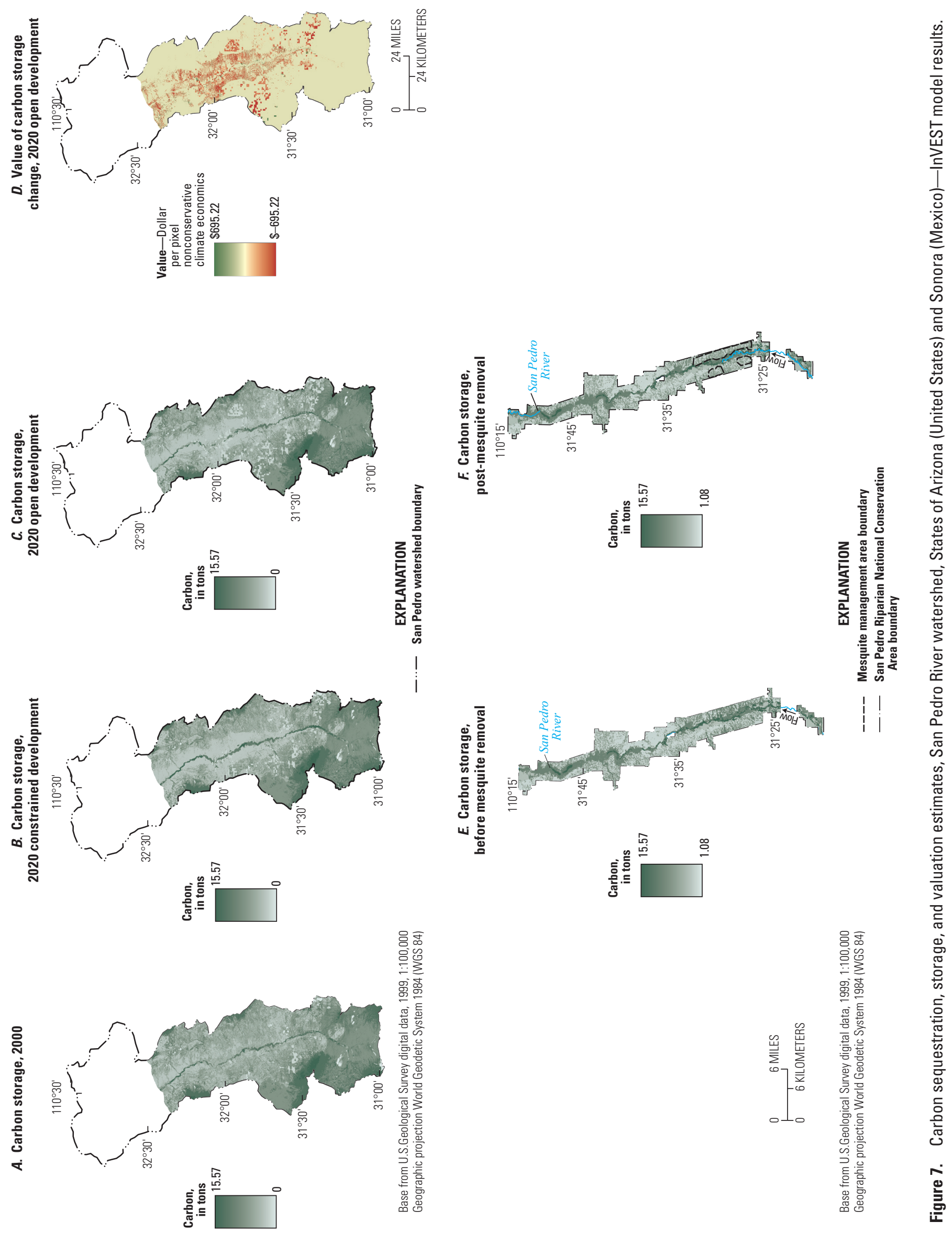
Table 7. Carbon sequestration, storage, and valuation estimates, San Pedro River watershed, States of Arizona (United States) and Sonora (Mexico)—InVEST model results.

\begin{tabular}{|c|c|c|c|}
\hline \multirow[t]{2}{*}{ Scenario } & \multirow[t]{2}{*}{$\begin{array}{l}\text { Carbon storage } \\
\text { (tons) [change] }\end{array}$} & \multicolumn{2}{|c|}{$\begin{array}{c}\text { Net present value of sequestered carbon and stock } \\
\text { change during a 20-year interval under two sets } \\
\text { of economic assumptions } \\
\text { (United States dollars 2011) [change] }\end{array}$} \\
\hline & & Conservative & Nonconservative \\
\hline \multicolumn{4}{|c|}{ Urban growth } \\
\hline 2000 baseline & $53,019,000$ & & \\
\hline 2020 open & $49,660,000[-3,359,000]$ & {$[-\$ 35,811,000]$} & {$[-\$ 144,357,000]$} \\
\hline 2020 constrained & $50,817,000[-2,202,000]$ & {$[-\$ 26,174,000]$} & {$[-\$ 105,508,000]$} \\
\hline \multicolumn{4}{|c|}{ Mesquite management ${ }^{1}$} \\
\hline Before & $1,557,000$ & & \\
\hline After & $1,523,000[-34,000]$ & {$[-\$ 756,000]$} & {$[-\$ 3,057,000]$} \\
\hline
\end{tabular}

${ }^{1}$ For all services, the results presented for before and after mesquite-management conditions show ecosystem services results for the San Pedro Riparian National Conservation Area.

models). As was true for InVEST results, ARIES results also suggest loss in carbon sequestration under the urban growth scenarios (loss of 110-115 thousand tons of sequestration per year, valued at \$2.4-10.3 million) and mesquite management scenario (loss of 148 tons of sequestration per year, valued at $\$ 0.003-0.013$ million). All scenarios also resulted in reduced potential for the release of stored carbon - with greater reduced potential in the open than in the constrained development scenario - because fire will likely be suppressed on and around newly developed land, thus lowering the risk for loss of stored carbon from fire. Although Bayesian network training (Villa and others, 2011) is available within the ARIES system, the quality of the training data was such that trained networks produced more spatially homogeneous results and had poor sensitivity to changing conditions in the scenarios, with only a minimal improvement in fit to the training data relative to untrained results. Improved training data may improve the quality of ARIES results that use trained Bayesian networks.

InVEST and ARIES carbon estimates are not directly comparable. InVEST estimates carbon storage on the basis of a table of carbon pools linking land use and land cover to carbon storage. Carbon sequestration is then estimated based on change with time between baseline and future scenarios. Although simple, this model provides relatively straightforward results based on the carbon pools data. ARIES estimates carbon sequestration based on factors influencing sequestration itself, the potential release of stored carbon due to fire, and greenhouse-gas emissions in the geographic area of interest in order to estimate a regional carbon budget. ARIES also produces uncertainty estimates for carbon sequestration and potential stored carbon release, as derived from results of Baysian network models. Both models would benefit from further calibration, testing, and refinement of carbon storage values by regional experts. Monetary values for ARIES carbon results are in dollars per year, whereas InVEST carbon results are in dollars during a 20-year period, so InVEST results need to be converted to annual values or ARIES results to net present values in order for the results to be directly comparable. Annualized results appear for both models in the subsequent section, Valuation Results of Scenarios.
Changes in carbon sequestration were estimated for the mesquite management and urban growth scenarios, but not for the water augmentation scenario. The InVEST model relies on changes in land use or land cover, and this study lacked a land-use land-cover typology and carbon pools data with fineenough detail to identify differences in carbon sequestration in riparian communities with perennial and with ephemeral streamflow. The ARIES carbon model uses factors such as percentage of tree canopy cover, mean annual precipitation, and fire frequency in estimating carbon sequestration and potential stored carbon release. A lack of information on how (and to what extent) water augmentation would change these factors meant that these changes were too poorly understood to model them accurately (we tested the relationship between riparian tree canopy cover and riparian condition class but found it to be extremely weak).

\section{Water}

InVEST models annual water yield by using average annual precipitation and the Budyko curve (Budyko, 1974), subtracting evapotranspiration from combined infiltration and runoff without differentiating between surface water, subsurface water, and base flow. Additionally, InVEST can estimate water demand by assigning a water-use coefficient to each land use or land-cover type to estimate total anthropogenic water demand. InVEST's tier 1 water model quantifies these values on an annual basis. However, spatially explicit water demand could not be quantified by using InVEST, owing to limitations in the scenario input data (table 9). InVEST's water yield output is designed to be interpreted at the subwatershed to watershed scale, because "pixel-scale representations of some outputs (are) for calibration and model-checking purposes only" (Tallis and others, 2011). The water yield submodel of the InVEST reservoir hydropowerproduction model was used to map water yield based on 2002 (representative dry year) and 2007 (representative wet year) precipitation, in addition to water demand for the urban growth and mesquite management scenarios (fig. 9, table 9) (see appendix A for assumptions and data sources used with 

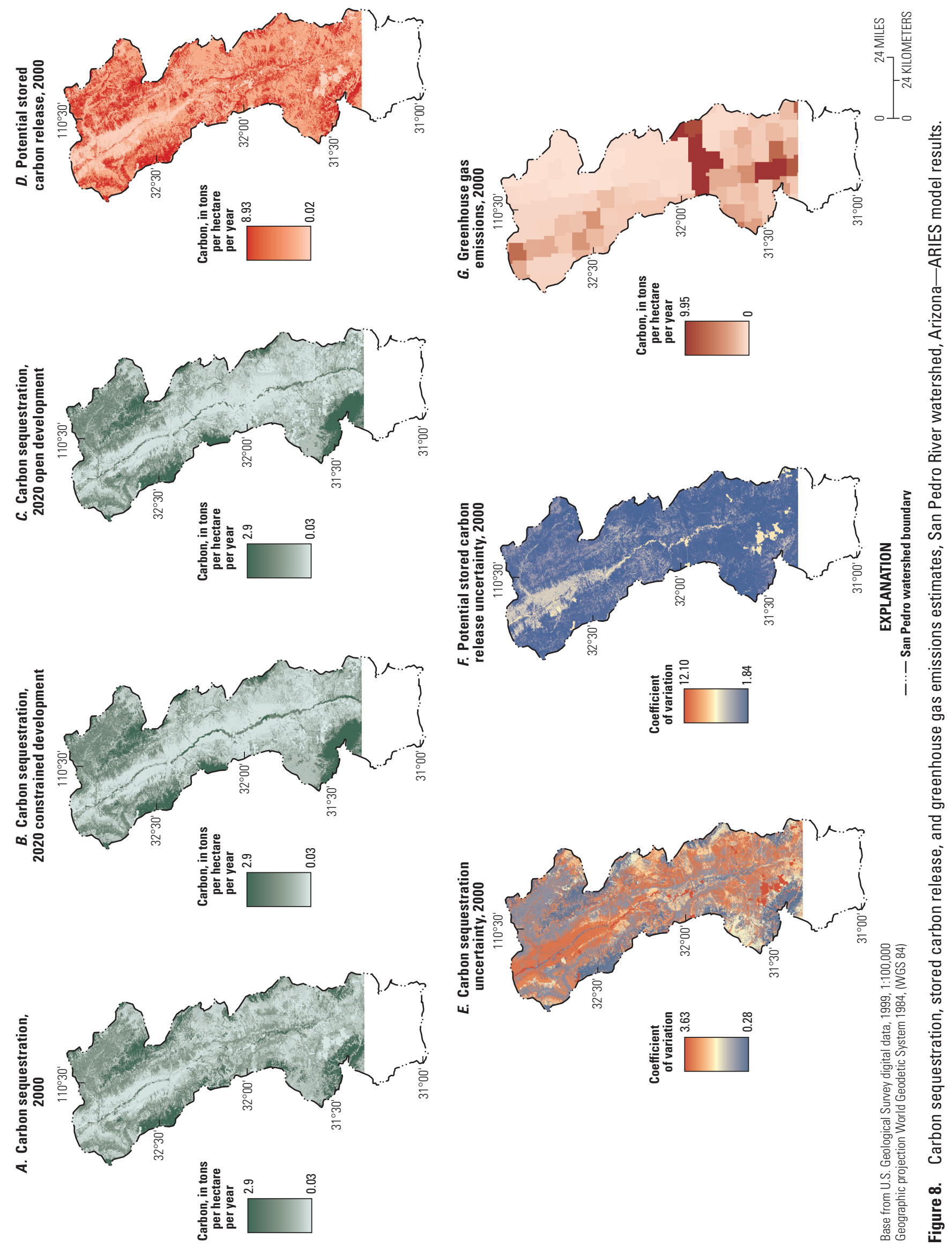


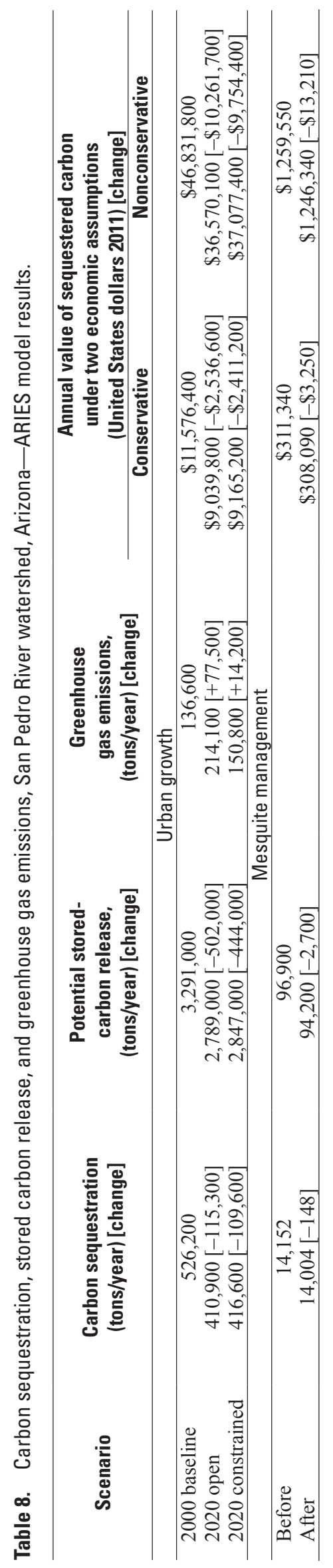



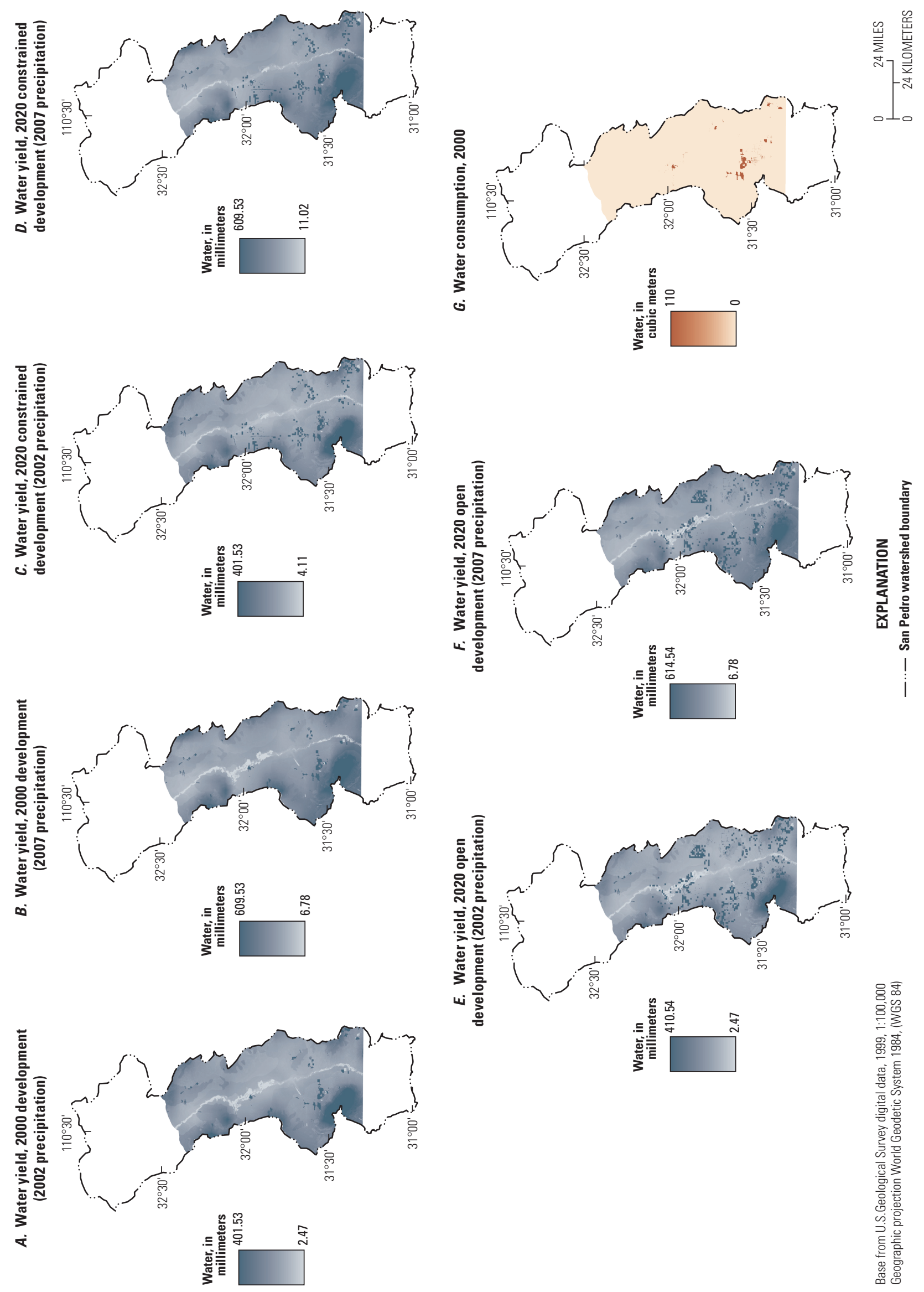
Table 9. Water yield and demand estimates, San Pedro River watershed, Arizona-InVEST model results.

\begin{tabular}{l}
$\begin{array}{c}\text { Housing } \\
\text { development } \\
\text { scenario }\end{array}$ \\
\cline { 2 - 3 }
\end{tabular}

the InVEST models). Total water-yield values were obtained by multiplying the sum of all pixel values in millimeters by the area of a cell $(30 \times 30$ meters $)$ and divided by 1,000 to convert water yield in millimeters into water yield in cubic meters. In InVEST model estimates, water yield substantially increased under both urban growth scenarios but showed greater yield under the open development (as opposed to the constrained) scenario (table 9). The increase in water yield reflects greater area of impervious surfaces that results in faster runoff. Faster runoff generally is undesirable because it can increase erosion, degrade water quality and aquatic habitat, and reduce groundwater recharge (this study did not quantify those effects). A small increase in water yield for the mesquite management scenario was expected given the lower evapotranspiration typical of grasslands relative to mesquite (Nie and others, 2012). In contrast to the urbanization scenario, increase in water yield is beneficial for the ecosystem, because grasslands near the riparian aquifer promote greater infiltration and base flow.

ARIES water models quantify (1) annual precipitation as the "source" of surface water, (2) evapotranspiration and infiltration and their uncertainty as "sinks" that deplete the quantity of surface water for downstream flows, (3) use areas where surface water is extracted for human use, and (4) flow models that map the movement of water across the landscape. In early 2012, ARIES did not account for groundwater flows, and thus results presented here refer only to surface-water flows and users (two small agricultural surface diversions near St. David, Ariz. (fig. 2)). In addition, groundwater-use data are not available in Arizona, severely limiting spatially explicit modeling of groundwater use and flows. The ARIES surface-water flow algorithm used in this study takes water only immediately upstream of a user to satisfy its water needs, so far-upstream impacts do not affect model results.

As in InVEST, these processes in early 2012 are modeled at the annual time step, and output was converted from millimeters to cubic meters. The ARIES surface water model, mapped theoretical and actual sources, sinks, and surfacewater users for the urban-growth and mesquite-management scenarios (fig. 10, table 10) (see appendix B for assumptions and data sources used with the ARIES models). Theoretical values show potential evapotranspiration and infiltration, whereas actual values show results when connected with a flow model (that is, accounting for what happens to water as it flows across the landscape). The most interesting ARIES results are the theoretical sink values - quantified potential landscape-scale infiltration and evapotranspiration. Watershedwide theoretical sink strength decreased by 2.7 percent under the open-development scenario and by 2.3 percent under the constrained-development scenario. Mesquite management reduced the sink strength within the SPRNCA by 0.3 percent. These results mean that under these scenarios less infiltration and evapotranspiration are likely to reduce surface water flows, largely owing to reduced infiltration in the urban growth scenarios, and reduced evapotranspiration for the mesquite management scenario. Similar to the increase in surface-water yield found in the InVEST water yield model, the reduced sink strength in the urban-growth scenarios is a detrimental effect, whereas in the mesquite management scenario it is a positive effect.

Both InVEST and ARIES estimate water yield and demand, but the modeling approaches and output are quite different for these two modeling systems. ARIES spatially links surface-water users to surface-water provision, whereas InVEST models basin-wide water yield. InVEST simplifies water movement by considering the combined movement of groundwater and surface water, assuming that groundwater follows the same flow path as surface water and reaches a stream where it is eventually discharged as base flow. In the San Pedro River watershed, this process is very slow, and individual water molecules may take as little as 50 years or as many as 10,000 years (1,100 years on average) to move from recharge zones to the river (Mac Nish and others, 2009). However, InVEST water-yield models have been tested in other groundwater-dominated systems, where they were deemed to perform acceptably, provided that the results could be calibrated to time-series streamflow data (Mendoza and others, 2011, their box 4.1).

The ARIES water models in early 2012 considered only surface flow and account for locally important mountainfront and ephemeral-channel infiltration processes. However, the flow model values are lower than expected (table 10), indicating that evapotranspiration and infiltration sinks may be acting too strongly. Because layers containing spatially explicit data for infiltration and evapotranspiration were either at inadequate spatial resolution (evapotranspiration) or were 

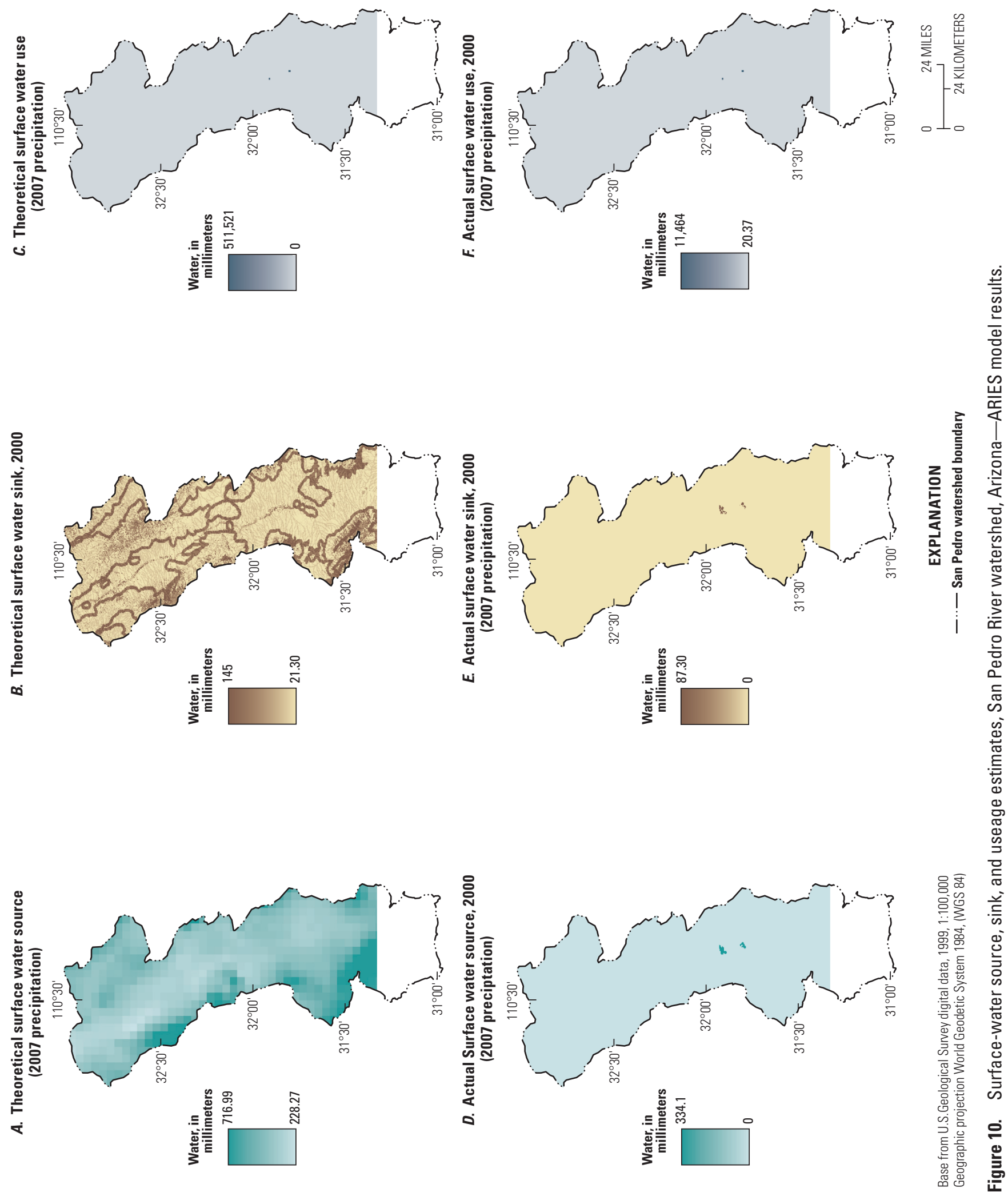


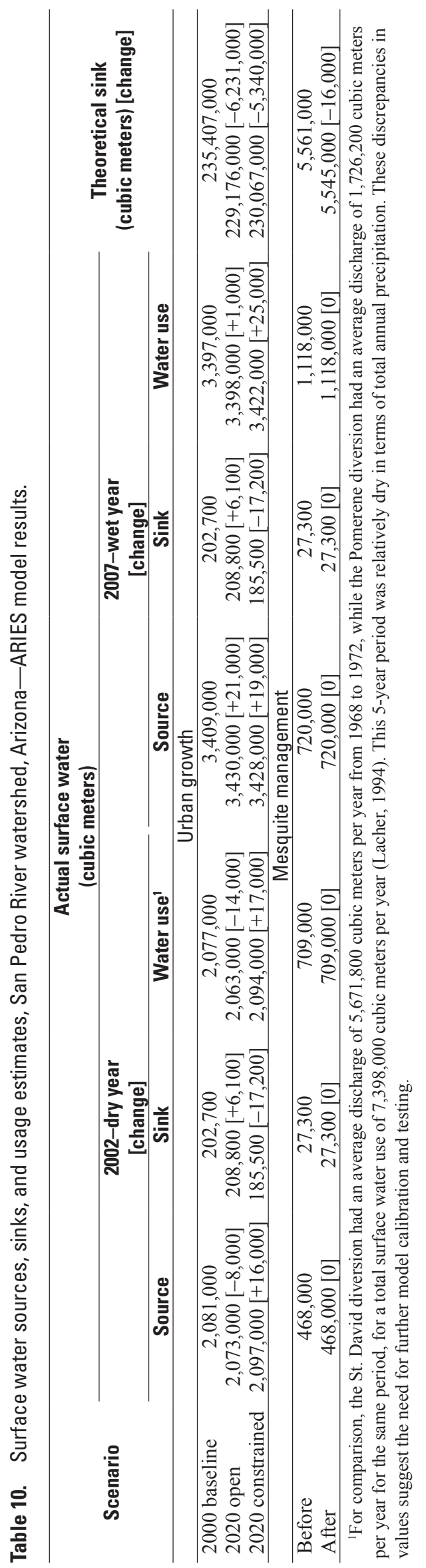


deemed inappropriate by experts for use in basin-and-range topography (infiltration), Bayesian training was not applied to the surface-water-sink model. The model would benefit from further testing and calibration.

As with the carbon models, changes in water yield were estimated for the mesquite-management and urban-growth scenarios, but not for the water-augmentation scenario. Both models rely on changes in land use or land cover (the ARIES model also uses percentage of tree canopy cover as an input), but the data did not support using a land-use-land-cover typology fine enough to consider differences in water yield in ephemeral compared with perennial riparian communities. Hydrologic dynamics of the riparian community, particularly evapotranspiration, are likely to change with water augmentation, but these changes were too poorly understood to model them by using InVEST or ARIES.

An economic value can be placed on water by using market price, replacement cost, or WTP (table 11), although none of these methods gives complete estimates of the full social, ecological, or economic value of water. Market prices for water in the San Pedro range from $\$ 1.31$ to $\$ 3.39$ per thousand gallons (2011 United States dollars), on the basis of water rates for the Arizona American Water Company's service in Sierra Vista, Bisbee, San Manuel, and Winkelman, Ariz. (fig. 2) (Water Infrastructure Finance Authority of Arizona, 2009). Replacement costs for water range from $\$ 4.03$ to $\$ 9.17$ per thousand gallons (Bureau of Reclamation, 2007). One study found values for household WTP for improved water quality and water system reliability to range from \$4.63-18.06 per month in the rural Western United States (Piper and Martin, 1997). On the basis of regression coefficients from Piper and Martin (1997, their table 4) and values for the independent variables for Cochise County, household WTP ranged from $\$ 4.51$ to 14.99 per month in Cochise County, Ariz. This dollar amount is in addition to an average water bill of $\$ 53.70$ per month (Water Infrastructure Finance Authority of Arizona, 2009); in 2011 water expenditures plus WTP would have been $\$ 1.49-4.00$ per thousand gallons, somewhat closer to the lower bound replacement cost. These values were applied to scenario results from the InVEST and ARIES models.

Table 11. Economic value of water in the San Pedro River watershed, Arizona.

\begin{tabular}{llcc}
\hline \multirow{2}{*}{ Valuation method } & \multicolumn{2}{c}{$\begin{array}{c}\text { Value } \\
\text { (United States dollars 2011) }\end{array}$} \\
\cline { 3 - 4 } & & $\begin{array}{c}\text { Per } \\
\mathbf{1 , 0 0 0} \text { gallons }\end{array}$ & $\begin{array}{c}\text { Per } \\
\text { cubic meter }\end{array}$ \\
\hline Market price & - lower bound & 1.31 & 0.34 \\
& - upper bound & 3.39 & 0.90 \\
Replacement cost & - lower bound & 4.03 & 1.07 \\
& - upper bound & 9.17 & 2.42 \\
Willingness to pay & - lower bound & 1.49 & 0.40 \\
& - upper bound & 4.00 & 0.93 \\
\hline
\end{tabular}

\section{Biodiversity}

The InVEST terrestrial and aquatic biodiversity model links land-use and land-cover data with experts' estimates of habitat quality for each land-use or land-cover type maps of drivers of landscape change, such as grazing, groundwater pumping, roads, climate change, or the United States-Mexico border fence; and the degree of change caused by each of these drivers. By using the InVEST biodiversity model, habitat quality was mapped for the urban growth and mesquite management scenarios (fig. 11, table 12) (see appendix A for assumptions and data sources used with the InVEST models). Modeling results showed a decrease in habitat quality under the open-development scenario, a very slight increase in habitat quality under the constrained-development scenario, and an increase in habitat quality under the mesquite-management scenario (table 12). Both urban-growth scenarios assumed large-scale urbanization, which reduced habitat quality, but in the constrained-development scenario, conversion of other vegetation types from lower- to higher-quality habitat offset habitat loss from urbanization and produced a small gain in habitat quality for that scenario. ARIES does not have a biodiversity model, but instead it incorporates biodiversity as an input into other ecosystem service models, such as recreation, discussed in the next section.

Like the ARIES open-space proximity, viewshed, and recreation models described below, the InVEST biodiversity model estimates values in relative units (for example, $0-100$ ). Lacking underlying biophysical units, the numeric outputs from these models are less amenable to monetization than biophysical outputs of other models such as tons of carbon or cubic meters of water. However, the percentage change in the service can be a useful metric for comparison of scenarios. Although model outputs scored using expert-supplied relative values may invite less criticism than outputs that measure up poorly against empirically measured ecosystem processes, the underlying model inputs must be carefully scrutinized to reduce subjectivity.

\section{Cultural Services: Viewsheds, Open-Space Proximity, Recreation}

The ARIES viewshed and open-space-proximity models quantify the contribution of nature toward amenity values, typically measured by using hedonic pricing of real estate. These models produce maps of (1) sources of high-quality open space that are desirable to live near or views that are desirable to see; (2) sinks that degrade these features, such as transmission lines or mines (visual blight of viewsheds) or highways that reduce privacy, increase noise, and block openspace access at the neighborhood scale; and (3) users of open space or viewsheds, in this case homeowners. The models account for recognizable endpoints related to viewsheds and open-space proximity - desirable and undesirable landscape 


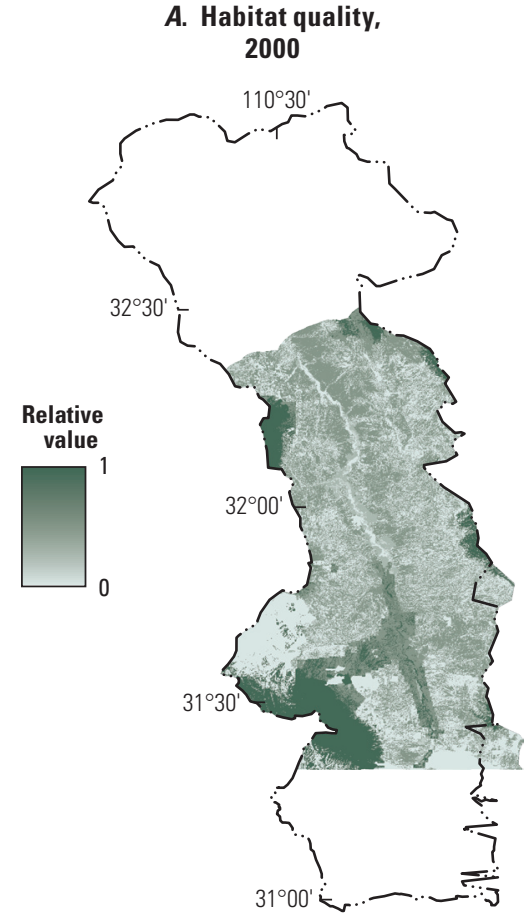

Base from U.S.Geological Survey digital data, 1999, 1:100,000 Geographic projection World Geodetic System 1984, (WGS 84)
B. Habitat quality,

2020 constrained development

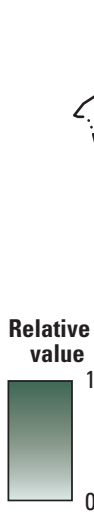

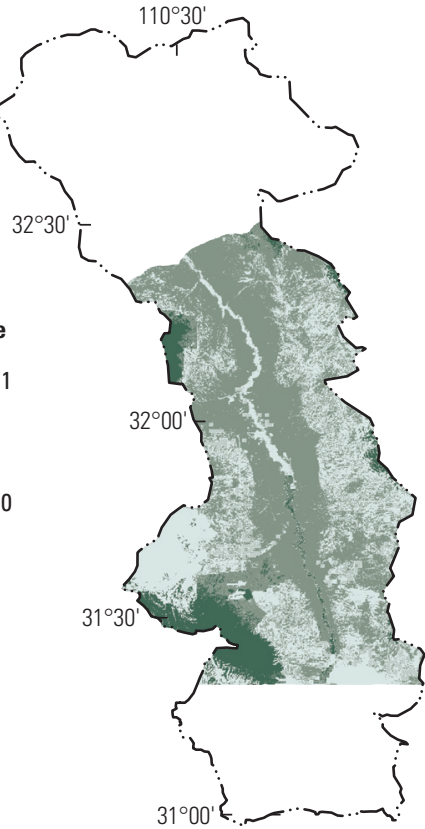

EXPLANATION

---- Mesquite management area boundary

- - San Pedro Riparian National Conservation Area boundary
C. Habitat quality 2020 open development

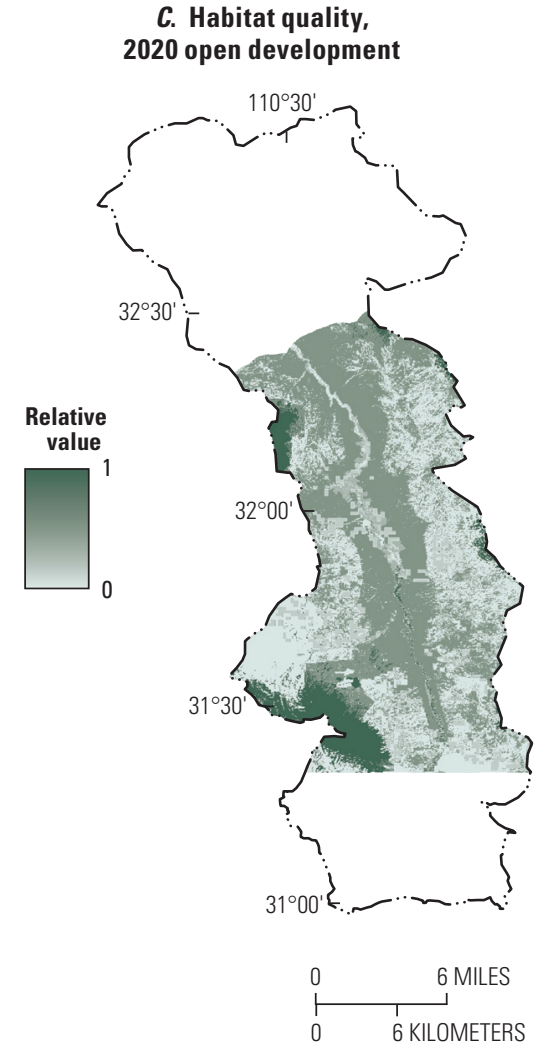

E. Habitat quality, before mesquite removal
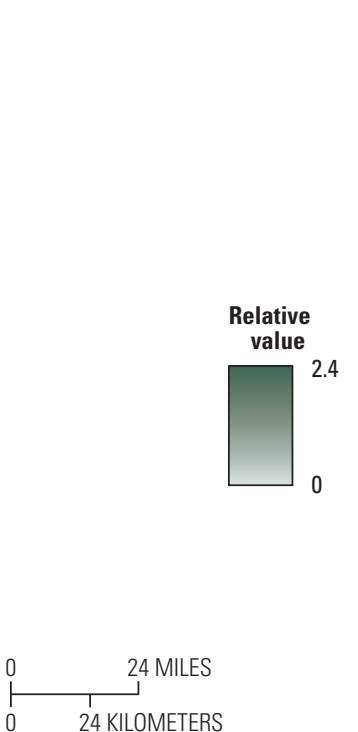

F. Habitat quality, after mesquite removal

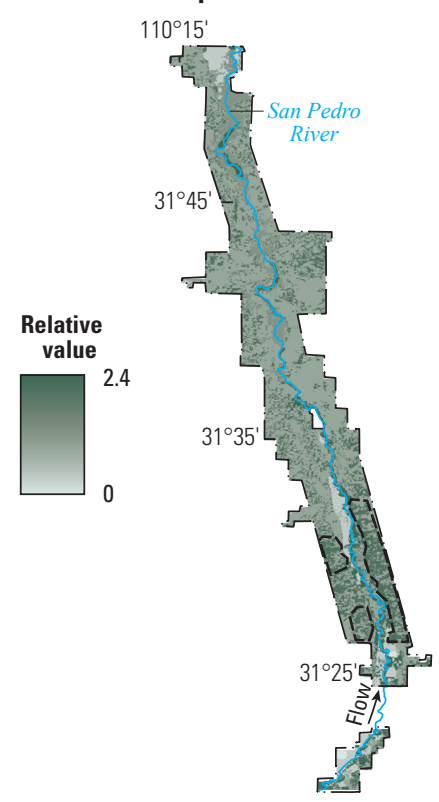

Base from U.S.Geological Survey digital data, 1999, 1:100,000 Geographic projection World Geodetic System 1984, (WGS 84)

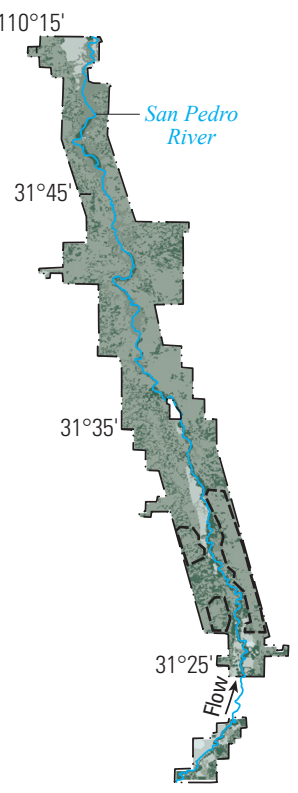

EXPLANATION

- .. - San Pedro watershed boundary

Figure 11. Biodiversity (habitat quality) and change estimates under urban growth and mesquite management scenarios, San Pedro River watershed, Arizona-InVEST model results. 
Table 12. Habitat quality estimates, San Pedro River watershed, Arizona-InVEST model results.

\begin{tabular}{lcc}
\hline \multirow{2}{*}{ Scenario } & \multicolumn{2}{c}{ Habitat quality } \\
\cline { 2 - 3 } & Urban growth & \\
\hline & 170,700 & \\
\hline 2000 baseline & 158,400 & -7.2 \\
2020 open & 170,800 & +0.03 \\
2020 constrained & Mesquite management & \\
\hline Mesquite baseline & 128,000 & +3.2 \\
After mesquite removal & 132,000 & \\
\hline
\end{tabular}

features that provide or degrade views and access to highquality open space. Sources, sinks, and users are linked by using the appropriate flow model (lines of sight for viewsheds and a Gaussian decay function for open-space proximity). Uncertainty estimates, produced as the outputs of Bayesian network models and variance propagation through the flow models, are provided for all outputs. These model outputs are quantified by using relative values, which could theoretically be linked to hedonic values for real estate.

Using the ARIES viewshed and proximity models, we mapped the theoretical source (viewshed or open-space quality independent of the location of homeowners and sinks) and actual-use values (dependent on user presence and flow characteristics) for open-space proximity and viewsheds (fig. 12, table 13) (see Appendix B for assumptions and data sources used with the ARIES models). We then modeled changes in these values under urban growth scenarios. Lacking data on how changes in mesquite cover or surface flow would be translated into higher or lower aesthetic value, we did not run the models for these scenarios, although we did calculate baseline theoretical proximity and viewshed values for the SPRNCA.

The urban-growth scenarios showed a slight decline in the provision of high-quality open space and view quality as natural ecosystems were replaced by development. They also showed a large increase in actual open space and view use as many new low-density developments were spread throughout the landscape where they were close to open space or had views of visually appealing objects such as mountains or riparian vegetation.

Regrettably, the underlying equations from the most locally applicable open-space-proximity hedonic studies (Sengupta and Osgood, 2003; Bark and others, 2009) do not readily lend themselves to value transfer to the San Pedro River watershed. Because this region lacked studies of the value of views, it was not possible to obtain economic values to apply toward ARIES viewshed results. Bourassa and others (2006) found that view-value premiums were greater when high-quality views were scarcer. In other words, when many new housing units have high-quality views, as might be the case in the San Pedro River watershed development scenarios, we might expect the value premium for each unit to be relatively small.
The InVEST aesthetic viewsheds model, suitable for use in marine and terrestrial settings, quantifies visual impact in terms of the number of "visual blight" points visible on the landscape, on the basis of data for visual blight points (in this study, highways, transmission lines, development, and mines), population counts, and a digital elevation model (fig. 13) (see appendix A for assumptions and data sources used with the InVEST models). Unfortunately, the model automatically combines results based on quartile breaks. Without the flexibility for the user to analyze raw results, precise quantification of changes in visual impacts between the baseline and scenario conditions is impossible (table 14).

The ARIES recreation models quantify the potential contribution of nature to different recreational activities. Other influences on recreational value include site accessibility, infrastructure, and visitor preferences, but the ecosystem service component of recreation is the relative contribution of underlying natural features toward the quality of the recreational experience. The ARIES recreation models produce maps of the relative value and uncertainty of potential birding, wildlife viewing, and hunting sites for important game species (fig. 14, table 15) (see appendix B for assumptions and data sources used with the ARIES models). Recreational-use models would show the locations of potential users of recreation sites, whereas flow models would link users to potential sites through a transportation-network model. Fully parameterized recreational use and flow models require higher-quality data on visitor use, preferences, and points of origin than are available for many recreation sites, including those on the San Pedro River watershed, however. Changes in potential recreation value for birding, wildlife viewing, and hunting under urban growth and water augmentation scenarios were modeled, but not for mesquite management, owing to a lack of information on how this scenario would influence recreational value.

The estimates produced by the ARIES recreation models showed increases in recreation potential in the SPRNCA associated with groundwater augmentation, corresponding to improvements in wildlife-habitat quality. Potential recreation values declined in both urban-growth scenarios, and a greater decline was associated with the open-development scenario. Both scenarios produce new development spread throughout the landscape, which diminished habitat quality and connectivity. Urban growth, however, also increased new residents, who may be recreational users, which could actually increase the value of recreation despite declines in habitat quality. More intensive modeling of recreational use and flows could produce a better understanding of recreational use.

The Wildlife Habitat Benefits Estimation Toolkit provided estimates for several relevant biodiversity and cultural values. For hunting on public land a use value of $\$ 70.24$ per

Figure 12 (facing page). Estimates of relative value of openspace proximity and viewsheds (source, use, and flow results) under urban growth scenarios, San Pedro River watershed, Arizona-ARIES model results. 

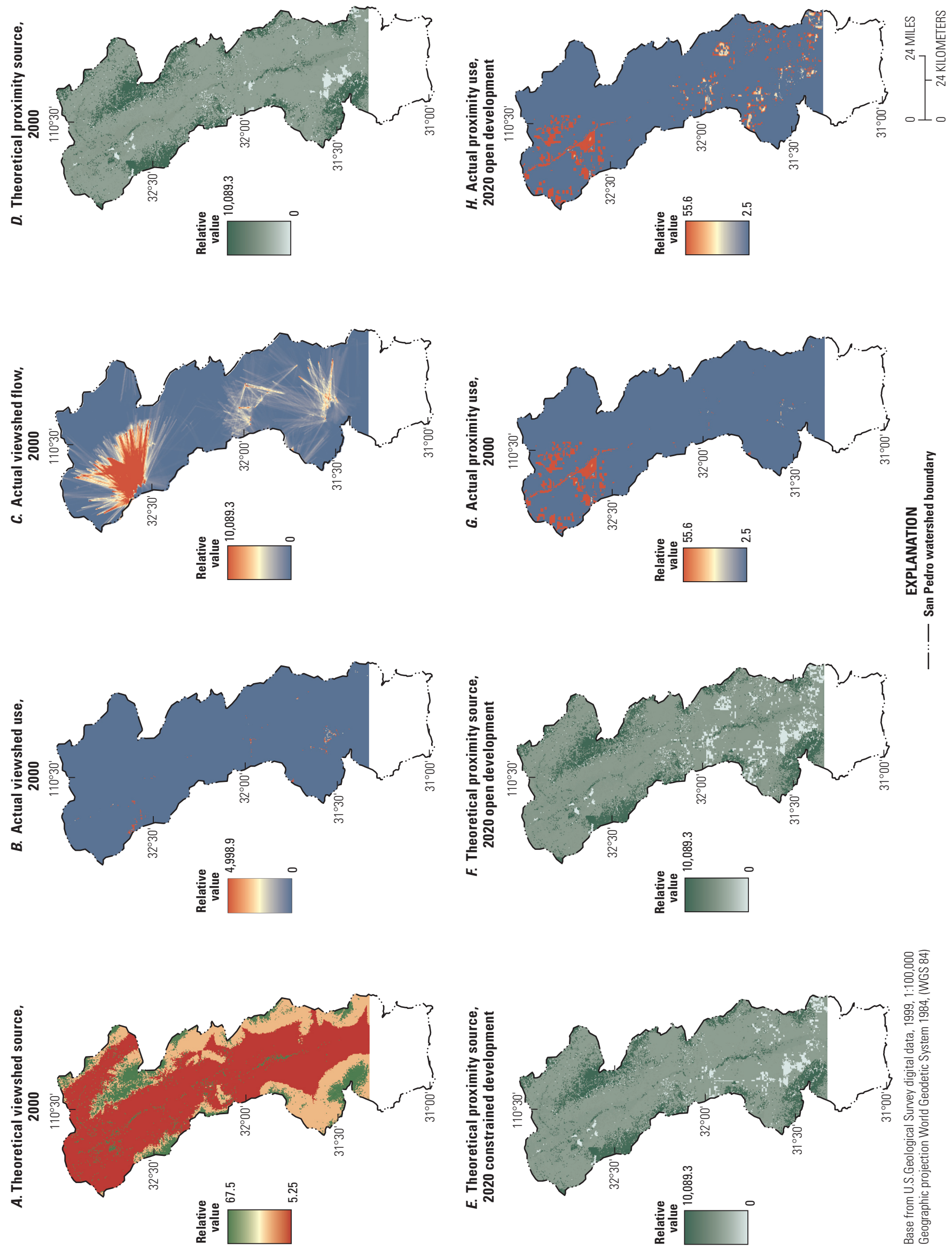
Table 13. Relative value of open space proximity and viewsheds, San Pedro River watershed, Arizona-ARIES model results.

$[--$, not applicable $]$

\begin{tabular}{|c|c|c|c|c|}
\hline \multirow{3}{*}{ Scenario } & \multicolumn{4}{|c|}{ Relative value } \\
\hline & \multicolumn{2}{|c|}{$\begin{array}{l}\text { Viewsheds } \\
\end{array}$} & \multicolumn{2}{|c|}{ Proximity of open space } \\
\hline & $\begin{array}{l}\text { Theoretical source } \\
\text { [percent change] }\end{array}$ & $\begin{array}{c}\text { Actual use } \\
\text { [change] }\end{array}$ & $\begin{array}{l}\text { Theoretical source } \\
\text { [percent change] }\end{array}$ & $\begin{array}{c}\text { Actual use } \\
\text { [change] }\end{array}$ \\
\hline 2000 baseline & $1,026,000$ & 142,200 & $1,698,000$ & $1,146,000$ \\
\hline 2020 open & $1,025,000[-0.1]$ & $931,000[+554.7]$ & $1,649,000[-2.9]$ & $1,607,000[+40.2]$ \\
\hline 2020 constrained & $1,026,000[-0.04]$ & $483,900[+240.3]$ & $1,679,000[-1.1]$ & $1,327,000[+15.7]$ \\
\hline $\begin{array}{l}\text { Baseline, San Pedro Riparian } \\
\text { National Conservation Area only }\end{array}$ & 14,100 & -- & 43,000 & -- \\
\hline
\end{tabular}

\section{EXPLANATION}

Impact-Number of features visible in parentheses

No impact (0)

Low impact $(1-2,608)$

Low-medium impact $(2,609-10,732)$

Medium-high impact $(10,733-30,214)$

High impact $(30,215-193,150)$

—... San Pedro watershed boundary

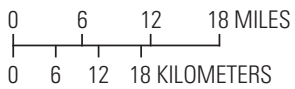

Base from U.S.Geological Survey digital data, 1999, 1:100,000 Geographic projection World Geodetic System 1984, (WGS 84)

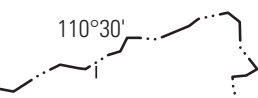<smiles>C1CCCC1</smiles>
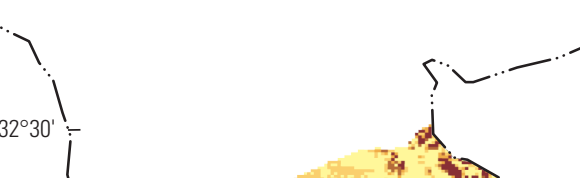

.<smiles>C1CCCC1</smiles>
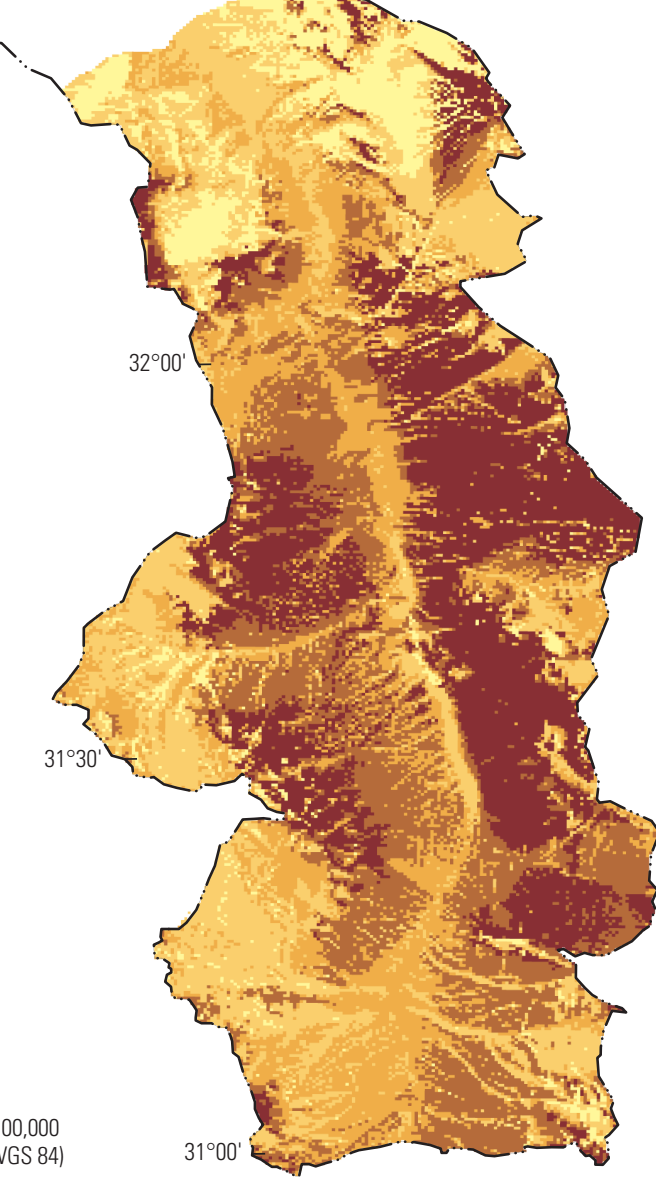

Figure 13. Visual impacts to viewsheds, San Pedro River watershed, States of Arizona (United States) and Sonora (Mexico)—InVEST model results. 
Table 14. Visual impacts to viewsheds, San Pedro River watershed, Arizona-InVEST model results.

\begin{tabular}{lccccc}
\hline \multirow{2}{*}{$\begin{array}{c}\text { Urban growth } \\
\text { scenario }\end{array}$} & \multicolumn{5}{c}{$\begin{array}{c}\text { Number of blight points visible for different quartiles of impact } \\
\text { (cell count) }\end{array}$} \\
\cline { 2 - 6 } & None & Low & Low to medium & Medium to high & High \\
\hline 2000 baseline & $0(3,871)$ & $0-2,608(11,203)$ & $2,608-10,732(11,204)$ & $10,732-30,214(11,200)$ & $30,214-193,150(11,202)$ \\
2020 open & $0(3,307)$ & $0-7,308(11,344)$ & $7,308-49,016(11,343)$ & $49,016-145,360(11,343)$ & $145,360-738,436(11,343)$ \\
2020 constrained & $0(3,754)$ & $0-3,832(11,233)$ & $3,832-21,123(11,230)$ & $21,123-63,341(11,231)$ & $63,341-385,979(11,232)$ \\
\hline
\end{tabular}

hunter-day was estimated for both big- and small-game hunting. The toolkit's visitor-use model estimated annual visitation to the SPRNCA at 118,147, as compared with the BLM estimate of 150,000 . The toolkit's aquatic habitat nonuse value worksheet was inappropriate for the San Pedro River. Although it is intended to estimate public nonuse values for aquatic habitat, this worksheet values changes in water quality rather than water quantity or flow permanence, the changes that are most relevant for the San Pedro River. The Wildlife Habitat Benefits Estimation Toolkit also includes an openspace property premium model. However, this model accounts for values from forests, parks, and wetlands in urban or suburban settings rather than desert vegetation in rural settings, so its transfer functions were unable to estimate open-space values for the San Pedro.

\section{Valuation Results for Scenarios}

\section{Urban Growth Scenarios}

Traditionally, quantified economic benefits such as increased employment and municipal tax base are often used to justify the negative environmental and social impacts that can accompany urban growth. Consideration of ecosystem services as an opportunity cost of urban growth can more fully show the costs and benefits of urban expansion. Because the aesthetic, recreation, and biodiversity models did not produce results amenable to monetization, the use of multicriteria analysis, which allows comparison of results using nonmonetary units-where decisionmakers compare the total "basket" of ecosystem services produced under alternative scenariosis the most feasible way to use these results in decisionmaking. InVEST model results show a loss of carbon storage, an increase in water yield, increased water demand, and a small gain (under constrained development) or larger loss (under open development) in habitat quality. These changes were more extreme in the open-development scenario (table 16). ARIES model results show a reduction in carbon sequestration, potential stored carbon release, theoretical surface water sinks (evapotranspiration and infiltration), viewshed and open-space quality, and recreational-value quality; again, changes were more extreme in the open-development scenario. ARIES models also show large gains in the amount of viewshed and open-space-proximity use, based on the increase in new housing units in the watershed (table 17). By using economic values, changes in carbon and water can be monetized, and annual social costs in the constrained scenario were \$1.6-7.2 million (InVEST results) and \$2.7-12.1 million (ARIES results). Annual social costs in the open-development scenario were \$3.3-17.8 million (InVEST results) and \$3.3-16.0 million (ARIES results) (tables 18, 19).

Raw water volumes are difficult to interpret socially and ecologically. For the urban growth scenarios, increased runoff from impervious surfaces leads to a variety of water quality and quantity problems - most important for the San Pedro River watershed is reduced infiltration that can recharge groundwater. To more rigorously value water yield changes more precise biophysical models need to link changes in water yield to other groundwater and aquatic system impacts while valuing changes to water supply for people in terms of increased groundwater pumping or municipal water costs. Because the models lacked such precision on both ecological impacts and economic costs, our monetization of water-yield change is a relatively nonconservative estimate, and it should be interpreted with caution. Although monetary values could be applied to the change in recreational-site quality, proper quantification of recreational value change would require development of a more extensive visitation model than was possible for this study or would be possible in the context of a typical BLM decision (Loomis, 1995). Although aesthetic viewshed and open-space-proximity results could theoretically be valued by using hedonic studies, the available literature for the San Pedro River watershed did not support monetization of these values.

The results reported here for all scenarios cover a wide range of dollar values. This range is entirely due to the differences in economic values applied to the biophysical outputs of the ARIES and InVEST models. In other words, the value difference for carbon sequestration is attributable to differential social costs of carbon, and the value differences for water to the three different methods used to value water. These results do not include additional sources of uncertainty, such as different discount rates used to convert between annual and net present values, or uncertainty outputs of the ARIES models. Given the lack of clarity on preferred discount rates or model uncertainty measures to use, it was easier at this point to leave these sources of uncertainty open for future discussion. Eventually, if such approaches were adopted by BLM or other agencies, explicit guidance on valuation methods, discount rates, and model uncertainty measures should be developed. 

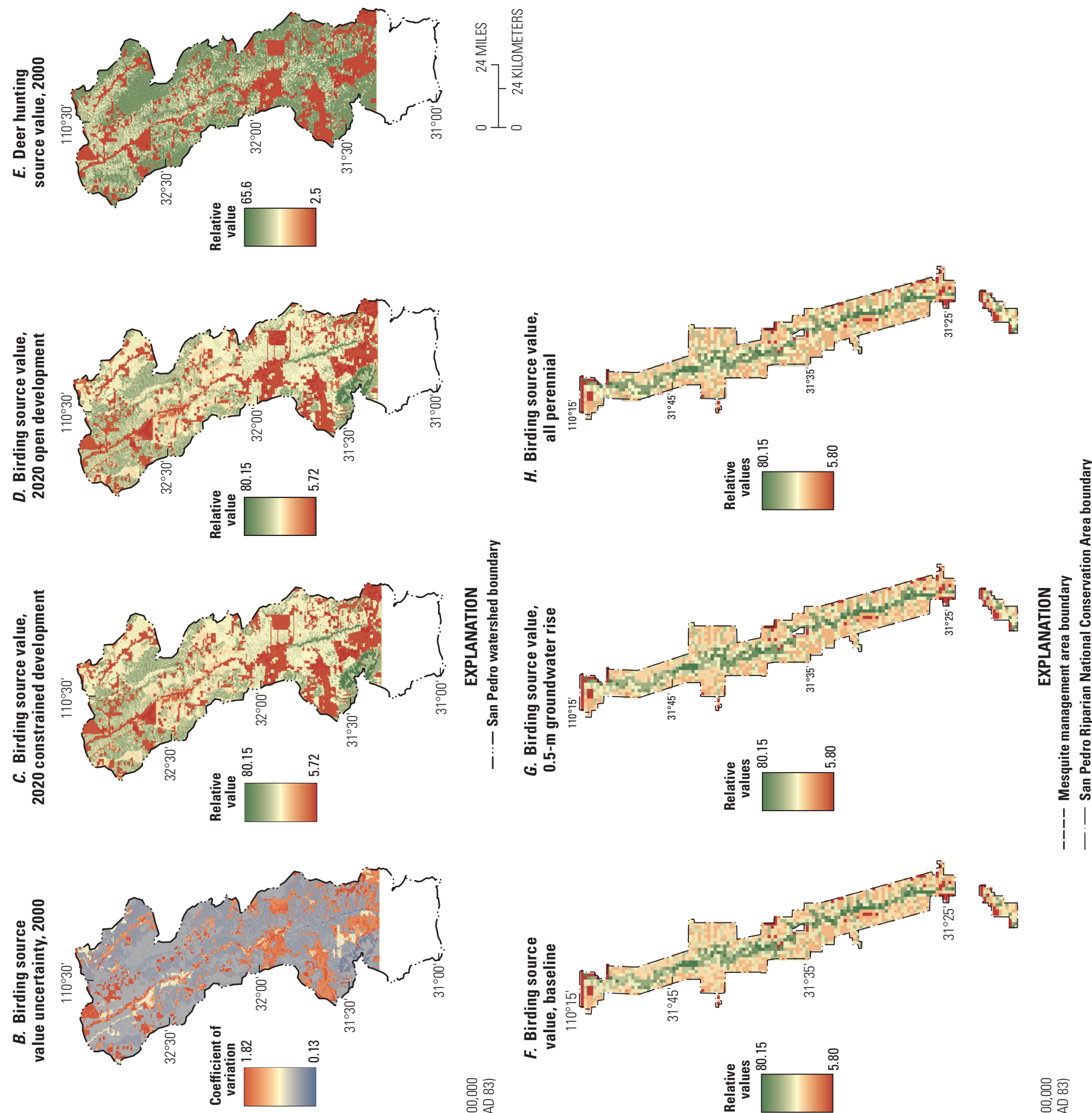

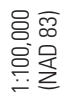
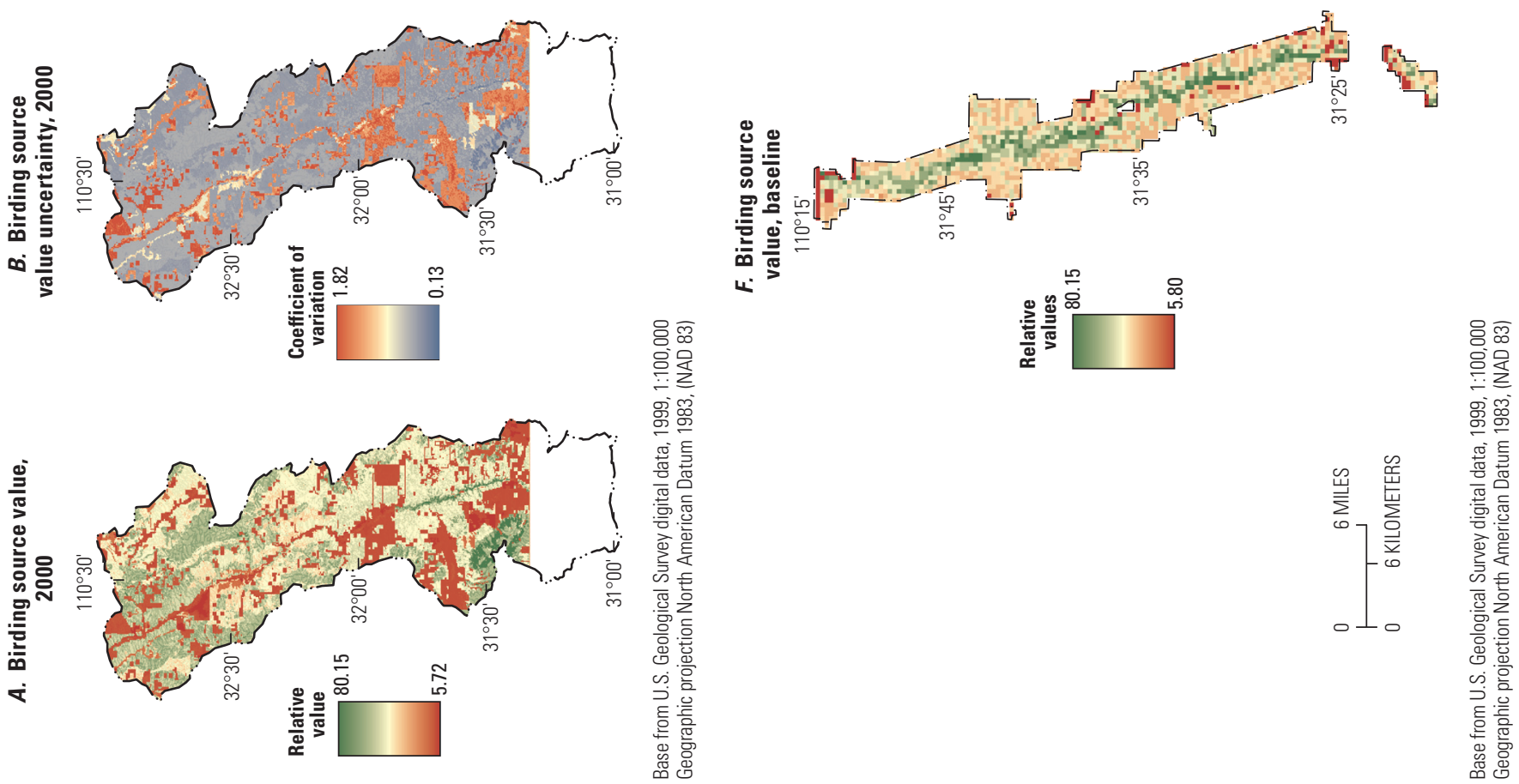
Table 15. Relative recreation source value estimates, San Pedro River watershed, Arizona-ARIES model results.

\begin{tabular}{|c|c|c|c|c|c|c|}
\hline \multirow{2}{*}{ Scenario } & \multicolumn{6}{|c|}{$\begin{array}{l}\text { Recreation source value and relative value } \\
\text { (relative value) [percent change] }\end{array}$} \\
\hline & Birding & $\begin{array}{l}\text { Wildlife } \\
\text { viewing }\end{array}$ & Javelina & Dove & Deer & Quail \\
\hline 2000 baseline & $2,034,000$ & $2,770,000$ & $2,489,000$ & $2,583,000$ & $2,483,000$ & $2,601,000$ \\
\hline 2020 open & $2,012,000[1.1]$ & $2,729,000[1.5]$ & $2,459,000[1.2]$ & $2,513,000[2.7]$ & $2,441,000[1.7]$ & $2,461,000[5.4]$ \\
\hline 2020 constrained & $2,020,000[0.7]$ & $2,748,000[0.8]$ & $2,475,000[0.6]$ & $2,529,000[2.1]$ & $2,457,000[1.1]$ & $2,478,000[4.7]$ \\
\hline Uniform $0.5-\mathrm{m}$ groundwater rise & $68,000[+3.9]$ & $89,200[+3.7]$ & $82,000[+4.1]$ & $85,900[+3.4]$ & $78,300[+4]$ & $86,800[+3.3]$ \\
\hline Entire area perennial & $68,700[+4.9]$ & $90,300[+4.9]$ & $82,400[+4.6]$ & $86,300[+3.9]$ & $78,700[+4.6]$ & $87,200[+3.8]$ \\
\hline
\end{tabular}

For the constrained-development scenario, changes in ecosystem service values were greater when modeled by ARIES rather than InVEST. The reverse was true, however, for the open-development scenario. The InVEST and ARIES models produced more divergent results for the constraineddevelopment scenario (table 20).

\section{Mesquite Management Scenario}

Restoration projects such as mesquite management fall under the SPRNCA's mandate "to protect, enhance, and maintain the riparian area and the aquatic, wildlife, archaeological, paleontological, scientific, cultural, educational, and recreational resources of the public lands surrounding the San Pedro River in Cochise County, Arizona" (16 U.S.C. 460xx). In real-world terms, however, restoration decisions hinge on prioritization of scarce resources and the cost of and public response to alternative restoration projects. Ecosystem services provide a quantifiable metric for comparison with other costs and benefits. For example, InVEST modeling results quantified the loss of carbon storage and increase in water yield and habitat quality associated with mesquite management (table 21). Similarly, ARIES quantified a reduction in summed evapotranspiration and infiltration, effectively increasing water yield (table 22).

By applying monetary values to the changes in carbon sequestration and water yield, the summed annual social cost of lost carbon storage and benefit of increased water yield ranged from $-\$ 127,400$ to $+\$ 142,000$ (InVEST results; table 23) and $-\$ 7,750$ to $+\$ 35,135$ (ARIES results; table 24 ). Unlike the urbanization scenario, for which increased water yield equated with reduced groundwater recharge and a

Figure 14 (facing page). Source values for birding and deer hunting (San Pedro River watershed, Arizona) and for birding (San Pedro Riparian National Conservation Area)—ARIES model results. flashier hydrograph, water yield in the mesquite management scenario increased largely through reduced evapotranspiration as mesquite is replaced by grassland, and we thus considered it a positive value (Nie and others, 2011). As mentioned previously, both models would benefit from further parameterization and testing. In the mesquite management scenario, changes in ecosystem service values were greater for InVEST model estimates than in ARIES model estimates. The ARIES and InVEST models produced more divergent results for the mesquite management scenario than either of the urban growth scenarios (table 25).

\section{Water-Augmentation Scenarios}

As previously discussed, the underlying data, models, and scenario definition of water augmentation lent themselves poorly to analysis by the InVEST and ARIES models. Improved scenarios that better described the biophysical change brought on by water augmentation, combined with better underlying datasets and models, would enable better ecosystem services quantification for the water augmentation scenarios. Relative change in recreation-site quality was obtained for the SPRNCA by using the ARIES recreation models (table 26). Valuing these effects on recreational use was beyond the scope of this study, so it was not attempted.

\section{Conclusions}

\section{General Findings}

Ecosystem services for the San Pedro River watershed were successfully quantified by using multiple ecosystem services tools, modeling changes under managerially relevant scenarios, and monetizing some services for comparison in common units. Despite problems with time requirements, uncomparable outputs, and inability to monetize all services, this process could successfully be replicated by BLM or other management agencies in high-profile cases with adequate 


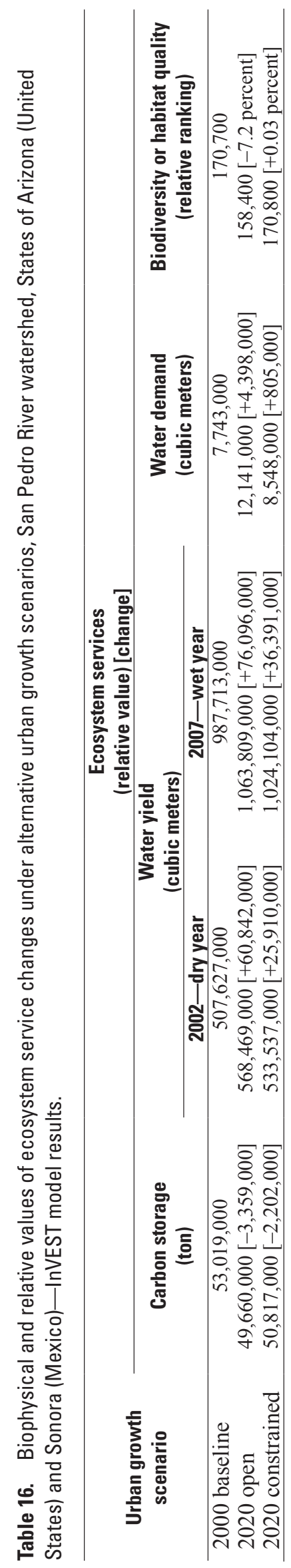




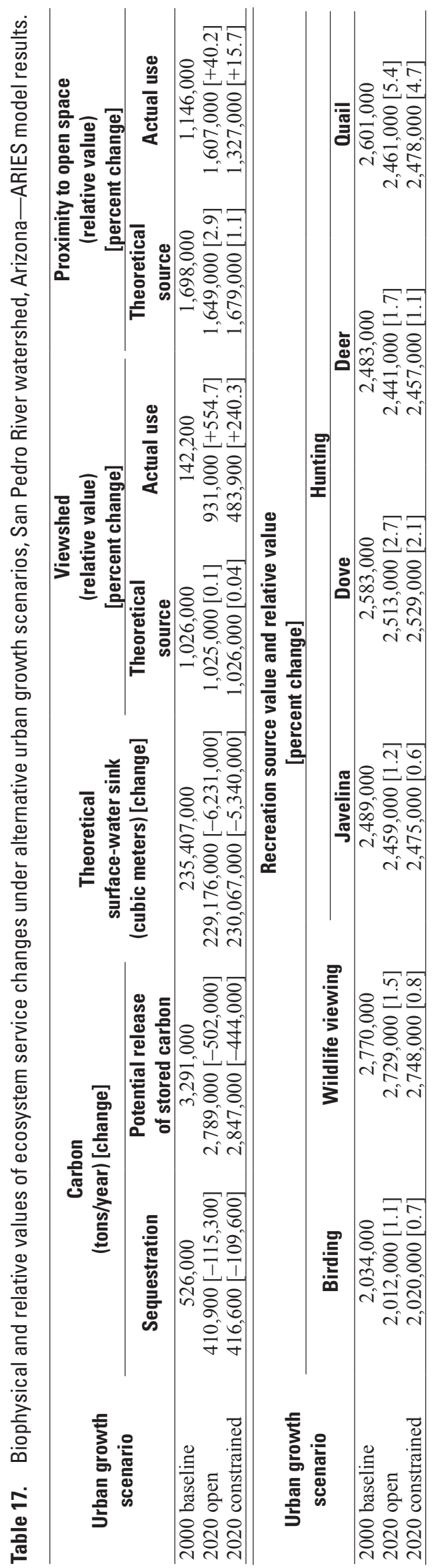


Table 18. Economic value of ecosystem service changes under alternative urban growth scenarios, San Pedro River watershed, States of Arizona (United States) and Sonora (Mexico)—InVEST mode results.

\begin{tabular}{lccc}
\hline \multirow{2}{*}{$\begin{array}{c}\text { Urban growth } \\
\text { scenarios }\end{array}$} & \multicolumn{3}{c}{$\begin{array}{c}\text { Annual value } \\
\text { (United States dollars 2011) }\end{array}$} \\
\cline { 2 - 4 } & Sequestered carbon & Added water supply & Total \\
\hline 2020 open & $-\$ 1,791,000$ to $-7,218,000$ & $-\$ 1,516,000$ to $-10,660,000$ & $-\$ 3,307,000$ to $-17,878,000$ \\
2020 constrained & $-\$ 1,308,000$ to $-5,275,000$ & $-\$ 278,000$ to $-1,952,000$ & $-\$ 1,586,000$ to $-7,227,000$ \\
\hline
\end{tabular}

Table 19. Economic value of ecosystem service changes under alternative urban growth scenarios, San Pedro River watershed, Arizona-ARIES model results.

\begin{tabular}{lccc}
\hline $\begin{array}{c}\text { Urban growth } \\
\text { scenario }\end{array}$ & \multicolumn{3}{c}{$\begin{array}{c}\text { Annual value } \\
\text { (United States dollars 2011) }\end{array}$} \\
\cline { 2 - 4 } & Sequestered carbon & Reduced infiltration ${ }^{1}$ & Total \\
\hline 2020 open & $-\$ 2,436,000$ to $-10,258,000$ & $-\$ 822,000$ to $-5,777,000$ & $-\$ 3,258,000$ to $-\$ 16,035,000$ \\
2020 constrained & $-\$ 2,412,000$ to $-9,756,000$ & $-\$ 327,000$ to $-2,301,000$ & $-\$ 2,739,000$ to $-\$ 12,057,000$ \\
\hline
\end{tabular}

${ }^{1}$ Calculated as the reduced infiltration component of the ARIES surface water sink models, in other words, the reduced groundwater recharge caused by development.

Table 20. Total annual cost of ecosystem service loss under urban-growth scenarios, San Pedro River watershed, Arizona—ARIES and InVEST model results.

\begin{tabular}{|c|c|c|c|}
\hline \multirow{2}{*}{$\begin{array}{l}\text { Urban growth } \\
\text { scenario }\end{array}$} & \multicolumn{2}{|c|}{$\begin{array}{l}\text { Estimate of change in value } \\
\text { (United States dollars 2011) }\end{array}$} & \multirow{2}{*}{$\begin{array}{c}\text { Value } \\
\text { differential } \\
\text { (percent) }\end{array}$} \\
\hline & ARIES & InVEST & \\
\hline 2020 open & $-3,258,000$ to $-16,035,000$ & $-3,307,000$ to $-17,878,000$ & 1.5 to 11.5 \\
\hline
\end{tabular}

Table 21. Biophysical and relative values of ecosystem service changes under mesquite management scenario, San Pedro River watershed, Arizona_InVEST model results.

\begin{tabular}{|c|c|c|c|c|}
\hline \multirow{3}{*}{$\begin{array}{l}\text { Mesquite } \\
\text { management } \\
\text { scenario }\end{array}$} & \multicolumn{4}{|c|}{$\begin{array}{l}\text { Ecosystem services } \\
\text { [change] }\end{array}$} \\
\hline & \multirow{2}{*}{$\begin{array}{l}\text { Carbon storage } \\
\text { (ton) [change] }\end{array}$} & \multicolumn{2}{|c|}{$\begin{array}{l}\text { Water yield } \\
\text { (cubic meters) }\end{array}$} & \multirow{2}{*}{$\begin{array}{l}\text { Biodiversity or habitat quality } \\
\text { (relative value) [change] }\end{array}$} \\
\hline & & 2002—dry year & 2007-wet year & \\
\hline Before & $1,557,000$ & $9,859,000$ & $25,264,000$ & 128,000 \\
\hline After & $1,523,000[-34,000]$ & $9,935,000[+76,000]$ & $25,338,000[+74,000]$ & $132,100[+3.2$ percent $]$ \\
\hline
\end{tabular}

Table 22. Biophysical and relative values of ecosystem service changes under mesquite management scenario, San Pedro River watershed, Arizona-ARIES model results.

\begin{tabular}{cccc}
\hline $\begin{array}{c}\text { Mesquite } \\
\text { management } \\
\text { scenario }\end{array}$ & Sequestration & $\begin{array}{c}\text { Carbon } \\
\text { (tons/year) [change] }\end{array}$ & $\begin{array}{c}\text { Theoretical surface-water sink } \\
\text { and reduced evapotranspiration } \\
\text { (cubic meters/year) [change] }\end{array}$ \\
\cline { 2 - 4 } & 14,152 & $\begin{array}{c}\text { Potential stored- } \\
\text { carbon release }\end{array}$ & $5,561,000$ \\
After & $14,004[-148]$ & 96,900 & $5,545,000[-16,000]$ \\
\hline
\end{tabular}


Table 23. Economic value of ecosystem service changes under mesquite management scenario, San Pedro River watershed, Arizona-InVEST model results.

\begin{tabular}{cccc}
\hline $\begin{array}{c}\text { Mesquite } \\
\text { management } \\
\text { scenario }\end{array}$ & \multicolumn{3}{c}{$\begin{array}{c}\text { Estimate of change in value } \\
\text { (United States dollars 2011) }\end{array}$} \\
\cline { 2 - 4 } & Sequestered carbon & Added water supply & Total \\
\hline After & $-\$ 37,800$ to $-152,900$ & $+\$ 25,600$ to 179,700 & $-\$ 127,400$ to $+\$ 142,000$ \\
\hline
\end{tabular}

Table 24. Economic value of ecosystem service changes under mesquite management scenario, San Pedro River watershed, Arizona-ARIES model results.

\begin{tabular}{cccc}
\hline $\begin{array}{c}\text { Mesquite } \\
\text { management } \\
\text { scenario }\end{array}$ & Sequestered carbon & $\begin{array}{c}\text { Estimate of change in value } \\
\text { (United States dollars 2011) }\end{array}$ & \\
\cline { 2 - 4 } & Reduced transpiration & Total \\
\hline After & $-\$ 3,250$ to 13,210 & $+\$ 5,460$ to 38,400 & $-\$ 7,750$ to $+\$ 35,150$ \\
\hline
\end{tabular}

Table 25. Total annual cost or benefit of ecosystem service gain or loss under mesquite management scenario, San Pedro River watershed, Arizona—ARIES and InVEST model results.

\begin{tabular}{cccc}
\hline $\begin{array}{c}\text { Mesquite } \\
\text { management } \\
\text { scenario }\end{array}$ & \multicolumn{2}{c}{$\begin{array}{c}\text { Estimate of change in value } \\
\text { (United States dollars, 2011) }\end{array}$} & $\begin{array}{c}\text { Value differential } \\
\text { (percent) }\end{array}$ \\
\cline { 2 - 4 } & ARIES & InVEST & 304 to 1,544 \\
\hline After & $-\$ 7,750$ to $+\$ 35,150$ & $-\$ 127,400$ to $+\$ 142,000$ & 300 \\
\hline
\end{tabular}

Table 26. Relative values of ecosystem service changes under water augmentation scenarios, San Pedro River watershed, ArizonaARIES model results.

\begin{tabular}{|c|c|c|c|c|c|c|}
\hline \multirow{3}{*}{$\begin{array}{l}\text { San Pedro Riparian National } \\
\text { Conservation Area scenario }\end{array}$} & \multicolumn{6}{|c|}{$\begin{array}{c}\text { Recreation source } \\
\text { (relative value) [percent change] }\end{array}$} \\
\hline & \multirow{2}{*}{ Birding } & \multirow{2}{*}{$\begin{array}{l}\text { Wildlife } \\
\text { viewing }\end{array}$} & \multicolumn{4}{|c|}{ Hunting } \\
\hline & & & Javelina & Dove & Deer & Quail \\
\hline Uniform 0.5 -meter groundwater rise & $68,000[+3.9]$ & $89,200[+3.7]$ & $82,000[+4.1]$ & $85,900[+3.4]$ & $78,300[+4]$ & $86,800[+3.3]$ \\
\hline Entire area perennial & $68,700[+4.9]$ & $90,300[+4.9]$ & $82,400[+4.6]$ & $86,300[+3.9]$ & $78,700[+4.6]$ & $87,200[+3.8]$ \\
\hline
\end{tabular}

resources. This section further discusses these problems and potential solutions to lower the barriers to widespread adoption of ecosystem services in decisionmaking.

\section{Comparability of Spatially Explicit Results from ARIES and InVEST Models}

Although the magnitude of change in ecosystem services was not always comparable when InVEST and ARIES were used, the sign of the change was typically equivalent, and for this case study a decisionmaker would reach similar conclusions about ecosystem services by using either tool.

Monetized results generated by the ARIES and InVEST models were most similar under conditions of the greatest landscape change, the open development scenario, and most divergent under the mesquite management scenario, which took place over a relatively limited spatial extent. There are two possible reasons for the divergent values obtained by using ARIES and InVEST: use of different ecosystem service metrics, and different modeling approaches or philosophies behind the two tools.

Most of the ARIES and InVEST outputs use different ecosystem service metrics. The fact that these modeling tools use different ecosystem service metrics likely stems in part from differences in their underlying modeling approaches. InVEST relies on published production-function information wherever possible, whereas ARIES focuses on the beneficiaries of ecosystem services and ecosystem service flow quantification by modeling and mapping ecosystem-service sources, sinks, use, and flows. InVEST's tier 1 models are largely populated by linking land cover to service provision by means of coefficient tables for each land-cover type (for example, for carbon storage, evapotranspiration coefficient, or nutrient-filtering capacity); data for the coefficient tables are typically derived from field experiments. The 
ARIES models, by contrast, commonly use remotely sensed or modeled spatial datasets for Bayesian network training or calibration. It is thus not surprising that these approaches yield divergent results. Both approaches have scientific validity, and further comparative applications, perhaps in concert with more robust biophysical models, are needed to identify the conditions under which each more accurately quantifies ecosystem services.

\section{Advantages and Disadvantages of Alternative Approaches}

A key tradeoff in the application of any ecosystemservice tool is the time required to apply it relative to the depth and quality of information that it adds to the decisionmaking process (table 27). If the quality and quantity of information added by these tools is high relative to the time requirements, such tools are more likely to add value to the decision process. The time needs of many tools could be substantially reduced if they were better developed and supported by high-quality archives of spatial, ecological, and economic data. Such data would permit more rapid model parameterization, reduce the likelihood that practitioners will overlook important data sources, and potentially facilitate adoption of these tools by resource managers. We further discuss such data archives in the "Implications for Future Work" section.

The approaches evaluated in this study differed greatly in their performance against the seven evaluative criteria described in the Methods section (table 28). No tool performs well in all categories, suggesting that different tools will be most appropriate in different situations and highlighting the value of rigorous comparisons of available tools. Some complementarity exists between tools, which suggests that some tools could be used together to fill different ecosystem service assessment needs (fig. 15). For example, the ESR or UNEP-WCMC Ecosystem Services Toolkit can serve as screening tools to evaluate ecosystem services of importance, either in the absence of local stakeholders who can provide informed input or in collaboration with local stakeholders as a way to structure their input. This preliminary assessment could then be used as a broader analytical frame within which to conduct more detailed analyses from mapping and modeling tools that quantify landscape-scale ecosystem services tradeoffs (for example, ARIES, EcoAIM, Envision, EPM, InVEST, InFOREST, MIMES, SolVES). If needed, EcoMetrix can be used for site-scale modeling to compare tradeoffs at fine spatial scales. Finally, model outputs can be valued by multicriteria analysis tools (for example, EcoAIM, ESValue) or monetary valuation by NAIS, SERVES, or the Wildlife Habitat Benefits Estimation Toolkit. General strengths and limitations of each tool are discussed in the following sections. Specific strengths and weaknesses of individual ecosystem service models within each toolkit are discussed in the Results section.

\section{Application of Past Primary Valuation Studies}

Although it is not feasible to conduct new primaryvaluation studies to support all but the most high-profile decisions, past primary-valuation studies can often aid in decisionmaking. Past studies are used in some BLM district and field offices, but there are no standard practices for applying past-valuation studies, and their use typically depends on the capability of individual analysts. BLM offices should be aware that past local primary studies typically capture only a limited number of ecosystem services or decision contexts. Searching for, reviewing, and distilling data from these studies into useful information can also be relatively time consuming, and it requires a thorough understanding of various econometric methods. Such searches also require access to academic journal articles, which may further limit feasibility for BLM district and field offices. Compilation of such studies into an existing or new database, however, could reduce the time needed to compile and synthesize local studies for use in decisionmaking.

\section{Value Transfer}

The Wildlife Habitat Benefits Estimation Toolkit provides a well-documented, spreadsheet-based set of transfer functions, reducing the need to develop new transfer functions or use unreliable point transfers (see appendix $\mathrm{C}$ for further discussion of value transfer). Point transfers or other value transfers known to be inadequate are sometimes justified by noting that any value is better than the implicit value of zero that natural resources too commonly are given. However, a consequence of such transfers is the risk of discrediting all environmental valuation techniques (Smith, 1992), a risk that may be greater in higher-profile decision contexts. Most of the literature supports the notion that if a resource value cannot be defensibly monetized, it is preferable to provide a qualitative description or utilize a framework that allows for various types of values (for example, multicriteria analysis (Spash and Vatn, 2006)). The benefits of a single unit (money) to compare disparate resources, however, can be substantial. For instance, Office of Management and Budget (OMB) economists have been skeptical that qualitative descriptions of ecosystem service benefits would be able to offset monetary estimates of the opportunity cost of their preservation (Loomis and Rosenberger, 2006).

BLM is encouraged to be cautious when using value transfer. Monetization may give a false sense of precision, particularly to nonexpert audiences. The value transfer literature has found value estimate errors that are as high as 7,000 percent (Loomis, 1992). Errors ranging from 20-40 percent are probably in the acceptable range (Navrud and Ready, 2007). Deciding on acceptable errors depends on the context in which the values will be used (Rosenberger and Stanley, 2006). A cost-benefit analysis on a small-scale project will require less precision than a Natural Resource Damage Assessment where legal compensation is decided. Value transfer may be appropriate for the former case but is probably inappropriate for the latter (Navrud and Ready, 2007). Although one needs to appreciate the potential pitfalls of value transfer, this method 
Table 27. Estimated time to complete ecosystem service assessment and valuation by use of alternative methods.

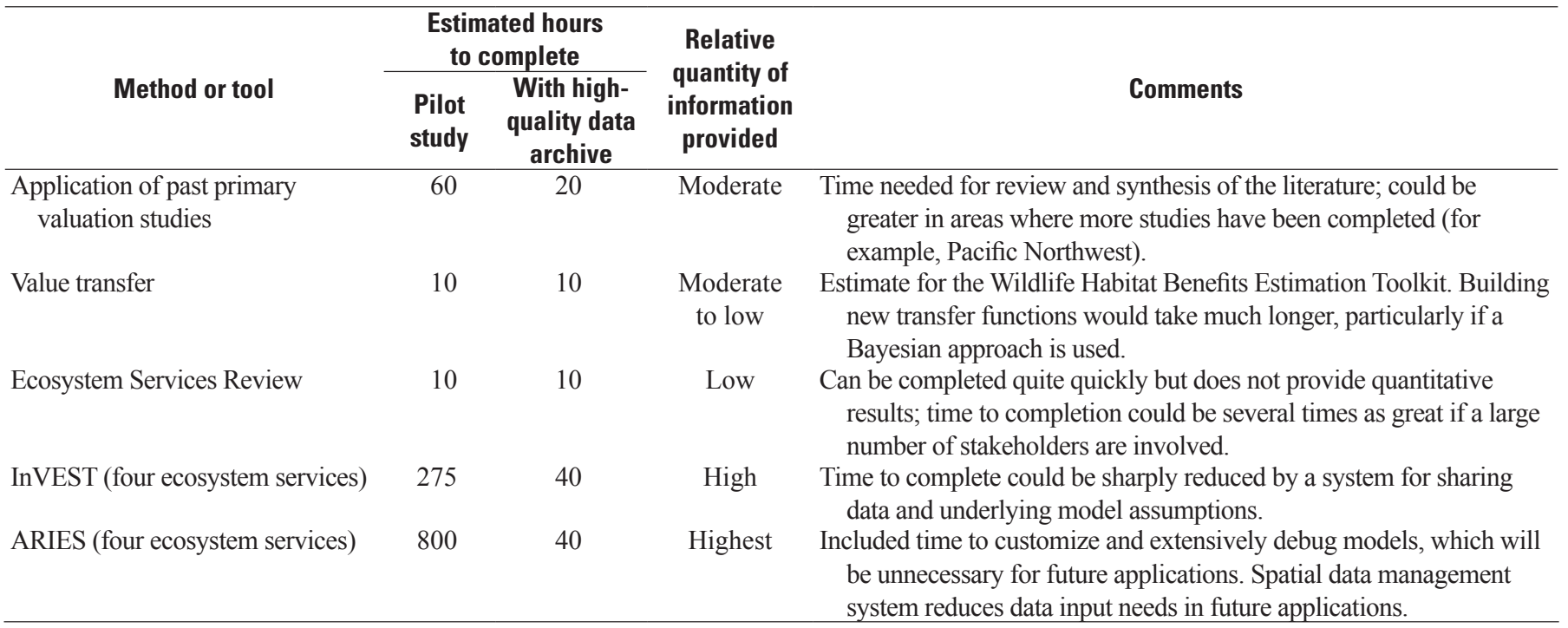

can be a useful aid for decisionmaking in BLM, particularly if functions are incorporated into well-documented, user-friendly spreadsheets such as the Wildlife Habitat Benefits Estimation Toolkit. Support for keeping this toolkit up to date and incorporating additional transfer functions from the literature into a similar framework would be worthwhile for BLM and other agencies to consider. Regardless of the applications of value transfer and the transfer errors that BLM decides are acceptable, the best-practice principles outlined in appendix C provide guidelines for more defensible value transfer.

\section{Ecosystem Services Review}

Ecosystem Services Review is a well-documented, spreadsheet-based tool that can be used to rapidly but qualitatively describe the effects of ecosystem services. Although it was originally developed for private sector use it could be adapted for ecosystem service impact analysis by public agencies involved in extractive resource use, such as the BLM or USDA Forest Service. Although the ESR requires relatively little time to complete, it does not provide any quantitative or spatial information about the distribution of ecosystem service values or impacts. Its greatest value may thus be as a screening tool to pair with another method that will provide a quantitative or spatial ecosystem services assessment.

\section{Integrated Valuation of Ecosystem Services and Tradeoffs (InVEST)}

InVEST enables mapping and quantification of ecosystem services and of tradeoffs between services by using well-documented models that have appeared extensively in the recent peer-reviewed literature. InVEST's tier 1 models are relatively simple but are transparent and could be used by BLM district and field offices given adequate supporting data, ArcGIS software, and a moderate level of GIS expertise. Underlying data are the largest obstacle to regular use of
InVEST: assembling the needed spatial data and parameterizing InVEST's underlying data tables can be time consuming and risks subjectivity if done poorly. A central data archive that supports InVEST modeling would greatly reduce the time required for analysis, and it could make widespread application of InVEST much more feasible. InVEST requires the user to conduct all up-front spatial-data preparation, which for cross-boundary cases such as we encountered on the San Pedro River watershed can include the sometimes-difficult task of merging multiple datasets by using common concepts, units, spatial resolution, and projection. This task limited our ability to map ecosystem services for the entire San Pedro River watershed, in particular for the Mexican side of the watershed, as had initially been hoped. These limitations could cause problems when InVEST is applied throughout contiguous regions having different underlying datasets. Improperly formatted input data and files are apt to produce errors, making it critical for the user to closely follow the file formats provided with the initial download of the InVEST tool.

Uncertainty was not addressed in early 2012 InVEST models, although future releases of InVEST may support Monte Carlo simulation. Kareiva and others (2011) recommend including a range of values for relevant ecological coefficients needed to parameterize the InVEST models, which would produce a range of values in the model results. Use of high and low ecological coefficients in future applications of InVEST (not done in the San Pedro River watershed study) could better capture the range of likely values to be found within different land use and land-cover types.

InVEST tier 2 models have been described (Kareiva and others, 2011), but they are not yet linked to a modeling or mapping platform as the tier 1 models are. The tier 2 models are substantially more data intensive, which may make them even more time intensive for BLM use in the near term. Future InVEST releases may improve the system's usability, quality of outputs, and ability to link to external ecological process models, potentially enhancing the tool's functionality for BLM. 
Table 28. All ecosystem service tools relative to key evaluative criteria.

[BLM, Bureau of Land Management; GIS, geographic information system; $\mathrm{n}$ vs. k, sample size versus number of independent variables]

\begin{tabular}{|c|c|c|c|c|c|}
\hline Tool & $\begin{array}{l}\text { Quantifiable, } \\
\text { approach to } \\
\text { uncertainty }\end{array}$ & Time required & $\begin{array}{l}\text { Open source } \\
\text { or proprietary }\end{array}$ & $\begin{array}{c}\text { Level of } \\
\text { development }\end{array}$ & Scalability \\
\hline Primary valuation & $\begin{array}{l}\text { Quantitative, uncertainty } \\
\text { estimates provided in } \\
\text { statistical models }\end{array}$ & $\begin{array}{l}\text { High (1 year or more), unless } \\
\text { local studies have been } \\
\text { previously completed }\end{array}$ & $\begin{array}{l}\text { Results typically accessible } \\
\text { via publication in the } \\
\text { peer-reviewed or gray } \\
\text { literature }\end{array}$ & $\begin{array}{l}\text { Theoretically well } \\
\text { developed. Requires } \\
\text { survey development and } \\
\text { administration, analysis }\end{array}$ & $\begin{array}{l}\text { Results are properly } \\
\text { interpreted as } \\
\text { dependent on the } \\
\text { scenario posed } \\
\text { to respondents }\end{array}$ \\
\hline Point transfer & $\begin{array}{l}\text { Quantitative, uncertainty } \\
\text { through reporting a } \\
\text { range of values }\end{array}$ & $\begin{array}{l}\text { Low (less than } 1 \text { month; less } \\
\text { if there is access to a good } \\
\text { valuation database) }\end{array}$ & $\begin{array}{l}\text { Varies; databases range from } \\
\text { open source to proprietary }\end{array}$ & Theoretically well developed & Site to landscape scale \\
\hline $\begin{array}{l}\text { Function transfer } \\
\text { (multiple } \\
\text { regression) }\end{array}$ & $\begin{array}{l}\text { Quantitative, uncertainty } \\
\text { estimates provided in } \\
\text { regression models }\end{array}$ & $\begin{array}{l}\text { Low for previously } \\
\text { developed functions, } \\
\text { high if developing } \\
\text { original functions }\end{array}$ & $\begin{array}{l}\text { Results typically accessible } \\
\text { by means of publication } \\
\text { in peer-reviewed or gray } \\
\text { literature }\end{array}$ & $\begin{array}{l}\text { Well-developed for some } \\
\text { services and ecosystems, } \\
\text { poorly developed } \\
\text { for others }\end{array}$ & Site to landscape scale \\
\hline $\begin{array}{l}\text { Function transfer } \\
\text { (Defenders of } \\
\text { Wildlife) }\end{array}$ & $\begin{array}{l}\text { Quantitative, uncertainty } \\
\text { through varying inputs }\end{array}$ & Low & Publicly available & $\begin{array}{l}\text { Fully developed } \\
\text { and documented }\end{array}$ & Site to landscape scale \\
\hline InVEST & $\begin{array}{l}\text { Quantitative, uncertainty } \\
\text { through varying inputs }\end{array}$ & $\begin{array}{l}\text { Moderate to high, depending } \\
\text { on availability of GIS } \\
\text { and ecological data to } \\
\text { support modeling }\end{array}$ & $\begin{array}{l}\text { Publicly available, } \\
\text { requires ArcGIS }\end{array}$ & $\begin{array}{l}\text { "Tier 1" models } \\
\text { fully developed and } \\
\text { documented; "Tier 2" } \\
\text { models documented but } \\
\text { not yet released }\end{array}$ & $\begin{array}{l}\text { Watershed or } \\
\text { landscape scale }\end{array}$ \\
\hline Ecometrix & Quantitative & $\begin{array}{l}\text { Approximately } 150 \text { hours of } \\
\text { consultant's time for field } \\
\text { visits, data analysis in } \\
\text { regions where tool has not } \\
\text { yet been applied }\end{array}$ & Proprietary & $\begin{array}{l}\text { High for Pacific Northwest } \\
\text { and Southwestern } \\
\text { U.S., requires further } \\
\text { development elsewhere. } \\
\text { Some documentation } \\
\text { available }\end{array}$ & Site scale \\
\hline EcoAIM & Quantitative & $\begin{array}{l}\text { Variable: biodiversity } \\
\text { model required } 25 \text { hours, } \\
\text { inclusion of preferences, } \\
\text { mathematical models, } \\
\text { tradeoff modeling, decision } \\
\text { support system framework, } \\
\text { monetization more time } \\
\text { consuming. }\end{array}$ & $\begin{array}{l}\text { Proprietary, requires } \\
\text { contracting with Exponent }\end{array}$ & $\begin{array}{l}\text { Public documentation } \\
\text { unavailable }\end{array}$ & $\begin{array}{l}\text { Watershed or } \\
\text { landscape scale }\end{array}$ \\
\hline ESValue & $\begin{array}{l}\text { Quantitative, uncertainty } \\
\text { through Monte Carlo } \\
\text { simulation }\end{array}$ & $\begin{array}{l}\text { Approximately } 400 \text { hours of } \\
\text { consultant's time per case } \\
\text { study. }\end{array}$ & $\begin{array}{l}\text { Proprietary, requires } \\
\text { contracting with Entrix }\end{array}$ & $\begin{array}{l}\text { Well developed but formal } \\
\text { documentation not } \\
\text { publicly available. }\end{array}$ & $\begin{array}{l}\text { Landscape to } \\
\text { watershed scale }\end{array}$ \\
\hline
\end{tabular}


Table 28. All ecosystem service tools relative to key evaluative criteria.-Continued

[BLM, Bureau of Land Management; GIS, geographic information system; n vs. k, sample size versus number of independent variables]

\begin{tabular}{|c|c|c|c|c|}
\hline Generalizability & $\begin{array}{l}\text { Nonmonetary } \\
\text { and cultural } \\
\text { perspectives }\end{array}$ & Other notes & $\begin{array}{l}\text { Feasibility } \\
\text { for BLM }\end{array}$ & $\begin{array}{l}\text { Information } \\
\text { content for BLM }\end{array}$ \\
\hline $\begin{array}{l}\text { Moderate; results can be } \\
\text { used in value transfer }\end{array}$ & $\begin{array}{l}\text { Accommodates other perspectives; } \\
\text { does not have to use dollars } \\
\text { to report preferences }\end{array}$ & $\begin{array}{l}\text { Although completion of new } \\
\text { studies is typically infeasible, } \\
\text { completed studies for area of } \\
\text { interest can be applied with } \\
\text { low resource needs }\end{array}$ & $\begin{array}{l}\text { Low, time and expense to } \\
\text { develop is too high for } \\
\text { all but the most high- } \\
\text { profile decisions }\end{array}$ & $\begin{array}{l}\text { High relevance to the } \\
\text { decision at hand. }\end{array}$ \\
\hline High & $\begin{array}{c}\text { Typically uses dollars } \\
\text { to aggregate value }\end{array}$ & $\begin{array}{l}\text { Substantial assumptions when } \\
\text { not using a transfer function }\end{array}$ & $\begin{array}{l}\text { High, low time and } \\
\text { resource requirements }\end{array}$ & $\begin{array}{l}\text { Low, often used to get } \\
\text { "ballpark numbers" } \\
\text { or build awareness of } \\
\text { the value of ecosystem } \\
\text { services but less relevant } \\
\text { for decisionmaking. }\end{array}$ \\
\hline $\begin{array}{l}\text { High, within the constraints } \\
\text { of the transfer function }\end{array}$ & $\begin{array}{l}\text { Typically uses dollars } \\
\text { to aggregate value }\end{array}$ & $\begin{array}{l}\text { Not all services have functions } \\
\text { developed. "n vs. k" problem, } \\
\text { the tradeoff between number of } \\
\text { usable studies and information } \\
\text { content in transfer functions }\end{array}$ & $\begin{array}{l}\text { High were previously } \\
\text { developed; low otherwise }\end{array}$ & $\begin{array}{l}\text { Intermediate between } \\
\text { primary valuation } \\
\text { and point transfer. }\end{array}$ \\
\hline High & Dollar values only & $\begin{array}{l}\text { Not all services have functions } \\
\text { developed. Few primary studies } \\
\text { drawn from desert ecosystems }\end{array}$ & $\begin{array}{l}\text { High, transfer functions } \\
\text { are contained within } \\
\text { Excel spreadsheets }\end{array}$ & $\begin{array}{l}\text { Intermediate between } \\
\text { primary valuation } \\
\text { and point transfer. }\end{array}$ \\
\hline $\begin{array}{l}\text { High, assuming availability } \\
\text { of underlying data }\end{array}$ & $\begin{array}{l}\text { Biophysical values, } \\
\text { can be monetized }\end{array}$ & $\begin{array}{l}\text { Well-vetted coarse-scale models; } \\
\text { local offices would need } \\
\text { to determine usefulness of } \\
\text { the outputs }\end{array}$ & $\begin{array}{l}\text { Moderate; time to assemble } \\
\text { data to parameterize } \\
\text { models limits broad } \\
\text { applicability }\end{array}$ & $\begin{array}{l}\text { High; quantifies tradeoffs } \\
\text { across multiple } \\
\text { ecosystem services. }\end{array}$ \\
\hline $\begin{array}{l}\text { High, once global models } \\
\text { are completed }\end{array}$ & $\begin{array}{l}\text { Biophysical values, } \\
\text { can be monetized }\end{array}$ & $\begin{array}{l}\text { Models are still in development; } \\
\text { beta release planned for } \\
\text { late } 2012\end{array}$ & $\begin{array}{l}\text { Moderate; highly feasible } \\
\text { to use online models but } \\
\text { use elsewhere depends on } \\
\text { release of global models }\end{array}$ & $\begin{array}{l}\text { Very high; quantifies } \\
\text { tradeoffs across multiple } \\
\text { ecosystem services while } \\
\text { providing uncertainty } \\
\text { estimates and spatial flow } \\
\text { information. }\end{array}$ \\
\hline
\end{tabular}

Requires field visits and data analysis for the sites to be evaluated, which must be completed for application of Ecometrix in new regions

High, though results are specific to the issues and stakeholder group

\section{high resolution or spatial exten} The only tool analyzed that uses site-level analysis; could be paired with a landscape-scale tool to provide fine-grained site analysis

High, if applied in a region where it has been developed and site-level analysis was desirable.

Moderate, could be applied if High, if combined weighted funding were available to

\footnotetext{
Results would be specific to the issues and stakeholder group involved in the process.

Explicitly incorporates preferences nonmonetarily via ranked analysis of tradeoffs by stakeholders
}

Designed as a credit calculator, no economic valuation
Incorporates stakeholder preferences via modified risk analysis approach hire consultants

if funding were aval to hire consultants

\author{
Moderate, could be applied High, if nonmonetary \\ if funding were available preferences are important.
}


Table 28. All ecosystem service tools relative to key evaluative criteria.-Continued

[BLM, Bureau of Land Management; GIS, geographic information system; $\mathrm{n}$ vs. k, sample size versus number of independent variables]

\begin{tabular}{|c|c|c|c|c|c|}
\hline Tool & $\begin{array}{c}\text { Quantifiable, } \\
\text { approach to } \\
\text { uncertainty } \\
\end{array}$ & Time required & $\begin{array}{l}\text { Open source } \\
\text { or proprietary }\end{array}$ & $\begin{array}{c}\text { Level of } \\
\text { development }\end{array}$ & Scalability \\
\hline NAIS & $\begin{array}{l}\text { Quantitative, reports } \\
\text { range of values }\end{array}$ & $\begin{array}{l}\text { Variable depending on } \\
\text { stakeholder involvement } \\
\text { in developing the study }\end{array}$ & Proprietary & $\begin{array}{l}\text { Developed but } \\
\text { public documentation } \\
\text { unavailable }\end{array}$ & $\begin{array}{l}\text { Watershed or } \\
\text { landscape scale }\end{array}$ \\
\hline SolVES & $\begin{array}{l}\text { Quantitative, no explicit } \\
\text { handling of uncertainty }\end{array}$ & $\begin{array}{l}\text { High if primary surveys } \\
\text { needed to be developed, } \\
\text { administered, and } \\
\text { analyzed; low if } \\
\text { compatible survey data } \\
\text { were available or function } \\
\text { transfer approach is used }\end{array}$ & $\begin{array}{l}\text { Publicly available, } \\
\text { requires ArcGIS }\end{array}$ & $\begin{array}{l}\text { Fully developed and } \\
\text { documented }\end{array}$ & $\begin{array}{l}\text { Watershed or } \\
\text { landscape scale }\end{array}$ \\
\hline Envision & Quantitative & $\begin{array}{l}\text { California, } 1 \text { year, } \\
\$ 100,000-150,000 \text { to } \\
\text { develop a new case study }\end{array}$ & Publicly available & $\begin{array}{l}\text { Developed and documented } \\
\text { for Pacific Northwest } \\
\text { case study sites }\end{array}$ & Landscape scale \\
\hline InFOREST & Quantitative & $\begin{array}{l}\text { Low; accessed through } \\
\text { online interface }\end{array}$ & Publicly available & $\begin{array}{l}\text { Developed and documented } \\
\text { only for Virginia }\end{array}$ & Site to landscape scale \\
\hline ESR & Qualitative & $\begin{array}{l}\text { Low (1 week to } 1 \text { month, } \\
\text { depending on number of } \\
\text { stakeholders involved) }\end{array}$ & Publicly available & $\begin{array}{l}\text { Fully developed and } \\
\text { documented }\end{array}$ & Multiple scales \\
\hline $\begin{array}{l}\text { UNEP-WCMC } \\
\text { Ecosystem } \\
\text { Services Toolkit }\end{array}$ & Qualitative & $\begin{array}{l}\text { Low, depending on } \\
\text { involvement of } \\
\text { stakeholders in the } \\
\text { ES survey process }\end{array}$ & Publicly available & $\begin{array}{l}\text { Documented but tool has not } \\
\text { yet been publicly released }\end{array}$ & Multiple scales \\
\hline
\end{tabular}


Table 28. All ecosystem service tools relative to key evaluative criteria.-Continued

[BLM, Bureau of Land Management; GIS, geographic information system; n vs. k, sample size versus number of independent variables]

\begin{tabular}{|c|c|c|c|c|}
\hline Generalizability & $\begin{array}{l}\text { Nonmonetary } \\
\text { and cultural } \\
\text { perspectives }\end{array}$ & Other notes & $\begin{array}{l}\text { Feasibility } \\
\text { for BLM }\end{array}$ & $\begin{array}{l}\text { Information } \\
\text { content for BLM }\end{array}$ \\
\hline $\begin{array}{l}\text { High, within limits } \\
\text { of point transfer }\end{array}$ & Dollar values only & $\begin{array}{l}\text { Point transfer often used to get } \\
\text { "ballpark numbers" or build } \\
\text { awareness of ecosystem } \\
\text { service values }\end{array}$ & $\begin{array}{l}\text { Moderate, could be applied } \\
\text { if funding were available } \\
\text { to hire consultants }\end{array}$ & $\begin{array}{l}\text { Low, often used to get } \\
\text { approximate numbers } \\
\text { or build awareness of } \\
\text { the value of ecosystem } \\
\text { services but less relevant } \\
\text { for decisionmaking. }\end{array}$ \\
\hline $\begin{array}{l}\text { High, if value transfer can } \\
\text { be shown to successfully } \\
\text { estimate values at } \\
\text { new sites }\end{array}$ & $\begin{array}{l}\text { Nonmonetary preferences } \\
\text { (rankings) of relative } \\
\text { values for stakeholders }\end{array}$ & $\begin{array}{l}\text { Unique in providing maps of } \\
\text { social values for ecosystem } \\
\text { services; time consuming } \\
\text { to run new studies but } \\
\text { lower cost for as-yet } \\
\text { untested value transfer }\end{array}$ & $\begin{array}{l}\text { High if primary survey data } \\
\text { are available (currently } \\
\text { only for forests in } \\
\text { Colorado) or value transfer } \\
\text { results are acceptable. New } \\
\text { applications could expand } \\
\text { versatility of SolVES' } \\
\text { value transfer function }\end{array}$ & $\begin{array}{l}\text { High, particularly if primary } \\
\text { survey data are available } \\
\text { and nonmonetary values } \\
\text { are desired. Initial } \\
\text { transferability of results } \\
\text { using value transfer } \\
\text { appears promising (that } \\
\text { is, to still offer high } \\
\text { information content in } \\
\text { the absence of primary } \\
\text { survey data), though this } \\
\text { should be tested further } \\
\text { before extensively rely- } \\
\text { ing on SolVES' value } \\
\text { transfer function. }\end{array}$ \\
\hline Place specific & $\begin{array}{l}\text { Designed to allow stakeholders } \\
\text { to compare tradeoffs using } \\
\text { nonmonetary perspective, also } \\
\text { to support monetary valuation }\end{array}$ & $\begin{array}{l}\text { Links ecological and } \\
\text { economic process models } \\
\text { to measure and map impact } \\
\text { to "landscape metrics," } \\
\text { including ecosystem services }\end{array}$ & $\begin{array}{l}\text { High in regions where it } \\
\text { has been developed, } \\
\text { low elsewhere }\end{array}$ & $\begin{array}{l}\text { High in regions where } \\
\text { it has been developed. }\end{array}$ \\
\hline Currently place specific & $\begin{array}{l}\text { Designed as a credit calculator, no } \\
\text { economic valuation }\end{array}$ & $\begin{array}{l}\text { Cost effective in regions where } \\
\text { it has been developed; } \\
\text { otherwise time consuming } \\
\text { for new applications }\end{array}$ & $\begin{array}{l}\text { High, if developed for } \\
\text { western United States }\end{array}$ & $\begin{array}{l}\text { Moderate to high if } \\
\text { developed for the western } \\
\text { United States. Minimal } \\
\text { value for BLM otherwise. }\end{array}$ \\
\hline High & No valuation component & $\begin{array}{l}\text { Most useful as a low-cost } \\
\text { screening tool }\end{array}$ & Feasible now & $\begin{array}{l}\text { Low, though can be used } \\
\text { as a screening tool for } \\
\text { quantitative ecosystem } \\
\text { service assessment } \\
\text { using other tools. }\end{array}$ \\
\hline High & No valuation component & $\begin{array}{l}\text { Most useful as a low-cost } \\
\text { screening tool }\end{array}$ & $\begin{array}{l}\text { Feasible once tool } \\
\text { is released }\end{array}$ & $\begin{array}{l}\text { Low, though can be used } \\
\text { as a screening tool for } \\
\text { quantitative ecosystem } \\
\text { service assessment } \\
\text { using other tools. }\end{array}$ \\
\hline
\end{tabular}




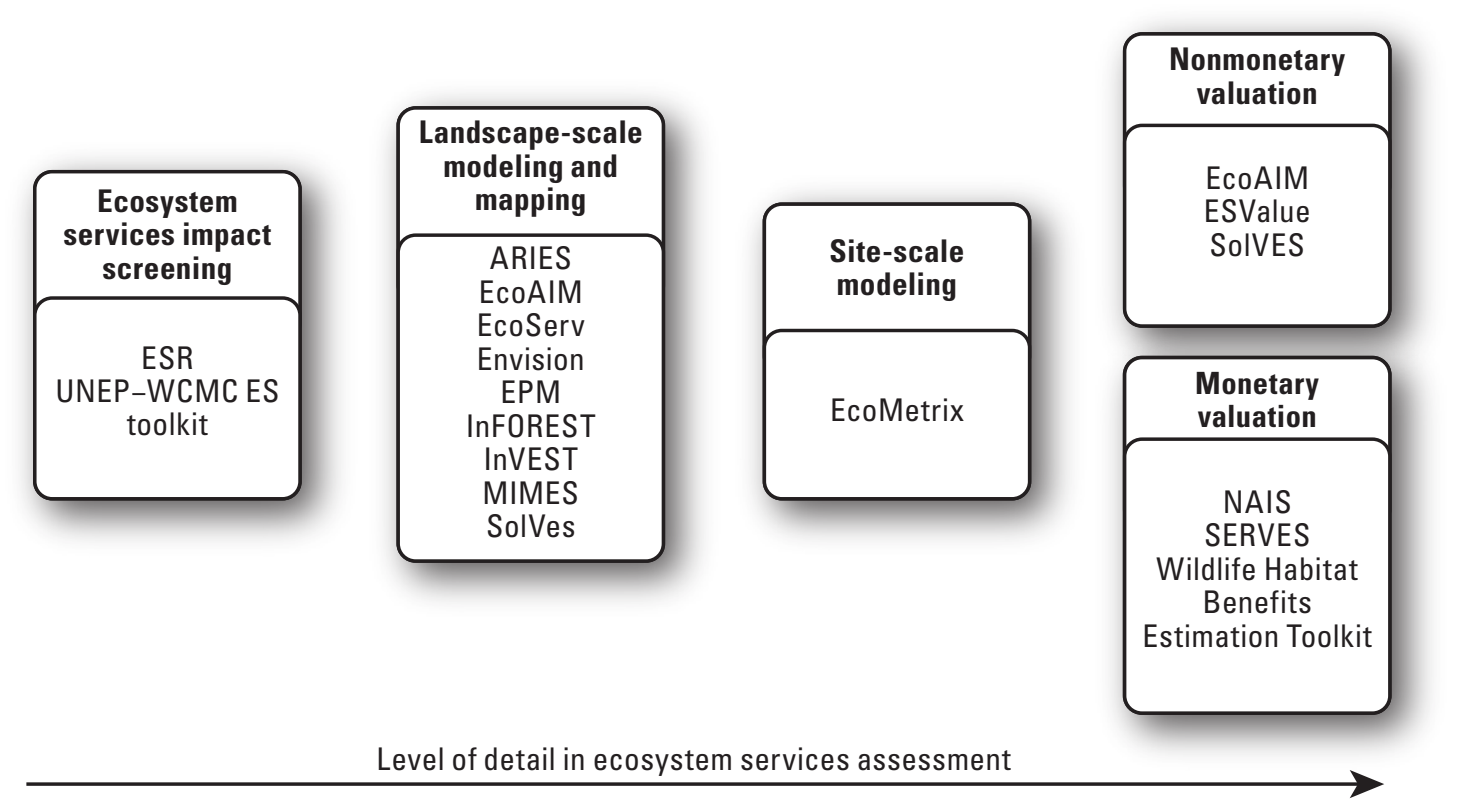

Figure 15. Potential steps in assessing ecosystem services.

\section{Artificial Intelligence for Ecosystem Services (ARIES)}

Like InVEST, ARIES quantifies and maps ecosystem services and supports scenario analysis for evaluating ecosystem service tradeoffs. ARIES is a more flexible modeling system than InVEST, because it is easier to customize scenarios and models to account for locally important ecological and socioeconomic conditions. It provides uncertainty estimates associated with results and ecosystem service flows by explicitly evaluating provision, use, and flow characteristics for each service. This type of analysis provides maps of actual ecosystem service provision and use rather than just potential provision in the absence of human beneficiaries (Johnson and others, 2012). Finally, ARIES minimizes local spatial data handling requirements by linking to a GeoServer - an open-source database that can serve spatial data for modeling (http://www.geoserver.org) — that in early 2012 stored over 400 datasets relevant to ecosystem service modeling. These datasets can be called on for any ecosystem service model, and results can be delivered to the user by means of a web interface.

However, in early 2012 ARIES had several key limitations. Constructing new ARIES models is time consuming, although substantially less time consuming upon completion of this project than at its start, and currently it requires use of a particular open-source but poorly documented modeling language. Although this currently makes it impractical for BLM district and field offices to construct new models, future improvements such as a fully documented, graphical user interface (GUI)-based modeling language may make localmodel editing much more feasible. Although ARIES models account for local influences on service provision and use, a generalized model for each ecosystem service that is globally or nationally applicable has not yet been developed.
Until global models are ready, ARIES can be run only in its case-study regions (southern Arizona, Southern California, Colorado, and western Washington as case-studies regions containing BLM land). Even for these regions, further model testing and refinement would be desirable in order to improve the models' quality and relevance for decisionmaking. ARIES currently runs in a command line interface that is not useful for external users; however, access through an internet browser was planned by late 2012. As is true for InVEST, ARIES currently integrates cross-boundary datasets poorly. It was not possible to run these models for the Mexican side of the watershed, despite the intent of the ARIES model to be able to run under conditions of data scarcity. Improved handling of cross-boundary datasets, which will improve model results, is planned for future ARIES releases. Future releases of ARIES (similar to those of InVEST) intend to link to external models, further improving the accuracy and credibility of results.

\section{Other Tools Not Tested in the Pilot Study}

We were unable to test a number of other ecosystem services tools within the scope of this pilot study (table 5). Some of these tools are proprietary methods that could be used for high-profile decisions where contracting with consultants is feasible, but for which repeated bureau-wide application is not likely (for example, EcoAIM, EcoMetrix, ESValue, NAIS). For details about these tools' strengths, weaknesses, and application to the San Pedro River watershed, see BSR (2011).

Other approaches require intensive, place-specific modeling that would be too expensive and time consuming to apply to bureau-wide decisionmaking (for example, Envision, Ecosystem Portfolio Model). However, these tools could be 
quite informative if they had previously been developed in areas where BLM wanted to bring ecosystem services assessment into the decision process.

The remaining tools were at too early a stage of development to allow independent application to the San Pedro River watershed. Although its models are open source, as of early 2012 MIMES had limited documentation, requires proprietary modeling software, and is too complex to run without contracting with its developer. SolVES lacked local primary survey data and has not yet been used in a wide enough variety of case studies to test the capacity of its value-transfer functions. As SolVES is used more, and if the accuracy of its value transfer approach can be demonstrated, it could be widely used by BLM. EcoServ's online interface and promised seamless integration of data and models could make it a useful tool for BLM as well. However, in early 2012 EcoServ was at too early a stage of development for testing or use. The SERVES valuation tool, planned for release as a subscriptionbased service, could be a useful economic valuation database for BLM, but it was under development as of early 2012. A booklet describing the UNEP-WCMC Ecosystem Services Toolkit was released in late 2011, but full guidance on the toolkit remained in development at the conclusion of this pilot study. Finally, InFOREST is another web-accessible ecosystem service modeling approach that could be used by agencies such as BLM but as of early 2012 is planned only for use in the Eastern United States. Although it may be useful for eastern land managers, InFOREST is unlikely to be a relevant tool for BLM unless its models are adapted for western states.

Although none of these tools were used during this pilot study, follow-up studies could reconsider their relevance for BLM as their capability, documentation, stability, and generalizability improve with time.

\section{Lessons Learned in the Valuation Process: Steps to Follow and Avoid}

All model developers face tradeoffs. Is it better to accurately capture locally important factors that influence ecosystem service values but sacrifice generalizability to other locations? Or is it better to be generalizable but produce results that neglect important local factors and potentially sacrifice accuracy? Although ARIES uses a more modular modeling approach to better account for local processes, its data and models are not yet available for the entire Western United States. InVEST models, on the other hand, may be used anywhere but may not account for locally important ecological factors. The planned approach of ARIES and EcoServgeneralized, intentionally simple global models for coarsescale analysis, combined with locally specific case-study models - is one way around this problem. However, neither of these tool features were available for this pilot study. Similarly, InVEST tier 2 models may better account for local processes but were not available for the pilot study. Place-specific tools such as Envision and the Ecosystem Portfolio Model model only local conditions rather than provide a generalizable model, which limits their bureau-wide value for BLM but improves their scientific and policy relevance in places where they have been developed.

It is important to run spatial ecosystem service models such as InVEST and ARIES at the highest feasible spatial resolution within the confines of time and computer processing requirements. Land cover and carbon storage compared manually (by using data at $30 \times 30$-meter resolution) showed storage to be greatest in year 2000, lowest in the year 2020 open scenario, and intermediate in the year 2020 constraineddevelopment scenario. However, the InVEST carbon model run at $100 \times 100$-meter resolution showed the greatest level of carbon storage in the 2020 open-development scenario, a nonintuitive result. The resampling process tends to lose individual high-value pixels and, through this averaging process, the value of ecosystem services analyzed at coarse spatial resolution is likely to be less than the value produced by a fine-scale analysis (Konarska and others, 2002). Running InVEST at 30-meter resolution produced the expected results, as reported in the Results section. BLM and other users need to be aware that overly coarse scale analysis could lead to incorrect conclusions, such as the (incorrect) finding that carbon storage is maximized in an open-development scenario as described above.

As previously noted, some scenarios are much easier to run in existing ecosystem service models than others. For tier 1 InVEST models, land-use and land-cover change drives ecosystem services, and for the water-augmentation scenario, a good understanding of how water augmentation affects land cover was lacking. It is reasonable to expect a shift from mesquite- and tamarisk-dominated to cottonwoodwillow-dominated riparian communities, given restoration of shallow groundwater, surface flows, and vegetation management. Eventual senescence of mature cottonwood trees on the San Pedro River is also reasonable to expect, because the stream channel has not migrated across the floodplain in recent decades, and thus opportunities for establishment of new cottonwood stands are limited (Dixon and others, 2009). However, the lack of spatial data on the extent of riparian community types and how they would be expected to differ in terms of ecosystem service delivery, made it impractical to run InVEST models for this type of scenario. The greater flexibility of the ARIES model allowed it to accommodate water-augmentation scenarios in the recreation models. This accommodation shows the importance of understand how potential scenario changes will interact with ecosystem service models given the primacy of land-use and land-cover change as a driver of ecosystem services in the tier 1 InVEST models. BLM, The Nature Conservancy, and BOR continue work on optimal hydrologic restoration scenarios, and their guidance can facilitate better ecosystem service modeling for water augmentation scenarios. 
Integration of Past Work on the San Pedro River Watershed into Ecosystem Service Models

Although the San Pedro River watershed was selected for its large body of past research, much of this scientific knowledge was not useful for parameterizing the ecosystem service models that were tested. This finding has been documented by others; even for areas whose ecology is well understood and richly documented, that knowledge is not always the type needed to support ecosystem service modeling, mapping, valuation, and decisionmaking (Norgaard, 2010). Ecosystem services researchers can improve this situation by collaborating with disciplinary researchers to fully understand the state of disciplinary research, incorporate existing models where they are appropriate, and build new models that reflect the state of the ecological science. Where research gaps prevent disciplinary science from supporting ecosystem services assessment and valuation, these research needs should be articulated to the scientific community. Such collaboration can help to integrate existing work and develop new research to better understand the ecological cause and effect that underlie ecosystem service production functions (Daily and others, 2009). The US EPA-ORD is beginning to catalog ecological production functions for use in ecosystem services modeling, which could inform future modeling efforts and tradeoff quantification for a number of the ecosystem services tools.

Ecosystem service tools are designed to be relatively simple in their application, to facilitate quantification of tradeoffs between services, and to link to human beneficiaries. Yet in some contexts discipline-specific biophysical models may be more appropriate: specific hydrologic models such as Soil and Water Assessment (SWAT), Variable Infiltration Capacity (VIC), Water Evaluation and Planning (WEAP), or Hydrologic Engineering Center-River Analysis System (HEC-RAS) and large-scale carbon modeling efforts such as the USGS LandCarbon program (Zhu and others, 2010). Where such resources and modeling expertise are available, disciplinespecific models may better quantify ecosystem services. When one chooses an ecosystem service tool, deterministic models may be more appropriate in regions with more data, whereas probabilistic approaches (such as those in ARIES) may be more appropriate in areas with sparse data and high uncertainty (Vigerstol and Aukema, 2011).

\section{Nonmonetary and Tribal Values}

The San Pedro River watershed holds immeasurable significance to numerous American Indian tribes (Ferguson and Colwell-Chanthaphonh, 2006). As of early 2012, Fort Huachuca consulted with 11 Federally recognized tribes that have a cultural affiliation with the San Pedro Valley (Marty Tagg, Fort Huachuca, written commun., 2012). Viewed within the westernized construct of ecosystem services,
American Indians could be said to value the San Pedro River watershed for cultural, symbolic, spiritual, and historic reasons, along with its many provisioning services.

A direct assessment of how tribes value the environment and ecosystem services was beyond the scope of this project, but even so the ecosystem services tools and methods evaluated for this project were not amenable to estimating tribal values. Tribes may not be willing to share with outsiders the information needed to map key points on the landscape, preventing the use of spatial mapping tools for ecosystem services. However, tribes might be amenable to indicating and possibly ranking their preferences for landscape-change alternatives and tradeoffs between ecosystem services as measured in biophysical units. Tools that are designed to incorporate nonmonetary stakeholder preferences (for example, EcoAIM, ESValue, SolVES, and Envision) could aid in understanding tribal values for ecosystem services, although these tools were not tested as part of this study.

\section{San Pedro Riparian National Conservation Area Outcomes}

Our results demonstrate how ecosystem services could be used by a BLM district or field office to aid in decisionmaking. Before undertaking this modeling exercise, local stakeholders held that urban growth, particularly at low densities, would entail some loss of ecosystem services, that mesquite management would involve tradeoffs between carbon, water, and habitat quality, and that water augmentation of the San Pedro River would provide some ecosystem services benefits. However, SPRNCA managers lack jurisdiction on basin-wide urban growth choices, and even county planners may desire information on ecosystem services changes at smaller spatial scales (for example, to measure the impacts of development of a particular parcel of land). InVEST and ARIES are landscape-scale models that can be run at smaller scales such as subwatersheds, and their results can be clipped to measure smaller-scale impacts. To truly measure site-scale changes in ecosystem services (for example, on alternative development approaches to the same parcel), a site-scale tool such as EcoMetrix is most appropriate.

Rising demand for ecosystem services can increase their value, even as ecosystems are being degraded. ARIES viewshed and proximity results are good examples: in both urbanization scenarios, landscape quality declined while ecosystem service use went up, as more users were present on the landscape. It is thus important that rising ecosystem service values not be automatically equated with improvements in ecosystem quality.

Our results map and quantify ecosystem services tradeoffs and provide monetized values for some services. All scenarios illustrate some degree of uncertainty in the results, on the basis of the models themselves and the economic values and discount rate applied. For scenarios such as mesquite management, the total value ranges from a loss to 
a gain in annual value, depending on how water and carbon are valued. Because of this uncertainty and the inability to monetize habitat quality, incorporation of economic values into a strict cost-benefit framework for decisionmaking is likely inappropriate for some management decisions. Using water augmentation scenarios with the InVEST and ARIES ecosystem service models was difficult. Well-defined scenarios and spatial and ecological data to support them are important in order to successfully model ecosystem-service change in scenarios. BLM and others are working to define optimal flows to better understand the costs and benefits of water augmentation under alternative scenarios, which could produce better input data for ecosystem service models in the future.

Given the large effort needed to develop and apply these tools to southeast Arizona, USGS will supply BLM national, State, district, and field offices with the data and models developed for this project. However, local users will likely need some training and support to use these models independently. Models continue to be developed and tested by USGS, which can provide BLM district and field offices the opportunity to learn about and apply locally appropriate models to management questions. Additionally, State, Gila District, and BLM field offices would benefit from further guidance on how and when to apply ecosystem services in decisionmaking, and particularly how to deal with valuation and uncertainty. Guidance on technical, economic, and policy matters related to ecosystem services can likely be provided to BLM district and field offices by National office, DOI Office of Policy Analysis, and USGS, among others. At the conclusion of this pilot, the Arizona, Gila District, and SPRNCA offices have the opportunity to lead BLM in applying ecosystem services toward decisionmaking, but they would benefit from further technical support, training, and policy guidance to be able to use these tools in regular decisionmaking.

\section{Agency-Wide Outcomes}

Quantifying, mapping, and valuing ecosystem services offers BLM a promising way to quantify and communicate resource management tradeoffs, particularly when resource extraction could degrade ecosystem services. Ecosystem services can enable BLM to better address the "tragedy of ecosystem services" (Lant and others, 2008) or the "macroallocation problem" between ecosystem structure and function (Farley, 2008), where commodities or ecosystem goods are overconsumed at the expense of ecosystem services. Ecosystem services need not be analyzed for every decision throughout the bureau. Ecosystem services may be of use in an analysis when (1) substantial social or environmental effects are likely (as identified in the NEPA process); (2) a substantial tradeoff may exist between preservation of ecosystem services and extraction of market goods (oil, gas, coal, minerals, timber, grazing); or (3) the proposed change is large (Winthrop, 2011).
The tools evaluated in this report differ in their appropriateness for use by BLM and in the value of their outputs for decisionmaking (tables 25-26). The mid-2012 bureau-wide readiness of these tools and methods is summarized below. Given the rapid state of evolution in the field, new tools may appear on the landscape and the capabilities of existing tools may change, so periodic review of tools of particular interest to BLM is desirable.

- Feasible for immediate bureau-wide use by BLM:

- Ecosystem Services Review, UNEP-WCMC Ecosystem Services Toolkit, Wildlife Habitat Benefits Estimation Toolkit.

- Potentially feasible for bureau-wide use by BLM given development of supporting databases for spatial data and literature:

- function transfer

- InVEST, point transfer

- application of past primary valuation studies.

- Potentially feasible for bureau-wide use by BLM given pending development of global models or expanded underlying datasets:

- ARIES

- EcoServ

- SolVES.

- Proprietary tools, feasible for use in high-profile cases where contracting with consultants or developers, or paying for a subscription is possible:

- EcoAIM

- EcoMetrix

- ESValue

- NAIS

- SERVES.

- Open-source tools that are place specific, require a long lead time to develop, and require contracting with universities or consultants. If models have been previously developed for an area of interest they could be immediately applied:

- Ecosystem Portfolio Model

- Envision

- InFOREST

- MIMES.

BLM has made at least one previous effort to quantify ecosystem services prior to this pilot study. BLM's California State Office contracted with Spatial Informatics Group to use NAIS to estimate ecosystem services in Napa, Humboldt, and San Bernardino counties in association with the State's fire management program (TSS Consultants, 2005). The intent of the study was to provide monetary values for ecosystem 
services to compare with cost estimates for firefighting, fuels management, and property loss from wildfire. The study used point transfer, identified land-cover types in each county and assigned ecosystem service values from the literature based on these land-cover types. The California BLM noted that ecosystem services have not yet been an effective argument in increasing funding for their fire and fuels management program, and that the state, district, and field offices are waiting for national guidance on how and when to use ecosystem services in decisionmaking. Despite these limitations, the study did provide potentially useful information to inform land management and funding allocation decisions, and it has been used internally by California BLM. The study would have been more useful had it provided values for the entire state, rather than just three counties, and California BLM would have preferred not to have to contract out the work. Because national-level data may be too imprecise to inform local decisionmaking, giving BLM state, district, and field offices the tools and guidance to run consistent analyses would be highly desirable (Craig Barnes, California State BLM, oral commun., 2010). Although the California study did not result in on-the-ground changes in ecosystem-services-based management for BLM, it further demonstrated the importance of this pilot study and the need for national-level guidance on ecosystem services to be provided to BLM state, district, and field offices.

\section{Implications for Future Work}

\section{Incorporating Ecosystem Service and Value Information into the Decision Process}

The promise of using ecosystem service assessment tools to support decisionmaking, particularly within BLM's NEPA and RMP processes, rests on being able to systematically measure impacts in a way that is credible, quantifiable, and replicable. Ecosystem service impacts may already be described qualitatively without the use of valuation methods or models. However, the goal is to present results as a change in ecosystem services measured in biophysical units, weighted preferences, or dollars for baseline conditions and for potential management scenarios. Quantified changes as presented in the Results section of this report are thus desirable. Maps of impacts, tradeoffs, and values can facilitate clearer communication to decisionmakers and the public, and they can be an important addition to the decision process.

Given the complexity inherent in modeling and valuing ecosystem services and the desire to incorporate them into decisionmaking, it makes sense to estimate and convey uncertainty in model outputs and valuation results. Reporting a single value can inspire false confidence in the certainty of results. Many primary valuation studies report a range of values, and function transfers report standard errors for regression coefficients. ARIES reports uncertainty associated with Bayesian network models and can use Monte Carlo simulation. ESValue can also use Monte Carlo simulation to estimate and report uncertainty. It would be highly useful for model developers to know what uncertainty metrics are most valuable to decisionmakers, and how uncertainty is or can be used in decisionmaking. Are outcomes with a highly uncertain but large gain in ecosystem service provision preferable over a small gain with greater certainty? A better understanding of how to communicate and use of uncertainty information would thus be desirable for the entire ecosystem services science and policy community. Such guidance might be best provided by BLM and DOI's Office of Policy Analysis.

Along with uncertainty, ARIES reports a number of outputs to fully map spatial flows of ecosystem services, in some cases as many as 16 maps for each ecosystem service's theoretical, possible, actual, inaccessible, and blocked service provision, sinks, uses, and flows (Bagstad and others 2011; Johnson and others, 2012). As is true for reporting of uncertainty estimates, such outputs will need to be reviewed and considered in decision contexts so that they can be presented in a way that adds value to the decision process rather than leaving a potential user "drowning in data."

It would be also useful to better define the specific ecosystem service metrics that are most useful for economic valuation and decisionmaking. The lack of clearly defined metrics is a broad issue faced by researchers throughout the field of ecosystem services who are working to better quantify ecosystem services tradeoffs to inform resource management (Boyd and Krupnick, 2009). Some outputs of the San Pedro River watershed modeling exercise, particularly for water yield, translated poorly into metrics that were amenable to valuation. Models that can better quantify ecological endpoints will generally be more useful for economic valuation. Few ARIES and InVEST outputs are directly comparable. For carbon, for instance, it would be useful to better know which metrics decisionmakers found to be most useful: carbon storage and storage change through time (reported in InVEST), potential stored carbon release, carbon sequestration, and greenhouse gas emissions (reported in ARIES), or some combination? In each case, a better understanding of what BLM and other users need to support decisionmaking and how tools can better meet those needs would be helpful. The concept of ecological endpoints or "final ecosystem goods and services" is gaining preliminary consensus (Boyd and Banzhaf, 2007; Nahlik and others, 2012) as metrics that can be measured or modeled. Final Ecosystem Goods and Services link directly to green accounting frameworks and avoid the problem of double counting of benefits that has plagued past efforts at quantifying ecosystem services. This approach also meshes well with the beneficiaries-centric approach taken by ARIES (Villa and others, 2011).

Lastly, consistent application of models or tools that produces replicable results is important to maintain credibility in ecosystem service valuation, because the tools used to estimate these values are newer and less well established than nonmarket valuation methods or biophysical-process models. Using consistent data sources, approaches to tool applications, and reporting of results is critical. It also means that consistent 
use of generalizable tools such as those tested in this pilot study may be of more value bureau-wide than a series of independent, special-purpose tools applied to multiple sites at regional scales, where cross-comparison and development of best practices for each tool becomes less feasible.

\section{Data Sharing to Support Widespread Ecosystem Services Mapping and Valuation}

A system of data sharing for spatial data, ecological studies needed to parameterize the ecosystem service models, and economic studies needed to conduct valuation would immensely aid ecosystem service valuation efforts within BLM. The time spent on this pilot study would have been substantially reduced had such resources been available. Although such a system could be developed by and housed within BLM, it might be more sensible to pool resources with other Federal agencies and departments to create a system for ecosystem services-based decisionmaking on public lands for all agencies within the Department of the Interior, perhaps housed within USGS but ideally also including agencies outside the Department of the Interior that are involved in resource management and ecosystem services research (such as the National Oceanic and Atmospheric Administration (NOAA), USDA Forest Service, US EPA, and DOD). Spatial data underlie nearly all ecosystem service modeling and valuation tools. Although the USGS houses abundant public data on land cover, hydrology, and geology, and other sources such as the Natural Resources Conservation Service (NRCS) Spatial Data Gateway offer one-stop locations for data downloads, no single site contained all the spatial data needed to run the ecosystem service models (appendixes A, B). Collecting, storing, and preprocessing relevant spatial data in a single location could save future users substantial time and effort. In this regard, the ARIES approach to handling spatial data is sophisticated and worth further investigation. ARIES uses a GeoServer that can call on annotated spatial data to support multiple ecosystem service models, and it also automatically handles simple GIS operations such as rasterization, resampling, reprojection, and reclassification, which would otherwise require substantial time and expertise by a GIS technician. Preparing data to run the InVEST models, for instance, was the second most time-consuming part of running those models, aside from the substantial time required to collect the ecological data needed to parameterize the InVEST data tables.

Ecosystem service valuation databases have been completed in the past (McComb and others, 2006). The Ecosystem Services Database (Villa and others, 2002) was a National Science Foundation-funded valuation database, but it has not received funding for maintenance and its underlying database has not been updated in nearly 10 years, a problem common to ecosystem-based management tools (Curtice and others, 2012). The NAIS and the SERVES databases are both outgrowths of the ESD. NAIS is a proprietary database and is not available for public access, and a subscription service is planned to provide access to SERVES. The EVRI database has been relatively well-maintained, but searches of this database for this pilot project revealed that it is missing a number of key valuation studies for the Western United States. A 2011 release of the database also eliminated the ability to search for studies by state in the United States, making searches more cumbersome and time consuming. Each of these databases thus has its own limitations. However, with better support and cooperation from Federal agencies, expansion and updating of such databases could become more feasible.

Just as databases cataloging primary economic studies can support valuation, databases could also be constructed for the ecological studies needed to support modeling efforts. As we better understand the data needs for major ecosystem service models, it would be valuable to have a database that can be used to identify key ecological parameters to support such models. For instance, the tier 1 InVEST models link ecosystem service provision to land use and land cover by means of tables. Having accurate coefficients (for example, for carbon storage, rooting depth, nutrient loading, and evapotranspiration coefficients by land-use and land-cover type) for use in these tables is needed to run the models and obtain credible results. ARIES offers flexibility in its capacity to build and use models for local cases where influences on ecosystem services supply and demand vary. However, this modular approach and the ARIES global models under development needs to be underlain by relevant ecological research, particularly to identify relevant ecological production functions (Daily and others, 2009). As previously mentioned, US EPA-ORD's work on ecological production functions may be helpful for modelers.

If centralized sources of spatial data and underlying ecological and economic knowledge were available, it would be feasible for BLM district and field offices to regularly run more complex ecosystem service models with greatly reduced resource requirements.

\section{Follow-Up Studies}

At the beginning of this project, BLM and USGS agreed that it would be useful to identify a second site for a companion study, preferably in a region with greatly different ecological and socioeconomic characteristics than southeast Arizona. With the completion of this study, we are now aware that the San Pedro's strong prior research base was not as important as initially thought in supporting modeling and valuation. Although sophisticated process models have been developed linking the San Pedro's groundwater, surface water, vegetation, and avian habitat (Serrat-Capdevila and others, 2009), ecosystem service models as of early 2012 did not support integration of external-process models. Future versions of several models, however, intend to link accepted hydrologic and ecological models with ecosystem services provision and use, which would be a major step forward in ecosystem service modeling. In this pilot study, the largest contribution 
from other researchers was their expert assistance in reviewing model inputs (appendix D), rather than in providing a library of past studies that seamlessly filled our valuation and modeling needs.

As a result, BLM can be less hesitant about attempting to use these methods and models in poorly studied environments, because all sites can be considered data poor to some degree for the purposes of ecosystem service modeling. The data and models assembled and documented for this project can assist future researchers, particularly those working on ecosystem services-based decisionmaking for public lands. Since the results of this project represent state-of-the-modeling and valuation literature as of mid-2012, and because of the rapid evolution and proliferation of models, periodic follow-up projects would be sensible.

Aside from these projected future improvements to ecosystem services tools, other tools may offer improved features and documentation, and growth of the valuation literature will offer continual, even if slow, change in the state of the science. Given the speed of evolution in the science of ecosystem services, a periodic (annual to biennial) review of the science as it applies to decisionmaking on public lands would be desirable both for BLM and other public land management agencies. Such reviews could take the form of more focused case studies that explore particular nuances of new tools and methods, rather than the broad survey undertaken for this initial study.

Lessons learned from this project are applicable for decisionmakers on public land outside of BLM. Given the importance of ecosystem services for a variety of Federal departments and agencies (for example, DOD, NOAA, DOI, USDA, and US EPA), BLM need not necessarily shoulder all the burden of testing tools for all Federal agencies. Ideally, Federal agencies would share funding, research responsibilities, and scientific findings; in return, well-documented data, case studies, and lessons learned could be shared throughout departments and agencies with a vested interest in facilitating ecosystem-services-based management. At a minimum, DOI, with USGS as the lead scientific agency, could implement such sharing internally although participation of other departments and agencies is desirable. Emerging efforts such as the National Ecosystem Services Partnership (http://nicholasinstitute.duke.edu/ecosystem/nesp), which brings together Federal and non-Federal researchers, practitioners, and decisionmakers, could also provide a platform for such collaboration, data sharing, and periodic reviews of the state of ecosystem service tools.

\section{Acknowledgments}

Chris Colvin, Driss Ennaanay, Gary Johnson, Heather Tallis, Ferdinando Villa, Brian Voigt, and Stacie Wolny greatly assisted with data and model development for the ARIES and InVEST models. Additionally, numerous other individuals assisted the coauthors of this report with project scoping, model review, and report development. A full list of these individuals is provided in appendix D.

\section{References Cited}

Ackerman, Frank, and Stanton, E.A., 2012, Climate risks and carbon prices: Revising the social cost of carbon: Economics-The open-access, open-assessment e-journal, v. 6, no. $2012-10$, p. 1-25.

Allen, B.P., and Loomis, J., 2008, The decision to use benefit transfer or conduct original valuation research for benefitcost and policy analysis: Contemporary Economic Policy, v. 26 , no. 1, p. $1-12$.

Arizona Department of Water Resources, 2005, Upper San Pedro Basin Active Management Area review report: Arizona Department of Water Resources, Phoenix, 219 p.

Arizona Game and Fish Department, 2009, Hunt Arizona, 2009 edition - Survey, harvest, and hunt data for big and small game: Arizona Game and Fish Department, Phoenix, $192 \mathrm{p}$.

Arrow, Kenneth, Solow, R., Portney, P., Leamer, E., Radner, R., and Schuman, H., 1993, Report of the NOAA panel on contingent valuation: U.S. Department of Commerce, National Oceanic and Atmospheric Administration. Available at $h t t p: / / w w w . c b e . c s u e a s t b a y . e d u / \sim a l i m a / c o u r s e s / 4306 /$ articles/NOAA\%20on\%20contingent\%20valuation $\% 20$ 1993.pdf, last accessed September 21, 2012.

Atkinson, S.E., Crocker, T., and Shogren, J., 1992, Bayesian exchangeability, benefit transfer, and research efficiency: Water Resources Research, v. 28, no. 3, p. 715-722.

Bagstad, K.J., Villa, F., Johnson, G., and Voigt, B., 2011, ARIES - Artificial Intelligence for Ecosystem Services, a guide to models and data, version 1.0 Beta., ARIES report series n.1. Available at $h t t p: / / w w w$.ariesonline.org/docs/ ARIESModelingGuide1.0.pdf; last accessed August 23, 2012.

Bark, R.H., Osgood, D.E., Colby, B.G., Katz, G., and Stromberg, J., 2009, Habitat preservation and restorationDo homebuyers have preferences for quality habitat?: Ecological Economics, v. 68, p. 1465-1475.

Bark-Hodgins, Rosalind, and Colby, B.G., 2006, An economic assessment of the Sonoran Desert Conservation Plan: Natural Resources Journal, v. 46, p. 709-726.

Barrio, Melina, and Loureiro, M.L., 2010, A meta-analysis of contingent valuation forest studies: Ecological Economics, v. 69 , no. 5 , p. $1023-1030$.

Baskaran, Ramesh, Cullen, R., and Colombo, S., 2010, Testing different types of benefit transfer in valuation of ecosystem services-New Zealand winegrowing case studies: Ecological Economics, v. 69, p. 1010-1022.

Bateman, I.J., and Willis, K., 1999, Valuing environmental preferences-Theory and practice of the contingent valuation method in the US, EU, and developing countries: New York, Oxford University Press, 692 p. 
Bateman, I.J., Day, B.H., Georgiou, S., and Lake I., 2006, The aggregation of environmental benefit values - Welfare measures, distance decay, and total WTP: Ecological Economics, v. 60 , p. $450-460$.

Bergstrom, J.C., and De Civita, P., 1999, Status of benefits transfer in the United States and Canada-A review: Canadian Journal of Agricultural Economics, v. 47, no. 1, p. $79-87$.

Bergstrom, J.C., and Taylor, L., 2006, Using meta-analysis for benefits transfer-Theory and practice: Ecological Economics, v. 60 , no. 2 , p. 351-360.

Berrens, R.P., Bohara, A.K., Silva, C.L., Brookshire, D., and McKee, M., 2000, Contingent values for New Mexico instream flows - With tests of scope, group size reminder and temporal variability: Journal of Environmental Management, v. 58, p. 73-90.

Berrens, R.P., Brookshire, D., Ganderton, P., and McKee, M., 1998, Exploring nonmarket values for the social impacts of environmental policy change: Resource and Energy Economics, v. 20, p. 117-137.

Berrens, R.P., Ganderton, P., and Silva, C.L., 1996, Valuing the protection of minimum instream flows in New Mexico: Journal of Agricultural and Resource Economics, v. 21, no. 2, p. 294-309.

Bierwagen, B.G., Theobald, D.M., Pyke, C.R., Choate, A., Groth, P., Thomas, J.V., and Morefield, P., 2010, National housing and impervious surface scenarios for integrated climate impact assessments: Proceedings of the National Academy of Sciences, v. 107, no. 49, p. 20,887-20,892.

Bockstael, N.E., Freeman, A.M., III, Kopp, R.J., Portney, P.R., and Smith, V.K., 2000, On measuring economic values for nature: Environmental Science and Technology, v. 34, p. 1384-1389.

Bolte, J.P., Hulse, D.W., Gregory, S.V., and Smith, C., 2006, Modeling biocomplexity-Agents, landscapes, and alternative futures: Environmental Modelling and Software, v. 22, no. 5 , p. $570-579$.

Bourassa, S.C., Hoesli, M., and Sun, J., 2006, The price of aesthetic externalities: The Appraisal Journal, v. LXXIIII, no. 1, p. 14-29.

Boyd, J.W., 2007, The endpoint problem: Resources, v. 165, p. 25-28.

Boyd, J.W., and Banzhaf, S., 2007, What are ecosystem services? The need for standardized environmental accounting units: Ecological Economics, v. 63, p. 616-626.

Boyd, J.W., and Krupnick, A., 2009, The definition and choice of environmental commodities for nonmarket valuation: Resources for the Future Discussion Paper 09-35, Washington, D.C., Resources for the Future Press, 60 p.
Boyle, K.J., and Bergstrom, J.C., 1992, Benefit transfer studies-Myths, pragmatism, and idealism: Water Resources Research, v. 28, no. 3, p. 657-663.

Brand, L.A., White, G.C., and Noon, B.R., 2008, Factors influencing species richness and community composition of breeding birds in a desert riparian corridor: The Condor, v. 110 , no. 2, p. 199-210.

Brander, L.M., Florax, R.J.G.M., and Vermaat, J.E., 2006, The empirics of wetland valuation-A comprehensive summary and a meta-analysis of the literature: Environmental and Resource Economics, v. 33, p. 223-250.

Brander, L.M., van Beukering, P., and Cesar, H.S.J., 2007, The recreational value of coral reefs - A meta-analysis: Ecological Economics, v. 63, p. 209-218.

Brookshire, D.S., Goodrich, D., Dixon, M.D., Brand, L.A., Benedict, K., Lansey, K., Thacher, J., Broadbent, C.D., Stewart, S., McIntosh, M., and Kang, D., 2010, After restoration-A framework for preserving semi-arid regions in the Southwest: Journal of Contemporary Water Research and Education, v. 144, p. 60-74.

Brookshire, D.S., and Neill, H.R., 1992, Benefit transfersConceptual and empirical issues: Water Resources Research, v. 28, no. 3, p. 651-655.

Brouwer, Roy, 2000, Environmental value transfer-State of the art and future prospects: Ecological Economics, v. 32, p. 137-152.

Brouwer, Roy, Langford, I.H., Bateman, I.J., and Turner, R.K., 2003, A meta-analysis of wetland ecosystem valuation studies, in Turner, R.K., van den Bergh., J.C.J.M., and Brouwer, Roy, eds., Managing wetlands-An ecological economics approach: Northampton, Mass., Edward Elgar Publishing, p. 108-129.

Brown, Joel, Angerer, J., Salley, S.W., Blaisdell, R., and Stuth, J.W., 2010, Improving estimates of rangeland carbon sequestration potential in the US Southwest: Rangeland Ecology and Management, v. 63, p. 147-154.

Brown, T.C., Harding, B.L., and Payton, E.A., 1990, Marginal economic value of streamflow-A case study for the Colorado River Basin: Water Resources Research, v. 26, no. 12, p. 2845-2859.

BSR Environmental Services, Tools, and Markets Working Group, 2011, New business decision-making aids in an era of complexity, scrutiny, and uncertainty-Tools for identifying, assessing, and valuing ecosystem services: San Francisco, Calif., BSR Environmental Services, 40 p.

Budyko, M.I., 1974, Climate and life: San Diego, Calif., Academic Press, 508 p.

Bureau of Land Management, 2005, BLM land use planning handbook, H-1601-1: Washington, D.C.: U.S. Department of the Interior, Bureau of Land Management, 163 p. 
Bureau of Land Management, 2008, BLM National Environmental Policy Act handbook, H-1790-1: Washington, D.C.: U.S. Department of the Interior, Bureau of Land Management, $184 \mathrm{p}$.

Bureau of Reclamation, 2007, Appraisal report-Augmentation alternatives for the Sierra Vista sub-watershed, Arizona-Lower Colorado Region: Denver, Colo., U.S. Department of the Interior Bureau of Reclamation, $95 \mathrm{p}$.

Canadell, Joseph, Jackson, R.B., and Mooney, H., 1996, Maximum rooting depth of vegetation types at the global scale: Oecologia, v. 108, p. 583-595.

Chattopadhyay, Sudip, 2003, A repeated sampling technique in assessing the validity of benefit transfer in valuing nonmarket goods: Land Economics, v. 79, no. 4, p. 576-596.

Colby, B.G., and Orr, P., 2005, Economic tradeoffs in preserving riparian habitat: Natural Resources Journal, Winter, 17 p. (unpaged).

Colby, B.G., and Wishart, S., 2002, Quantifying the influence of desert riparian areas on residential property values: The Appraisal Journal, v. LXX, no. 3, p. 304-308.

Colby, Bonnie, and Smith-Incer, E., 2005, Visitor values and local economic impacts of riparian habitat preservationCalifornia's Kern River Preserve: Journal of the American Water Resources Association, v. 41, no. 3, p. 709-717.

Crandall, K.B., Colby, B.G., and Rait, K.A., 1992, Valuing riparian areas-A southwestern case study: Rivers, v. 3, no. 2 , p. $88-98$.

Curtice, Corrie, Dunn, D.C., Roberts, J.J., Carr, S.D., and Halpin, P.N., 2012, Why ecosystem-based management may fail without changes to tool development and financing: BioScience, v. 62, no. 5, p. 508-515.

Daily, G.C., Polasky, S., Goldstein, J., Kareiva, P.M., Mooney, H.A., Pejchar, L., Ricketts, T.H., Salzman, J., and Shallenberger, R., 2009, Ecosystem services in decision making-Time to deliver: Frontiers in Ecology and the Environment, v. 7, no. 1, p. 21-28.

de Steiguer, J.E., 2008, Semi-arid rangelands and carbon offset markets-A look at the economic prospects: Rangelands, v. 30, p. $27-32$.

Desvousges, W.H., Naughton, M.C., and Parsons, G.R., 1992, Benefit transfer-Conceptual problems in estimating water quality benefits using existing studies: Water Resources Research, v. 28, no. 3, p. 675-683.

Dixon, M.D., Stromberg, J.C., Price, J.T., Galbraith, H., Fremier, A.K., and Larsen, E.W., 2009, Potential effects of climate change on the Upper San Pedro riparian ecosystem, in Stromberg, J.C., and Tellman, B., eds., Ecology and conservation of the San Pedro River: Tucson, University of Arizona Press, p. 57-72.
Elith, Jane, Phillips, S.J., Hastie, T., Dudik, M., Chee, Y.E., and Yates, C.J., 2011, A statistical explanation of MaxEnt for ecologists: Diversity and Distributions, v. 17, p. 43-57.

Engelman, R.M., Shwiff, S.A., Smith, H.T., and Constantin, B., 2004, Monetary valuation of rare species and imperiled habitats as a basis for economically evaluating conservation approaches: Endangered Species Update, v. 21, no. 2, p. 66-73.

Environmental Valuation Reference Inventory, 2011, Environmental Valuation Reference Inventory (EVRI): Available at https://www.evri.ca/Global/HomeAnonymous.aspx; last accessed January 20, 2011.

Farley, Joshua, 2008, The role of prices in conserving critical natural capital: Conservation Biology, v. 22, no. 6, p. 1399-1408.

Feng, Min, Liu, S., Euliss, N.H., Jr., Young, C., and Mushet, D.M., 2011, Prototyping an online wetland ecosystem services model using open model sharing standards: Environmental Modelling and Software, v. 26, no. 4, p. 458-468.

Ferguson, T.J., and Colwell-Chanthaphonh, C., 2006, History is in the land-Multivocal tribal traditions in Arizona's San Pedro Valley: Tucson, University of Arizona Press, $336 \mathrm{p}$.

Fisher, Brendan, Turner, K., Zylstra, M., Brouwer, R., de Groot, R., Farber, S., Ferraro, P., Green, R., Hadley, D., Harlow, J., Jefferiss, P., Kirkby, C., Morling, P., Mowatt, S., Naidoo, R., Paavola, J., Strassburg, B., Yu, D., and Balmford, A., 2008, Ecosystem services and economic theory-Integration for policy-relevant research: Ecological Applications, v. 18, no. 8, p. 2050-2067.

Freeman, A.M., III, 2003, The measurement of environmental and resource values - Theory and methods, ( $2 \mathrm{~d}$ ed.): Washington, D.C., Resources for the Future Press, 420 p.

French, D.D., and Hitzhusen, F., 2001, Status of benefits transfer in the United States and Canada - Comment: Canadian Journal of Agricultural Economics, v. 49, no. 2, p. 259-261.

Galbraith, Hector, Dixon, M.D., Stromberg, J.C., and Price, J.T., 2009, Predicting climate change risks to riparian ecosystems in arid watersheds-The Upper San Pedro as a case study, in Kapustka, L.A., and Landis, W.G., eds., Environmental risk and management from a landscape perspective: Hoboken, N.J., John Wiley, p. 187-202.

Ghermandi, Anderea, van den Bergh, J.C.J.M., Brander, L.M., de Groot, H.L.F., and Nunes, P.A.L.D., 2008, The economic value of wetland conservation and creation-A metaanalysis: Fondazione Eni Enrico Mattei Working Paper Series, Nota di lavoro 79.2008. Available at ideas.repec.org/p/fem/ femwpa/2008.79.html; last accessed October 12, 2009. 
Giraud, K.L., Loomis, J.B., and Johnson, R.L., 1999, Internal and external scope in willingness-to-pay estimates for threatened and endangered wildlife: Journal of Environmental Management, v. 56, p. 221-229.

Groothuis, P.A., 2005, Benefit transfer-A comparison of approaches: Growth and Change, v. 36, no., 4, p. 551-564.

Guzy, M.R., Smith, C.L., Bolte, J.P., Hulse, D.W., and Gregory, S.V., 2008, Policy research using agent based modeling to assess future impacts of urban expansion into farmlands and forests: Ecology and Society, v. 13, no. 1, p. 37.

Hand, M.S., Thacher, J.A., McCollum, D.W., and Berrens, R.P., 2008, Intra-regional amenities, wages, and home prices - The role of forests in the Southwest: Land Economics, v. 84, no. 4, p. 635-651.

Hoehn, J.P., 2006, Methods to address selection effects in the meta regression and transfer of ecosystem values: Ecological Economics, v. 60, no. 2, p. 389-398.

Housman, D.C., Powers, H.H., Collins, A.D., and Belnap, J., 2006, Carbon and nitrogen fixation differ between successional stages of biological soil crusts in the Colorado Plateau and Chihuahuan Desert: Journal of Arid Environments, v. 66, p. $620-634$.

Huxman, T.E., Snyder, K.A., Tissue, D., Leffler, A.J., Ogle, K., Pockman, W.T., Sandquist, D.R., Potts, D.L., and Schwinning, S., 2004, Precipitation pulses and carbon fluxes in semiarid and arid ecosystems: Oecologia, v. 141, p. $254-268$.

Huxman, T.E., Wilcox, B.P., Breshears, D.D., Scott, R.L., Snyder, K.A., Small, E.E., Hultine, K., Pockman, W.T., and Jackson, R.B., 2005, Ecohydrological implications of woody plant encroachment: Ecology, v. 86, no. 2, p. 308-319.

Intergovernmental Panel on Climate Change (IPCC), 2007, Climate change 2007-Synthesis report. Contribution of working groups I, II and III to the fourth assessment report of the Intergovernmental Panel on Climate Change. Core writing team, Pachauri, R.K., and Reisinger, A., eds. Geneva, Switzerland, IPCC, 104 p.

Iovanna, Richard, and Griffiths, C., 2006, Clean water, ecological benefits, and benefits transfer-A work in progress at the U.S. EPA: Ecological Economics, v. 60, no. 2, p. 473-482.

Johnson, G.W., Bagstad, K.J., Snapp, R., and Villa, F., 2012, Service path attribute networks (SPANs) - A network flow approach to ecosystem service assessment: International Journal of Agricultural and Environmental Information Systems, v. 3, no. 2, p. 54-71.
Johnston, R.J., Besedin, E., and Ranson, M., 2006, Characterizing the effects of valuation methodology in functionbased benefits transfer: Ecological Economics, v. 60, no. 2, p. 407-419.

Kareiva, Peter, Tallis, H., Ricketts, T.H., Daily, G.C., and Polasky, S., eds., 2011, Natural capital-Theory and practice of mapping ecosystem services: Oxford, U.K., Oxford University Press, 432 p.

Katz, Gabrielle, Haney, J.A., Paradzick, C.E., and Harris, D.B., 2009, Mitigation, restoration, and endangered species-Hydrologic restoration on the Lower San Pedro River, in Stromberg, J.C., and Tellman, B., eds., Ecology and conservation of the San Pedro River: Tucson, University of Arizona Press, p. 245-270.

Kaye, J.P., Majumdar, A., Gries, C., Byantuyev, A., Grimm, N.B., Hope, D., Jenerette, G.D., Zhu, W.X., and Baker, L., 2008, Hierarchical Bayesian scaling of soil properties across urban, agricultural, and desert ecosystems: Ecological Applications, v. 18, no. 1, p. 132-145.

Kepner, W.G., Semmens, D.J., Bassett, S.D., Mouat, D.A., and Goodrich, D.C., 2004, Scenario analysis for the San Pedro River, analyzing hydrological consequences for a future environment: Environmental Modeling and Assessment, v. 94, p. 115-127.

Kepner, W.G., Semmens, D.J., Heggem, D.T., Evanson, E.J., Edmonds, C.M., and Scott, S.N., 2003, The San Pedro River geo-data browser and assessment tools: EPA/600/C-03/008 . Available at http://www.epa.gov/nerlesd1/land-sci/ san_pedro/index.html; last accessed August 23, 2012.

Kepner, W.G., Watts, C.J., Edmonds, C.M., Maingi, J.K., Marsh, S.E., and Luna, G., 2000, Landscape approach for detecting and evaluating change in a semiarid environment: Environmental Monitoring and Assessment, v. 64, p. $179-195$.

Kirchoff, Stephanie, Colby, B., and LaFrance, J., 1997, Evaluating the performance of benefit transfer-An empirical inquiry: Journal of Environmental Economics and Management, v. 33, no. 1, p. 75-93.

Konarska, K.M., Sutton, P.C., and Castellon, M., 2002, Evaluating scale dependence of ecosystem service valuation-A comparison of NOAA-AVHRR and Landsat TM datasets: Ecological Economics, v. 41, p. 491-507.

Kroeger, Timm, 2005, Economic benefits of reintroducing the river otter (Lontra canadensis) into rivers in New Mexico: Washington, D.C., Defenders of Wildlife, 35 p. Available at http://www.defenders.org/sites/default/files/publications/ economic_benefits_of_reintroducing_the_river_otter lontra_canadensis_into_rivers_in_new_mexico.pdf; last accessed August 23, 2012. 
Labiosa, W.B., Bernknopf, R., Hearn, P., Hogan, D., Strong, D., Pearlstine, L., Mathie, A.M., Wein, A.M., Gillen, K., and Wachter, S., 2009, The South Florida ecosystem portfolio model-A map-based multicriteria ecological, socioeconomic, and community land-use planning tool: U.S. Geological Survey Scientific Investigations Report 2009-5181, $53 \mathrm{p}$.

Lacher, L.J., 1994, Hydrologic and legal issues of the Upper San Pedro River Basin, Arizona: SALSA On-Line Publication. Available at http://www.tucson.ars.ag.gov/salsa/ archive/publications/lacher/lacher0.html; last accessed August 23, 2012.

Lant, C.L., Ruhl, J.B., and Kraft, S.E., 2008, The tragedy of ecosystem services: BioScience, v. 58, no. 10, p. 969-974.

Leenhouts, J.M., Stromberg, J.C., and Scott, R.L., 2005, Hydrologic requirements of and consumptive groundwater use by riparian vegetation along the San Pedro River, Arizona: U.S. Geological Survey Scientific Investigations Report 2005-5163, $211 \mathrm{p}$.

Leon, Carmelo, Vazquez-Polo, F., and Leon-Gonzalez, R., 2003, Elicitation of expert opinion in benefit transfer of environmental goods: Environmental and Resource Economics, v. 26, no. 2, p. 199-210.

Loomis, J.B., 1992, The evolution of a more rigorous approach to benefit transfer-Benefit function transfer: Water Resources Research, v. 28, no. 3, p. 701-705.

Loomis, J.B., 1995, Four models for determining environmental quality effects on recreational demand and regional economics: Ecological Economics, v. 12, p. 55-65.

Loomis, J.B., 2000, Vertically summing public good demand curves-An empirical comparison of economic versus political jurisdictions: Land Economics, v. 76, no. 2, p. 312-321.

Loomis, J.B., Douglas, A.J., and Harpman, D.A., 2005, Recreation use values and nonuse values of Glen and Grand Canyons, in Gloss, S.P., Lovich, J.E., and Melis, T.S., eds., The state of the Colorado River ecosystem in Grand CanyonA report of the Grand Canyon Monitoring and Research Center, 1991-2004: U.S. Geological Survey Circular 1282, p. $153-164$.

Loomis, J.B., Kroeger, T., Richardson, L., and Casey, F., 2008, A benefit transfer toolkit for fish, wildlife, wetlands, and open space: Western Economics Forum, v. 7, no. 2, p. 33-43.

Loomis, J.B., and Rosenberger, R., 2006, Reducing barriers in future benefit transfers-Needed improvements in primary study designs and reporting: Ecological Economics, v. 60, no. 2 , p. 343-350.
Lowry, John, Ramsey. R.D., Thomas, K., Schrupp, D., Sajwaj, T., Kirby, J., Waller, E., Schrader, S., Falzarano, S., Langs, L., Manis, G., Wallace, C., Schulz, K., Comer, P., Pohs, K. Reith, W., Velasquez, C., Wolk, B., Kepner, W., Boykin, K., O'Brien, L., Bradford, D., Thompson, B., and Prior-Magee, J., 2007, Mapping moderate-scale land-cover over very large geographic areas within a collaborative frameworkA case study of the Southwest Regional Gap Analysis Project (SWReGAP): Remote Sensing of Environment, v. 108, p. 59-73.

Mac Nish, Robert, Baird, K.J., and Maddock, T., III, 2009, Groundwater hydrology of the San Pedro River Basin, in Stromberg, J.C., and Tellman, B., eds., Ecology and conservation of the San Pedro River: Tucson, University of Arizona Press, p. 285-299.

Marine Ecosystem Services Partnership, 2011, Explore ecosystem services. Available at $h t t p: / / w w w . m a r i n e e c o s y s t e m s e r v i c e s$. org/explore-ecosystem-services; last accessed August 23, 2012.

Martens, D.A., Emmerich, W., McLain, J.E.T., and Johnsen, T.N., 2005, Atmospheric carbon mitigation potential of agricultural management in the southwestern USA: Soil and Tillage Research, v. 83, p. 95-119.

Martens, D.A., and McLain, J.E.T., 2005, Climate mitigation potential of the San Pedro River riparian zone: USDA Forest Service Proceedings RMRS-P-36, p. 491-495.

McComb, Greg, Lantz, V., Nash, K., and Rittmaster, R., 2006, International valuation databases - Overview, methods, and operational issues: Ecological Economics, v. 60, p. $461-472$.

McLain, J.E.T., and Martens, D.A., 2003, Vegetation community impacts on soil carbon, nitrogen, and trace gas fluxes, in Renard, K.G., McElroy, S.A., Gburek, W.J., Canfield, H.E., and Scott, R.L., eds., First Interagency Conference on Research in the Watersheds, October 27-30, 2003: U.S. Department of Agriculture Agricultural Research Service, p. 542-547.

McLain, J.E.T., and Martens, D.A., 2005, Studies of methane fluxes reveal that desert soils can mitigate global change: Conference on Biodiversity and Management of the Madrean Archipelago II-Connecting Mountain Islands and Desert Seas, May 11-14, Tucson, Ariz., Proceedings, p. 496-499.

McLain, J.E.T., and Martens, D.A., 2006, Moisture controls on trace gas fluxes in semiarid riparian soils: Soil Science Society of America Journal, v. 70, p. 367-377.

McLain, J.E.T., Martens, D.A., and McClaran, M.P., 2008, Soil cycling of trace gases in response to mesquite management in a semiarid grassland: Journal of Arid Environments, v. 72 , p. $1654-1665$. 
Mendoza, Guillermo, Ennaanay, D., Conte, M., Walter, M.T., Freyberg, D., Wolny, S., Hay, L., White, S., Nelson, E., and Solorzano, L., 2011, Water supply as an ecosystem service for hydropower and irrigation, in Kareiva, P., Tallis, H., Ricketts, T.H., Daily, G.C., and Polasky, S., eds., Natural capital-Theory and practice of mapping ecosystem services: Oxford, U.K., Oxford University Press, p. 53-72.

Millennium Ecosystem Assessment, 2005, Millennium ecosystem assessment; Living beyond our means - Natural assets and human well-being: Washington, D.C., World Resources Institute, 28 p. Available at http://www.maweb.org/ documents/document.429.aspx.pdf; last accessed August 23, 2012.

Miller, S.N., Kepner, W.G., Mehaffey, M.H., Hernandez, M., Miller, R.C., Goodrich, D.C., Devonald, K.K., Heggem, D.T., and Miller, W.P., 2002, Integrating landscape assessment and hydrologic modeling for land-cover change analysis: Journal of the American Water Resources Association, v. 38, no. 4, p. 915-929.

Miller, S.N., Semmens, D.J., Goodrich, D.C., Hernandez, M., Miller, R.C., Kepner, W.G., and Guertin, D.P., 2007, The Automated Geospatial Watershed Assessment tool: Environmental Modelling and Software, v. 22, no. 3, p. 365-377.

Moeltner, Klaus, Boyle, K.J., and Patterson, R.W., 2007, Meta-analysis and benefit transfer for resource valuation, addressing classical challenges with Bayesian modeling: Journal of Environmental Economics and Management, v. 53 , p. 250-269.

Moeltner, Klaus, and Woodward, R., 2009, Meta-functional benefit transfer for wetland valuation-Making the most of small samples: Environmental and Resource Economics, v. 42 , p. $89-108$.

Moran, M.S., Emmerich, W.E., Goodrich, D.C., Heilman, P., Holifield Collins, C.D., Keefer, T.O., Nearing, M.A., Nichols, M.H., Renard, K.G., Scott, R.L., Smith, J.R., Stone, J.J., Unkrich, C.L., and Wong, J., 2008, Preface to special section on fifty years of research and data collection-U.S. Department of Agriculture Walnut Gulch Experimental Watershed: Water Resources Research, v. 44, W05S01. Available at http://naldc.nal.usda.gov/ download/17972/PDF; last accessed August 23, 2012.

Morrison, Mark, and Bergland, Olvar, 2006, Prospects for the use of choice modeling for benefits transfer: Ecological Economics, v. 60, no. 2, p. 420-428.

Multiscale Integrated Models of Ecosystem Services, 2011, MIMES model. Available at http://www.afordablefutures. com/services/mimes; last accessed August 23, 2012.

Nahlik, A.M., Kentula, M.E., Fennessy, M.S., and Landers, D.H., 2012, Where is the consensus? A proposed foundation for moving ecosystem service concepts into practice: Ecological Economics, v. 77, p. 27-35.
Navrud, Stale, and Ready, R., 2007, Lessons learned for environmental value transfer, in Navrud, Stale, and Ready, R., eds., Environmental value transfer-Issues and methods: New York, Springer, p. 283-290.

Nelson, E.J., and Daily, G.C., 2010, Modelling ecosystem services in terrestrial ecosystems: Faculty of 1000 Biology Reports, v. 2, p. 53, 6 p. (unpaged). (doi:10.3410/B2-53). Available at http://f1000.com/reports/biology/content/2/53; last accessed August 23, 2012.

Nelson, J.P., and Kennedy, P.E., 2008, The use (and abuse) of meta-analysis in environmental and natural resource economics - An assessment: Working paper series. Available at http://ssrn.com/abstract $=1117490$; last accessed August 12, 2008.

Nie, Wenming, Yuan, Y., Kepner, W., Erickson, C., and Jackson, M., 2012, Hydrological impacts of mesquite encroachment in the Upper San Pedro watershed: Journal of Arid Environments, v. 82, p. 147-155.

Nie, Wenming, Yuan, Y., Kepner, W., Nash, M.S., Jackson, M., and Erickson, C., 2011, Assessing impacts of land use and land cover changes on hydrology for the Upper San Pedro watershed: Journal of Hydrology, v. 407, p. 105-114.

Norgaard, R.B., 2010, Ecosystem services-From eye-opening metaphor to complexity blinder: Ecological Economics, v. 69 , p. 1219-1227.

Norman, Laura, Tallent-Halsell, N., Labiosa, W., Weber, M., McCoy, A., Hirschboeck, K., Callegary, J., van Riper, C., III, and Gray, F., 2010, Developing an ecosystem services online decision support tool to assess the impacts of climate change and urban growth in the Santa Cruz watershed, where we live, work, and play: Sustainability, v. 2, no. 7, p. 2044-2069.

Orr, Patricia, and Colby, B.G., 2002, Nature-oriented visitors and their expenditures-Upper San Pedro River Basin: Department of Agricultural and Resource Economics, University of Arizona, 17 p. Available at http://ag.arizona.edu/ AREC/pubs/san_pedro_report.pdf; last accessed August 23, 2012.

Parametrix, 2010, An introduction to EcoMetrix-Measuring change in ecosystem performance at the site scale: Portland, Ore., Parametrix, 15 p. Available online at http:// ecometrixsolutions.com/uploads/EcoMetrix_Tool_101.pdf; last accessed August 23, 2012.

Pate, Jennifer, and Loomis, J., 1997, The effect of distance on willingness to pay values - A case study of wetlands and salmon in California: Ecological Economics, v. 20, p. 199-207.

Piper, Steven, and Martin, W.E., 1997, Household willingness to pay for improved rural water supplies - A comparison of four sites: Water Resources Research, v. 33, no. 9, p. 2153-2163. 
Plummer, M.L., 2009, Assessing benefit transfer for the valuation of ecosystem services: Frontiers in Ecology and the Environment, v. 7, no. 1, p. 38-45.

Pool, D.R., and Dickinson, J.E., 2007, Ground-water flow model of the Sierra Vista and Sonoran portions of the Upper San Pedro Basin, southeastern Arizona, United States and northern Sonora, Mexico: U.S. Geological Survey Scientific Investigations Report 2006-5228, 60 p.

Rankin, A.G., Eiler, L.M., and Joaquin, J.T., 2008, Water and the human spirit-Traditional sacred natural surface waters, in Altschul, J.H., and Rankin, A.G., eds., Fragile patternsThe archaeology of the western Papagueria: Tucson, SRI Press, p. 595-604.

Ready, Richard, and Navrud, S., 2006, International benefit transfer-Methods and validity tests: Ecological Economics, v. 60 , no. 2 , p. 429-434.

Richardson, Leslie, and Loomis, J., 2009, The total economic value of threatened, endangered, and rare species-An updated meta-analysis: Ecological Economics, v. 68, no. 5, p. $1535-1548$.

Richardson, R.B., 2008, Conceptualizing the value of ecosystem services in deserts, in Chapman, R.L., ed., Creating sustainability within our midst - Challenges for the 21st century: New York, Pace University Press, 225-248.

Rimbey, N.R., Torell, L.A., and Tanaka, J.A., 2007, Why grazing permits have economic value: Journal of Agricultural and Resource Economics, v. 32, no. 1, p. 20-40.

Rosenberger, R.S., and Loomis, J., 2000, Using meta-analysis for benefit transfer-In-sample convergent validity tests of an outdoor recreation database: Water Resources Research, v. 36 , no. 4 , p. $1097-1107$.

Rosenberger, R.S., and Loomis, J.B., 2001, Benefit transfer of outdoor recreation use values-A technical document supporting the Forest Service Strategic Plan (2000 revision), General Technical Report RMRS-GTR-72: Fort Collins, Colo., U.S. Department of Agriculture Forest Service Rocky Mountain Research Station, 64 p.

Rosenberger, R.S., and Phipps, T., 2007, Correspondence and convergence in benefit transfer accuracy-Meta-analytic review of the literature, in Navrud, Stale., and Ready, R., eds., Environmental value transfer-Issues and methods: New York, Springer, p. 23-43.

Rosenberger, R.S., and Stanley, T.D., 2006, Measurement, generalization, and publication-Sources of error in benefit transfer and their management: Ecological Economics, v. 60 , no. 2 , p. $372-378$.

Ruhl, J.B., Kraft, S.E., and Lant, C.L., 2007, The law and policy of ecosystem services: Washington, D.C., Island Press, $360 \mathrm{p}$.
Salzman, James, 2005, Creating markets for ecosystem services-Notes from the field: New York University Law Review, v. 80, no. 3, p. 870-961. Available at http://www.obwb.ca/fileadmin/docs/NYU302.pdf; last accessed August 24, 2012.

Samuelson, P.A., 1954, The pure theory of public expenditure: Review of Economics and Statistics, v. 36, no. 4, p. 387-389.

Schenk, H.J., and Jackson, R.B., 2002a, Rooting depths, lateral root spreads and below-ground/above-ground allometries of plants in water-limited ecosystems: Journal of Ecology, v. 90, no. 3, p. 480-494.

Schenk, H.J., and Jackson, R.B., 2002b, The global biogeography of roots: Ecological Monographs, v. 72, p. 311-328.

Schlessinger, W.H., 1982, Carbon storage in the caliche of arid soils - A case study from Arizona: Soil Science, v. 133, no. 4 , p. $247-255$.

Schlessinger, W.H., Belnap, J., and Marion, G., 2009, On carbon sequestration in desert ecosystems: Global Change Biology, v. 15, no. 6, p. 1488-1490.

Scott, R.L., Cable, W.L., Huxman, T.E., Nagler, P.L., Hernandez, M., and Goodrich, D.C., 2008, Multiyear riparian evapotranspiration and groundwater use for a semiarid watershed: Journal of Arid Environments, v. 72, p. 1232-1246.

Scott, R.L., Edwards, E.A., Shuttleworth, W.J., Huxman, T.E., Watts, C., and Goodrich, D.C., 2004, Internannual and seasonal variation in fluxes of water and carbon dioxide from a riparian woodland ecosystem: Agricultural and Forest Meteorology, v. 122, p. 65-84.

Scott, R.L., Huxman, T.E., Williams, D.G., and Goodrich, D.C., 2006, Ecohydrological impacts of woody-plant encroachment-Seasonal patterns of water and carbon dioxide exchange within a semiarid riparian environment: Global Change Biology, v. 12, p. 311-324.

Scott, R.L., Jenerette, G.D., Potts, D.L., and Huxman, T.E., 2009, Effects of seasonal drought on net carbon dioxide exchange from a woody-plant-encroached semiarid grassland: Journal of Geophysical Research, v. 114, G04004, 13 p. (unpaged). (doi:10.1029/2008JG000900). Available at http://naldc.nal.usda.gov/download/44349/PDF; last accessed August 23, 2012.

Sengupta, Sanchita, and Osgood, D.E., 2003, The value of remoteness - A hedonic estimation of ranchette prices: Ecological Economics, v. 44, p. 91-103. 
Serrat-Capdevila, Aleix, Browning-Aiken, A., Lansey, K., Finan, T., and Valdes, J.B., 2009, Increasing socio-ecological resilience by placing science at the decision table-The role of the San Pedro Basin (Arizona) decision support system model: Ecology and Society, v. 14, no. 1, p. 37, 19 p. (unpaged). Available at http://www.ecologyandsociety.org/ vol14/iss 1/art37/; last accessed August 23, 2012.

Serrat-Capdevila, Aleix, Valdes, J.B., Gonzalez Perez, J., Baird, K., Mata, L.J., and Maddock, T., III, 2007, Modeling climate change impacts - and uncertainty — on the hydrology of a riparian system: The San Pedro Basin (Arizona/ Sonora): Journal of Hydrology, v. 347, p. 48-66.

Sherrouse, B.C., Clement, J.M., and Semmens, D.J., 2011, A GIS application for assessing, mapping, and quantifying the social values of ecosystem services: Applied Geography, v. 31, no. 2, p. 748-760.

Simple and Effective Resource for Valuing Ecosystem Services, 2012, SERVES portal. Available at http://esvaluation.org/; last accessed September 25, 2012.

Smith, J.E., Heath, L.S., Skog, K.E., and Birdsey, R.A., 2006, Methods for calculating forest ecosystem and harvested carbon with standard estimates for forest types of the United States: USDA Forest Service General Technical Report NE-343, 222 p.

Smith, V.K., 1992, On separating defensible benefit transfers from "smoke and mirrors": Water Resources Research, v. 28 , no. 3, p. $685-694$.

Smith, V.K., and Kaoru, Y., 1990, Signals or noise? Explaining variation in recreation benefit estimates: American Journal of Agricultural Economics, v. 72, no. 2, p. 419-433.

Smith, V.K., Pattanayak, S., and Van Houtven, G., 2006, Structural benefit transfer-An example using VSL estimates: Ecological Economics, v. 60, no. 2, p. 361-371.

Smith, V.K., Van Houtven, G., and Pattanayak, S., 2002, Benefit transfer via preference calibration - "Prudential algebra" for policy: Land Economics, v. 78, no. 1, p. 132-152.

Smith, V.K., Van Houtven, G., Pattanayak, S., and Bingham, T., 2000, Improving the practice of benefit transferA preference calibration approach: Washington, D.C., U.S. Environmental Protection Agency, 66 p.

Spash, C.L., and Vatn, A., 2006, Transferring environmental value estimates-Issues and alternatives: Ecological Economics, v. 60, p. 379-388.

Steinitz, Carl, Arias, H., Bassett, S., Flaxman, M., Goode, T., Maddock, T., III, Mouat, D., Peiser, R., and Shearer, A., 2003, Alternative futures for changing landscapes-The Upper San Pedro River Basin in Arizona and Sonora: Washington, D.C., Island Press, 202 p.

Stern, Nicholas, 2007, The economics of climate change-The Stern Review: Cambridge, U.K., Cambridge University Press, $712 \mathrm{p}$.
Striegl, R.G., McConnaughey, T.A., Thorstenson, D.C., Weeks, E.P., and Woodward, J.C., 1992, Consumption of atmospheric methane by desert soils: Nature, v. 357, p. $145-147$.

Stromberg, J.C., Beauchamp, V.B., Dixon, M.D., Lite, S.J., and Paradzick, C., 2007a, Importance of low-flow and high-flow characteristics to restoration of riparian vegetation along rivers in the arid south-western United States: Freshwater Biology, v. 52, p. 651-679.

Stromberg, J.C., Lite, S.J., Marler, R., Paradzick, C., Shafroth, P.B., Shorrock, D., White, J.M., and White, M.S., 2007b, Altered stream-flow regimes and invasive plant speciesThe Tamarix case: Global Ecology and Biogeography, v. 16, p. 381-393.

Stromberg, J.C., Lite, S.J., Rychener, T.J., Levick, L.R., Dixon, M.D., and Watts, J.M., 2006, Status of the riparian ecosystem in the Upper San Pedro River-Application of an assessment model: Environmental Monitoring and Assessment, v. 115 , p. 145-173.

Stromberg, J.C., and Tellman, B., eds., 2009, Ecology and conservation of the San Pedro River: Tucson, University of Arizona Press, 544 p.

Svejcar, Tony, Angell, R., Bradford, J.A., Dugas, W., Emmerich, W., Frank, A.B., Gilmano, T., Haferkamp, M., Johnson, D.A., Mayeux, H., Mielnick, P., Morgan, J., Saliendra, N.Z., Schuman, G.E., Sims, P.L., and Snyder., K., 2008, Carbon fluxes on North American rangelands: Rangeland Ecology and Management, v. 61, p. 465-474.

Tallis, H.T., and Polasky, S., 2009, Mapping and valuing ecosystem services as an approach for conservation and natural-resource management: Annals of the New York Academy of Sciences, v. 1162, p. 265-283.

Tallis, H.T., Ricketts, T., Guerry, A., Nelson, E., Ennaanay, D., Wolny, S., Olwero, N., Vigerstol, K., Pennington, D., Mendoza, G., Aukema, J., Foster, J., Forrest, J., Cameron, D., Arkema, K., Lonsdorf, E., Kennedy, C., Verutes, G., Kim, C., Guannel, G., Papenfus, M., Toft, J., Marsik, M., and Bernhartdt, J., 2011, InVEST 2.2 beta user's guide: Stanford, Calif., The Natural Capital Project. Available at http://ncp-dev.stanford.edu/ dataportal/invest-releases/ documentation/current_release/; last accessed March 7, 2012.

Texas Agricultural Extension Service, [n.d.], Water requirements for beef cattle: Texas Agricultural Extension Service, College Station, Texas A\&M University, BCM-16, 2 p.

Tol, R.S.J., 2005, The marginal damage costs of carbon dioxide emissions-An assessment of the uncertainties: Energy Policy, v. 33, p. 2064-2074.

Tol, R.S.J., 2008, The social cost of carbon-Trends, outliers, and catastrophes: Economics, the open-access, openassessment e-journal, v. 2, 2008-25, p. 1-22. 
Torell, L.A., Rimbey, N.R., Ramirez, O.A., and McCollum, D.W., 2005, Income earning potential versus consumptive amenities in determining ranchland values: Journal of Agricultural and Resource Economics, v. 30, no. 3, p. 537-560.

Troy, Austin, and Wilson, M.A., 2006, Mapping ecosystem services-Practical challenges and opportunities in linking GIS and value transfer: Ecological Economics, v. 60, p. 435-449.

TSS Consultants Spatial Informatics Group, 2005, Assessment of the efficacy of the California Bureau of Land Management community assistance and hazardous fuels programs: Washington, D.C., U.S. Bureau of Land Management, 81 p.

United Nations Environment Programme-World Conservation Monitoring Centre, 2011, Measuring and monitoring ecosystem services at the site scale-Introducing a practical toolkit: Cambridge, U.K., United Nations Environment Programme-World Conservation Monitoring Centre, $12 \mathrm{p}$.

U.S. Department of Agriculture, 2007, 2007 Census of Agriculture. Available at http://www.agcensus.usda.gov/ Publications/2007/index.php, last accessed September 21, 2012.

U.S. Environmental Protection Agency, 2006, Report of the EPA Work Group on VSL meta-analysis-National Center for Environmental Economics, Report NCEE-0494. Available at http://yosemite.epa.gov/ee/epa/eerm.nsf/ vwRepNumLookup/EE-0494?OpenDocument; last accessed August 23, 2012.

van Beukering, P.J.H., Cesar, H.S.J., and Janssen, M.A., 2003, Economic valuation of the Leuser National Park on Sumatra, Indonesia: Ecological Economics, v. 44, p. 43-62.

van Houtven, George, Powers, J., and Pattanayak, S.K., 2007, Valuing water quality improvements in the United States using meta-analysis - Is the glass half-full or half-empty for national policy analysis?: Resource and Energy Economics, v. 29, p. 206-228.

Venn, T.J., and Quiggin, J., 2007, Accommodating indigenous cultural heritage values in resource assessment - Cape York Peninsula and the Murray-Darling Basin, Australia: Ecological Economics, v. 61, p. 334-344.

Vigerstol, K.L., and Aukema, J.E., 2011, A comparison of tools for modeling freshwater ecosystem services: Journal of Environmental Management, v. 92, p. 2403-2409.

Villa, Ferdinando., Bagstad, K., Johnson, G., and Voigt, B., 2011, Scientific instruments for climate change adaptation-Estimating and optimizing the efficiency of ecosystem service provision: Economia Agraria y Recursos Naturales, v. 11, no. 1, p. 105-128.
Villa, Ferdinando, Wilson, M.A., de Groot, R., Farber, S., Costanza, R., and Boumans, R.M.J., 2002, Designing an integrated knowledge base to support ecosystem services valuation: Ecological Economics, v. 41, p. 445-456.

Walsh, R.G., Johnson, D.M., and McKean, J.R., 1992, Benefit transfer of outdoor recreation demand studies, 1968-1988: Water Resources Research, v. 28, no. 3, p. 707-713.

Water Infrastructure Finance Authority of Arizona, 2009, 2008 water and wastewater residential rate survey for the State of Arizona-Phoenix, Ariz.: Phoenix, Water Infrastructure Finance Authority of Arizona, $51 \mathrm{p}$.

Weber, M.A., and Berrens, R.P., 2006, Value of instream recreation in the Sonoran Desert: Journal of Water Resources Planning and Management, v. January/February 2006, p. 53-60.

Weber, M.A., and Stewart, S., 2009, Public values for river restoration options on the Middle Rio Grande: Restoration Ecology, v. 17, no. 6, p. 762-771.

Wheeler, C.W., Archer, S.R., Asner, G.P., and McMurtry, C.R., 2007, Climatic/edaphic controls on soil carbon/nitrogen response to shrub encroachment in desert grassland: Ecological Applications, v. 17, no. 7, p. 1911-1928.

Wilson, M.A., and Hoehn, J.P., 2006, Valuing environmental goods and services using benefit transfer-The state of the art and science: Ecological Economics, v. 60, p. 335-342.

Winthrop, Robert, 2011, Estimating nonmarket environmental values, draft guidance (ver. 2e): Washington, D.C., Socioeconomics Program, Bureau of Land Management, $7 \mathrm{p}$.

Woodward, R.T., and Wui, Y., 2001, The economic value of wetland services-A meta-analysis: Ecological Economics, v. 37, p. 257-270.

World Resources Institute, 2012, The corporate Ecosystem Services Review - Guidelines for identifying business risks and opportunities arising from ecosystem change, version 2.0: Washington, D.C., World Resources Institute, $48 \mathrm{p}$.

Zhu, Zhiliang, ed., Bergamaschi, B., Bernknopf, R., Clow, D., Dye, D., Faulkner, S., Forney, W., Gleason, R., Hawbaker, T., Liu, J., Liu, S., Prisley, S., Reed, B., Reeves, M., Rollins, M., Sleeter, B., Sohl, T., Stackpoole, S., Stehman, S., Striegl, R., Wein, A., and Zhu, Z., 2010, A method for assessing carbon stocks, carbon sequestration, and greenhouse-gas fluxes in ecosystems of the United States under present conditions and future scenarios: U.S. Geological Survey Scientific Investigations Report 2010-5233, $188 \mathrm{p}$. 


\section{Appendixes}





\section{Appendix A. Spatial Data and Assumptions Used in InVEST Models}

This appendix describes the data sources and assumptions used to populate the InVEST biodiversity, carbon, aesthetic quality, and water yield and demand models for the San Pedro River watershed. Table A1 lists spatial data sources used for the San Pedro application of the InVEST models, and table A2 describes the general data needs, both spatial and nonspatial, of the InVEST models described by Tallis and others (2011).

The InVEST biodiversity model used the 30-class Steinitz and others (2003) land-use-land-cover layer to estimate baseline habitat quality for year 2000 and year 2020 open- and constrained-development scenarios. Five items mapped drivers of biodiversity change: (1) highways (because they fragment habitat and act as vectors for movement of invasive species), (2) a density layer of groundwater wells (representing the impacts of groundwater pumping), (3) the United States-Mexico border fence (for its habitat fragmentation), (4) Arizona State Trust land grazing allotments (representing the effects of grazing), and (5) mountains at elevations over 2,000 meters (potentially susceptible to loss of alpine communities owing to climate change). The intensity of the effects of these drivers of change was based on land ownership, by using values of 0.1 for land owned and managed by NPS, The Nature Conservancy, and BLM and USDA Forest Service wilderness (including the SPRNCA), military, and tribal lands; 0.33 for county land and nonwilderness BLM and national forest land; 0.67 for State trust lands and ejidos (communally owned parcels of land, primarily used for agriculture, in Mexico); and 0.9 for private land. Model coefficients linked land use and land cover to the various drivers of change listed in tables A3 and A4. Like all InVEST coefficient tables, these were reviewed by a group of researchers who work in Southwestern ecosystems. These tables have been reformatted here for presentation purposes, and users who wish to use them as inputs to the InVEST models must alter table headings to conform to those supplied in the InVEST user's guide (Tallis and others, 2011).

The InVEST carbon model used the 10-class Steinitz and others (2003) land-use-land cover-data for the year 2000 baseline and year 2020 open- and constrained- development scenarios. Estimating carbon storage for these 10 land-use-landcover types was challenging, because data on carbon storage by Southwestern ecosystems are sparse. Standard references such as J.E. Smith and others (2006) are more useful for forested ecosystems in other parts of the United States, although their data were used for aboveground and woody debris carbon storage in montane forests. We took the average of tables A34, A36, and A38 from J.E. Smith and others (2006), assuming 65 -year old stands, and used this value for montane and riparian forests, half this value for oak woodlands, and one third of this value for mesquite woodlands. We drew aboveground and belowground carbon storage in desert scrub from Schlessinger and others (2009). We used soil carbon data for all ecosystem types except urban from Schlessinger (1982), and used Kaye and others (2008) for data on urban soil carbon storage.
Martens and McLain (2005) and Martens and others (2005) provide soil carbon storage data for western agricultural and rangeland ecosystems in general and for a single specific site on the San Pedro River, respectively. However, Schlessinger's (1982) study was an extremely comprehensive statewide study so for the purpose of providing generalizable rather than sitespecific data to use at the watershed scale, we chose to use this study rather than those by Martens and McLain.

Much of the carbon literature, at least for the arid Southwest (for example, Huxman and others, 2004; Svejcar and others, 2008; Scott and others, 2009), reports carbon fluxes, net ecosystem exchange, net primary productivity, or carbon sequestration rather than carbon storage, which is the input data required by the InVEST carbon model. References such as McLain and Martens (2006) report carbon storage in the soil in grams of carbon per kilogram of soil, which is not a useful measurement unless soil bulk density is also reported. The large number of zeroes in the input data table (table A5) is problematic. Many carbon pools lacked data, meaning that the amount of carbon actually stored by ecosystems is uncertain and likely to be underestimated. Still, the resulting values for relative change in carbon pools can be informative for decisionmaking.

To value carbon storage, we used a set of conservative valuation assumptions ( $\$ 22 /$ ton social cost of carbon (2011 United States dollars), 7 percent discount rate, 0 percent rate of annual change in the value of carbon, median values from Tol's $(2005,2008)$ meta-analyses) and a set of nonconservative valuation assumptions $(\$ 89 /$ ton social cost of carbon, 1 percent discount rate, 6 percent annual change in the value of carbon, for the most part based on Stern, 2007). The value of carbon and the assumptions that go into these estimates are debated in the literature, and even high values may underestimate the social cost of carbon (Ackerman and Stanton, 2012). However, these estimates do provide defensible high and low values. We did not use market prices for carbon owing to the extreme fluctuation in prices on European markets and the now-defunct Chicago Climate Exchange, due largely to the artificial constraints imposed on these markets.

The InVEST aesthetic-quality model used features identified by Steinitz and others (2003) as contributing to visual blight or undesirable view features, such as mines, transmission lines, highways, and development. We rasterized all data and combined them into a single layer, then converted the data to points. When these data were combined with a digital elevation model and population counts raster data for the San Pedro River watershed, the model produced results that identify the population with views of a given number of blight features along with areas of the landscape that have a given number of blight features visible.

The InVEST water model used root-depth data for key species for which measured rooting depths were available within each of the land-use-land-cover types (data from Canadell and others, 1996; and Schenk and Jackson, 2002a,b) 
Table A1. Data used in InVEST (integrated valuation of ecosystem services and tradeoffs) models, San Pedro River watershed, Arizona.

[--, not applicable; m, meter; U.S. EPA, U.S. Environmental Protection Agency]

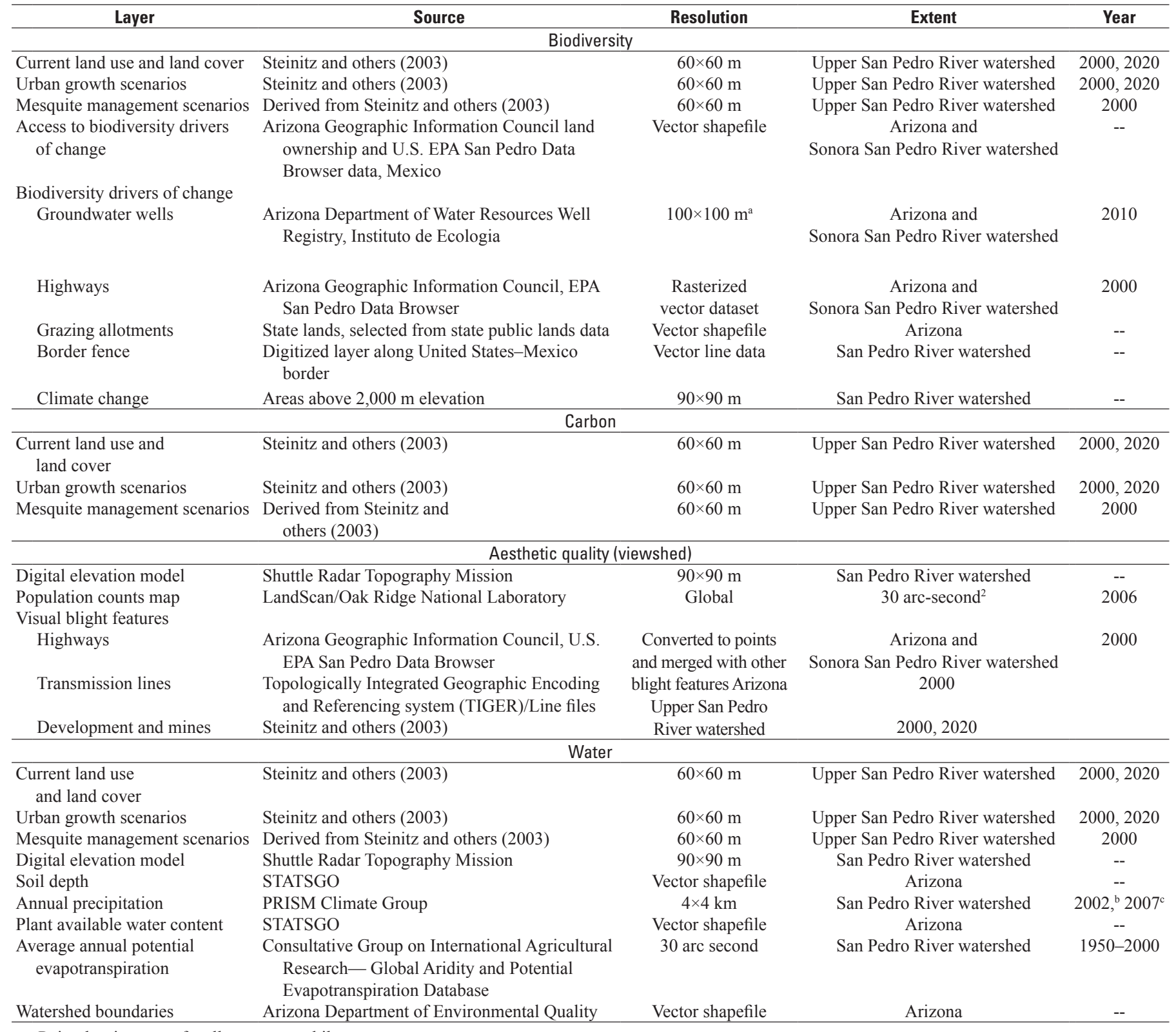

aPoint density map of wells per square kilometer.

${ }^{\mathrm{b}}$ Representative dry year.

'Representative wet year

(table A6). The evapotranspiration coefficient value for riparian species came from Scott and others (2008). For other land-use-land-cover types, alfalfa was set equal to 1,000 and all other types equal to the mean annual precipitation received by that vegetation type in the San Pedro River watershed, on the basis of the spatial extent of each vegetation type. These data were overlaid on Parameter-elevation Regressions on Independent Slopes Model (PRISM) 30-year mean annual precipitation data. The water yield models were run with rainfall data from 2002, a relatively dry year, and 2007, a relatively wet year, rather than with mean annual precipitation data. Average precipitation values are less meaningful in arid climates than in humid climates, which typically have less interannual variation in precipitation. Values for water demand by land-use-land-cover types (table A7) were derived by multiplying population times per capita use (Arizona Department of Water Resources, 2005) and then dividing the product by the area of developed land in the watershed. This 
Table A2. Data needs for other InVEST models.

[--, not applicable; R, required; O, optional; see Tallis and others (2011) for details]

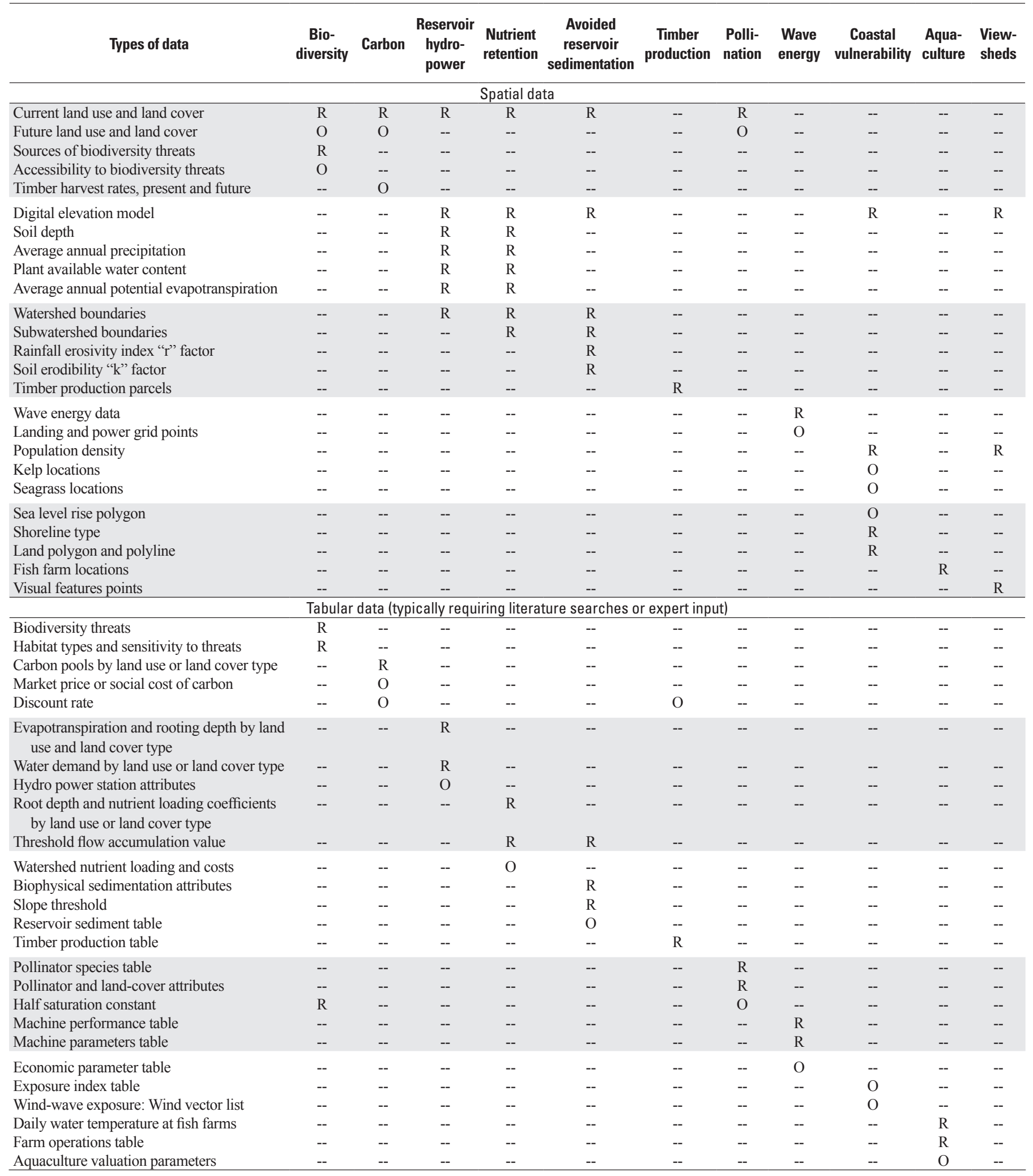


Table A3. Threats to biodiversity, San Pedro River watershed, Arizona.

[Decay: 0 , exponential decay; 1 , linear decay]

\begin{tabular}{lcll}
\hline \multicolumn{1}{c}{ Threat } & $\begin{array}{c}\text { Maximum } \\
\text { distance } \\
\text { (kilometers) }\end{array}$ & Weight & Decay \\
\hline Roads & 0.5 & 0.5 & 0 \\
Grazing land & 0.25 & 0.25 & 1 \\
Groundwater pumping & 20 & 1 & 1 \\
United States-Mexico border fence & 1 & 0.75 & 1 \\
Climate change (alpine communities) & 0.1 & 1 & 1 \\
\hline
\end{tabular}

procedure gave a value for human consumption of water, which was then divided by the existing acreage of developed land. To estimate water consumption by livestock, the total number of cattle in Cochise County (U.S. Department of Agriculture, 2007) was multiplied by per capita water use for cattle (Texas Agricultural Extension Service, [n.d.]) and divided by the acreage of state trust land and BLM land used for grazing. We then applied this value to mesquite, grassland, desert scrub, and riparian land-cover types.

\section{Limitations and Areas for Improvement}

The InVEST carbon model would be improved if better carbon storage values were available for Southwestern ecosystems. Existing carbon storage data do not support use of land-use-land cover maps with complex typologies. For instance, completing a carbon-pools table based on the Southwest Regional Gap Analysis land-cover dataset, which categorizes land-cover into 125 different types, would have been nearly impossible given the state of the data in early 2012 .

The InVEST biodiversity model provides a simple model of habitat quality and degradation that is compatible with other ecosystem service models, enabling tradeoff estimates between biodiversity and other ecosystem services. Because the supporting data tables for the biodiversity model rely on rankings and expert opinion rather than on measured data, it was easier to complete the biodiversity data tables for more complex land-use-land-cover typologies. The portion of the watershed located in Mexico lacked data on grazing lands or intensity, so the model was run only for the United States portion of the San Pedro River watershed. An improved understanding of grazing patterns in Mexico could allow the model run to be extended beyond the United States portion of the watershed. The wells data, which relied on well locations as a measure of degradation, do not precisely measure the effects of groundwater pumping, because effects are felt in areas where groundwater flow is influenced by cones of depression. A better indicator of the consequences of groundwater depletion is thus desirable for use in the InVEST biodiversity model. As noted in the InVEST user's guide, biodiversity drivers of change can be split into many categories indicating degree of use (for example, dirt road, paved road, divided highway), each with different levels of impact (Tallis and others, 2011). In this application different levels of infrastructure use were not specified, but this additional information could be desirable for measuring effects on biodiversity. A final limitation of our application of the biodiversity model is that not all of the drivers of change layers were updated for

Table A4. Habitat type and sensitivity to threats, San Pedro River watershed, Arizona.

[Sensitivity: 0, minimum; 1, maximum]

\begin{tabular}{|c|c|c|c|c|c|c|c|}
\hline \multicolumn{2}{|r|}{ Land use or land cover } & \multirow{2}{*}{ Habitat } & \multirow{2}{*}{ Road } & \multirow{2}{*}{ Graze } & \multirow{2}{*}{ Pump } & \multirow{2}{*}{ Fence } & \multirow{2}{*}{ Climate } \\
\hline Code & Name & & & & & & \\
\hline 2 & Oak & 0.8 & 0.5 & 0.5 & 0 & 0.5 & 0 \\
\hline 5 & Grassland (introduced) & 0.3 & 1 & 1 & 0.1 & 0.5 & 0 \\
\hline 6 & Mesquite & 0.4 & 1 & 1 & 0.1 & 0.5 & 0 \\
\hline 7 & Desert scrub & 0.4 & 1 & 1 & 0 & 0.5 & 0 \\
\hline 10 & Urban & 0 & 0 & 0 & 0 & 0 & 0 \\
\hline 11 & Suburban & 0.1 & 0 & 0 & 0 & 0 & 0 \\
\hline 12 & Rural residential & 0.2 & 0 & 0.5 & 0 & 0.5 & 0 \\
\hline 13 & Mines & 0 & 0 & 0 & 0 & 0 & 0 \\
\hline 14 & Water & 1 & 0.1 & 0.75 & 1 & 0.5 & 0 \\
\hline 25 & Commercial & 0 & 0 & 0 & 0 & 0 & 0 \\
\hline 26 & Mesquite bosque & 0.5 & 1 & 1 & 0.1 & 0.5 & 0 \\
\hline 27 & Cottonwood-willow bosque & 0.9 & 0.1 & 0.75 & 1 & 0.5 & 0 \\
\hline 28 & Cottonwood-willow/mesquite bosque & 1 & 0.1 & 0.75 & 1 & 0.5 & 0 \\
\hline
\end{tabular}


Table A5. Carbon pools, San Pedro River watershed, Arizona.

\begin{tabular}{|c|c|c|c|c|c|}
\hline \multicolumn{2}{|c|}{ Land use or land cover } & \multicolumn{4}{|c|}{$\begin{array}{c}\text { Carbon pool } \\
\text { (tons/hectare/year) }\end{array}$} \\
\hline Code & Name & $\begin{array}{l}\text { Above- } \\
\text { ground }\end{array}$ & $\begin{array}{l}\text { Below- } \\
\text { ground }\end{array}$ & Soil & $\begin{array}{c}\text { Dead plant } \\
\text { debris }\end{array}$ \\
\hline 1 & Forest & 59.2 & 0 & 76 & 38 \\
\hline 2 & Oak woodland & 29.6 & 0 & 76 & 19 \\
\hline 3 & Mesquite woodland & 19.7 & 0 & 76 & 12.7 \\
\hline 4 & Grassland & 0 & 0 & 73 & 0 \\
\hline 5 & Desert scrub & 0.6 & 1 & 22 & 0 \\
\hline 6 & Riparian & 59.2 & 0 & 76 & 38 \\
\hline 7 & Agriculture & 0 & 0 & 42 & 0 \\
\hline 8 & Urban & 0 & 0 & 12.6 & 0 \\
\hline 9 & Water & 0 & 0 & 0 & 0 \\
\hline 10 & Barren & 0 & 0 & 0 & 0 \\
\hline
\end{tabular}

Table A6. Biophysical characteristics used in water yield model, San Pedro River watershed, Arizona.

\begin{tabular}{|c|c|c|c|}
\hline \multicolumn{2}{|c|}{ Land use or land cover } & \multirow{2}{*}{$\begin{array}{l}\text { Root depth } \\
\text { (millimeters) }\end{array}$} & \multirow{2}{*}{$\begin{array}{c}\text { Evapo- } \\
\text { transpiration } \\
\text { coefficient }\end{array}$} \\
\hline Code & Name & & \\
\hline 1 & Forest & 4,000 & 420 \\
\hline 2 & Oak woodland & 8,000 & 330 \\
\hline 3 & Mesquite woodland & 14,000 & 260 \\
\hline 4 & Grassland & 1,000 & 275 \\
\hline 5 & Desert scrub & 1,500 & 245 \\
\hline 6 & Riparian & 6,000 & 750 \\
\hline 7 & Agriculture & 3,700 & 1,000 \\
\hline 8 & Urban & 500 & 1 \\
\hline 9 & Water & 1 & 1 \\
\hline 10 & Barren & 1 & 1 \\
\hline
\end{tabular}

Table A7. Water demand, San Pedro River watershed, Arizona.

\begin{tabular}{|c|c|c|}
\hline \multicolumn{2}{|c|}{ Land use or land cover } & \multirow{2}{*}{$\begin{array}{c}\text { Demand } \\
\text { (cubic meters/year) }\end{array}$} \\
\hline Code & Name & \\
\hline 1 & Forest & 0 \\
\hline 2 & Oak woodland & 0 \\
\hline 3 & Mesquite woodland & 0.05 \\
\hline 4 & Grassland & 0.05 \\
\hline 5 & Desert scrub & 0.05 \\
\hline 6 & Riparian & 0.05 \\
\hline 7 & Agriculture & 0 \\
\hline 8 & Urban & 110 \\
\hline 9 & Water & 0 \\
\hline 10 & Barren & 0 \\
\hline
\end{tabular}

each scenario. For instance, to properly update urban growth scenarios in the biodiversity model, well-pumping and roads data would have been needed for each new scenario. Acquiring these data would have been too time consuming and subjective a process for this pilot study, so our impact maps for future scenarios are somewhat conservative. In a full application of InVEST, it is better if modelers use scenario data that incorporate not just changes in land use and land cover but also in the accompanying infrastructure that can affect biodiversity.
As discussed in the body of the report, interpretation of results of the InVEST viewshed model is relatively straightforward. However, because users are unable to manually control the breakpoints for visualizing results, as of early 2012 there was no way to quantitatively compare the increase in viewshed impacts between scenarios. For example, in our baseline scenario, "low impacts" were classified as 0-2,608 features visible and "high impacts" as 30,214-193,150 features visible. In the opendevelopment scenario, "low impacts" are classified as 0-7,308 features visible while "high impacts" are classified as 145,360-738,436 features visible. Although the opendevelopment scenario has greater visual impacts, the two sets of results cannot be directly compared given the constraints of the early 2012 model release.

Spatially explicit hydrologic modeling is challenging in arid regions where precipitation is patchy, infiltration dynamics differ from those in humid systems, and the signal:noise ratio for runoff is very small. Hydrologists working in the area expressed concern about whether the InVEST water models would capture these nuances. However, InVEST water yield models have been tested in other groundwater-dominated systems, where they were deemed to perform acceptably, provided that the results could be calibrated to time-series streamflow data (Mendoza and others, 2011, their box 4.1). Data integration to support water modeling between United States and Mexican or global datasets was cumbersome. In particular, integrating United Nations Food and Agriculture Organization and State Soil Geographic (STATSGO) soils data was an extremely cumbersome operation that left us unable to model water yield in the Mexican portion of the watershed. Finally, it is critical to display water yield and water demand maps side by side, in order to present a balanced view of supply and demand for water. Presentation of water yield maps alone could provide a misleading view that since development increases runoff, more development would lead to greater ecosystem services provision. By also showing changes to water demand, we can get a more complete view of changes to supply of and demand for water under alternative development scenarios.

Because InVEST relies on land-use-land-cover changes to map ecosystem services changes, it could not be used for the groundwater augmentation scenarios owing to the much finer detail in the land-use-land cover typologies upon which InVEST relies. The underlying data do not support use of detailed typologies, but the simplistic 10-class typologies cannot represent fine-scale changes in riparian habitat (for example, from tamarisk to cottonwood-willow). There is thus a disconnect between the data available and the applicability of complex scenarios in InVEST. In some cases, this disconnect can be resolved through creative changes to land-useland cover typologies (for example, combining land-useland-cover data with another layer to generate a slightly more complex, but realistic, land-use-land-cover dataset), although so doing can be time consuming. 


\section{Appendix B. Spatial Data and Assumptions Used in ARIES Models}

Underlying data and assumptions for the Artificial Intelligence for Ecosystem Services (ARIES) models, which are provided in the ARIES modeling guide (Bagstad and others, 2011), are too detailed to include in this appendix. Chapters 2, 3,8 , and 9 of that guide describe the models, underlying data, and assumptions used for carbon sequestration and storage, aesthetic views and proximity, water supply, and recreation, respectively. Chapter 1 of that guide provides an overview of the ARIES modeling system and includes an introduction to spatial flow concepts for ecosystem services.

\section{Limitations and Areas for Improvement}

Many of ARIES' limitations relate to its relatively early stage of development at the start of this pilot project. A release of ARIES models and full documentation by means of a web tool (http://ariesonline.org) was scheduled for late 2012. However, full functionality, availability of global models, deployment of a more user-friendly modeling language, and tools to speed the modeling process for new case studies are unlikely to be completed by this date, and the interface and functionality are likely to go through substantial evolution through future releases. Construction of new ARIES models for the San Pedro River watershed was extremely time consuming and took more time than envisioned at the start of the project. Although ARIES offers the user great flexibility in constructing ecosystem service models and scenarios, its early stage of development led to numerous time-consuming bugs, errors, and new feature requests that delayed delivery of final results. The system's stability improved greatly during the project, and development of future models will be less time consuming than those of the pilot study.

Like InVEST, ARIES performed poorly in handling cross-border datasets. Although improved handling of crossborder datasets is planned for future ARIES releases, this model comparison did not enable ecosystem-services mapping for Mexican portions of the watershed. 


\section{Appendix C. Literature Review of Value Transfer and Best Practices}

\section{Introduction and Overview of Value Transfer}

Benefit transfer is the practice of taking valuation estimates from one location (study site) and applying them in a new context (policy site). Value transfer has become tremendously popular, especially among Federal agencies, which are faced with constrained budgets, limited staff, and short deadlines. Although original valuation studies continue to be viewed as the "first-best" option for nonmarket valuation and ecosystem services research, value transfer has the potential to inform decisionmaking in situations where primary research is not feasible.

The increased use of value transfer has sparked a substantial amount of research into its capabilities and limitations. At least two major natural resource or environmental publications devoted entire issues to this topic (Water Resources Research, 1992, v. 28, no. 3; Ecological Economics, 2006, v. 60, no. 2). Despite advancements in techniques and best-practice principles during the past 20 years, the use of value transfer remains controversial. Compounding the controversy is that the underlying primary research methods, such as contingent valuation, are commonly disputed as well.

As long as Federal agencies face resource constraints and demands for environmental valuation, value transfer is likely to remain an important valuation method. Focus, therefore, is best placed on how to best utilize value transfer given its limitations. This literature review will focus on types of value transfer, the advantages and disadvantages of each method, sources of transfer errors and how to best address them, and best-practice principles for using value transfer in decisionmaking and policy analysis.

\section{Types of Value Transfer}

The literature describes numerous value transfer methods that have been studied and implemented (Wilson and Hoehn, 2006). These methods range from simple (point transfer) to complex (meta-regression analysis). Choosing the appropriate method for the situation will depend on the time and expertise of the value transfer analyst, the availability of primary studies, the availability of policy site data, and the need for precision. No single method will be appropriate in all situations.

In most value transfer studies, the "true" value of a nonmarket good or service is assumed to be the value obtained from primary research. The difficulties in estimating economic values of nonmarket goods and services are well documented, which makes it likely that estimates from primary research are not equal to the true (but unknown) value (for example, Arrow and others, 1993). However, all else being equal, primary valuation is the best available method for estimating the value of nonmarket goods and services, so the values obtained from primary research are generally used as proxies for true values (although like all studies they contain some margin of error). All subsequent discussion of transfer errors are based on the assumption that primary valuation estimates are the true values.

\section{Point Transfer}

The earliest method of value transfer was point transfer, which directly applies value estimates from the study site to the policy site. Point transfer may use a benefit estimate from a single primary study or an average of several studies (Boyle and Bergstrom, 1992; Bergstrom and De Civita, 1999; Brouwer, 2000; Baskaran and others, 2010). The primary weakness of point transfer is its inability to systematically account for differences between sites. Any adjustments to the transferred values are made on a case-by-case basis that relies on the professional judgment of the analyst. The simplicity of this method is attractive in situations with limited staff expertise and quick deadlines. However, the defensibility of this method is low unless there is a high degree of correspondence between the study site and the policy site (Bergstrom and De Civita, 1999; Brouwer, 2000).

\section{Benefit Function Transfer}

Benefit function transfers are based on the notion that environmental and resource values are a function of numerous attributes, including biophysical attributes, market characteristics, and the socioeconomic profile. A benefit function transfer uses the statistical model from an existing study and applies it to the policy site, using data from the policy site for the independent variables (Groothius, 2005). For example, a function may relate the WTP for improved water quality for recreation (the dependent variable) to a series of independent variables, such as baseline water quality, type and intensity of recreational use, population within driving distance of the recreation site, number of substitute sites within a specified radius, and per capita income of the user group. The previously specified relationship between the independent variables and the dependent variable will translate the site-specific data inputs into an estimate of WTP at the policy site.

Loomis (1992) found that benefit function transfers resulted in lower errors than point transfers 70 percent of the time. Transferring benefit functions is more appropriate than point estimates when the policy site and the study site correspond less well (Loomis, 1992). For instance, where the study site and the policy site correspond closely, point transfer can perform as well as benefit function transfer (Chattopadhyay, 
2003). However, as conditions become less favorable, benefit function transfer outperforms point transfer. Nevertheless, as correspondence between sites deteriorates, transfer errors increase for both point transfer and function transfer.

The relative advantage of function transfer over point transfer may be debatable, as both methods can yield high transfer error (Navrud and Ready, 2007). Part of the reason that benefit functions may not consistently outperform point transfer is that a point transfer based on a study with a high degree of correspondence to the policy site may be expected to outperform a function based on studies of an area with weaker correspondence to the policy site. Some authors recommend that unless a meta-valuation function is defined (discussed in the next section), only studies with a high degree of correspondence are appropriate to use in the benefit function (Rosenberger and Phipps, 2007).

\section{Meta-Regression Analysis}

Meta-regression analysis is similar to benefit function transfer in that it assumes that resource values are systematically related to study site attributes through a "meta-valuation function" (Rosenberger and Stanley, 2006; Rosenberger and Phipps, 2007). The key difference between these functions and the benefit functions described in the previous section is the number of studies used to develop the function. In a function transfer, a function from a single study is applied to the policy area. In contrast, meta-regression analysis treats each study as an observation. The differences between the observations (for example, WTP) can be systematically related to the different attributes of the study site (for example, differing socioeconomic characteristics). This analysis may be particularly valuable when substantial differences exist between the study site or sites and the policy site. Although the explanatory power of function transfer is typically reduced when substantial differences exist between the study site and the policy site, these differences can be exploited by meta-regression analysis to identify relationships between the resource value and attributes of the site, population, or study design (Rosenberger and Loomis, 2000; Morrison and Bergland, 2006).

The general form of a meta-regression analysis includes market prices, household income, quantity of nonmarket commodity available, quality of the nonmarket commodity, a measure of substitutes for the nonmarket commodity, nonincome characteristics of the household, and the information available (Bergstrom and Taylor, 2006). Microeconomic theory assumes that a utility function can be defined that accounts for an individual's consumption of all goods and services. The utility function can be maximized such that well-being (utility) is maximized subject to income limits. The maximization problem changes when the price of a good or service changes (as a result of both income and substitution effects). A change in market prices will affect consumption of nonmarket goods and services. Therefore, it is important that market information is included in the regression equation. The complexity of ecosystem processes makes their decomposition into ecosystem services difficult even for professional ecologists. Without adequate knowledge on how an individual benefits from an ecosystem service, valuation estimates are unlikely to reflect the true value. A measure of the information available helps to identify the uses for which the individual is expressing value. The explanatory variables used will depend on the specific context as well as the available studies.

Meta-regression analysis, however, is not without its difficulties. Several key problems plague it, such as data heterogeneity (for example, different dependent variables), heteroskedasticity (differing variances), correlated observations (for example, several studies may use the same underlying dataset), and the conflation of different economic concepts (for example, Hicksian and Marshallian consumer surplus (Nelson and Kennedy, 2008)). Another difficulty with this type of analysis is how to synthesize studies that use different sets of regressors (Moeltner and others, 2007). Bayesian modeling, discussed next, can help to overcome some of the difficulties with classical meta-analyses.

\section{Bayesian Meta-Regression Analysis}

Bayesian statistics differs from classical statistics principally in its use of past experiences to derive an expected probability distribution. Bayesian value transfer uses information from past studies and expert opinion to establish a prior distribution (for example, our belief of how observations such as WTP are distributed). The predictive distribution gives the probability of observing data that do not correspond with the prior distribution. As new information becomes available, the distribution may be updated to reflect changes. This updated set then becomes the posterior distribution (Atkinson and others, 1992; Morrison and Bergland, 2006; Moeltner and others, 2007).

Bayesian meta-regression analysis can solve several difficulties that arise in its classical counterpart. For instance, the Bayesian version can help to overcome the " $n$ vs. k" dilemma that is present in most classical versions (Bergstrom and Taylor, 2006; Moeltner and others, 2007). The " $n$ vs. k" dilemma refers to the tradeoff between the number of studies (n) and the number of explanatory variables $(\mathrm{k})$ to be included in the analysis. A larger number of studies can improve estimation; however, it is unlikely that all studies will contain the desired explanatory variables. Reducing the number of independent variables can lead to omitted-variable bias. Bayesian metaregression analysis, however, is able to incorporate a large number of studies without losing explanatory variables. It is a two-step process: all available studies are first used to inform the development of the prior distribution, and then all studies with the desired explanatory variables are used to develop the meta-regression (Moeltner and others, 2007). 
Additionally, Bayesian meta-regression analysis may be able to provide more robust estimates in the presence of collinearity than its classical counterpart (Chattopadhyay, 2003). Moreover, the Bayesian version has a comparative advantage in value transfers when only a small sample is available (Moeltner and others, 2007). This advantage is driven by the use of a prior distribution to determine model parameters.

Bayesian meta-regression analysis requires specialized statistical expertise, and thus it may not be feasible for use in all situations.

\section{Preference Calibration}

The preference calibration method was developed in response to perceived shortcomings in more common value transfer methods, particularly point transfer and function transfer (Smith and others, 2000). The researchers who pioneered this approach attempted to more closely align the value transfer process with economic theory. Major problems with previous methods include the possibility of obtaining WTP estimates that exceed available income; the assumption that WTP is linear (that is, each additional unit of the good or service adds an equal amount to value), which is counter to the principle of diminishing marginal utility; and the limited consideration of other uses of the same resource (for example, improved water quality may lead to increased water consumption, increased recreational uses, and higher nonuse values) that may affect its total value (Smith, Van Houtven and others, 2000, 2006; Smith, Pattanayak and others, 2002).

Preference calibration attempts to overcome these shortcomings with an approach that is explicitly linked to microeconomic theory. Preference calibration, also known as the structural approach, begins with the selection of a "preference specification," which describes an individual's choices from a set of goods and services (market and nonmarket). The value transfer analyst is responsible for making explicit assumptions about the functional form of the individual's utility function (Smith and others, 2000). The "utility function" defines how an individual's well-being (utility) is related to the consumption of various goods and services. Among those goods and services is the ecosystem service of interest. Once the utility function is defined, determining WTP for the ecosystem service of interest becomes a standard maximization problem (that is, given income constraints, what is the highest level of utility possible?). The analyst can observe how a change in consumption of the ecosystem service affects utility, and can then infer the income necessary to offset the change, either positive or negative (Smith and others, 2002; Groothius, 2005).

This approach has four advantages: (1) the transfers are consistent with economic theory (for example, estimates cannot exceed household income), (2) the method can deliver "observable predictions" to assess validity of transfers, (3) the structural method can reconcile different value estimates from different studies, and (4) the method systematically adjusts for changes in the baseline and extent and resource changes (Smith and others, 2002). In addition, preference calibration makes analyst judgment more transparent. Although professional judgment is present in all value transfers, the preference calibration approach is explicit in its incorporation of analyst judgment in defining the parameters of the utility function (Smith and others, 2000).

As is true for meta-regression analysis (Bayesian and classical), preference calibration requires economic modeling expertise that is not readily available to Federal agencies. An additional limitation is that only a handful of value-transfer researchers have tested this approach. Thus, it may be less well scrutinized than more common value transfer approaches.

\section{Expert Judgment}

Several authors identify expert opinion as a reasonable means of conducting value transfer. Expert opinion may be used to establish an expected value distribution at the policy site, to adjust transferred values based on knowledge of the policy site, or to predict results (Leon and others, 2003). Generally, expert opinion is used in combination with other methods. This overlap between methods may be beneficial (French and Hitzhusen, 2001). For instance, the development of a prior distribution, which may incorporate expert judgment, is a central element of Bayesian meta-regression analysis. Also, as discussed in the preference calibration section, the analyst's professional judgment is an explicit component of the approach.

\section{Sources of Error}

The sources of error discussed in this section relate only to errors that arise from the value transfer process, not the challenges inherent in estimating the value of nonmarket goods and services. A substantial body of literature exists on the limitations of primary valuation of nonmarket goods and services (for example, Arrow and others, 1993; Bateman and Willis, 1999; Freeman, 2003), and it is not the intent of this report to repeat those findings. The value transfer literature identifies four principal sources of error: generalization error, measurement error, publication bias, and research-priority bias (Rosenberger and Stanley, 2006; Hoehn, 2006).

The most commonly cited source of error is generalization error, which stems from a lack of correspondence between sites. This error is common where environmental resources or user populations differ between sites (Plummer, 2009).

Measurement error occurs when methods or empirical techniques reduce the accuracy of value estimates. The valuation method, elicitation method, survey design, and units of measurement have all been found to have statistically significant influence on value (Rosenberger and Stanley, 2006). 
Additionally, lack of understanding of complex biophysical processes can induce measurement error (Bergstrom and De Civita, 1999). Measurement error may be present in both original studies and transferred estimates. Transferring values with this type of error may magnify the errors, so many studies advise that particular care be taken to address the potential for measurement error (Bergstrom and De Civita, 1999; Johnston and others, 2006; Rosenberger and Stanley, 2006; U.S. Environmental Protection Agency, 2006; Baskaran and others, 2010).

Publication selection bias can also be a potential source of bias in transferred values. Publication selection bias occurs when results are more likely to be published if they have statistically significant results, conform to theoretical expectations, or explore novel concepts in valuation (Rosenberger and Stanley, 2006).

Research-priority bias arises from the fact that research is not randomly distributed in space and resources. Instead, research is more likely to be driven by the importance of a given resource, human awareness, and potential for conflict: "ecosystems that are considered valuable up front by some segment of the public seem more likely to be researched and valued" (Hoehn, 2006, p. 390). These characteristics may upwardly bias transferred estimates of resource value.

\section{Addressing Error}

Generalization errors are reduced when functions, rather than point estimates, are transferred (Rosenberger and Phipps, 2007). In-state transfers have lower generalization errors than between-state transfers (Loomis, 1992). This finding supports the conventional view that improved correspondence between sites reduces generalization error. However, some studies still find very large generalization errors even between closely corresponding sites. A value transfer between the SPRNCA and Ramsey Canyon, another recreation site in southern Arizona that is renowned for its birding opportunities, is a case in point (Kirchoff and others, 1997). Despite the similarities between these sites in resources and populations, transfer of value estimates from Ramsey Canyon to the SPRNCA was rejected (that is, the transferred estimates were statistically different from the primary valuation estimates). However, the rejection rate fell to 40 percent for transfers in the reverse directionfrom SPRNCA to Ramsey Canyon. The authors find this result troubling and could not explain why value transfers may be appropriate in only one direction.

Because measurement error is inherent in all primary studies, it is difficult for the value transfer analyst to control (Rosenberger and Stanley, 2006). However, several steps can be taken to reduce the likelihood of including studies that have excessive measurement error. The U.S. Environmental Protection Agency work group (2006) recommends the development of explicit and consistent research-quality criteria to determine which studies can usefully be included in the value transfer. These criteria may include adequate data, sound economic method, and correct empirical technique (Brouwer, 2000; Plummer, 2009). Some types of value transfer, such as meta-regression analysis, are able to partially control for measurement error (Bergstrom and Taylor, 2006; Moeltner and others, 2007).

Publication selection bias may be overcome through the inclusion of "gray literature" such as dissertations, technical reports, and government studies (Bergstrom and Taylor, 2006). However, the inclusion of nonpeer-reviewed literature may also introduce "nonpublication error," or errors stemming from poorly designed and executed studies (Bergstrom and Taylor, 2006). The inclusion of such studies has the potential to increase other errors (such as measurement error).

Heckman's two-stage estimation method may be used to avoid research priority selection (Hoehn, 2006). This test is used to draw conclusions about the larger population, not just the nonrandomly selected subpopulation (that is, prioritized research). First, a selection equation is specified to estimate the probability that a given study falls within the selected subpopulation. Second, the results from the first stage are used to correct for selection bias in the value-estimation equation.

\section{Defining Acceptable Errors}

The tolerable error in a benefit-transfer exercise depends on the context in which the estimated values will be used. Some applications, such as a cost-benefit analysis on a smallscale project, may not require very high confidence in the estimates. High anticipated transfer error may also be acceptable if the estimated values will be only one of many factors influencing a decision. However, some applications, such as decisions that could lead to irreversible losses or determining liability for environmental damages, demand a high level of precision. In these situations, it is not advisable to use value transfer to estimate values (Bergstrom and De Civita, 1999; Navrud and Ready, 2007; Baskaran and others, 2010). Many projects will fall between these extremes. Decisionmakers and researchers need to work together to determine if value transfer is appropriate for a situation and, if so, then which method will best meet specific objectives. Whether to use value transfer or to conduct original research likely will depend on an estimate of the expected value of a primary study. Except for small projects (net present value less than $\$ 500,000$ ), original research typically yields positive economic returns through improved decisions (Allen and Loomis, 2008). If several projects may have positive returns from original research, they can be ranked from largest to smallest to identify research priorities. 


\section{Best Practice Principles}

\section{Clearly Define Aims of Study}

Transfer errors are more likely to arise when the issue or resource to be studied is not clearly defined. Without a clear and common understanding of the precise services that are being valued, double counting is more likely to occur (Brouwer, 2000). Additionally, care should be taken to ensure that the estimates from the primary studies are valuing the same resource (and associated change) as is being considered at the policy site (Iovanna and Griffiths, 2006; Nelson and Kennedy, 2008). Different benefit concepts, such as Hicksian and Marshallian consumer surplus, should not be combined (V.K. Smith and others, 2006).

\section{Collect Data on Biophysical Attributes of Policy Site}

Much of the literature on value transfer focuses on the difficulty of taking economic values obtained at one site and applying them to another. There is much less discussion, however, of the inherent difficulty in conducting economic valuation of complex ecosystem processes. Environmental attributes usually contribute to economic values through many channels, not all of which are apparent to even experienced observers. It is important to identify ecological and economic linkages in both original research and value transfer (Bergstrom and De Civita, 1999). Clearly identified flows and descriptions of ecological processes can reduce the likelihood of double counting.

\section{Collect Data on Socioeconomic Attributes of a Policy Site}

Most nonmarket valuation studies use aggregate measures of WTP to determine the economic value of a good or service. This measure is not a universal value, because this WTP is tempered by ability to pay. Substantial differences in income between sites may lead to large differences in estimates of value. Other demographic attributes, such as education and family status, may also systematically change WTP. The benefit transfer analyst should consider these and other demographic characteristics that may affect this WTP for an environmental good or service (Brouwer, 2000). These attributes, however, are incomplete proxies for the human element. The attitudes, beliefs, and values of the population are also key drivers of WTP (Loomis and Rosenberger, 2006; Baskaran and others, 2010). These variables are difficult to capture in value transfer function, and so they usually are ignored. Thus, careful consideration of characteristics of the public and stakeholders (discussed in the next section) is an important component of a robust value transfer.
The accuracy of value transfer may also be improved through better identification of the beneficiaries of the ecosystem services, rather than by relying on a single geographic area (Plummer, 2009). Benefits may have divergent flow patterns that necessitate the consideration of several subpopulations.

\section{Collect Data on Market Attributes of Policy Site}

Transferred estimates may markedly overestimate or underestimate resource values if the natural resource "markets" differ substantially across sites. Particularly, the benefit transfer analyst should assess the existence of resource substitutes and complements at each site. In addition to resource and site substitutes, the analyst should consider the market characteristics at each site. Microeconomic theory dictates that a change in the price of one good or service will affect demand for other goods and services through income and substitution effects. Therefore, a change in the price of market goods and services is expected to affect WTP for nonmarket goods and services. Failure to account for these changes violates core economic principles and could lead to highly inaccurate estimates (Desvousges and others, 1992; Bergstrom and De Civita, 1999; Bergstrom and Taylor, 2006; Navrud and Ready, 2007).

\section{Research Transparency}

Nelson and Kennedy (2008) urge analysts to report source protocol, including the criteria used to select studies and the sources used to gather studies (for example, Environmental Valuation Reference Inventory, 2011; the EconLit database). The number of observations obtained from each study should be reported, as should the method used to weight multiple observations from a single study (U.S. Environmental Protection Agency, 2006). If and how missing data were treated should also be included in the benefit transfer report (Nelson and Kennedy, 2008). In addition to the study selection criteria, Bergstrom and Taylor (2006) recommend that all studies be considered, including those that failed to meet selection criteria.

\section{Conduct Sensitivity and Validity Tests}

The value transfer analyst should report the sensitivity of the value estimates to changes in the parameters (Nelson and Kennedy, 2008). If meta-regression analysis is used, the analyst should test the sensitivity of the results to the exclusion of each observation to determine if a single data point has a disproportionate influence on the value estimate (U.S. Environmental Protection Agency, 2006). If the results 
are found to be fragile, the implications for policy analysis should be considered (for example, how to treat sensitive results as opposed to robust estimates (Nelson and Kennedy, 2008)).

As described above, transferred benefit estimates may be subject to estimation error resulting from generalization error, measurement error, publication selection bias, or research priority bias. Where feasible, tests should be undertaken to correct for these potential biases. If the benefit estimates are uncorrected, this fact should be made explicit in the report.

\section{Stakeholder Engagement}

One of the key elements in increasing correspondence between study site and policy site values is to include socioeconomic characteristics as an independent variable. However, "latent variables, such as the attitudes, beliefs, and perceptions of respondents," usually need to be addressed to minimize transfer errors (Loomis and Rosenberger, 2006). Understanding these "latent variables" is difficult without stakeholder engagement. Public outreach strategies are an important component of value transfer. Additionally, public engagement can be a useful means of validating the value estimates. If the public finds an estimate unreasonable, it might be cause to reconsider the method or other inputs (Brouwer, 2000; Spash and Vatn, 2006).

\section{Value Incremental Changes}

The decisions that BLM makes based on the analyses presented in RMPs and NEPA documents tend to result in marginal and incremental changes in resource quality and quantity. Obtaining the total economic value of a resource, therefore, may be of limited use. Rather, BLM is advised to focus on transferring values from studies with resources changes that correspond to the expected changes at the policy site (Loomis and Rosenberger, 2006).

\section{Conclusions: BLM-USGS Ecosystem Services Valuation Pilot Study}

Value transfers known to be inadequate (or worse, grossly inaccurate) are sometimes justified by noting that any value is better than the implicit value of zero that natural resources are commonly given in cost-benefit analyses and other monetary decisionmaking tools. However, this practice can discredit all environmental valuation techniques (Smith, 1992). Most of the literature supports the notion that if a resource value cannot be defensibly monetized, it is preferable to provide a qualitative description or utilize a framework that allows for various types of values (for example, multicriteria analysis (Spash and Vatn, 2006). The benefits of a single unit (money) to compare disparate resources, however, can be substantial. OMB economists, in conversation, were skeptical that qualitative descriptions of benefits would be able to offset monetary estimates of cost (Loomis and Rosenberger, 2006). What can be defensibly monetized should be monetized. However, applying highly inaccurate values just for the sake of having any value should be avoided. Furthermore, monetary estimates of value are only one influence on decisions. Economic valuation should not exclude the usefulness of qualitative descriptions and noneconomic quantitative data. Economic estimates have the advantage of simplifying complex information, but this advantage is also a constraint. The ability to explain complexity and nuance makes qualitative analysis central to any defensible environmental valuation study. Similarly, data on ecological thresholds and other biophysical indicators should inform the decisionmaking process.

BLM is encouraged to be cautious in its use of value transfer. Monetization may give a sense of false precision, particularly to nonexpert audiences. The value transfer literature has found value estimate errors that are as high as 7000 percent (Loomis, 1992). Errors ranging from 20-40 percent are probably in the acceptable range (Navrud and Ready, 2007). Deciding on "acceptable errors" depends on the context in which the values will be used. Conducting a cost-benefit analysis on a small-scale project will require less precision than a Natural Resource Damage Assessment, where legal compensation is decided. In the case of the latter, value transfer is probably inappropriate (Navrud and Ready, 2007). Regardless of the errors that BLM decides are "acceptable," care should be taken to follow the best practice principles outlined above. 


\section{Appendix D. Additional Participants in Model and Document Review Process}

Table D1. Additional participants in Bureau of Land Management-U.S. Geological Survey ecosystem services valuation pilot study, San Pedro River watershed, Arizona.

[DOI, Department of Interior; USDA, U.S. Department of Agriculture]

\begin{tabular}{|c|c|}
\hline Name & Affiliation \\
\hline \multicolumn{2}{|c|}{ Economics review panel } \\
\hline Boyd, Jim & Resources for the Future \\
\hline Brown, Paul & Bureau of Land Management \\
\hline Casey, Frank & U.S. Geological Survey \\
\hline Gascoigne, Billy & U.S. Geological Survey \\
\hline Koontz, Lynne & U.S. Geological Survey \\
\hline \multicolumn{2}{|c|}{ Model review workshop } \\
\hline Boykin, Ken & New Mexico State University \\
\hline De Steiguer, Ed & University of Arizona \\
\hline Diffendorfer, Jay & U.S. Geological Survey \\
\hline Francis-Begay, Juanita & U.S. Geological Survey \\
\hline Goodrich, Dave & USDA-Agricultural Research Service \\
\hline Halper, Eve & Bureau of Reclamation \\
\hline Holler, Eric & Bureau of Reclamation \\
\hline Kepner, Bill & U.S. Environmental Protection Agency \\
\hline Kralovec, Mary & Bureau of Land Management \\
\hline Lansey, Kevin & University of Arizona \\
\hline Lomeli, Ben & Bureau of Land Management \\
\hline Mahoney, Jim & Bureau of Land Management \\
\hline Osterkamp, Waite & USDA-Agricultural Research Service \\
\hline Pattison, Malka & DOI-Office of Policy Analysis \\
\hline Perrings, Charles & Arizona State University \\
\hline Piper, Steve & Bureau of Reclamation \\
\hline Rekshynskyj, Mark & Bureau of Land Management \\
\hline Simms, Jeff & Bureau of Land Management \\
\hline Simonit, Silvio & Arizona State University \\
\hline Sobiech, Amy & Bureau of Land Management \\
\hline van Riper, Charles & U.S. Geological Survey \\
\hline Villareal, Miguel & University of Arizona \\
\hline Vukomanovic, Jelena & University of Arizona \\
\hline \multicolumn{2}{|c|}{ General project consultation } \\
\hline Pattison, Malka & DOI-Office of Policy Analysis \\
\hline Rekshynskyj, Mark & Bureau of Land Management \\
\hline
\end{tabular}




\section{Appendix E. Annotated Bibliography of Ecological and Socioeconomic References Related to the San Pedro River Watershed and the U.S. Southwest}

Bark-Hodgins, Rosalind, and Colby, B.G., 2006, An economic assessment of the Sonoran Desert Conservation Plan: Natural Resources Journal, v. 46, p. 709-726.

This study compared property premiums (calculated by using hedonic pricing) and tax revenues compared with the cost of water leases and ecological restoration to support waterdependent habitats from the Sonoran Desert Conservation Plan. The authors estimated property premiums at \$127-253 million, generating \$1.2-2.5 million in annual property tax revenues, and the cost of water leases to be $\$ 0.5$ million per year, with annualized restoration costs estimated at $\$ 235$ /acre-year to restore 9,400 acres of riparian habitat.

Bark, R.H., Osgood, D.E., Colby, B.G., Katz, G., and Stromberg, J., 2009, Habitat preservation and restoration-Do homebuyers have preferences for quality habitat?: Ecological Economics, v. 68, p. 1465-1475.

The authors estimated property premiums using hedonic pricing for different types of open space and the quality of riparian vegetation, including biodiversity, upland connectivity, and wetness metrics. The survey included Rillito Creek and its tributaries in northeast Tucson. The authors found that wetness, biodiversity, and upland connectivity increase property value, whereas biomass does not.

Berrens, R.P., Ganderton, P., and Silva, C.L., 1996, Valuing the protection of minimum instream flows in New Mexico: Journal of Agricultural and Resource Economics, v. 21, no. 2, p. 294-309.

The authors used a dichotomous-choice contingentvaluation telephone survey to estimate public values for protecting in-stream flows on New Mexico's rivers. They compared results for protecting one endangered fish species, the silvery minnow, on a 170-mile river stretch of the Middle Rio Grande with protecting 11 threatened and endangered fish species on four New Mexico rivers extending more than 1,000 miles. They found mean annual WTP for a 5-year period to be $\$ 28.73$ for the silvery minnow on the Middle Rio Grande and $\$ 89.68$ for 11 species on four rivers.

Berrens, R.P., Brookshire, D., Ganderton, P., and McKee, M., 1998, Exploring nonmarket values for the social impacts of environmental policy change: Resource and Energy Economics, v. 20, p. 117-137.

The authors used a telephone survey of New Mexico residents to estimate WTP to maintain traditional extractive land uses, in the context of offsetting potential increases to grazing permit prices on public land. Two thirds of respondents were unwilling to pay anything, indicating that many felt that the public should not compensate ranchers forced to pay higher lease prices for grazing on public land. Average WTP was $\$ 21.68$ per household per year.

Berrens, R.P., Bohara, A.K., Silva, C.L., Brookshire, D., and McKee, M., 2000, Contingent values for New Mexico instream flows-With tests of scope, group size reminder and temporal variability: Journal of Environmental Management, v. 58, p. 73-90.

This study expanded on the Berrens and others (1996) study to estimate public values for protecting in-stream flows for threatened and endangered native fish species on New Mexico's rivers. The authors incorporated additional experimental work, including trying to separate how the public responds to the concept of paying to purchase an environmental public good compared with contributing to a worthy cause. The authors, using logistic regression models, found mean WTP for a 5-year period to be $\$ 26.42$ for the silvery minnow on the Middle Rio Grande and $\$ 72.18$ for 11 species on four rivers.

Brand, L.A., White, G.C., and Noon, B.R., 2008, Factors influencing species richness and community composition of breeding birds in a desert riparian corridor: The Condor, v. 110, no. 2, p. 199-210.

The authors compared bird species richness, cooccurrence, and uniqueness at multiple sites and plots on the San Pedro River to explore the influence of riparian vegetation type, surface flow permanence, and floodplain compared with terrace location. They found greater species richness and more uniqueness in cottonwood and mesquite vegetation types, lower species richness at ephemeral flow sites, and relatively high species richness but low uniqueness in tamarisk patches.

Brookshire, D.S., Goodrich, D., Dixon, M.D., Brand, L.A., Benedict, K., Lansey, K., Thacher, J., Broadbent, C.D., Stewart, S., McIntosh, M., and Kang, D., 2010, After restoration-A framework for preserving semi-arid regions in the Southwest: Journal of Contemporary water Research and Education, v. 144, p. 60-74.

The authors described the process of integrating economic valuation into an established decision support system linking water and water management to surface flows, vegetation, and bird communities on the San Pedro River. They developed a survey for nine surface and groundwater futures for the San Pedro, with valuation to be conducted using contingent valuation and choice modeling for alternative attribute bundles of water, vegetation, and birds. They also describe a future study that would include comparable valuation for the Middle Rio Grande and explore the transferability of results between the two watersheds. 
Brown, Joel, Angerer, J., Salley, S.W., Blaisdell, R., and Stuth, J.W., 2010, Improving estimates of rangeland carbon sequestration potential in the US Southwest: Rangeland Ecology and Management, v. 63, p. 147-154.

The authors estimated changes in soil carbon sequestration under alternative range management practices for the Southwestern United States, using the CENTURY model to estimate soil carbon sequestration and associated uncertainty. They found that current model results have uncertainty levels that are too high to guide management and policy, and that greater integration of site-specific data is needed to improve the quality of model outputs in the Southwestern United States.

Brown, T.C., Harding, B.L., and Payton, E.A., 1990, Marginal economic value of streamflow-A case study for the Colorado River Basin: Water Resources Research, v. 26, no. 12, p. 2845-2859.

The authors estimated the economic value of increased runoff from reduced evapotranspiration caused by logging in the Colorado River Basin. This study combined economic valuation, water routing, basin modeling, the effect of flow changes on salinity, consumptive water use, and hydropower production. Economic values and costs were estimated for increased consumptive use, increased hydropower production, increased deliveries to Mexico, enlarged reservoirs for recreation, changes in salinity and agriculture, increased flows for recreation and fish habitat, dilution of dissolved solids, reduced damage to pipes, better agricultural yields, and increased flooding potential. Using linear programming to optimize water allocation, the authors found increased water availability tended to go toward storage in Lakes Powell and Mead rather than to lower-priority Lower Colorado Basin users.

\section{Bureau of Reclamation, 2007, Appraisal report. Augmen- tation alternatives for the Sierra Vista Subwatershed, Arizona-Lower Colorado Region: U.S. Department of the Interior Bureau of Reclamation, $95 \mathrm{p}$.}

This study compared alternatives, including their cost and feasibility, for increasing water supplies in the Sierra Vista subwatershed of the San Pedro River. The goal of potential water augmentation alternatives is to maintain flow in the San Pedro while meeting growing water needs as population expands in the watershed. Alternatives included water harvesting and recharge along with water transfers both within and outside the San Pedro River watershed.

\section{Colby, B.G., and Orr, P., 2005, Economic tradeoffs in preserving riparian habitat: Natural Resources Journal, Winter, 17 p. (unpaged).}

The authors, using payment-card contingent valuation, estimated WTP of nonlocal visitors to the San Pedro River watershed to avoid dewatering and degradation to the river. Surveys were administered to nonlocal visitors to the
SPRNCA and to Ramsey Canyon. The authors found mean WTP to be a one-time payment of $\$ 79.31$, with a total ranging from \$2.1-3.5 million depending on estimates of the annual number of nonlocal users.

Colby, B.G., and Smith-Incer, E., 2005, Visitor values and local economic impacts of riparian habitat preservation-California's Kern River Preserve: Journal of the American Water Resources Association, v. 41, no. 3, p. 709-717.

The authors used payment-card contingent valuation and local economic assessment, including direct expenditures, indirect increased economic activity, and induced local wage increases to estimate the economic value of southern California's Kern River Preserve, a nationally renowned birding preserve. Visitors were asked their WTP to avoid streamflow loss, habitat degradation, and reduced numbers and diversity of birds and wildlife. The authors found annual values of $\$ 648,000-864,000$ in direct spending, \$1.1-1.5 million using economic impact including multiplier effects, and annual WTP of $\$ 467,000-616,000$ based on annual visitation of $6,000-8,000$.

Colby, B.G., and Wishart, S., 2002, Quantifying the influence of desert riparian areas on residential property values: The Appraisal Journal, v. LXX, no. 3, p. 304-308.

The authors used hedonic pricing to value riparian habitat in northeast Tucson for property near Tanque Verde Wash and adjacent tributaries. They found that by reducing a property's distance to the single largest urban riparian corridor from 1.5 to 0.1 miles, the sample mean house price rose by 6 percent. This relationship was nonlinear, and value declined steeply 0.1 to 0.5 miles from the river and more gradually 0.5 to 1.5 miles from the river. Given that 25,560 houses are located within 1.5 miles of Tanque Verde Wash, the total property premium is $\$ 103.1$ million.

Crandall, K.B., Colby, B.G., and Rait, K.A., 1992, Valuing riparian areas - A southwestern case study: Rivers, v. 3, no. 2, p. 88-98.

The authors used three alternative valuation methods (zonal travel cost, payment-card contingent valuation, and local economic assessment, including direct expenditures, indirect increased economic activity, and induced local wage increases) to estimate the economic value of the 600 -acre Hassayampa River Preserve near Wickenburg, Ariz. This section of the Hassayampa has perennial surface flow that supports cottonwood-willow riparian forests. The authors found annual values of $\$ 52,000$ in direct spending, $\$ 88,000$ using economic impact including multiplier effects, $\$ 613,000$ in consumer surplus using the travel cost method, and annual WTP of $\$ 520,000$ based on annual visitation of 8,000 . 
de Steiguer, J.E., 2008, Semi-arid rangelands and carbon offset markets-A look at the economic prospects: Rangelands, v. 30, p. 27-32.

The author described how rangeland management could be improved by changing management practices to encourage carbon sequestration, with financing obtained from carbon markets. He described the baseline compared with simulated carbon storage using the Erosion-productivity impact calculator (EPIC) model, and he estimated the potential value of carbon as compared to current returns for grazing on State trust lands in Arizona.

Ferguson, T.J., and Colwell-Chanthaphonh, C., 2006, History is in the land-Multivocal tribal traditions in Arizona's San Pedro Valley: Tucson, University of Arizona Press, 336 p.

The authors described the connections of four tribal groups to the San Pedro Valley - the O'odham, Hopi, Zuni, and Apache. Although written Western histories most closely associate the San Pedro River watershed with eastern relatives of today's O'Odham, the Apache, the Zuni, and Hopi have strong connections to the San Pedro River region by means of their historical migrations, as do other tribes not discussed in detail in this book. Although the book does not explicitly use the frame of ecosystem services in describing American Indian connections to the land, it does describe the historical, cultural, and spiritual links that tribes hold to the landscape.

Galbraith, Hector, Dixon, M.D., Stromberg, J.C., and Price, J.T., 2009, Predicting climate change risks to riparian ecosystems in arid watersheds-The Upper San Pedro as a case study, in Kapustka, L.A., and Landis, W.G., eds., Environmental risk and management from a landscape perspective: Hoboken, N.J.: John Wiley, p. 187-202.

The authors modeled potential climate-change effects on the San Pedro River watershed's hydrology, geomorphology, and vegetation. Scenarios included no change, warming of 4- $6^{\circ} \mathrm{C}$, and warming with a decline or increase in precipitation. Channel migration, changes in dominant vegetation, and shifts in avian communities were documented for the different scenarios. Wetter winters were more likely to maintain cottonwood and willow recruitment, which is likely to decline on the basis of the river's geomorphic history. Bird species vary in their vulnerability to climate change, likely because of changes in plant communities.

Giraud, K.L., Loomis, J.B., and Johnson, R.L., 1999, Internal and external scope in willingness-to-pay estimates for threatened and endangered wildlife: Journal of Environmental Management, v. 56, p. 221-229.

The authors estimated WTP for protecting the Mexican spotted owl alone compared with the Mexican spotted owl as part of a package of 62 other Four Corners region threatened and endangered species. Four million dollars have been budgeted during 10 years for spotted owl recovery. The authors used dichotomous-choice mail surveys, of which half were sent to the Four Corners region and half to the rest of the United States. They found that WTP for 62 species was greater than for the spotted owl alone, so the "scope test" in contingent-valuation surveying was passed.

Hand, M.S., Thacher, J.A., McCollum, D.W., and Berrens, R.P., 2008. Intra-regional amenities, wages, and home prices-The role of forests in the Southwest: Land Economics, v. 84, no. 4, p. 635-651.

The authors used hedonic pricing to estimate the value of forest land and tradeoffs between forest cover and wages in Arizona and New Mexico. They found that forest area carries an implicit annual price of \$27-36 per square mile, based on estimates of forest cover within Census Public Use Microdata Areas. Using the same approach, they found that wilderness areas carry a higher value, whereas surface water carries a lower value.

\section{Housman, D.C., Powers, H.H., Collins, A.D., and Belnap, J., 2006, Carbon and nitrogen fixation differ between successional stages of biological soil crusts in the Colo- rado Plateau and Chihuahuan Desert: Journal of Arid Environments, v. 66, p. 620-634.}

The authors compared rates of carbon and nitrogen fixation in early- and late-successional biological soil crusts on the Colorado Plateau and Chihuahuan Desert. Relative to early-successional soil crusts, late-successional soil crusts had fixation 1.2-1.3 times as great on the Colorado Plateau and fixation 2.4-2.8 times as great in the Chihuahuan Desert. Because succession in soil crusts is very slow, the protection of late-successional soil crusts in deserts is important in maintaining terrestrial carbon sequestration and storage.

Huxman, T.E., Snyder, K.A., Tissue, D., Leffler, A.J., Ogle, K., Pockman, W.T., Sandquist, D.R., Potts, D.L., and Schwinning, S., 2004, Precipitation pulses and carbon fluxes in semiarid and arid ecosystems: Oecologia, v. 141, p. 254-268.

This article discussed the role of precipitation on carbon fluxes in desert ecosystems. Small precipitation pulses can initiate soil microbial respiration, leading to the release of carbon from ecosystems, whereas larger precipitation pulses or a sequence of small events are needed to trigger periods of greater photosynthetic activity that lead to carbon sequestration. The timing and magnitude of the precipitation pulses help determine rates of respiration or photosynthesis, which determines whether an ecosystem is a net source of or sink for carbon at seasonal and annual time scales. 
Huxman, T.E., Wilcox, B.P., Breshears, D.D., Scott, R.L., Snyder, K.A., Small, E.E., Hultine, K., Pockman, W.T., and Jackson, R.B., 2005, Ecohydrological implications of woody plant encroachment: Ecology, v. 86, no. 2, p. 308-319.

The authors discussed the consequences of woody plant expansion into former grasslands on water balance, including streamflow, evaporation, and transpiration. Where subsurface flow dominates, woody plant encroachment would be expected to reduce streamflow. Shifts in transpiration relative to evapotranspiration are also expected, but they would differ in mesic, semiarid, and arid systems.

Kaye, J.P., Majumdar, A., Gries, C., Byantuyev, A., Grimm, N.B., Hope, D., Jenerette, G.D., Zhu, W.X., and Baker, L., 2008, Hierarchical Bayesian scaling of soil properties across urban, agricultural, and desert ecosystems: Ecological Applications, v. 18, no. 1, p. 132-145.

The authors used hierarchical Bayesian models to scale up results for landscape carbon, nitrogen, and phosphorus pools from the plot level to the regional level in the Central Arizona-Phoenix Long-Term Ecological Research site. They provided soil nutrient pool data for five land-cover types: urban xeric yards, urban mesic yards, urban nonresidential, deserts, and agriculture.

Kepner, W.G., Watts, C.J., Edmonds, C.M., Maingi, J.K., Marsh, S.E., and Luna, G., 2000, A landscape approach for detecting and evaluating change in a semi-arid environment: Environmental Monitoring and Assessment, v. 64, p. 179-195.

The authors estimated vegetation change with time in the San Pedro River watershed and quantified changes at the watershed scale. They measured change on the basis of classified Landsat Multispectral Scanner System images for the years 1973, 1986, and 1992. They found that the total area and patch size of grassland and desert scrub decreased, whereas mesquite and urban area increased.

Kepner, W.G., Semmens, D.J., Bassett, S.D., Mouat, D.A., and Goodrich, D.C., 2004, Scenario analysis for the San Pedro River, analyzing hydrological consequences for a future environment: Environmental Modeling and Assessment, v. 94, p. 115-127.

The authors used urbanization scenarios developed for the San Pedro by Steinitz and others (2003) to compare runoff and sediment under each scenario. They compared year 2000 and three 2020 land-use-land-cover grids (constrained, planned, and open-development scenarios) using the Soil and Water Assessment Tool (SWAT) and Kinematic Runoff and Erosion Model (KINEROS2), with no climate change assumed. For runoff, sedimentation, and percolation, constrained and planned scenarios showed similar results, with some change in several watersheds. The open-development scenario predicted more intense runoff and sedimentation and reduced percolation, particularly near Benson, Ariz.

Kirchhof, Stephanie, Colby, B., and LaFrance, J., 1997, Evaluating the performance of benefit transfer-An empirical inquiry: Journal of Environmental Economics and Management, v. 33, no. 1, p. 75-93.

The authors used value transfer to compare transfer error for southwestern riparian recreation at four sites: Ramsey Canyon and the SPRNCA (both used for birdwatching), and Taos Box and the Lower Gorge (both used for rafting). The authors used payment-card contingent valuation mail surveys to estimate WTP. The equality of benefit functions between sites was rejected. Value transfer was most feasible from SPRNCA to Ramsey Canyon, but it was not supported from Ramsey Canyon to the SPRNCA or between the two New Mexico rafting sites.

Kroeger, Timm, 2005, Economic benefits of reintroducing the river otter (Lontra canadensis) into rivers in New Mexico: Washington, D.C., Defenders of Wildlife, 35 p.

The author used value transfer to estimate the benefits for New Mexico counties in which otter reintroduction was planned (estimated at \$6-9.5 million net present value), using beneficiaries throughout the entire state of New Mexico (\$9.812.9 million net present value), using out-of-state anglers and wildlife watchers as beneficiaries ( $\$ 5.8$ million net present value), and using residents of the rest of the United States as beneficiaries (\$1.2-3.2 million net present value). These values included recreational and nonuse values only; they did not include ecosystem services generated by otters and effects on fisheries themselves. This study is most useful in showing how to use a transfer function to look at the value of species reintroduction or population increases for the San Pedro, as it realistically accounts for beneficiary group size and WTP at different spatial scales.

Leenhouts, J.M., Stromberg, J.C., and Scott, R.L., 2005, Hydrologic requirements of and consumptive groundwater use by riparian vegetation along the San Pedro River, Arizona: U.S. Geological Survey Scientific Investigations Report 2005-5163, 211 p.

The authors estimated the riparian water needs for the Upper San Pedro River, on the basis of annual-water-use data for individual species and open water, the spatial extent of riparian vegetation, and the relationships between hydrology, water use, and species distribution. Evapotranspiration data are provided for mesquite woodland, mesquite shrubland, cottonwood in perennial and intermittent-flow stream reaches, sacaton, open water, and seepwillow vegetation types. 
Loomis, J.B., Douglas, A.J., and Harpman, D.A., 2005, Recreation use values and nonuse values of Glen and Grand Canyons, in Gloss, S.P., Lovich, J.E., and Melis, T.S., eds., The State of the Colorado River Ecosystem in Grand Canyon-A report of the Grand Canyon Monitoring and Research Center, 1991-2004: U.S. Geological Survey Circular 1282, p. 153-164.

The authors estimated recreational, regional economic, and nonuse values for Glen Canyon and the Grand Canyon under various dam-management scenarios. Recreational values included fishing- and rafting-associated expenditures, and local economic impacts estimated by using input-output modeling. Nonuse values were derived from a national survey and showed substantial WTP to improve flows and ecological conditions in the canyons, as might be expected for such well-recognized and charismatic sites.

Lowry, John, Ramsey, R.D., Thomas, K., Schrupp, D., Sajwaj, T., Kirby, J., Waller, E., Schrader, S., Falzarano, S., Langs, L., Manis, G., Wallace, C., Schulz, K., Comer, P., Pohs, K., Reith, W., Velasquez, C., Wolk, B., Kepner, W., Boykin, K., O'Brien, L., Bradford, D., Thompson, B., and Prior-Magee, J., 2007, Mapping moderate-scale land-cover over very large geographic areas within a collaborative framework-A case study of the Southwest Regional Gap Analysis Project (SWReGAP): Remote Sensing of Environment, v. 108, p. 59-73.

This paper described the results of the first multistate USGS Gap Analysis Program, which produced consistent mapping products for Arizona, Colorado, Nevada, New Mexico, and Utah. Landsat ETM+ data for 1999-2001 and digital elevation model derivatives were used to build a publicly available land-cover dataset with 125 land-cover classes, at $30 \times 30$ meter spatial resolution. Although not described in this paper, the group has since produced Southwest Regional Gap Analysis Project habitat models for 819 species in the five-state region.

Martens, D.A., Emmerich, W., McLain, J.E.T., and Johnsen, T.N., 2005, Atmospheric carbon mitigation potential of agricultural management in the southwestern USA: Soil and Tillage Research, v. 83, p. 95-119.

The authors reviewed and synthesized articles that report soil carbon storage, soil carbon sequestration, nitrous oxide, and methane fluxes from native ecosystems and agricultural systems under different crops and agricultural-management practices. Values were reported from the entire intermountain west - all four major North American deserts, California Mediterranean ecosystems, and tallgrass prairie in Texas and Oklahoma.
Conservation tillage, crop rotation, past cropping, irrigation, salinity, grazing, soil texture, temperature, and precipitation are important influences on soil carbon in these ecosystems.

Martens, D.A., and McLain, J.E.T., 2005, Climate mitigation potential of the San Pedro River riparian zone, in Gottfried, G.J., Gebow, B.S., Eskew, L.G., Edminster, C.B., comps. Connecting mountain islands and desert seas-Biodiversity and management of the Madrean Archipelago II conference, May 11-14, Tucson, Ariz.: Fort Collins, Colo., U.S. Department of Agriculture Forest Service Rocky Mountain Research Station: Proceedings, RMRS-P-36, p. 491-495.

The authors estimated soil carbon content of soils in mesquite, acacia, mesquite-open, sacaton-mesquite, sacaton, and open herbaceous plant communities. Unlike McLain and Martens (2003), this report provides bulk density data, allowing estimation of carbon storage per unit area under various vegetation types.

McLain, J.E.T., and Martens, D.A., 2003, Vegetation community impacts on soil carbon, nitrogen, and trace gas fluxes, in Renard, K.G., McElroy, S.A., Gburek, W.J., Canfield, H.E., and Scott, R.L., eds., First Interagency Conference on Research in the Watersheds, October 27-30, 2003, U.S. Department of Agriculture Agricultural Research Service, p. 542-547.

The authors reported on soil carbon storage in mesquite, sacaton, and annual herbaceous communities on the San Pedro River. They found mesquite patches to have about twice the soil carbon content of sacaton patches, mesquite-sacaton patches to have an intermediate content, and open herbaceous communities to have the lowest soil carbon content.

McLain, J.E.T., and Martens, D.A., 2005, Studies of methane fluxes reveal that desert soils can mitigate global change, in Gottfried, G.J., Gebow, B.S., Eskew, L.G., Edminster, C.B., comps. Connecting mountain islands and desert seas-Biodiversity and management of the Madrean Archipelago II conference, May 11-14, Tucson, Ariz.: Fort Collins, Colo., U.S. Department of Agriculture Forest Service Rocky Mountain Research Station: Proceedings, RMRS-P-36, p. 496-499.

The authors estimated methane consumption by microorganisms in desert soils for the San Pedro River and Santa Rita Experimental Range. They found methane consumption to be greatest in open patches, intermediate in mesquite, and lowest in sacaton grasslands. Methane consumption was strongly seasonal-rainfall pulses stimulated methane consumption, whereas the driest periods of the year had negligible consumption. 
McLain, J.E.T., and Martens, D.A., 2006, Moisture controls on trace gas fluxes in semiarid riparian soils: Soil Science Society of America Journal, v. 70, p. 367-377.

The authors reported similar results as their 2003 study on carbon and nitrous oxide fluxes in mesquite, sacaton, and annual herbaceous communities on the San Pedro River. However, this study reported results for a 15 -month period, providing results for two growing seasons with varying precipitation. As in past studies, precipitation strongly controlled gas flux patterns; greater activity generally characterized wetter seasons of the year and wetter compared with drier years.

\section{McLain, J.E.T., Martens, D.A., and McClaran, M.P.,} 2008, Soil cycling of trace gases in response to mesquite management in a semiarid grassland: Journal of Arid Environments, v. 72, p. 1654-1665.

The authors reported soil carbon storage data for live mesquite, dead mesquite, and open herbaceous patches in the Santa Rita Experimental Range, southern Arizona, and nitrous oxide and methane fluxes. They reported results from 2003 and 2004 which, as did the San Pedro data from their 2006 study, showed strong seasonal variation in soil moisture that subsequently drives respiration, photosynthesis, nitrous oxide fluxes, and methane consumption.

Miller S.N., Kepner, W.G., Mehaffey, M.H., Hernandez, M., Miller, R.C., Goodrich, D.C., Devonald, K.K., Heggem, D.T., and Miller, W.P., 2002, Integrating landscape assessment and hydrologic modeling for landcover change analysis: Journal of the American Water Resources Association, v. 38, no. 4, p. 915-929.

The authors applied the Soil and Water Assessment Tool (SWAT) and Kinematic Runoff and Erosion Model (KINEROS) hydrologic models to the San Pedro (Arizona) and Cannonsville (New York) watersheds. Increasing urbanization, agriculture, and invasion of grasslands by woody plants led to greater annual and event runoff, flashier floods, and increased sedimentation, which can be used as indicators of watershed condition. The authors used KINEROS to model rainfall-runoff relationships on small watersheds and used SWAT for modeling larger watersheds at coarser time scales. The most useful hydrologic models in arid regions account for intense local rainfall, transmission losses into ephemeral stream channels, high evapotranspiration, lower total runoff, flashier events, less vegetation, and greater erosion potential. A lack of gaging stations was problematic for both models, because in arid environments regular gaging is needed for small watersheds, which respond differently to patchily distributed rainfall events.
Moeltner, Klaus, and Woodward, R., 2009, Meta-functional benefit transfer for wetland valuation-Making the most of small samples: Environmental and Resource Economics, v. 42, p. 89-108.

The authors used Bayesian meta-regression modeling to estimate the value of aridland wetlands in Nevada. These wetlands are fed by groundwater that is proposed for a transfer out of the basin to Las Vegas. Although the authors valued rare and unique wetlands using a sophisticated statistical technique, they did not draw on any primary wetland valuation studies that were specific to arid and semiarid environments or the Intermountain West.

Norman, Laura, Tallent-Halsell, N., Labiosa, W., Weber, M., McCoy, A., Hirschboeck, K., Callegary, J., van Riper, C., III, and Gray, F., 2010, Developing an ecosystem services online decision support tool to assess the impacts of climate change and urban growth in the Santa Cruz watershed-Where we live, work, and play: Sustainability, v. 2, no. 7, p. 2044-2069.

The authors described an application of the Ecosystem Portfolio Model to the Santa Cruz watershed in Arizona. This model incorporates environmental, economic, and quality-oflife metrics, such as human health and environmental justice, key considerations for cross-boundary watersheds. This model contains underlying hydrologic, urban growth, and habitat models based on Soil and Water Assessment Tool, Slope, Land cover, Exclusion, Urbanization, Transportation, and Hillshade model, and Southwest Regional Gap Analysis Project, respectively, and it uses an Intergovernmental Panel on Climate Change scenario to evaluate the effects of climate change on the watershed.

Orr, Patricia, and Colby, B.G., 2002, Nature-oriented visitors and their expenditures-Upper San Pedro River Basin: Department of Agricultural and Resource Economics, University of Arizona. Available at: http://ag.arizona.edu/ AREC/pubs/san_pedro_report.pdf, p. 17.

The authors administered expenditure surveys to 843 visitors living outside the Upper San Pedro River watershed; the surveys were collected in February to May and in August 2001 from the Ramsey Canyon Preserve and SPRNCA. Annual expenditures totaled \$10.1-16.9 million. Use of a 1.68 local multiplier gives \$17-28.3 million per year in total local economic effects, providing $350-590$ jobs. These expenditures do not include the opportunity cost of time and are only a partial component of consumer surplus from birding on the San Pedro River. 
Piper, Steven, and Martin, W.E., 1997, Household willingness to pay for improved rural water supplies-A comparison of four sites: Water Resources Research, v. 33, no. 9, p. 2153-2163.

The authors estimated WTP for improved rural water at four sites in the Western United States: southeast South Dakota, northwest Oklahoma, north-central Montana, and the Navajo reservation of western New Mexico. Values ranged from $\$ 4.43$ to $\$ 17.29$ per household per month, which are comparable to values used in previous contingent-valuation studies of rural water supply. The authors concluded that value transfer is permissible using demographic and situational characteristics in a transfer function, including income, the cost of obtaining water, and measures of use.

Pool, D.R., and Dickinson, J.E., 2007, Ground-water flow model of the Sierra Vista and Sonoran portions of the Upper San Pedro Basin, southeastern Arizona, United States and northern Sonora, Mexico: U.S. Geological Survey Scientific Investigations Report 2006-5228, 60 p.

The authors described a groundwater model for portions of the Upper San Pedro River watershed using MODFLOW 2000. Key elements in the model included groundwater flow in sedimentary rocks underlying alluvial basin deposits, withdrawals for dewatering at the Tombstone mine, discharge to springs in the Huachuca Mountains, thick lowpermeability intervals of silt and clay that separate the groundwater flow system into deep-confined and shallow-unconfined systems, ephemeral-channel recharge, and seasonal variations in groundwater discharge by wells and evapotranspiration.

Rankin, A.G., Eiler, L.M., and Joaquin, J.T., 2008, Water and the human spirit-Traditional sacred natural surface waters, in Altschul, J.H., and Rankin, A.G., eds., Fragile patterns-The archaeology of the western Papagueria: Tucson, Ariz., SRI Press, p. 595-604.

The authors described how American Indians value the Western Papagueria region of southwest Arizona and northwestern Sonora. American Indians in the region view the land itself as sacred, with the landscape "dotted with special places of spiritual value and power," that are intersections of the physical and spirit worlds, such as Baboquivari Peak for the Tohono O'odham. Water plays a critical role, both physically and spiritually. Although the region has extremely limited surface waters (most streams are ephemeral), locally important features such as charcos (mudholes found on adobe flats and washes), playas, springs, and tinajas (rock-cut tanks, plunge pools, or potholes) are key resources for survival and are also held as sacred sites. These sites also have historical value as part of cultural migrations, trade routes, and creation or origin stories, as sources of healing.
Richardson, Leslie, and Loomis, J., 2009, The total economic value of threatened, endangered, and rare species-An update meta-analysis: Ecological Economics, v. 68 , no. 5, p. 1535-1548.

The authors updated Loomis and White's 1996 metaanalysis of endangered species values, incorporating newer studies (which have generally yielded higher WTP); along with survey, species, and respondent characteristics to identify how these factors influence WTP. The authors found an average transfer error of 34 percent for annual payments and 45 percent for lump-sum payments.

Richardson, R.B., 2008, Conceptualizing the value of ecosystem services in deserts, in Chapman, R.L., ed., Creating sustainability within our midst-Challenges for the 21st century: New York, Pace University Press, p. 225-248.

The author qualitatively described various ecosystem services provided by deserts, with a focus on public lands and their component wilderness areas within the Great Basin, Mojave, and Sonoran desert region of southeastern California. The area included 10 million acres of BLM land, 3 million acres of which are designated as wilderness. The study provided economic estimates for the value of dust control in reducing respiratory health problems for people, valued at \$24 million per year, the value of increased visibility for recreation in national parks, valued at $\$ 48$ million per year, and recreation, valued at $\$ 159$ million per year.

Rimbey, N.R., Torell, L.A., and Tanaka, J.A., 2007, Why grazing permits have economic value: Journal of Agricultural and Resource Economics, v. 32, no. 1, p. $20-40$.

The authors explored the question of why grazing permits have value in regions where livestock production potential is very low. The authors used a dataset of ranch sales from New Mexico and the Great Basin to show that less than 16 percent of the marginal value of grazing permits in New Mexico is attributed to livestock production, and this value is zero for some Great Basin ranches. The area of deeded land plus leased public land did matter, however, and size rather than productivity determined price. The market value of grazing permits has declined as public lands are managed more for other values, whereas the value of ranches themselves is increasingly determined by productivity, minus a discount for public land leases where the rancher can run cattle but does not own the land, plus other aesthetic, recreational, and locational values.

Schlessinger, W.H., 1982, Carbon storage in the caliche of arid soils-A case study from Arizona: Soil Science, v. 133, no. 4, p. 247-255.

The author recorded soil carbon storage in 91 of 189 Arizona soil profiles, which were sampled to depths of at least 125 centimeters. Noting the importance of carbon storage in 
carbonate minerals in the soil in arid environments, this study found overall carbonate carbon to be five times as great as soil organic carbon statewide. However, carbonate carbon is more prevalent on limestone-soil parent material and less important in regions with greater mean annual precipitation.

\section{Schlessinger, W.H., Belnap, J., and Marion, G., 2009, On carbon sequestration in desert ecosystems: Global Change Biology, v. 15, no. 6, p. 1488-1490.}

The authors compared recent reports of high levels of net ecosystem production in desert ecosystems (more than 100 grams of carbon per square meter per year) to numerous other values in the literature. They argued that these recent measurements are unrealistically high, and that gas exchange measurements need to be better compared to empirical data previously collected for desert carbon pools in vegetation and soils.

Scott, R.L., Edwards, E.A., Shuttleworth, W.J., Huxman, T.E., Watts, C., and Goodrich, D.C., 2004, Interannual and seasonal variation in fluxes of water and carbon dioxide from a riparian woodland ecosystems: Agricultural and Forest Meteorology, v. 122, p. 65-84.

The authors measured water, energy, and $\mathrm{CO}_{2}$ fluxes from a mesquite woodland along the San Pedro River using the eddy covariance method for the 2001 and 2002 growing seasons. Mesquite accessed groundwater when precipitation was scarce (particularly in 2002, the drier year), and evapotranspiration and carbon sequestration varied throughout the growing season on the basis of water availability and leaf biomass.

Scott, R.L., Huxman, T.E., Williams, D.G., and Goodrich, D.C., 2006, Ecohydrological impacts of woody-plant encroachment-Seasonal patterns of water and carbon dioxide exchange within a semiarid riparian environment: Global Change Biology, v. 12, p. 311-324.

This study compared carbon fluxes in riparian grasslands, grassland-shrubland mosaics, and woodlands on the San Pedro River. Data were for the year 2003, which was a dry year. Generally, woody plants can sequester more carbon, as they are better able to tap shallow groundwater and avoid drought limitation, but they also have greater litterfall, which enables more respiration, offsetting its higher photosynthetic potential. The authors found that before leaf-out, precipitation drove respiration (that is, respiration occurred when there was enough water), leading the ecosystem to be a net source of carbon. During the growing season, sequestration led vegetation to be a net sink for $\mathrm{CO}_{2}$, and the greatest sequestration and evapotranspiration was in woodlands, followed by shrublands, then grasslands.
Scott, R.L., Jenerette, G.D., Potts, D.L., and Huxman, T.E., 2009, Effects of seasonal drought on net carbon dioxide exchange from a woody-plant-encroached semiarid grassland: Journal of Geophysical Research, v. 114, G04004.

The authors compared seasonal and interannual effects of rainfall on carbon dioxide exchange, using 2004-2007 data for mesquite savannas at the Santa Rita Experimental Range. During this period, annual precipitation was below average, and monsoon precipitation was both above and below average in different years while winter rain totals were below average in all years. Ecosystems emitted low to moderate quantities of $\mathrm{CO}_{2}$ to the atmosphere. This effect was especially pronounced during drought years, when growth is water-limited and less overall photosynthesis takes place. The ecosystem was carbon neutral when rainfall was close to the long-term average in distribution and amount. Cool-season drought tended to lead to lower spring carbon uptake, greater summer respiration, and high net carbon loss. Thus, while these ecosystems are carbon sinks in wetter years, the dry winter rain periods led to their being sources of atmospheric carbon during this study period.

Sengupta, Sanchita, and Osgood, D.E., 2003, The value of remoteness-A hedonic estimation of ranchette prices: Ecological Economics, v. 44, p. 91-103.

The authors presented a hedonic model of ranchette prices in central Arizona, exploring the influence of greenness, access to roads, cities, and neighbors, adjacency to public land, and distance to rivers on property values. They found that greenness and proximity to rivers increased sale price, as did access to roads, cities, and neighbors - implying that isolation was a disamenity and water availability was valued as an amenity.

Serrat-Capdevila, Aleix, Valdes, J.B., Gonzalez Perez, J., Baird, K., Mata, L.J., and Maddock, T., III, 2007, Modeling climate change impacts—and uncertainty-on the hydrology of a riparian system-The San Pedro Basin (Arizona/Sonora): Journal of Hydrology, v. 347, p. 48-66.

The authors used seventeen general circulation models and four Intergovernmental Panel on Climate Change climate-change scenarios to explore their effects on the San Pedro River watershed for the period 2000-2100. They linked rainfall, recharge, groundwater extraction, and riparian health. The authors used an average of 17 models, along with high and low values for temperature and precipitation, to generate estimates of uncertainty. The authors estimated that recharge in the SPRNCA would decline $25-80$ percent depending on the severity of precipitation decline in the climate scenario. Subsequently, cottonwood, willow, and sacaton likely would decline and be replaced with more-drought-tolerant mesquite and tamarisk. 
Serrat-Capdevila, Aleix, Browning-Aiken, A., Lansey, K., Finan, T., and Valdes, J.B., 2009, Increasing socioecological resilience by placing science at the decision table-The role of the San Pedro Basin (Arizona) Decision Support System Model: Ecology and Society, v. 14, no. 1, p. 37.

This paper described the decision support system built to aid decisionmaking in the Upper San Pedro watershed. This system integrates hydrologic and ecologic models that allow users to explore alternative means to reduce the watershed's hydrologic deficit. The authors discussed the decision support system in the context of building resilience into the system and the involvement of stakeholders in the process of developing and using it.

Steinitz, Carl, Arias, H., Bassett, S., Flaxman, M., Goode, T., Maddock, T., III, Mouat, D., Peiser, R., and Shearer, A., 2003, Alternative futures for changing landscapesThe Upper San Pedro River Basin in Arizona and Sonora: Washington, D.C., Island Press, 202 p.

This book described model outputs that explored the consequences of alternative growth scenarios on numerous landscape and ecological metrics, including hydrology, vegetation, landscape connectivity, species of conservation concern, vertebrate species richness, and visual preference. They compared 9 urban growth scenarios for the year 2020, 3 each showing "open," "constrained," and intermediate "planned" scenarios compared with a year 2000 baseline. These scenarios differed in the degree of growth, its specific locations, the future of Fort Huachuca, and trends in conservation and agriculture in both the United States and Mexican parts of the watershed.

Striegl, R.G., McConnaughey, T.A., Thorstenson, D.C., Weeks, E.P., and Woodward, J.C., 1992, Consumption of atmospheric methane by desert soils: Nature, v. 357, p. 145-147.

The authors estimated consumption of atmospheric methane, a strong greenhouse gas, by microorganisms in desert soils. Like carbon sequestration, aridland methane consumption was highly seasonal, and rainfall was a strong driver of methane consumption. While per-acre methane consumption was relatively small when compared to global carbon sinks and greenhouse gas emissions, deserts had a larger combined influence on atmospheric methane owing to their large extent globally.
Stromberg, J.C., Lite, S.J., Rychener, T.J., Levick, L.R., Dixon, M.D., and Watts, J.M., 2006, Status of the riparian ecosystem in the Upper San Pedro River-Application of an assessment model: Environmental Monitoring and Assessment, v. 115, p. 145-173.

The authors developed and applied a model to assess stream segments on the basis of hydrologic, geomorphic, and biological indicators. They delineated 14 reaches on the Upper San Pedro River within the SPRNCA, and classified these reaches as dry (1 reach), intermediate ( 8 reaches), or wet (5 reaches). This assessment model can be used to quantify riparian condition and has been used in the Upper San Pedro Decision Support System and in studies to economically value restoration or avoided degradation of the riparian ecosystem.

Stromberg, J.C., Beauchamp, V.B., Dixon, M.D., Lite, S.J., and Paradzick, C., 2007, Importance of low-flow and high-flow characteristics to restoration of riparian vegetation along rivers in the arid south-western United States: Freshwater Biology, v. 52, p. 651-679.

The authors described the effect of surface-flow frequency (perennial to intermittent to ephemeral) and the role of flooding and flow regulation on riparian plant communities and processes. Species diversity and nativespecies dominance were influenced by surface flow and flood frequency, and "reference" rivers where these natural processes are still intact harbor greater species diversity, landscape heterogeneity, and abundance of wetland plant species. Maintaining these processes on reference rivers and restoring them on degraded rivers (for example, by dam removal, controlled dam releases, or purchase of water rights) is important to riparian restoration.

Stromberg, J.C., Lite, S.J., Marler, R., Paradzick, C., Shafroth, P.B., Shorrock, D., White, J.M., and White, M.S., 2007, Altered stream-flow regimes and invasive plant species-The Tamarix case: Global Ecology and Biogeography, v. 16, p. 381-393.

This study examined the relationship between flow regulation and the dominance of woody plant species within the Gila River and Lower Colorado River riparian corridors. Nonnative and more-drought-resistant species such as tamarisk are more common on flow-regulated regions, where typical dam management creates flows timed to favor their establishment rather than establishment of native cottonwood and willow. This observation shows the importance of flow management 
for maintaining and restoring native riparian communities, and the impracticality of restoration without addressing flooding, the key disturbance process in these systems.

Stromberg, J.C., and Tellman, B., 2009, Ecology and conservation of the San Pedro River: Tucson, University of Arizona Press, 544 p.

This book synthesized research on the hydrology, geomorphology, and ecology of the San Pedro River and placed this research within the watershed's historical and contemporary socioeconomic context. It discussed prospects for future restoration and degradation of the San Pedro on the basis of system drivers such as groundwater depletion, urbanization, and climate change.

Svejcar, Tony, Angell, R., Bradford, J.A., Dugas, W., Emmerich, W., Frank, A.B., Gilmano, T., Haferkamp, M., Johnson, D.A., Mayeux, H., Mielnick, P., Morgan, J., Saliendra, N.Z., Schuman, G.E., Sims, P.L., and Snyder., K., 2008, Carbon fluxes on North American rangelands: Rangeland Ecology and Management, v. 61, p. 465-474.

The authors synthesized data on rangeland net ecosystem exchange for eight United States grassland sites ranging from the Great Plains and northern Rockies to Texas and the desert Southwest. They found drought to be a critical influence on carbon sequestration, and that the Southwestern sites were sources rather than sinks of carbon in most years. Seasonal patterns shifted between carbon uptake during wet periods and balance or respiratory release of carbon during dry periods.

Torell, L.A., Rimbey, N.R., Ramirez, O.A., and McCollum, D.W., 2005, Income earning potential versus consumptive amenities in determining ranchland values: Journal of Agricultural and Resource Economics, v. 30, no. 3, p. 537-560.

This study estimated the hedonic value of ranches; amenities were compared with income-earning potential from traditional ranching. The authors found differential value for grazing leases on different types of land, in line with grazing fees and regulations on stocking rates. They concluded that grazing permit fee reform on public lands needs to account for the fact that many ranch owners are looking to maximize utility by means of recreational and amenity values, rather than by ranch production profit alone.
Venn, T.J., and Quiggin, J., 2007, Accommodating indigenous cultural heritage values in resource assessmentCape York Peninsula and the Murray-Darling Basin, Australia: Ecological Economics, v. 61, p. 334-344.

The authors discussed the limitations of nonmarket valuation in understanding indigenous preferences for landscape and environmental features. They suggested that incorporating quantity constraints on resource use that are compatible with indigenous rights and beliefs is a means of fairly addressing these challenges without imposing an external economic value system in the process.

\section{Weber, M.A., and Berrens, R.P., 2006, Value of instream recreation in the Sonoran Desert: Journal of Water Resources Planning and Management, v. January/ February 2006, p. 53-60.}

The authors used the zonal-travel cost method to estimate the value of backcountry recreation in the Aravaipa Canyon Wilderness (the Aravaipa River is a tributary to the San Pedro River, with perennial surface flow). They found consumer surplus of $\$ 25.06$ and $\$ 17.31$ for two access points which, given total annual visitation of 7,800 , corresponded to annual values of $\$ 55,000$ and $\$ 88,000$ for the two access points.

Weber, M.A., and Stewart, S., 2009, Public values for river restoration options on the Middle Rio Grande: Restoration Ecology, v. 17, no. 6, p. 762-771.

The authors used choice experiments and contingent valuation to estimate WTP for river restoration of the Middle Rio Grande Bosque in Albuquerque, N. Mex., covering 17 miles of river and 4,000 acres of riparian habitat. They estimated annual WTP on the order of $\$ 4.1$ million per river mile or $\$ 1,038$ per acre of riparian habitat on the basis of the number of households in Albuquerque.

\section{Wheeler, C.W., Archer, S.R., Asner, G.P., and McMurtry, C.R., 2007, Climatic/edaphic controls on soil carbon/ nitrogen response to shrub encroachment in des- ert grassland: Ecological Applications, v. 17, no. 7, p. 1911-1928.}

The authors compared soil carbon and nitrogen levels at plots with minimal mesquite cover, young mesquite cover, and old mesquite cover. Their study site was the Santa Rita Experimental Range south of Tucson, Ariz. The authors found increased carbon and nitrogen in soils progressing from grasslands to old mesquite patches. 


\section{Appendix F. Summary of Primary Economic Valuation Studies for the San Pedro River Watershed and the U.S. Southwest}

Table F1. Primary economic valuation studies for the San Pedro River watershed, Arizona, and the Southwest.

[See Appendix E for full references. n/a, not available; prep., preparation; SPRNCA, San Pedro Riparian National Conservation Area; T\&E, threatened and endangered; WTP, willingness to pay]

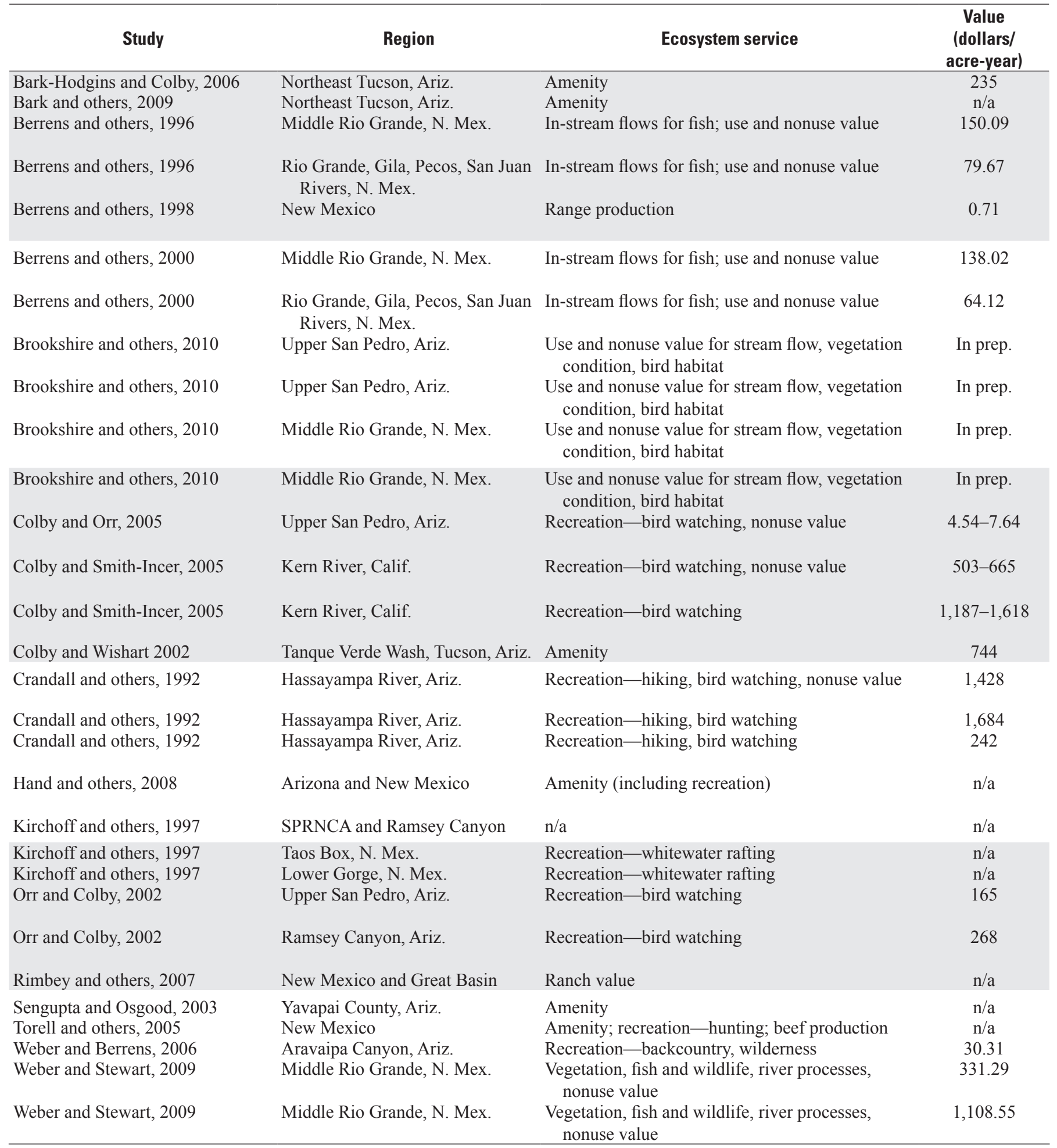


Table F1. Primary economic valuation studies for the San Pedro River watershed, Arizona, and the Southwest.-Continued

[See Appendix E for full references. n/a, not available; prep., preparation; SPRNCA, San Pedro Riparian National Conservation Area; T\&E, threatened and endangered; WTP, willingness to pay]

$\begin{array}{ll}\text { Study method } \quad \text { Beneficiaries } & \text { Scenario }\end{array}$

\begin{tabular}{|c|c|c|}
\hline Hedonic pricing & Northeast Tucson homeowners & Riparian restoration of 9,432 acres. \\
\hline $\begin{array}{l}\text { Contingent valuation } \\
\text { (open-ended) }\end{array}$ & New Mexico ranchers & WTP to compensate ranchers for higher Federal grazing lease prices. \\
\hline $\begin{array}{l}\text { Contingent valuation } \\
\text { (dichotomous choice) }\end{array}$ & New Mexico residents & $\begin{array}{l}\text { WTP, water rights to preserve in-stream flow for } 11 \mathrm{~T} \& \mathrm{E} \text { fish species } \\
\text { on } 1000+\text { miles of four major New Mexico rivers. }\end{array}$ \\
\hline $\begin{array}{l}\text { Contingent valuation } \\
\text { (dichotomous choice) }\end{array}$ & Arizona residents & Various degradation or restoration scenarios. \\
\hline Choice modeling & Arizona residents & Various degradation or restoration scenarios. \\
\hline $\begin{array}{l}\text { Contingent valuation } \\
\text { (payment card) }\end{array}$ & $\begin{array}{l}\text { Nonresident visitors to SRPNCA and } \\
\text { Ramsey Canyon }\end{array}$ & WTP, avoid dewatering and degradation. \\
\hline $\begin{array}{l}\text { Contingent valuation } \\
\text { (payment card) }\end{array}$ & Visitors to Kern River Preserve, Calif. & WTP, avoid loss of streamflow, habitat degradation, loss of key species. \\
\hline $\begin{array}{l}\text { Consumer expenditure } \\
\text { and multiplier }\end{array}$ & Visitors to Kern River Preserve, Calif. & $\mathrm{n} / \mathrm{a}$ \\
\hline Hedonic pricing & Northeast Tucson homeowners & $\mathrm{n} / \mathrm{a}$ \\
\hline $\begin{array}{l}\text { Contingent valuation } \\
\text { (payment card) }\end{array}$ & Visitors to Hassayampa Preserve & WTP to avoid loss of perennial flow. \\
\hline Zonal travel cost & Visitors to Hassayampa Preserve, Ariz. & $\mathrm{n} / \mathrm{a}$ \\
\hline $\begin{array}{l}\text { Consumer expenditure } \\
\text { and multiplier }\end{array}$ & Visitors to Hassayampa Preserve, Ariz. & $\mathrm{n} / \mathrm{a}$ \\
\hline $\begin{array}{l}\text { Consumer expenditure } \\
\text { and multiplier }\end{array}$ & Nonresident visitors to Ramsey Canyon & $\mathrm{n} / \mathrm{a}$ \\
\hline Hedonic pricing & New Mexico and Great Basin ranch owners & $\mathrm{n} / \mathrm{a}$ \\
\hline Hedonic pricing & Yavapai County ranchette owners & $\mathrm{n} / \mathrm{a}$ \\
\hline Hedonic pricing & New Mexico ranch owners & $\mathrm{n} / \mathrm{a}$ \\
\hline Zonal travel cost & Visitors to Aravaipa Canyon & $\mathrm{n} / \mathrm{a}$ \\
\hline $\begin{array}{l}\text { Contingent valuation } \\
\text { (payment card) }\end{array}$ & Albuquerque residents & WTP, various restoration scenarios. \\
\hline Choice modeling & Albuquerque residents & WTP, various restoration scenarios. \\
\hline
\end{tabular}


Publishing support provided by:

Denver Publishing Service Center, Denver, Colorado

For more information concerning this publication, contact:

Center Director, USGS Geosciences and

Environmental Change Science Center

Box 25046, Mail Stop 980

Denver, C0 80225

(303) 236-5345

Or visit the Geosciences and Environmental Change Science Center Web site at: http://esp.cr.usgs.gov/

This report is available at: http://pubs.usgs.gov/sir/2012/5251 
